



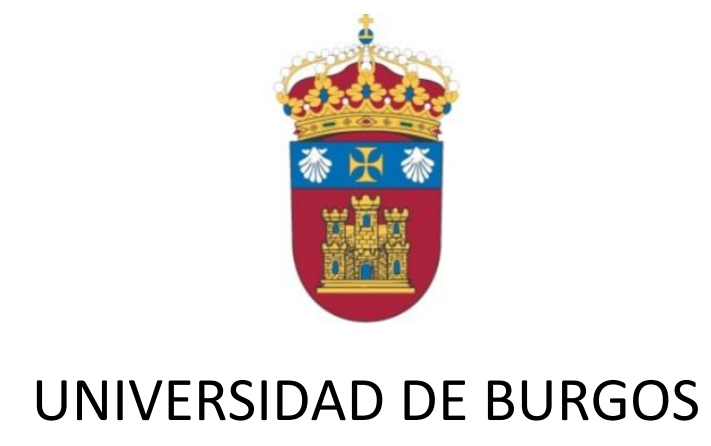

Departamento de Biotecnología y Ciencia de los Alimentos

Study of non-thermal technologies to preserve the quality of fresh foods

\section{TESIS DOCTORAL}

Alba Ester Illera Gigante

Burgos, 2019 



\title{
Study of non-thermal technologies to preserve the quality of fresh foods
}

\author{
Memoria que para optar al grado de \\ Doctor por la Universidad de Burgos \\ en el programa Avances en Ciencia y \\ Biotecnología Alimentarias presenta:
}

Alba Ester Illera Gigante 



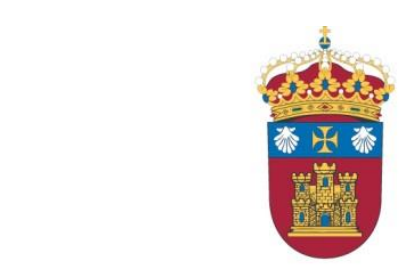

\section{UNIVERSIDAD DE BURGOS}

\section{Departamento de Biotecnología y Ciencia de los Alimentos}

Dña. MARÍA TERESA SANZ díEZ y Dña. SAGRARIO BELTRÁN CALVO, Profesoras del Departamento de Biotecnología y Ciencia de los Alimentos de la Universidad de Burgos,

\section{CERTIFICAN:}

Que la Graduada en Ciencia y Tecnología de los Alimentos y Máster en Seguridad y Biotecnología Alimentarias Dña. Alba Ester Illera Gigante ha realizado bajo su dirección el trabajo titulado "Study of non-thermal technologies to preserve the quality of fresh foods", cuyo título en castellano es: "Estudio de tecnologías no térmicas para preservar la calidad de alimentos frescos".

Considerando que dicho trabajo reúne los requisitos exigidos para ser presentado como Tesis Doctoral, expresan su conformidad con dicha presentación.

Para que conste, firman el presente certificado.

En Burgos, a 11 de Abril de 2019

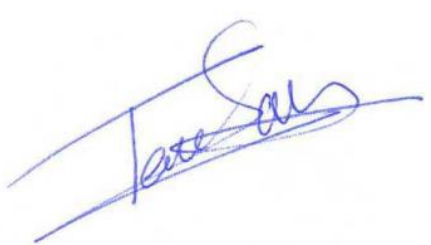

Fdo. María Teresa Sanz Díez

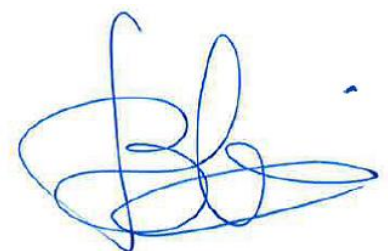

Fdo. Sagrario Beltrán Calvo 



\section{UNIVERSIDAD DE BURGOS}

\section{Departamento de Biotecnología y Ciencia de los Alimentos}

D. JOSÉ MANUEL BENITO MORENO, coordinador del programa de doctorado "Avances en Ciencia y Biotecnología Alimentarias" de la Universidad de Burgos,

\section{CERTIFICA:}

Que la memoria titulada "Study of non-thermal technologies to preserve the quality of fresh foods" presentada por Dña. Alba Ester Illera Gigante, Graduada en Ciencia y Tecnología de los Alimentos y Máster en Seguridad y Biotecnología Alimentarias, ha sido realizada en el Departamento de Biotecnología y Ciencia de los Alimentos bajo la dirección de las Dras. María Teresa Sanz Díez y Sagrario Beltrán Calvo, y en representación de la Comisión Académica del Programa de Doctorado, autoriza su presentación para ser defendida como Tesis Doctoral.

Para que conste, y surta los efectos oportunos, firmo el presente certificado.

En Burgos, a 11 de Abril de 2019

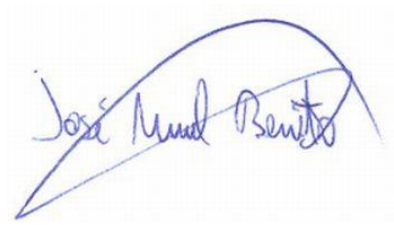

Fdo. José Manuel Benito Moreno

Coordinador del Programa de Doctorado 

Este trabajo ha sido realizado en el marco del siguiente proyecto de Investigación desarrollado en el seno del Grupo de investigación Biotecnología Industrial y Medioambiental, reconocido por la UBU (GIR-UBU BIOIND) y por la Junta de Castilla y León como Unidad de Investigación Consolidada UIC-128.

- optimización de nUEVOS PROCESOS EN la INDUSTRIa Alimentaria, BASADOS EN LA TECNOLOGÍA HPCD (HIGH PRESSURE CARBON DIOXIDE), PARA PRESERVAR LA CALIDAD DE ALIMENTOS FRESCOS, financiado por el Ministerio de Economía y Competitividad y el Fondo Europeo de Desarrollo Regional (CTQ2015-64396-R). 



\section{AGRADECIMIENTOS}

Al Ministerio de Economía y Competitividad y al Fondo Europeo de Desarrollo Regional por financiar el proyecto (CTQ2015-64396-R) en el que he trabajado.

A mis directoras de Tesis. A Tere, por su dedicación en este proyecto, por todo lo que he aprendido de ella, por la ayuda que me ha brindado en todo momento y por todo su apoyo e interés demostrado día a día. A Sagrario, por haber depositado su confianza en mí para formar parte de este proyecto y por toda su ayuda a lo largo de estos años.

A todos mis compañeros del Área de Ingeniería Química, que de una forma u otra han participado en esta Tesis. En especial agradecer a Beti su ayuda desde el principio y todo lo que me ha enseñado en este tiempo. Agradecer también a Óscar, por su ayuda y consejos, pero también por su compañía. A María, por su ayuda en el laboratorio, su compañía y la suerte de haber coincidido con ella. A toda la gente con la que he trabajado estos años y con los que he compartido tantos buenos momentos. También agradecerles a Esther, Sandra y Lara su ayuda y contribución a través de sus trabajos de investigación.

A la Dra. Paula Bourke, del Instituto Tecnológico de Dublín, por aceptarme en su grupo y darme la oportunidad de evolucionar en mi carrera investigadora. A Sonal, por su ayuda en el laboratorio, pero sobre todo por hacerme sentir como en casa.

A Yolanda, Lydia y Pablo, por ser la parte más divertida de esta tesis, por todas las comidas juntos y tantos buenos recuerdos que me llevo de estos años. A Alba, por sus visitas y buenos momentos compartidos. Gracias por vuestros consejos, comprensión y amistad.

A mi familia y a mis amigos, por apoyarme siempre, por vuestro interés y confianza en mi capacidad. Por haber estado conmigo en todo momento y por vuestros consejos.

Y por último, a la persona que me animó desde el primer momento a realizar esta Tesis y por su constancia en seguir animándome hasta el último día. A Aitor, por su infinita ayuda, comprensión, complicidad y por transmitirme su orgullo día a día a pesar de la distancia. Gracias. 

GENERAL INDEX 



\section{GENERAL INDEX}

SUMMARY OF THE THESIS

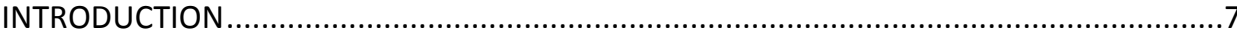

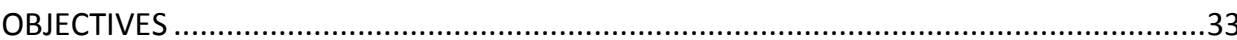

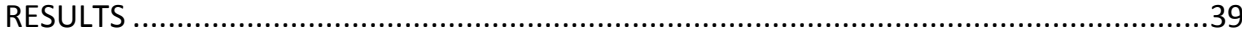

\section{Chapter 1:}

Evaluation of HPCD batch treatments on enzyme inactivation kinetics and selected quality characteristics of cloudy juice from Golden delicious apples.

\section{Chapter 2:}

Effect of Thermosonication batch treatment on enzyme inactivation kinetics and other quality parameters of cloudy apple juice

\section{Chapter 3:}

Enzyme inactivation and other properties of cloudy apple juice after High Pressure Carbon Dioxide and Thermosonication treatments and during refrigerated storage

\section{Chapter 4:}

Effect of Cold Plasma on polyphenol oxidase inactivation in cloudy apple juice and on the quality parameters of the juice during storage.

\section{Chapter 5:}

High pressure $\mathrm{CO}_{2}$ solubility in food model solutions and fruit juices 175

\section{Chapter 6:}

Optimization of polyphenol oxidase concentration by cationic reversed micellar extraction of Golden delicious apple: High Pressure Carbon Dioxide and Thermosonication enzyme inactivation.

\section{Chapter 7:}

Effect of High Pressure Carbon Dioxide on tomato juice: inactivation kinetics of pectin methylesterase and polygalacturonase and determination of other quality parameters. 


\section{Chapter 8:}

Effect of High Pressure Carbon Dioxide on polyphenol oxidase from Litopenaeus

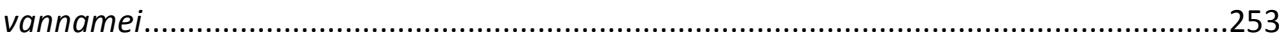

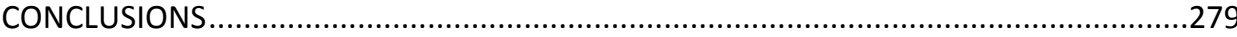

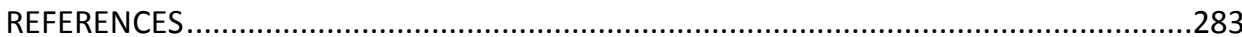




\section{SUMMARY / RESUMEN}





\section{SUMMARY OF THE THESIS}

In recent years, consumers are aware of the need to consume healthier food products, and this tendency is increasing. The demand for fresh-like, free of additives and minimally processed products has increased in a great extent. Regarding this life style, consumption of fruit and vegetable juices is in the ascendant. Anyway, it's difficult to acquire these products without added additives or without having suffered a heat treatment for their pasteurization, since it's necessary for the inactivation of deleterious enzymes and microorganisms. Heat treatment is the traditionally used treatment for juices, but it can produce the loss of nutrients of interest and important organoleptic properties. Thus, the main objective of this Thesis is the evaluation of alternative non-thermal technologies for achieving the needed enzymatic inactivation in order to avoid the spoilage of the product during processing and storage. The main technology studied in this Thesis is High Pressure Carbon Dioxide (HPCD), which employs pressurized $\mathrm{CO}_{2}$ but at lower temperatures than the ones used in traditional pasteurizations $\left(<50^{\circ} \mathrm{C}\right)$, avoiding the loss of thermolabile nutrients. The main investigated product has been cloudy apple juice from Golden delicious apples, but this technology has been also applied on tomato juice, shrimps and enzymatic extracts in order to compare the effect of HPCD in different matrixes. The effect of HPCD treatment has been compared with other non-thermal technologies, such as Thermosonication, Cold Plasma or High Hydrostatic Pressure.

Another important objective is the preservation of nutrients and organoleptic properties throughout storage, and therefore, studies of the changes during storage time have been carried out to know the effect of these treatments on properties of interest such as color, polyphenol content or antioxidant capacity of the treated food, as well as their changes during storage.

Enzymatic inactivation mechanism produced by these treatments has been also studied in order to get to know them better and try to optimize the processes for their posterior use in the Food Industry. 



\section{RESUMEN DE LA TESIS}

En los últimos años la preocupación de los consumidores por adquirir productos más saludables ha aumentado en gran medida. Se ha incrementado la demanda de alimentos con un aspecto natural, sin aditivos añadidos y mínimamente procesados. Debido a esta búsqueda de una alimentación más sana, el consumo de zumos de frutas y vegetales también está en auge. Sin embargo, no es fácil adquirir dichos productos sin que hayan sido tratados a altas temperaturas o que no contengan aditivos, ya que es necesario asegurar la destrucción de enzimas y microorganismos presentes en el alimento para su comercialización. El tratamiento térmico es la técnica habitual para el tratamiento de zumos, pero conlleva una pérdida significativa de nutrientes de interés, así como de propiedades organolépticas. Por ello, el principal objetivo de esta Tesis es la evaluación de tecnologías alternativas no térmicas que consigan la inactivación enzimática de los productos tratados para así evitar el deterioro del alimento durante su procesado y almacenamiento. La principal tecnología por la que se apuesta en esta Tesis es el dióxido de carbono presurizado ( $\mathrm{HPCD}$ ), donde se emplea $\mathrm{CO}_{2}$ a alta presión pero a temperaturas menores que en un tratamiento térmico $\left(<50^{\circ} \mathrm{C}\right)$, lo que evita la pérdida de nutrientes termolábiles. El principal alimento estudiado ha sido zumo de manzana no clarificado de manzana Golden delicious, pero esta tecnología también se ha aplicado en zumo de tomate, langostinos y extractos enzimáticos para comparar el efecto del tratamiento en diferentes matrices. La tecnología HPCD se ha comparado con otros tratamientos no térmicos como la termosonicación, el plasma frío o las altas presiones hidrostáticas.

Por otra parte, dado el gran interés de la conservación de nutrientes y de propiedades organolépticas de los alimentos tratados, se han realizado estudios de vida útil para conocer el efecto de los tratamientos empleados en propiedades de interés como el color, contenido en polifenoles totales o la capacidad antioxidante del alimento, así como su evolución a lo largo del tiempo de conservación.

También se ha estudiado el mecanismo de inactivación enzimática que tiene lugar cuando estos tratamientos son aplicados en los alimentos, con el fin de comprenderlos mejor y poder optimizar dichos procesos para su posterior uso en la industria alimentaria. 

INTRODUCTION 



\section{Non thermal technologies}

Nowadays there is a growing interest for high-quality, fresh like and minimally processed products that retain the natural and fresh appearance and the nutritional composition of food. Therefore, the Food Industry has the challenge of meeting consumers demand, whereas also producing safe food (Ferrentino \& Spilimbergo, 2011).

Conventional thermal processing methods, such as blanching, pasteurization, and sterilization are widely used in the Food Industry, since the high temperatures applied will cause a rapid inactivation of microorganisms and enzymes, the two main objectives for the assurance of safety, quality and long shelf life (Alexandre et al., 2012). However, the application of such high temperature conditions (thermal pasteurization up to $80^{\circ} \mathrm{C}$ and sterilization up to $120^{\circ} \mathrm{C}$ ) causes undesirable effects in several quality parameters of food products, such as color, flavor and texture, and can also destroy heat-sensitive nutritional components, such as vitamins and polyphenol compounds, producing a decrease in the organoleptic and nutritional quality and, therefore, in consumer's acceptance (Hu et al., 2013).

Chemical agents are also applied during processing and storage of many foods in order to prevent the deteriorative effect of many enzymes and microorganisms but, although they are highly effective, many of them are related to allergies and negative effects on human health. Furthermore, consumers now prefer food without additives, so the use of these agents also needs to be replaced.

In this regard, the Food Industry requires exploring the application of alternative non thermal technologies for assuring the safety and quality of their products while also meeting the requirements of the consumers. In particular, much attention has been paid to High Pressure Carbon Dioxide (HPCD), a promising technology that has already been applied in extent on different substrates. 
In this PhD Thesis, the application of non-thermal technologies for the assurance of quality in fresh food products has been studied. The main studied technology is High Pressure Carbon Dioxide (HPCD), whose application has been tested in many different substrates. First and basically, it has been applied in liquid food, specifically in fruit juices such as apple and tomato juices. The effect of HPCD has been also studied in solid foods, in particular on seafood.

Besides HPCD technology, the use of other non-thermal technologies has been also studied in this PhD Thesis. These have been Thermosonication (TS), Cold Plasma (CP) and to a lesser extent High Pressure Processing (HPP). Those are some of the possibilities in the area of non-thermal technologies, and their operation mode and application in food will be explained in next sections.

Although these technologies could be also applied for the control of deleterious microorganisms in food, in this PhD Thesis, their use has been focused on their effect on food enzymes that could produce undesirable effects on food products. The suitability of these technologies for the Food Industry has been also tested through their effect on the physical, chemical and nutritional properties of food substrates where they have been applied, as well as their evaluation during refrigerated storage.

\section{Enzymes of interest in the Food Industry}

The Food Industry has always taken advantage of the activity of certain enzymes to obtain desired products. However, the catalytic activity of some enzymes that are naturally present in food can be sometimes undesirable and produce a deleterious effect on the organoleptic and nutritional properties of a product. Therefore, knowing their mechanism of action and the procedure for their inactivation is an essential need for the Food Industry. Hereunder there is a detailed explanation of the different enzymes explored in this PhD Thesis. 


\subsection{Polyphenol oxidase}

Polyphenol oxidase, PPO (EC 1.10.3.1) is widely found in nature. It is typically present in the majority of plant tissues, but also in animals, fungi and bacteria. It is one of the most studied oxidative enzymes, since it is involved in the biosynthesis of browning in plants and melanosis in animals (De la Rosa et al., 2010). Polyphenol oxidase is a copper enzyme, whose active site is formed by two copper atoms, each one bound to three histidine residues. This is the site of interaction between PPO, the molecular oxygen and its substrate, phenolic compounds (Klomklao et al., 2012).

PPO is an enzymatic complex which generally refers to two enzymatic activities: monophenolase and diphenolase activity, both involved in phenol oxidation. The reaction that takes place depends on the available substrate. PPO substrate specificity changes with the source and type of the enzyme. PPO from plants and fungi can act on a wide range of monophenols and 0 -diphenols, while PPO from animals can be specific for tyrosine and DOPA (Gögus et al., 2010). In presence of molecular oxygen, PPO produces the hydroxylation of monophenols to $o$-diphenols, and then their consecutive oxidation to o-quinones (Figure I.1). Quinones formed by PPO are unstable molecules, and they may condense and react non-enzymatically with other phenolic compounds, proteins, amino acids, and other cellular constituents, producing brown melanoidin pigments (Gögus et al., 2010). These high weight and relatively insoluble molecules are the ones that cause the appearance of browned areas or black spots in many food products.

Main products affected by this problem are fresh fruit and vegetable products, such as juices, nectars and purees, but also seafood. Enzymatic browning is a problem of great importance, since it is directly related to the sensory and nutritional quality of food, and therefore, to consumer's acceptance. It causes large economic losses to the Food Industry, so, avoiding PPO activity is an action of main interest.

Several approaches to prevent or decrease browning have been explored and applied. Inhibition is focused on trying to eliminate one or more of the components that take part of the reaction, which are oxygen, enzyme, copper or substrate. 
In seafood products, reducing agents are used, mainly sulphites or similar compounds, such as sodium metabisulphite. They interfere in the phase of quinones polymerization, reducing the formed $o$-quinones, which are colored, to $o$-diphenols, which don't have any color, avoiding the formation of the brown polymers, and consequently, melanosis (Figure I.1). As explained before, the use of these chemicals in food is highly restricted to a few products due to their potentially pathological effects associated to allergies and asthmatic attacks, so, for example in fruits and vegetable products, inactivation of the enzyme is commonly achieved by heat treatment.

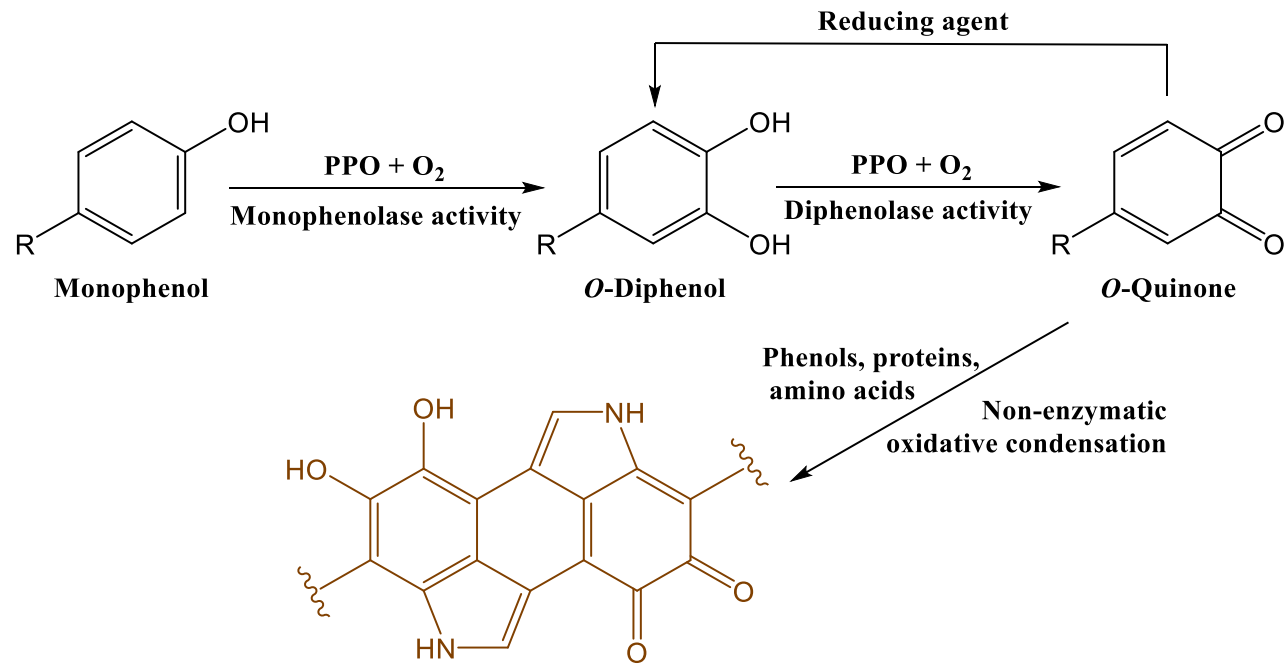

Brown melanoidin pigments

Figure I.1. Polyphenol oxidase action mechanism and effect of a reducing agent. Adapted from Yoruk \& Marshall (Yoruk \& Marshall, 2003)

\subsection{Pectin methylesterase}

Pectin methylesterase, PME (EC 3.1.1.11) has been found in plants as well as in pathogenic fungi and bacteria. This enzyme is present in the cell wall and catalyzes the hydrolysis of the methylester groups from pectin (Nguyen et al., 2002). Its action is especially important in fruits and vegetables, since structural and textural properties of fruit and vegetable tissues are largely dependent on the cell wall. 
Pectin substances give firmness and elasticity to tissues, and the modification of their structure by enzymes has a great impact on the texture of the resulting product (Balogh et al., 2004). Pectin is a group of heteropolysaccharides with a large molecular structure. It is composed of long chains of galacturonic acids residues. On each residue, there is a carboxyl group, sometimes esterified by the addition of methyl groups (Figure I.2). In natural pectin, nearly $80 \%$ of the carboxylic groups of galacturonic acid are esterified with methanol (Sharma \& Satyanarayana, 2017). PME catalyzes the specific demethylation of these carboxyl groups within plant cell walls, creating negatively charged carboxyl groups (Figure I.2) and releasing methanol and protons. Those demethylated groups can crosslink with divalent ions such as $\mathrm{Ca}^{2+}$ or $\mathrm{Mg}^{2+}$, present in many food matrixes. As a result, pectate gels are produced, forming insoluble pectate precipitates (Sila et al., 2009).

In some products, the action of this enzyme is required to get the desired final product, for example in clarified fruit juices and nectars, but its action is a problem for the production of cloudy fruit juices, whose demand is increasing due to their higher nutritional value (Oszmianski et al., 2007). The pectate gels formed after the action of PME will precipitate, producing clarification, and therefore, viscosity and cloud loss (Zhou et al., 2009). The main characteristic of these products is the presence of the 'cloud', which provides turbidity, flavor and color to cloudy juices. Its absence, or the presence or sediments is perceived by the consumer as lower quality juices (Baker \& Cameron, 1999). For that reason, although other peptic enzymes as well as external factors are involved in cloud loss, inhibition of PME activity is necessary in cloudy juices. In the Food Industry, pectin methylesterase inactivation is usually achieved by high heat treatments.

\subsection{Polygalacturonase}

Polygalacturonase, PG (EC 3.2.1.15) is, as well as PME, a pectinase; it degrades pectin. It has been found in some fungi, bacteria, yeasts and in several higher plants. The action of PG occurs over the bounds $\alpha-1,4-D$ galacturonan present in pectin. It hydrolyses the pectin chain, breaking it down. Polygalacturonase generally acts over non esterified substrate (Figure I.2), so its activity is closely related to the one of PME (Duvetter et al., 2009). When PG breaks pectin, in consequence, viscosity is also decreased, so as previously said, PG is 
also involved in cloud loss in cloudy juices, as PME. For that reason, this enzyme also needs to be inactivated in these juices, and heat treatments are usually used in the Food Industry.

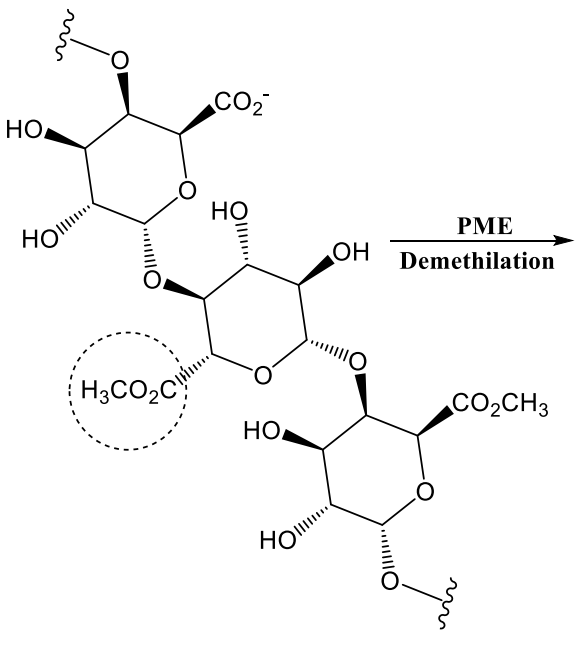

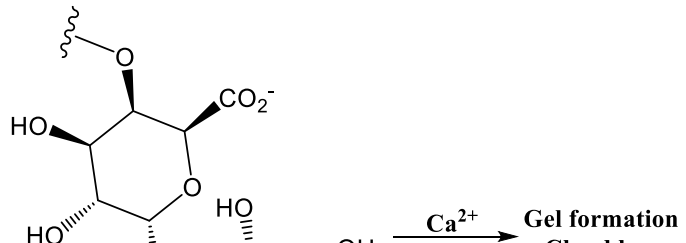

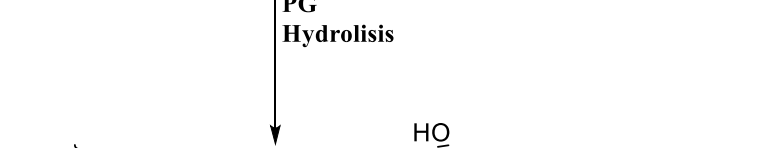

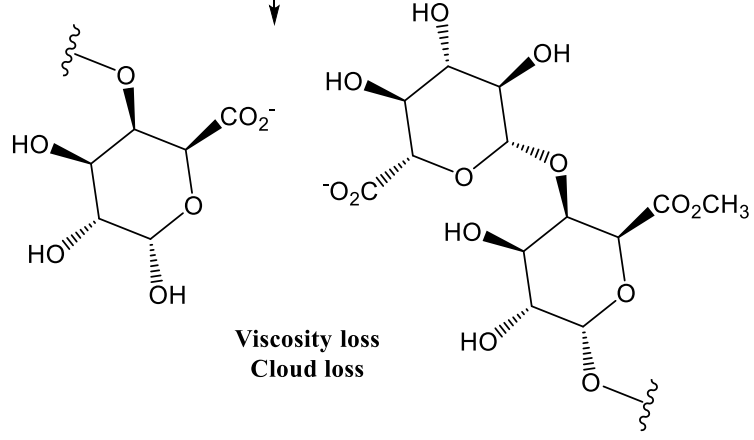

Figure I.2 Pectin methylesterase and polygalacturonase action mechanism on pectin. Adapted from Sila et al. (2009) 


\section{High Pressure Carbon Dioxide (HPCD)}

The use of compressed carbon dioxide has gained attention in the green chemistry industry, since it is non-toxic, non-flammable, widely available and it is easy to remove from the product where it is applied through a depressurization (Balaban, 2012). When pressurized $\mathrm{CO}_{2}$ technology is applied to food with the aim of inactivating microorganisms and enzymes, it is usually used under supercritical conditions, due to the special physicochemical properties that it acquires. Carbon dioxide critical point is $304.15 \mathrm{~K}$ and 7.38 MPa (Figure I.3). These mild critical conditions make HPCD an accessible technology, and also suitable for the treatment of food that may contain thermolabile compounds. In the supercritical region, $\mathrm{CO}_{2}$ presents intermediate properties between a gas and a liquid, what means that its density is similar to the one of a liquid, and its diffusivity and viscosity are gas-like. $\mathrm{SC}-\mathrm{CO}_{2}$ has a good solvent power and good transport properties, what can be very useful for the treatment of many foods (Brunner, 1994). However, $\mathrm{CO}_{2}$ is also used below critical conditions; usually by the use of temperature lower than the critical one. High pressurized carbon dioxide technology is widely applied for its effect on food properties, and, hereinafter, it will be named as HPCD technology.

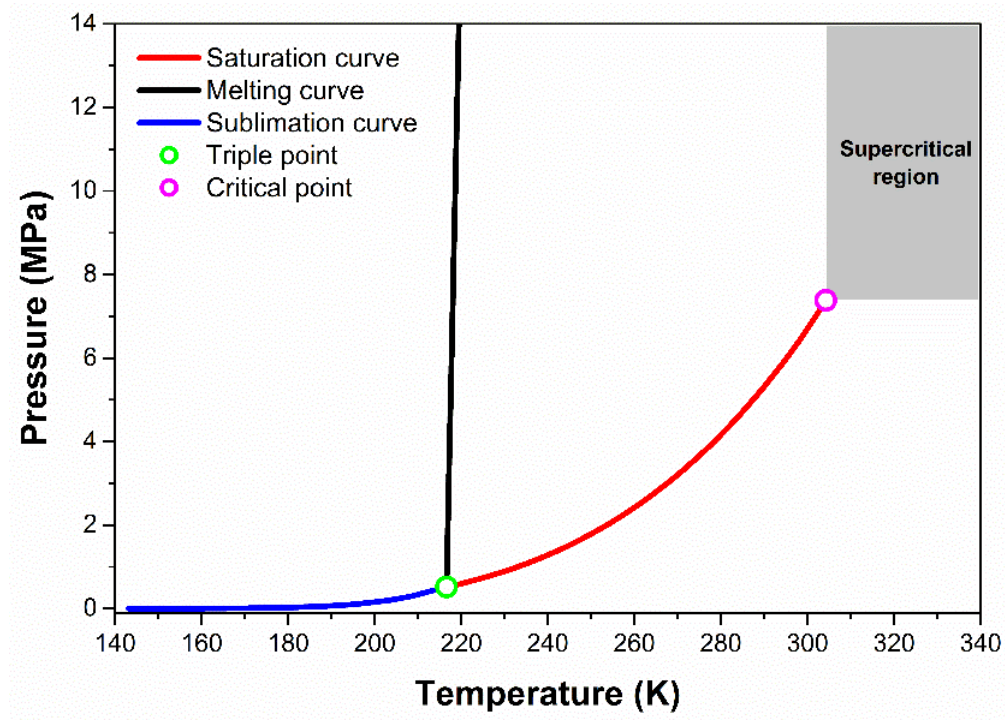

Figure I.3 Phase diagram of carbon dioxide illustrating the supercritical region above the critical temperature and pressure. Data taken from Angus et al. (1976) 
Due to the operating conditions of HPCD, this technology is considered a cold pasteurization, since it operates at low temperatures (between 5 and $60{ }^{\circ} \mathrm{C}$ ) in comparison to a traditional heat treatment. Furthermore, much lower pressure conditions are needed than in other technologies such as High Pressure Processing (HPP), since HPCD usually operates below $50 \mathrm{MPa}$.

\subsection{Use of HPCD on food products}

Although the application of HPCD technology in food for inactivation of enzymes is noticeably increasing in the last years, it has been widely studied with the aim of inactivating food microbiota. HPCD has been usually applied to liquid foods due to its excellent properties of diffusion and solubility. Fruit juices are a good target for the use of this technology, since they have plenty of nutrients that can be negatively affected by heat and the quality of those juices is noticeable decreased by the present enzymes. The variety of HPCD treated fruit juices is really wide, for example Zhou et al. (Zhou et al., 2009) treated carrot juice at $15 \mathrm{MPa}$ and $55^{\circ} \mathrm{C}$, and after 45 minutes of treatment, residual activity of PME was only 4.5 \%. Similar PPO inactivation was achieved by Liu et al. (Liu et al., 2013) on watermelon juice after HPCD treatment of $30 \mathrm{MPa}$ at $50^{\circ} \mathrm{C}$ during 30 minutes, where final residual activity was just $4.2 \%$. They achieved total inactivation of PPO in apple juice after treating it during 20 minutes at $20 \mathrm{MPa}$ and $55^{\circ} \mathrm{C}$.

Nevertheless, some studies have also focused the use of HPCD on solid foods, especially seafood, where enzymes have a key role in their quality. Chen et al. (Chen et al., 1992) first started treating seafood by HPCD, obtaining really high inactivation values. They treated Spiny lobster and Brown shrimp at 5.8 $\mathrm{MPa}$ at $43{ }^{\circ} \mathrm{C}$ during just one minute and final residual activity was 5 and $22 \%$ respectively. This difference on enzymatic inactivation rates gives an idea on how different the inactivation can be depending on the source of the enzyme, enzyme type or the food matrix where it is present. 


\subsection{Enzyme inactivation mechanism}

It is known that enzyme inactivation by HPCD is not only achieved by the effect of pressure and temperature, since this technology can inactivate some enzymes at temperatures where thermal treatment has no effect, as well as at much lower pressure values than the ones used on HPP treatments (Damar \& Balaban, 2006), concluding that the presence of carbon dioxide is essential for enzymatic inactivation. Inactivation mechanism by HPCD is not yet completely understood, but many approaches can be found in literature. It is important to consider that enzymes are delicate molecules, and their behavior depends on the interactions within the protein chain and with the surrounding solvent (Jaenicke, 1991).

First, a pH lowering due to the effect of $\mathrm{CO}_{2}$ dissolution has been pointed out as a possible inactivation cause. When carbon dioxide is dissolved in water, carbonic acid is produced, which will then dissociate and give bicarbonate, carbonate and $\mathrm{H}^{+}$ions (Figure I.4), decreasing the medium $\mathrm{pH}$, and in consequence, intracellular $\mathrm{pH}$, what would affect to enzymes activity (Sampedro \& Zhang, 2012). However, in juices with an initial low pH value, such as tomato or apple juices ( $\mathrm{pH}$ value around 4.0), carbonic acid will hardly dissociate because the dissociation constant of carbonic acid and bicarbonate are $\mathrm{pK}_{\mathrm{a}}=6.57$ and $\mathrm{pK}_{\mathrm{a}}=10.62$, respectively (Figure I.4), so $\mathrm{pH}$ value will not change noticeably (Zhou et al., 2015). Significant changes can be easily observed in juices with an initial pH value closer to the one of pKa. For example carrot juice with an initial pH value of 6.74 was treated by Zhou et al. (Zhou et al., 2009) at $10 \mathrm{MPa}$ and $25^{\circ} \mathrm{C}$ during 30 minutes and $\mathrm{pH}$ dropped to 5.95 .

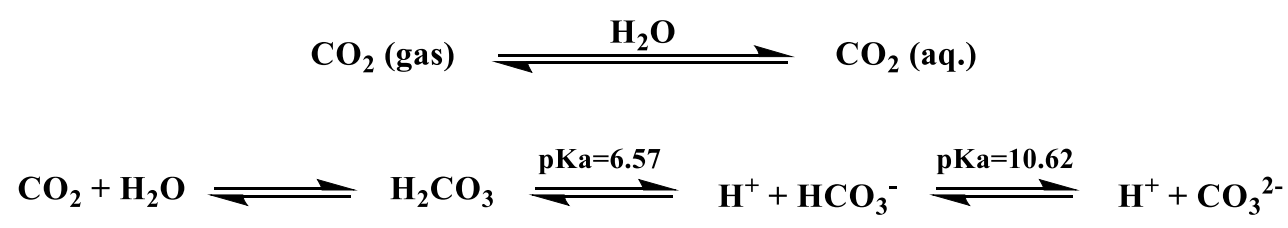

Figure I.4. $\mathrm{CO}_{2}$ dissociation equilibria when it is dissolved in water. Adapted from (Damar \& Balaban, 2006; Hu et al., 2013) 
Another HPCD-induced inactivation hypothesis is the inhibitory effect of molecular $\mathrm{CO}_{2}$. Some authors have suggested that enzymes may be inactivated by the formation of a complex with $\mathrm{CO}_{2}$ molecules. First, Weder \& Bokor (Weder \& Bokor, 1992) proposed that at low $\mathrm{pH}$, the arginine bound to proteins could interact with $\mathrm{CO}_{2}$ easily and form a bicarbonate complex. In the same way, Fricks et al. (Fricks et al., 2006), suggested that the free amino groups on the surface of the enzyme could interact with $\mathrm{CO}_{2}$ and form covalent carbamates. Formation of these carbamates would remove charges of amino acids residues and contribute to the loss of enzyme activity (Kamat et al., 1995).

Furthermore, there could be hydrophobic interactions between $\mathrm{CO}_{2}$ and the active site of the enzyme, causing its inactivation (Hu et al., 2013). This could be possible due to the fact that $\mathrm{CO}_{2}$ under supercritical conditions does not have surface tension, and therefore can penetrate easier in a molecule and reach the active site of the enzyme (Clifford \& Williams, 2000).

Depressurization also plays an important role on enzyme inactivation. Decompression consists of two steps, the formation of a gas-liquid interface and the quick release of $\mathrm{CO}_{2}$. Proteins are amphipathic molecules that may spontaneously move to the gas-liquid interface, where they would unfold and orientate nonpolar residues to the gas phase and polar residues to the liquid phase. On the non-polar phase, the unfolded protein would aggregate with $\mathrm{CO}_{2}$ molecules forming new complexes, as explained before (MacRichie, 1978). When the system is depressurized, a sudden release of the applied $\mathrm{CO}_{2}$ pressure from the solvent occurs, which results in rapid gas expansion from the enzymes, producing their inactivation (Kasche et al., 1988).

Finally, another possible cause of inactivation, which is highly accepted, is that HPCD induces structural changes in enzymes. Many studies show how secondary and tertiary structure of the enzyme can be changed in a great extent after HPCD treatment. Enzymes present a complex structure that can be modified under extreme conditions, producing their denaturation and therefore, loss of activity (Balaban, 2012). Circular dichroism is a spectroscopic technique that gives information about the secondary structure of a protein, and provides a direct characterization of the changes in the structure of the enzyme before and after a treatment. 
According to Zhong et al. (Zhong et al., 2004), the main reason for the loss of activity is the change of secondary structure in terms of a loss of $\alpha$-helical structure. For example, Gui et al. (Gui et al., 2006) observed that as pressure conditions were increased in HPCD treatments, the $\alpha$-helix relative content of HPCD-treated peroxidase from horseradish decreased, as well as enzyme residual activity, showing that the loss of enzyme secondary structure was directly related to the reduction of its activity.

Changes in tertiary structure of proteins can be also measured, in this case by fluorescence spectroscopy. Information about the structural changes can be obtained through the intrinsic fluorescence emission from tryptophan residue in proteins. Changes in tryptophan fluorescence can be used as an indicator of oxidation reactions and, in consequence, changes of the conformation and three-dimensional structure of proteins (Surowsky et al., 2013) This residue is sensitive to the environment that surrounds it, so if HPCD affects this environment, it will produce changes in the structure of the enzyme (Gui et al., 2006; Liao al., 2009; Zhou et al., 2009).

According to Gui et al. (Gui et al., 2006), when pressure of HPCD treatment increased, the fluorescence intensity of horseradish POD also increased. They suggested that HPCD treatment increased the distance between the tryptophan and the heme group in the enzyme, decreasing the energy transfer from tryptophan to the heme group. On the other hand, Liao et al. (Liao et al., 2009) obtained that the fluorescence intensity of lipoxygenase treated by HPCD decreased when pressure increased, and they explained it by the unfolding of the enzyme induced by HPCD, what would expose tryptophan to the solvent, and this one would act as a quencher, reducing fluorescence signal. After treating PME, Zhou et al. (Zhou et al., 2009) also reported changes in fluorescence intensity, but depending on the pressure applied, intensity decreased or increased. However, it can be said that an increase or reduction in the fluorescence signal indicates a change in the tertiary structure of the enzyme, induced by HPCD, and produces changes on enzymatic activity. The way in which the structure of the enzymes changes depends on the source of the enzyme and on the environment where it is present (Hu et al., 2013). 


\subsection{HPCD process parameters affecting enzymatic inactivation}

The stability and inactivation of enzymes exposed to HPCD depend on many factors, such as operating conditions of pressure and temperature as well as time of exposure to HPCD, depressurization mode and stirring speed. As previously said, also the matrix in which the enzyme is present will affect enzyme inactivation. For example, the effect of HPCD is enhanced by higher temperatures, because, although when temperature increases the solubility of carbon dioxide is lower, higher temperatures increase its diffusivity and can accelerate the molecular collisions between the enzyme and $\mathrm{CO}_{2}$ (Niu et al., 2010a). The same effect is observed when pressure is increased. As pressures levels increase, enzymatic activity decreases. For example Zhi et al. (Zhi et al., 2008) observed that by increasing pressure stepwise, the activity of apple PME decreased in the same way. Stirring speed also increases mass transfer and facilitates the solubilization of $\mathrm{CO}_{2}$, making its penetration in the molecules and the contact between $\mathrm{CO}_{2}$ and the enzyme easier (García-González et al., 2009).

The presence of nutrients such as sugar, salts and alcohols can protect proteins from denaturation. For example, Zhou et al. (Zhou et al., 2009b, 2010) treated both peach juice and commercial PME in a buffer at the same HPCD treatment conditions and they observed that residual activity was much higher in the juice, explaining this behavior with the interaction of PME with cell wall and other components present in the juice matrix.

\subsection{Effect of HPCD treatment on food properties}

Apart from the inactivation effect caused on food enzymes, HPCD technology is claimed not to produce negative changes on food quality properties. Study of the effect of HPCD treatments on food quality parameters and of their evolution are of great interest for the Food Industry and the viability of treated products.

For example, color of apple juice was maintained after HPCD treatment, and was lighter than the juice treated by a mild heat treatment. After storage during 7 days, the heat 
treated sample had suffered browning, as the untreated one, while the HPCD treated juice maintained its color (Niu et al., 2010b).

Another important property of fruit juices, highly valued by consumers, is the presence of polyphenol compounds due to their antioxidant activity. These compounds are thermolabile and destroyed when heat treatment is applied. As HPCD operates at lower temperatures, polyphenol content of juices should not decrease. An example is that Gasperi et al. (Gasperi et al., 2009) found no significant changes in total polyphenol content after applying an HPCD treatment (10 MPa, $36^{\circ} \mathrm{C}, 10$ minutes) on apple juice.

Finally, sensory properties are of great importance for the commercialization of a food product. Kincal et al. (Kincal et al., 2006) found no difference between the organoleptic properties of HPCD-treated and fresh samples and also after two weeks of storage at low refrigeration temperatures $\left(1.5^{\circ} \mathrm{C}\right)$.

HPCD has been shown to be a good alternative to traditional heat treatments on the inactivation of enzymes, as well as in the preservation of the quality properties of the food where it is applied. Nevertheless, many research needs to be done to elucidate enzymatic inactivation mechanism through HPCD.

\section{High Pressure Processing}

High Pressure Processing (HPP) is a cold pasteurization technique that consists of exposing food to a high level of hydrostatic pressure (300-600 MPa) from a few seconds to a few minutes (Figure I.5). This technology is a natural and environmentally friendly process that respects the ingredient and helps maintaining the fresh food characteristics like flavour and nutrients, since it is usually applied at room temperature. 


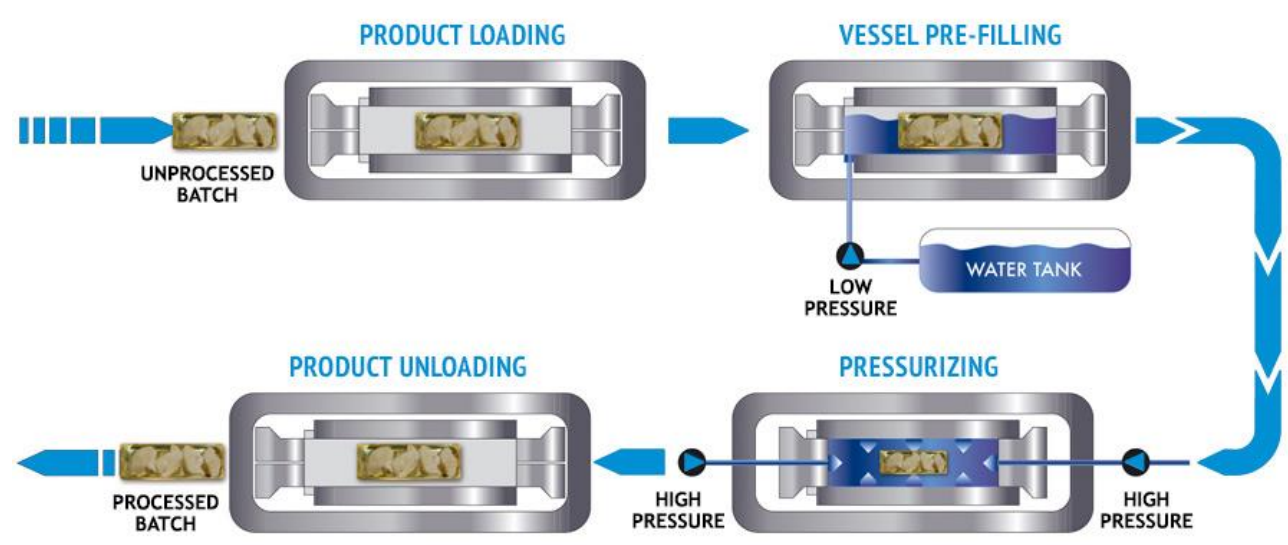

Figure I.5. HPP processing. Retrieved from (https://www.hiperbaric.com/es/)

Microorganisms and deteriorative enzymes can be inhibited or inactivated depending on the pressure and time applied to the product. This technology is mostly employed for the inhibition of microorganisms, where it is very efficient. According to Gögus et al. (Gögus et al., 2010), microorganisms (different to spores), can be inactivated at mild pressures, lower than $300 \mathrm{MPa}$, but inactivation is harder when talking about food quality-related enzymes.

Enzymes are usually pressure-stable and their inactivation depends in a big extent on the type of enzyme, medium composition, $\mathrm{pH}$ and many other conditions (Hendrickx et al., 1998). Hendrickx et al. also explain that when low pressures are used, around $100 \mathrm{MPa}$, many enzymes have shown their activity increased and quality parameters of the product can be changed in a negative way, especially color. Much higher pressure conditions are needed to achieve enzymatic inactivation. Enzyme inactivation by HPP technology can be explained by the secondary structure changes induced by high pressure, leading to irreversible denaturation. Hydrogen bonds are responsible for maintaining the helical structure of peptides. They are enhanced at low pressures and are only ruptured at very high pressure. The rupture of ionic bonds is strongly affected by pressure increases (Gross \& Jaenicke, 1994). 
Although HPP technology is usually applied at low temperatures, for the inactivation of some enzymes it is necessary to use mild temperatures combined with pressure for their inactivation. For example Kaur \& Rao (Kaur \& Rao, 2017) treated an extract of PPO enzyme from black tiger shrimp at $30^{\circ} \mathrm{C}$ and $500 \mathrm{MPa}$ during 15 minutes and only obtained a reduction of around $20 \%$ on the enzyme activity. Increasing temperature to $50{ }^{\circ} \mathrm{C}$, the decrease on PPO activity increased to $60 \%$, although it is still a low inactivation rate compared to other technologies where lower temperature and pressure conditions are used.

At room temperature conditions, apple juice was treated by HPP treatment between 430 and $570 \mathrm{MPa}$ from 1 to 8 minutes in the study carried by Juarez-Enriquez et al. (JuarezEnriquez et al., 2015). After this treatment they measured residual activity of both PPO and PME, showing two different effects. First, PME was completely inactivated and reactivation did not occur during storage time. On the other hand, PPO activity increased after HPP treatment, being this effect higher at lower pressure conditions and at shorter times.

These results show the difference in the effect of the treatment according to the type of the enzyme and its source. The main difference is based on the structure of each enzyme. Usually, a higher susceptibility has been attributed to the more complex structure of PPO with three or four subunits, in higher plants, than PME, with one subunit. This structure, makes PME more stable to inactivation (Niu et al., 2010a). This theory can be extended to other technologies, both thermal and non-thermal ones.

\section{Thermosonication}

Ultrasounds is defined as a sound wave that is transmitted with a frequency higher than the audible one, $20 \mathrm{kHz}$ (Butz \& Tauscher, 2002). The application of ultrasounds in the Food Industry has been studied for many years in two main areas of application. First, high-frequency $(1-10 \mathrm{MHz})$ or low-power ultrasound is used for superficial treatments and non-destructive measurement of food properties during processing and storage for quality 
control purposes. Low frequency $(20-1000 \mathrm{KHz})$ or high-power ultrasound is used for deeper treatments in food processing. It is useful in invasive applications, which have impact on physical, biological and chemical properties of food, such as microbial and enzymatic inactivation. Apart from frequency intensity, there are two different ultrasonication techniques. The sample can be treated indirectly in an ultrasonic bath or through direct application using a probe sonicator, as the one shown in Figure $\mathbf{I . 6}$ (Abdullah \& Chin, 2014; Mason et al., 1996).

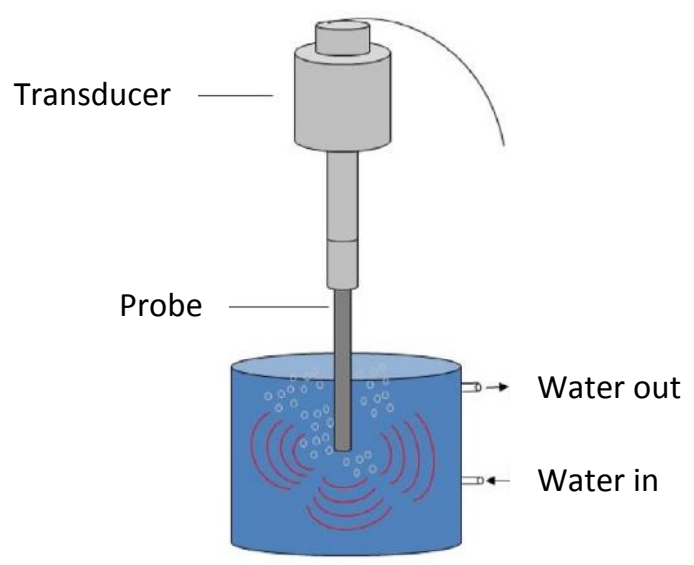

Figure I.6 Ultrasound probe components. Adapted from Chemat et al. (2017)

Many studies have reported that ultrasound technology on its own is not usually sufficient for achieving pasteurization of the product within a reasonable time or at feasible energy input levels. Therefore, ultrasounds are usually combined with other physical agents such as heat in order to improve effectiveness of the treatment. This combination of ultrasound and mild heat is called thermosonication (Terefe et al., 2015).

The effect of ultrasound on enzymes has been studied for a long time, and in particular, many studies can be found in literature regarding inactivation of enzymes present in fruit and vegetables juices. For example, Terefe et al. (Terefe et al., 2009) achieved almost complete inactivation of PME in tomato after a treatment at $75^{\circ} \mathrm{C}$ and just 4 minutes of treatment. High inactivation degree can also be obtained using lower temperatures. For example Jabbar et al. (Jabbar et al., 2015) treated carrot juice using an ultrasound probe of $13 \mathrm{~mm}$ diameter with a frequency of $20 \mathrm{kHz}$ during 10 minutes at $60{ }^{\circ} \mathrm{C}$, and they 
obtained that inactivation was more than $90 \%$ in all the enzymes studied, peroxidase, polyphenol oxidase and pectin methylesterase. Abid et al. (Abid et al., 2014) also obtained nearly total enzymatic inactivation in apple juice, where, after a treatment of 10 minutes at $60{ }^{\circ} \mathrm{C}$, the residual activity of PPO, POD and PME were around $6 \%, 9 \%$ and $7 \%$ respectively.

The inactivation effect of ultrasonication is mainly attributed to cavitation (Terefe et al., 2015). During the sonication process, when a sonic wave is produced in a liquid medium, longitudinal waves are created, what creates regions of compression and expansion (Sala et al., 1995). Cavitation is the formation, growth, and implosion of tiny gas bubbles or cavities during the propagation of these sound waves in a liquid (Raviyan et al., 2005). The changes in pressure depending of these implosions are the main mechanism of enzyme inactivation in treated food. The collapse of bubbles produces an extreme increase in temperature and pressure in a specific spot, which will produce a dispersion of a large energy concentration to the surroundings. The shock waves that are derived from bubble implosion have the ability of breaking large macromolecules by shear and mechanical stress. This process will cause the break of hydrogen bonds and Van der Waals interactions in the polypeptide chains of proteins, what induces conformational changes in the enzyme, and therefore, their loss of biological activity (Sala et al., 1995; Zhong et al., 2004).

In addition, as a result of intense cavitation, water molecules can be dissociated. This reaction is known as sonochemistry of water. The temperature in the hot spot can be so high that molecular bonds are broken, producing the dissociation of water vapour and generating highly reactive hydroxyl $\left(\mathrm{HO}^{\circ}\right)$ and hydrogen $\left(\mathrm{H}^{\circ}\right)$ free radicals. Two radicals can combine to form a new bond (Rooze et al., 2013). Additional radicals and reactive molecules may be formed when other chemical species are present, being the most common one $\mathrm{H}_{2} \mathrm{O}_{2}$. The free radicals and the new formed molecules may react with some amino acid residues that participate in enzyme stability, substrate binding or catalytic function with a consequent change in biological activity (López et al., 1994). Free radicals produced can attack specific sites such as disulphide bonds, destabilizing enzyme conformation, as well as oxidizing amino acid residues such as tryptophan, tyrosine, 
histidine and cysteine, involved in the catalytic activity of many enzymes (Cheng et al., 2007). When gas is added to the solution, the initiation of cavitation is easier, increasing the bubble volume. Furthermore, gases such as $\mathrm{O}_{2}$ and $\mathrm{N}_{2}$ influence the radical production. In the case of $\mathrm{N}_{2}$, its presence can produce the formation of nitrites and nitrates (Supeno \& Kruus, 2000). That way, addition of gas affects to enzyme inactivation, usually increasing it (Gielen et al., 2016).

Inactivation mechanisms are specific to each enzyme and depend on their amino acid composition and their conformational structure (Islam et al., 2014). It has also been probed that thermosonication is more effective in buffer systems than in real food systems, perhaps due to the protective effects of food components (Terefe et al., 2015).

Also the rate of enzyme ultrasonic inactivation highly depends on the processing conditions such as frequency, intensity, power input and temperature. An increase in the amplitude of ultrasound will lead to an increase in cavitation intensity and therefore in free radical production, what will probably cause a higher rate of enzyme inactivation (Vercet et al., 1998).

Although the effect of ultrasounds has been widely studied on enzymes inactivation, limited information is available on the effects of ultrasound on the nutritional and sensorial quality of treated food products. It may be possible that the free radicals generated during cavitation cause oxidation of nutrients and other food components leading to quality degradation. However, according to results found in literature, there is no evidence that sonication treatments cause higher quality degradation than an equivalent thermal process (Terefe et al., 2015). Furthermore, in some studies, thermosonication has shown to increase the level of bioactive compounds in fruit juices. For example Bhat et al. (Bhat et al., 2011) found that total phenolic content in kasturi lime juice increased significantly after thermosonication, and after longer treatments it was even higher. They explained this behavior through the theory that sonication causes the disruption of cell walls, where phenolic compounds are bound, releasing them to the medium. When total phenolic content increases, a corresponding increase in the antioxidant capacity of the juice also occurs, improving the juice quality. Similar results 
were obtained by Cheng et al. (Cheng et al., 2007), where after treating guava juice ascorbic acid content was increased.

The release of wall bound components to the medium could produce a change in color or rheological properties of the juices (Bhat et al., 2011). Anyway, many studies confirm that sonication can produce also an improvement in these properties. For example, after a sonication treatment of 5 minutes at $40{ }^{\circ} \mathrm{C}$, a slightly increase of $L^{*}, a^{*}$ and $b^{*}$ parameters of color was observed in apple juice, showing that browning of the juice didn't take place, and it was even lighter (Abid et al., 2015). The same effect was observed in the color of carrot juice in the study of Jabbar et al. (Jabbar et al., 2015). In both studies no change in $\mathrm{pH}$, total acidity and total soluble solids was observed. Finally, cloud value was also increased in some cloudy juices, where this parameter is of great interest. For example, cloud value was increased in cloudy apple juice after a thermosonication treatment of 10 minutes at $60^{\circ} \mathrm{C}$, and also stability and homogenization was increased (Baslar \& Ertugay, 2014).

Thermosonication has been shown to improve quality properties of juices. However, further research is needed to better understand the effects of ultrasound processing on bioactive compounds and sensory properties of foods (Sampedro \& Zhang, 2012).

\section{Cold Plasma}

Finally, Cold Plasma technology (CP) has also emerged as a non-thermal alternative in the past few years. Among all the emerging technologies, it is relatively a newer method for preserving the quality and safety of food products (Mandal et al., 2018). Plasma is usually defined as the fourth state of matter. In the same way that phase change happens from solid to liquid and from liquid to gas when energy input is increased, when this energy input is applied above a certain level in a gas state, it will cause ionization of molecules and yield the plasma state (Thirumdas \& Sarangapani, 2014). Plasma is a neutral charged group of ions, electrons, photons and atoms in their fundamental or excited states (Misra 
et al., 2011). Plasma can be generated in any neutral gas by providing enough energy for its ionization making plasma chemistry application wider (Pankaj et al., 2017a).

Plasma has been used in many different fields like textile, electronics, packaging, life sciences and the biomedical sector, being surface cleaning its main application. In recent years, the use of this technology has also expanded to the Food Industry, where usually chemicals and heat treatments are used with the purpose of surface disinfection in products like fruit, vegetables or seeds (Misra et al., 2016).

Plasma can be categorized as thermal plasma and non-thermal or cold plasma, differenced by their thermodynamic equilibrium. In thermal plasma, electrons and other gas species are in thermodynamic equilibrium, and in cold plasma they exist in non-equilibrium (Mandal et al., 2018). According to Coutinho et al. (Coutinho et al., 2018), cold plasma is generated at $30-60^{\circ} \mathrm{C}$, what makes it suitable for the treatment of heat sensitive food. Furthermore, cold plasma presents the advantage of minimal damage and non-toxic byproducts on food as well as low cost and short treatment times, what makes this technology to be an alternative to conventional heat treatments (Ziuzina et al., 2015).

Cold plasma technology applies electrical energy on carrier gases, like air, oxygen, nitrogen, or helium through the help of electrodes. Employing air as the plasma working gas confers many advantages for ease, cost, and flexibility of use.

There are many types of cold plasma generating systems, what offers a wide range of different applications in industry (Pankaj et al., 2017a). Common devices are dielectric barrier discharge (DBD), corona discharge, glow discharge and atmospheric pressure plasma jet (APPJ), being the most commonly used DBD and APPJ due to their simple design and working (Liao et al., 2017). Plasma devices can be also classified in two types, direct (Figure I.7) and indirect exposure, defined by the contact or not between plasma and sample, what will condition the effect of the treatment (Lu et al., 2017). Energy applied on these treatments dissociates the gas molecules into spark of ions, electrons, free radicals and other species which are active biologically. 
Different operating and design parameters will yield different types of reactive species, producing different effects on the treated sample (Mandal et al., 2018).

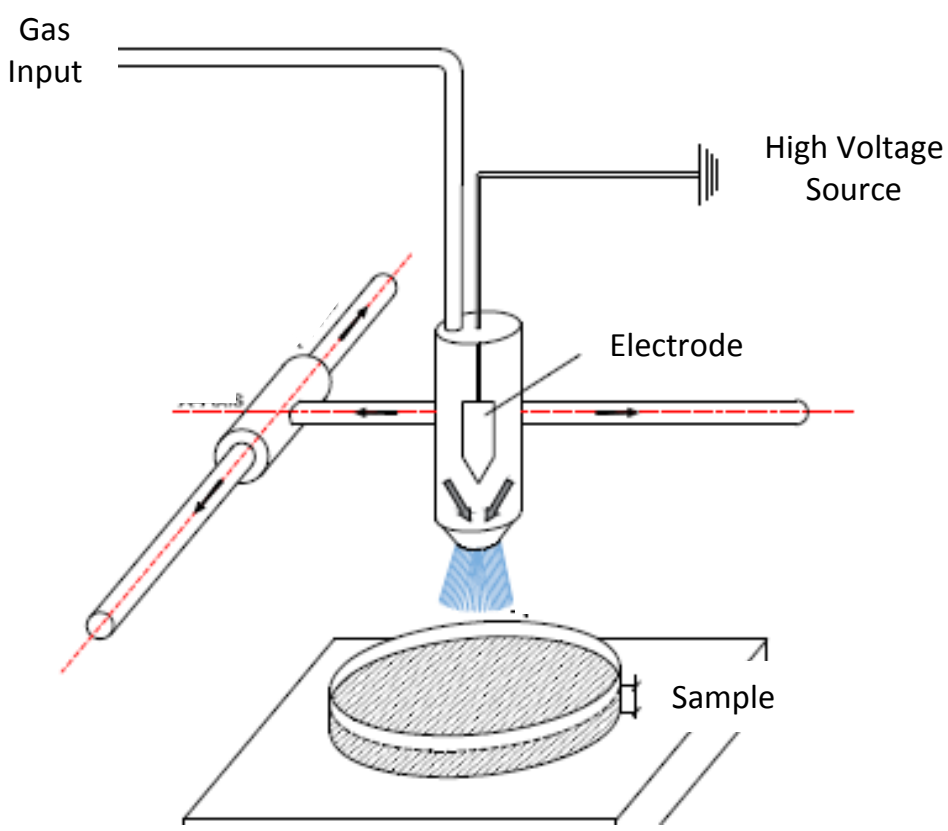

Figure I.7. Scheme of direct cold plasma system. Adapted from Dasan \& Boyaci (2018)

The effect of applying plasma has as result the formation of redox active species, reactive oxygen (ROS) and nitrogen (RNS) species, which are mainly generated near the gas-liquid interface and transported into the liquid phase. Some of these species are ozone $\left(\mathrm{O}_{3}\right)$, singlet oxygen $\left({ }^{1} \mathrm{O}_{2}\right)$, superoxide radical $\left(\mathrm{O}_{2}{ }^{\circ}\right)$, hydroxyl radical $\left(\mathrm{OH}^{\circ}\right)$, nitrogen monoxide radical $\left(\mathrm{NO}^{\circ}\right)$, and nitrogen dioxide radical $\left(\mathrm{NO}_{2}{ }^{\circ}\right)$. When these species get dissolved in the liquid, aqueous reactive species are formed, being the most important ones hydrogen peroxide $\left(\mathrm{H}_{2} \mathrm{O}_{2}\right)$, nitrite $\left(\mathrm{NO}_{2}^{-}\right)$and nitrate $\left(\mathrm{NO}_{3}^{-}\right)$since they are detected in plasma treated liquids and play an important role for biological effects (Lu et al., 2017a). As previously explained, different gases can be used, and therefore, different reactive species will be formed. According to Lu et al., (2017), $\mathrm{H}_{2} \mathrm{O}_{2}$ was the predominant species produced using argon plasma, while when using air plasma, mainly $\mathrm{NO}_{2}^{-}$and $\mathrm{NO}_{3}^{-}$are produced. Hydrogen peroxide formation is produced by the recombination of $\mathrm{OH}$ radicals formed after water molecule dissociation, and it is conditioned by the applied voltage and 
discharge duration, parameters that enhance it (Stara \& Krcma, 2004). Formation of these species is of great interest due to their known antimicrobial activity.

As explained, plasma has been applied in different fields, and specifically in the Food Industry its effect has been widely studied on microbial disinfection. In last years, there is a growing attention on the application of cold plasma for improving food quality through the inactivation of enzymes that may cause undesirable effects on the final product, although very few studies are still available in this field.

Cold plasma has been reported to inactivate a wide range of enzymes. For example, Tappi et al. (Tappi et al., 2014) treated apple slices with DBD plasma and inactivated $60 \%$ of polyphenol oxidase activity after 30 minutes at $22^{\circ} \mathrm{C}$. Much higher inactivation of mushroom PPO was found by Surowsky et al. (Surowsky et al., 2013) in a food model solution, achieving a $90 \%$ and $85 \%$ of inactivation after 3 and 4 minutes respectively using cold plasma jet. Nearly total inactivation of peroxidase activity was achieved in tomato extract after treating it with DBD plasma during 5 minutes, being residual activity of $3.6 \%$ (Khani et al., 2017).

The inactivation mechanism of enzymes by plasma treatments is not fully understood, but many theories can be found in literature. The effect of temperature was discarded by Surowsky et al. (Surowsky et al., 2013) due to no significant effect on loss of enzyme activity in their experiments, concluding that only the formed reactive species during plasma treatment are the responsible for enzyme inactivation.

Many authors agree on the fact that the mechanism of inactivation is primarily due to the loss of the secondary structure of the enzyme produced by the action of reactive species formed in plasma treatments. They can break peptide bonds and oxidize amino acids side chains. For example, Surowsky et al. (Surowsky et al., 2013) proved that plasma treatment produces changes in the secondary structure of enzymes. After treating polyphenol oxidase from mushrooms, they observed a significant decrease in $\alpha$-helix content using circular dichroism technology. They also observed changes in fluorescence emission, confirming that tertiary structure of the enzyme had changed. A small change in a protein structure can significantly change its function. 
The difference in the observed levels of enzyme inactivation that appear in the literature are due to the differences in the enzymes, their source, enzyme media, volume treated, plasma source and treatment conditions, including treatment time and input power (Pankaj et al., 2017b). Higher frequency and input voltage have been related to greater inactivation efficacy, as well as longer treatment times (Tappi et al., 2014).

Apart from enzyme inactivation, the maintenance of properties and nutrients present in the fresh product after the treatment is also of great interest for quality assurance. The potential use of $\mathrm{CP}$ will be conditioned by its effect on color, taste and nutritional content among other properties. Some studies have been performed in this direction, and mostly all have concluded that this technology does not affect in a deleterious way the quality parameters of food. For example, color in fresh cut melon and in white grape juice showed no significant changes after plasma treatment (Pankaj et al., 2017b; Tappi et al., 2016). Ramazzina et al. (Ramazzina et al., 2015) did not observe significant changes in total phenolic content of kiwifruit after different treatments of DBD plasma, and Dasan \& Boyaci (Dasan \& Boyaci, 2018) even obtained an increase of total phenolic content in all the juices that they treated, including apple, orange, and tomato juices.

With these results, it can be concluded that cold plasma is also an appropriate alternative for the treatment of fresh products for their quality preservation. 

OBJECTIVES 



\section{OBJECTIVES}

The main objective of this PhD Thesis is to study the effect of emerging non-thermal technologies on the quality and stability of different fresh products, what mainly means the inactivation of some deleterious naturally present enzymes, such as PPO, PME and PG, but also the maintenance or improvement of some quality properties.

Along the chapters, different technologies and substrates are evaluated in order to find out best treatments and conditions. The main targets of the present work are summarized below.

First, the effect of three different non-thermal technologies was studied on Golden delicious cloudy apple juice. Chapters 1-4 evaluate their effect on enzymes and some quality characteristics of this juice. Another important aspect to take into account is the maintenance of the quality properties during the storage of the products:

Chapter 1: "Evaluation of HPCD batch treatments on enzyme inactivation kinetics and selected quality characteristics of cloudy juice from Golden delicious apples": The effect of some HPCD process parameters on enzyme inactivation and quality properties of apple juice, such as PSD, color or polyphenol content were studied. Also the fitting of different kinetic models was used for describing enzyme inactivation kinetics.

Chapter 2: "Effect of Thermosonication batch treatment on enzyme inactivation kinetics and other quality parameters of cloudy apple juice": The effect of different TS process parameters, such as amount of energy transmitted to the juice, ultrasound amplitude, temperature and treatment time on enzyme inactivation were determined. Furthermore, the effect of the nature of the dissolved gas on enzyme inactivation was evaluated. TS and HPCD results were compared. Also the effect of TS on quality properties was studied.

Chapter 3: "Enzyme inactivation and other properties of cloudy apple juice after High Pressure Carbon Dioxide (HPCD) and Thermosonication (TS) treatments and during refrigerated storage": In this chapter, a study of the properties of apple juice at refrigerated temperature was carried out after HPCD and TS treatments, and results were 
compared. Some of the properties studied during the storage of 28 days were enzymatic activity, turbidity, particle size distribution and antioxidant capacity.

Chapter 4: "Effect of Cold plasma on polyphenol oxidase inactivation in cloudy apple juice and on the quality parameters of the juice during storage": The effect of CP process parameters such as gas composition, electrical input, exposure mode and treatment time were studied on inactivation of apple juice and on quality parameters responses. Also a study of juice quality during storage of 28 days at $4{ }^{\circ} \mathrm{C}$ was carried out.

The knowledge of the mechanism of enzyme inactivation is of great importance for the optimization of these new preservation methods. As HPCD technology is the main one that has been studied in this PhD Thesis over the other technologies, a deeper study of its effect on the treated samples has been carried out. Chapter 5 and 6 describe this study.

Chapter 5: "High pressure $\mathrm{CO}_{2}$ solubility in food model solutions and fruit juices": In this chapter, $\mathrm{CO}_{2}$ solubility was determined in two different citrate buffer solutions at $\mathrm{pH}$ of 3.8 and 6.2, similar to the $\mathrm{pH}$ of apple and carrot juices, respectively. Also the effect of different sugars found in apple and carrot juices was determined on $\mathrm{CO}_{2}$ solubility. Solubility in model buffer solutions was compared with $\mathrm{CO}_{2}$ solubility in real apple and carrot juices.

Chapter 6: "Optimization of polyphenol oxidase concentration by cationic reversed micellar extraction of Golden delicious apple: High Pressure Carbon Dioxide and Thermosonication enzyme inactivation": In this work, polyphenol oxidase was partially purified from Golden delicious apples in order to obtain a protein extract with PPO activity that was later treated by two non-thermal technologies, HPCD and TS. Fluorescence analysis of these extracts was carried out for trying to understand the effect of these technologies on enzyme inactivation.

Although the main substrate studied in this Thesis has been apple juice, the effect of nonthermal technologies has been also investigated in other food products, liquid and solid. Chapter 7 and 8 describe these studies: 
Chapter 7: "Effect of High Pressure Carbon Dioxide on tomato juice: inactivation kinetics of pectin methylesterase and polygalacturonase and determination of other quality parameters": The main objective of this chapter was to study the effect of HPCD treatment on PME and PG from tomato juice. Additionally, enzyme inactivation was compared with results obtained by a HPP treatment performed at Hiperbaric (Burgos, Spain). The effect of HPCD on other quality parameters of tomato juice such as particle size distribution (PSD) and $\zeta$ potential was also studied.

Chapter 8: "Effect of High Pressure Carbon Dioxide on polyphenol oxidase from Litopenaeus vannamei": The objective of this chapter was to study the effect of HPCD on PPO crude extracts from Litopenaeus vannamei. Also whole shrimps were treated and after the treatment of the shrimps, PPO was extracted to determine the effect of the treatment. Color was visually analyzed in whole treated shrimps right after treatment and during a study of 7 days at refrigerated storage conditions $\left(4^{\circ} \mathrm{C}\right)$. 

RESULTS 



\section{RESULTS}

The more outstanding results of this PhD Thesis are presented as different chapters which correspond to the scientific publications detailed below. A brief summary in Spanish language of each publication is included at the beginning of each chapter.

Chapter 1: Evaluation of HPCD batch treatments on enzyme inactivation kinetics and selected quality characteristics of cloudy juice from Golden delicious apples.

Chapter 2: Effect of Thermosonication batch treatment on enzyme inactivation kinetics and other quality parameters of cloudy apple juice.

Chapter 3: Enzyme inactivation and other properties of cloudy apple juice after High Pressure Carbon Dioxide (HPCD) and Thermosonication (TS) treatments and during refrigerated storage.

Chapter 4: Effect of Cold Plasma on polyphenol oxidase inactivation in cloudy apple juice and on the quality parameters of the juice during storage.

Chapter 5: High pressure $\mathrm{CO}_{2}$ solubility in food model solutions and fruit juices.

Chapter 6: Optimization of polyphenol oxidase concentration by cationic reversed micellar extraction of Golden delicious apple: High Pressure Carbon Dioxide and Thermosonication enzyme inactivation.

Chapter 7: Effect of High Pressure Carbon Dioxide on tomato juice: inactivation kinetics of pectin methylesterase and polygalacturonase and determination of other quality parameters.

Chapter 8: Effect of High Pressure Carbon Dioxide on polyphenol oxidase from Litopenaeus vannamei. 



\section{CHAPTER 1}

Evaluation of HPCD batch treatments on enzyme inactivation kinetics and selected quality characteristics of cloudy juice from Golden delicious apples

Based on the article:

A.E. Illera, M. T. Sanz, S. Beltrán, R. Melgosa. A. G. Solaesa, M. O. Ruiz (2018).

"Evaluation of HPCD batch treatments on enzyme inactivation kinetics and selected quality characteristics of cloudy juice from Golden delicious apples".

Journal of Food Engineering, 221, 141-150 



\section{Capítulo 1}

Estudio del efecto de un tratamiento HPCD sobre las cinéticas de inactivación enzimáticas y en características de calidad importantes de zumo no clarificado procedente de manzanas Golden delicious

\section{Resumen}

En este primer capítulo se comenzó con el estudio de la tecnología $\mathrm{HPCD}, \mathrm{O} \mathrm{CO}_{2}$ presurizado para evaluar su efecto como tecnología no térmica en la inactivación de las enzimas polifenoloxidasa y pectinmetilesterasa presentes en zumo de manzana no clarificado. Se observó que al aumentar la velocidad de agitación (de 200 a 600 rpm) se produjo un incremento en la velocidad de inactivación enzimática, mientras que un triple ciclo de presurización/despresurización no tuvo ningún efecto en la eficacia de inactivación. Se estudiaron las cinéticas de inactivación enzimática a diferentes temperaturas (de 35 a $45^{\circ} \mathrm{C}$ ) y a distintas presiones (de 10 a $20 \mathrm{MPa}$ ) y se representaron utilizando un modelo cinético de primer orden y el modelo de Weibull. El tiempo de reducción decimal del tratamiento $H P C D$ resultó ser menor que el de un tratamiento térmico moderado para ambos modelos.

El tratamiento HPCD produjo un efecto de homogenización en el zumo, ya que se observó un cambio en la distribución del tamaño de partícula hacia un tamaño de diámetro más pequeño. Por otra parte, el contenido en pectina tanto soluble en agua como en oxalato, los compuestos fenólicos totales y el contenido de hidroximetilfurfural no se vieron afectados por el tratamiento HPCD.

Palabras clave: Zumo de manzana no clarificado, tecnología HPCD, parámetros cinéticos de inactivación, propiedades. 



\section{Abstract}

Cloudy apple juice has been treated by High Pressure Carbon Dioxide (HPCD) as nonthermal technology to inactivate polyphenol oxidase and pectin methylesterase in batch mode.

Stirring speed (from 200 to $600 \mathrm{rpm}$ ) induced an increase in the enzyme inactivation rate while a triple cycle of pressurization/depressurization led to the same enzyme inactivation efficiency. Enzyme inactivation kinetics was determined at different temperatures (from 35 to $45^{\circ} \mathrm{C}$ ) and pressures (from 10 to $20 \mathrm{MPa}$ ). Data were described by the first order kinetic model and the Weibull model. For the first order kinetic model, decimal reduction time for HPCD treatment was found to be smaller than for mild heating, in the same temperature range. The same tendency was observed for the first decimal reduction time in the Weibull model.

HPCD treatment resulted in a homogenization effect reflected in the shifting of the particle size distribution towards smaller diameters after treatment. HPCD treatment did not result in a change of water and oxalate soluble pectin content, total phenolic compounds and hidroxymethylfurfural content.

Keywords: Cloudy apple juice, HPCD technology, inactivation kinetic parameters, properties. 



\section{Introduction}

Consumption of cloudy apple juice seems to be more beneficial than consuming clear apple juice due to changes in phenolic compounds and loss of pectin during clarification process (Markowski et al., 2015). However, color and cloud stability are main challenges in preservation of cloudy apple juice during its processing and storage. Enzymatic browning in cloudy apple juice is due to the action of polyphenol oxidase (PPO) that catalyzes the oxidation of phenolic compounds to quinones.

On the other hand, the mechanism of cloud stability is not yet understood. Among the different mechanisms proposed, electrostatic repulsion by negative charges present in the partly demethylated pectin due to galacturonic residues could be responsible of cloud stability avoiding aggregation (Zhao et al., 2008). In this regard, the activity of pectin methylesterase (PME) causes pectin demethylation that could precipitate with calcium ions present in the juice causing clarification and the loss of turbidity. However, other components with negative charge have been also reported in the literature as stabilizing agents of the cloud in the serum such as phosphatide acids of cloud lipids (Krapfenbauer et al., 2006).

Thermal treatments have been traditionally used for the inactivation of microorganisms and enzymes that affect negatively the quality of foods. However, these methods cause undesirable effects in quality attributes such as flavor and loss of nutritional components. High Pressure Carbon Dioxide (HPCD) treatment has been proposed as an alternative nonthermal pasteurization technique that can inactivate certain microorganisms and enzymes under mild operation conditions. Typically, operating pressure does not exceed $50 \mathrm{MPa}$ and temperature ranges between 20 and $50{ }^{\circ} \mathrm{C}$, below pasteurization temperature (Manzocco et al., 2016). The mechanism of pressurized $\mathrm{CO}_{2}$ on enzyme inactivation is not yet fully understood. In the literature different approaches can be found such as $\mathrm{pH}$ lowering due to dissolved $\mathrm{CO}_{2}$, conformational changes or formation of different complex with $\mathrm{CO}_{2}$ molecules (Hu et al., 2013). 
Some studies have been found in the literature regarding the effect of HPCD on enzymes of cloudy apple juice from Fuji apples. Niu et al. (2010b) evaluated the quality of cloudy Fuji apple juice processed from apple slices previously treated by HPCD. These authors found that PPO could be completely inactivated at $20 \mathrm{MPa}$ for $20 \mathrm{~min}$ and at temperature as low as $25^{\circ} \mathrm{C}$; however, residual activity of $18 \%$ was still found for PME after treatment at $65^{\circ} \mathrm{C}$ and $20 \mathrm{MPa}$ for $20 \mathrm{~min}$. Gui et al. (2007) found higher values of residual activity than the work of Niu et al. (2010), for PPO in HPCD-treated cloudy Fuji apple juice in a batch mode ( $40 \%$ at $30 \mathrm{MPa}$ and $55^{\circ} \mathrm{C}$ for $60 \mathrm{~min}$ ). When using a continuous HPCD system, holding times of $10 \mathrm{~min}$ were needed at $22 \mathrm{MPa}$ and $60^{\circ} \mathrm{C}$ to achieve complete inactivation of PPO but, at the same working conditions, still PME residual activity of $42 \%$ was obtained (Xu et al., 2011).

From previous reported results, it can be clearly observed that there is a great variety in the literature data on enzyme inactivation from cloudy apple. This is a main drawback in the commercialization of this technology and reliable data on juice quality are still needed.

According to Wang et al. (2010), the influence of agitation on enzyme inactivation under high-pressure environment is a key factor in the design of reactors of industrial scale volume. However, the effect of stirring speed on enzyme activity has not been considered in most of the studies. Wang et al. (2010) determined the effect of agitation at $40{ }^{\circ} \mathrm{C}$ on isoamylase, obtained from a fermentation broth from Pseudomonas amyloderamosa after cell removal, and a commercial $\beta$-amylase under supercritical carbon dioxide, at different operating times (up to $120 \mathrm{~min}$ ) and different operating pressure (from 11.0 to $17.2 \mathrm{MPa}$ ), observing that the activity of both enzymes decreased by increasing the speed of agitation.

In this work, the effect of HPCD treatment on some quality characteristics of cloudy apple juice from Golden delicious has been studied. The effect of some variables, non-previously studied in literature on enzyme inactivation from cloudy apple juice, has been considered, such as the effect of stirring speed and the number of successive pressurization and depressurization cycles. Enzyme inactivation kinetic data parameters are also necessary to scale-up HPCD process. This regard, enzyme inactivation kinetics of PPO and PME has 
been determined at different operating pressures and temperatures. Enzyme inactivation kinetic data have been described by the first order kinetic model and the Weibull model as an alternative to the classical first order kinetic model. Some other important quality parameters of cloudy apple juice have been also determined before and right after HPCD treatment, such as pectin content, particle size distribution, color and antioxidant capacity.

\section{Materials and methods}

\subsection{Juice preparation}

Golden delicious apples were peeled and cut in cubes and then added to a $0.3 \%$ of Lascorbic acid solution to avoid enzymatic browning during processing. Apple cubes were wiped and immediately squeezed with a screw juice extractor. The liqueur was filtered with 2 layers of cheesecloth. The $\mathrm{pH}$ of the juice obtained was $3.89 \pm 0.01$ and the soluble solid content was $12.5 \pm 0.1^{\circ} \mathrm{Brix}$. The juice was stored frozen at $-18^{\circ} \mathrm{C}$ until further use.

\subsection{HPCD equipment and processing}

The HPCD cell was made of stainless steel (SS-316) and had an internal volume of $100 \mathrm{ml}$ with a maximum operating pressure and temperature of $30 \mathrm{MPa}$ and $80^{\circ} \mathrm{C}$, respectively (Melgosa et al., 2017a). For each experiment, $40 \mathrm{ml}$ of apple juice were charged into the high pressure cell that was immersed in a thermostatic water bath at the operating temperature. The magnetic stirring was then connected and the system was pressurized by using a syringes pump with a pressure controller (ISCO $260 \mathrm{D}$ ) up to the desired pressure. $\mathrm{CO}_{2}$ was fed into the high pressure cell through a sintered stainless steel microfilter with a pore size of $10 \mu \mathrm{m}$ (Briongos et al., 2016). This regard, Ishikawa et al. (1995) showed that the concentration of $\mathrm{CO}_{2}$ in the sample was influenced by the way $\mathrm{CO}_{2}$ was fed into the sample, increasing by decreasing the pore size of the filter at $25 \mathrm{MPa}$ and $35^{\circ} \mathrm{C}$. 
Samples were collected periodically to follow the inactivation kinetics of the enzymes. Experiments were carried out in the ranges of temperature $(T)$ from 35 to $45^{\circ} \mathrm{C}$, pressure (p) from 10 to $20 \mathrm{MPa}$ and stirring speed from 200 to $600 \mathrm{rpm}$. The effect of the sampling procedure and the number of pressurization/depressurization cycles on enzyme activity was also analyzed.

To compare the effect of the HPCD treatment on enzyme activity with mild heating treatment, cloudy apple juice was heated at atmospheric pressure in the same temperature range (from 35 to $45^{\circ} \mathrm{C}$ ). Samples were taken periodically at different treatment times up to $120 \mathrm{~min}$.

Some other important quality attributes of cloudy apple juice, such as particle size distribution, $\xi$ potential, turbidity, $\mathrm{pH}$, pectin content, total phenolic compounds, nonenzymatic browning and antioxidant capacity were also determined before and right after HPCD treatment.

\subsection{Physico-chemical analysis}

\subsubsection{Determination of PPO activity}

The activity of PPO was determined spectrophotometrically by using a $0.05 \mathrm{M}$ catechol (Sigma Aldrich) solution prepared in a $0.1 \mathrm{M}$ phosphate buffer (pH 6.5) as substrate. Samples were analyzed by adding $100 \mu \mathrm{l}$ of apple juice into $2.9 \mathrm{ml}$ substrate solution. Oxidation of catechol was determined immediately by the increase in absorbance at $420 \mathrm{~nm}$ by using a Jasco V-750 spectrophotometer equipped with a Peltier thermostated cell holder and a water pump to keep the temperature constant at $30^{\circ} \mathrm{C}$. The PPO activity was taken as the very first linear part of the reaction curve. 


\subsubsection{Determination of PME activity}

PME activity was determined by using an automatic titrator system (Metrohm ${ }^{\circledR}$ Titrando) by using a $1 \%$ of pectin solution (Alfa Aesar $\AA$ pectin citrus) prepared in $\mathrm{NaCl} 0.3 \mathrm{M}$ as substrate.

$50 \mathrm{ml}$ of pectin solution was mixed with $1 \mathrm{ml}$ of cloudy apple juice and $\mathrm{pH}$ was adjusted to 7.5 with $\mathrm{NaOH} 0.02 \mathrm{~N}$. During pectin hydrolysis at $30^{\circ} \mathrm{C}$, pH was maintained at 7.5 by adding $\mathrm{NaOH} 0.02 \mathrm{~N}$. The amount of $\mathrm{NaOH}$ added for 15 min was recorded. One PME activity unit (UPE) is defined as the micromoles of carboxylic groups produced per minute and $\mathrm{ml}$ of juice at $\mathrm{pH} 7.5$ and $30^{\circ} \mathrm{C}$ (Briongos et al., 2016).

Relative residual activities of PPO and PME were evaluated as:

Residual activity $(\%)=\frac{\text { Enzyme specific activity after HPCD treatment }}{\text { Enzyme specific activity in the untreated juice }} \cdot 100=\frac{A}{A_{o}} \cdot 100$

\subsubsection{Determination of pectin substances}

Pectic substances in cloudy apple juice before and after HPCD treatment have been determined according to Robertson (1979) by progressive extraction of the alcohol insoluble solids by water (high methoxyl pectins are extracted) and ammonium oxalate (low methoxyl pectins are extracted). Water soluble pectins play an important role in the turbidity of the cloudy apple juices acting as colloid stabilizers, while oxalate-soluble fraction can form gels with polyvalent metal ions (Robertson, 1979). Pectic substances are determined spectrophotometrically at $520 \mathrm{~nm}$ after total hydrolysis to galacturonic acids by using m-hydroxydiphenil (MHDP) as a chromogenic reagent. Solutions were freshly prepared before analysis: $0.15 \%$ solution of m-hydroxydiphenyl (Sigma Aldrich) in $0.5 \%$ $\mathrm{NaOH}$ and $0.0125 \mathrm{M}$ sodium tetraborate (Panreac) in concentrated sulphuric acid. For pectin determination, $1 \mathrm{ml}$ of water extract and $5 \mathrm{ml}$ of the sodium tetraborate solution were mixed and placed in a water-ice bath. The mixture is then heated in water bath at $80^{\circ} \mathrm{C}$ for $6 \mathrm{~min}$ and subsequently cooled again in a water-ice bath. Then, $0.1 \mathrm{ml}$ of the $\mathrm{m}$ hydroxydiphenyl solution was added and after homogenization of the mixture, 
absorbance at $520 \mathrm{~nm}$ was measured as a function of time. According to Ibarz et al. (Ibarz et al., 2006) spectrophotometric data measurements were taken at the highest absorbance instead of at a certain reaction time. A calibration curve was prepared with standard solutions of D-galacturonic acid (Sigma Aldrich) by following the same colorimetric method. A blank was also prepared with no D-galacturonic acid.

\subsubsection{Particle size distribution and zeta potential}

Particle size distribution (PSD) was determined by laser diffraction with a Mastersizer 2000 (Malvern ${ }^{\circledR}$ Inst., MA). The system uses a laser light at $750 \mathrm{~nm}$ wavelength to size particles from 0.4 to $2000 \mu \mathrm{m}$ by light diffraction. Particle size distribution was calculated by the Fraunhofer model. Size distributions (volume fractions against particle size) before and after HPCD treatment were calculated and the weight-average sizes expressed as:

The equivalent surface area mean diameter:

$\mathrm{D}(3,2)=\sum \mathrm{n}_{\mathrm{c}} \mathrm{d}_{\mathrm{lc}}^{3} / \sum \mathrm{n}_{\mathrm{c}} \mathrm{d}_{\mathrm{lc}}^{2}$

The equivalent volume mean diameter:

$\mathrm{D}(4,3)=\sum \mathrm{n}_{\mathrm{c}} \mathrm{d}_{\mathrm{lc}}^{4} / \sum \mathrm{n}_{\mathrm{c}} \mathrm{d}_{\mathrm{lc}}^{3}$

Where $d_{l c}$ is the diameter of the particle and $n_{c}$ is the percentage of particles.

To describe distribution width one common parameter is the Span:

Span $=\frac{D_{\mathrm{v}, 0.9}-D_{v, 0.1}}{D_{v, 0.5}}$

Where Dv,0.9, Dv,0.1 and Dv,0.5 are the particle size bellow which, $90 \%, 10 \%$ and $50 \%$ of the particles lies.

$\zeta$-potential was determined with a Zetasizer Nano ZS apparatus, using the Laser Doppler Velocimetry techniques. Samples were diluted 1:50 with deionized water and filtered 
through $5 \mu \mathrm{m}$ filter. $\zeta$-potential gives an indication of the potential stability of a colloidal system and it is a good index of the colloidal electrostatic repulsive forces. Particles will repel each other when having a large negative or positive $\zeta$-potential. Soluble pectin

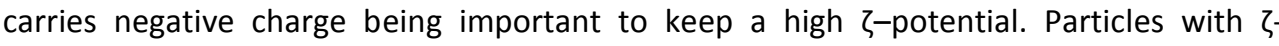
potentials more positive or negative than $30 \mathrm{mV}$ or $-30 \mathrm{mV}$ are normally considered stable (Genovese \& Lozano, 2001).

\subsubsection{Total phenolic compounds and antioxidant capacity}

Total phenolic compounds were determined by using the Folin-Ciocalteau reagent (VWR). First, $100 \mu \mathrm{l}$ of the juice were mixed with $2.8 \mathrm{ml}$ of water and subsequently $100 \mu \mathrm{l}$ of the Folin-Ciocalteau reagent, in that order. After that, $2 \mathrm{ml}$ of sodium carbonate $7.5 \%(\mathrm{w} / \mathrm{v})$ were added and the reaction started. Color was measured after $60 \mathrm{~min}$ of reaction at $750 \mathrm{~nm}$ at $21^{\circ} \mathrm{C}$. A blank was also prepared using water instead of juice. A calibration curve was prepared with standard solutions of gallic acid by following the same colorimetric method.

Antioxidant capacity was determined by the ABTS method. The ABTS method is based on the decolorization of the radical cation 2,2'-azinobis-(3-ethylbenzothiazoline-6-sulfonic acid) $\left(\mathrm{ABTS}^{++}\right)$. This radical is produced by oxidation of a $7 \mathrm{mM}$ solution of ABTS with potassium persulfate $(2.45 \mathrm{mM})$, allowing the mixture to stand in the dark at room temperature for $16 \mathrm{~h}$ before use (Re et al., 1999). The $\mathrm{ABTS}^{+}$solution was diluted with ethanol to reach an absorbance close to 0.7 at $734 \mathrm{~nm}$ and equilibrated at $21{ }^{\circ} \mathrm{C}$. Diluted $\mathrm{ABTS}^{+}$solutions were reduced in the presence of hydrogen-donating antioxidants present in the apple juice. For the antioxidant test, juice samples were diluted 1:10 with deionized water. A ratio of $100 \mu \mathrm{l} / 1 \mathrm{ml}$ (diluted cloudy apple juice/ABTS ${ }^{++}$solution) was chosen and absorbance was registered along time at $734 \mathrm{~nm}$, since antioxidant activity depends on the selected time point (Re et al., 1999). All the spectrophotometric measurements have been carried out at $21^{\circ} \mathrm{C}$ in a Jasco $(\mathrm{V}-750)$ spectrophotometer with Peltier temperature control. Results were expressed as inhibition percentage of the radical ABTS ${ }^{+}$. 


\subsubsection{Turbidity, $\mathrm{pH}$, color and non-enzymatic browning}

Turbidity of cloudy apple juice was measured at room temperature by diluting it $1 / 20$ with distilled water (Xu et al., 2011). A turbidimeter (Eutech Instruments, TN-100) was used and turbidity was expressed as nephelometric turbidity units (NTU). $\mathrm{pH}$ of apple juice was determined with a pH-meter (Crison $® \mathrm{pH}$ \& Ion-Meter GLP 22).

The $L^{*}, a^{*}$ and $b^{*}$ values were obtained respectively by a suitable program installed in a Beckman DU-650 spectrophotometer with diode-array of UV-vis (Beckman Instruments), representing brightness, red to green color and yellow to blue color, respectively. Other conditions are illuminant D65 (daylight source) and a $10^{\circ}$ standard observer (perception of a human observer) following the CIE recommendations. Changes in color were expressed as:

$\Delta \mathrm{E}=\sqrt{\left(\mathrm{L}_{\mathrm{before}}^{*}-\mathrm{L}_{\mathrm{after}}^{*}\right)^{2}+\left(\mathrm{a}_{\mathrm{before}}^{*}-\mathrm{a}_{\mathrm{after}}^{*}\right)^{2}+\left(\mathrm{b}_{\mathrm{before}}^{*}-\mathrm{b}_{\mathrm{after}}^{*}\right)^{2}}$

According to Krapfenbauer et al. (2006) a casual viewer can notice a difference between two colors when $\Delta \mathrm{E}$ is higher than 2-3.5, although they pointed out that a trained eye is capable of differentiating two colors that differ by $\Delta \mathrm{E}<2$.

Non enzymatic browning reactions are important parameters that determine the quality of food products during processing and storage. Non enzymatic browning in the juice is measured as hydroxymethylfurfural (HMF) concentration; $0.7 \mathrm{ml}$ of juice was mixed with $0.7 \mathrm{ml}$ of ethanol in a $1.5 \mathrm{ml}$ Eppendorf tube. The mixture was centrifuged at $12000 \mathrm{~g}$ for $10 \mathrm{~min}$. After that, $1 \mathrm{ml}$ of the supernatant was mixed with $1 \mathrm{ml}$ of a trichloroacetic acid solution $(734 \mathrm{mM})$ and $1 \mathrm{ml}$ of a thiobarbituric acid solution $(25 \mathrm{mM})$ in a closed recipient. Samples were incubated at $40^{\circ} \mathrm{C}$ during $50 \mathrm{~min}$ in an agitated batch and absorbance was measured at $443 \mathrm{~nm}$. A blank was also prepared with distilled water instead of juice. A calibration curve was prepared using different concentrations of HMF from $0.5 \mathrm{mg} / \mathrm{L}$ to $10 \mathrm{mg} / \mathrm{L}$. 


\subsection{Kinetic data analysis}

The knowledge of the kinetic parameters that describe the time course of the enzyme inactivation is of great importance for a correct design of a HPCD process. Gui et al. (2007) obtained good results by fitting the inactivation kinetics of PPO in cloudy apple juice to a linear kinetic model. In this work, the inactivation kinetic data at different operating temperatures and pressures were described by using two different models: a first-order kinetic model, and the Weibull model.

The first-order kinetic model can be described as:

$\log \frac{\mathrm{A}}{\mathrm{A}_{\mathrm{o}}}=-\mathrm{kt}$

Where $A_{o}$ is the initial activity of the enzyme, $A$ is the residual activity after different treatment times, $\mathrm{k}$ is the inactivation rate constant at the operating conditions $\left(\mathrm{min}^{-1}\right)$ and $\mathrm{t}$ is the treatment time ( $\mathrm{min})$.

$\mathrm{z}_{\mathrm{T}}$ and $\mathrm{z}_{\mathrm{P}}$ (temperature and pressure increase needed for a $90 \%$ reduction of the $\mathrm{D}$ value, respectively) were evaluated as the negative reciprocal slope of the regression line of $\log D$ as function of $T$ or $p$ respectively:

$\log \left[\frac{\mathrm{D}_{1}}{\mathrm{D}_{2}}\right]=\frac{\mathrm{T}_{2}-\mathrm{T}_{1}}{\mathrm{z}_{\mathrm{T}}}$

$\log \left[\frac{\mathrm{D}_{1}}{\mathrm{D}_{2}}\right]=\frac{\mathrm{p}_{2}-\mathrm{p}_{1}}{\mathrm{z}_{\mathrm{p}}}$

The dependence of the inactivation rate constant on temperature and pressure can be expressed through the Arrhenius and Eyring equations respectively:

$\ln \left[\frac{\mathrm{k}_{1}}{\mathrm{k}_{2}}\right]=\frac{\mathrm{E}_{\mathrm{a}}}{\mathrm{RT}}\left[\frac{1}{\mathrm{~T}_{2}}-\frac{1}{\mathrm{~T}_{1}}\right]$

$\ln \left[\frac{k_{1}}{k_{2}}\right]=\frac{\mathrm{V}_{\mathrm{a}}}{\mathrm{RT}}\left[p_{2}-\mathrm{p}_{1}\right]$ 
where $p_{2}, p_{1}, T_{2}, T_{1}$ are pressures and temperatures corresponding to the decimal reduction times $D_{1}$ and $D_{2}$ or constant $k_{1}$ and $k_{2}$, respectively, $R$ is the universal gas constant, Ea, the activation energy $(\mathrm{kJ} / \mathrm{mol})$ and $\mathrm{V}_{\mathrm{a}}\left(\mathrm{cm}^{3} / \mathrm{mol}\right)$, is the activation volume.

The non-linear Weilbull model can be written in the power-law form (Boekel, 2002):

$\log \frac{\mathrm{A}}{\mathrm{A}_{0}}=-\frac{1}{2.303}\left(\frac{t}{\alpha}\right)^{\beta}$

Where $\alpha$ is the scale parameter (a characteristic time) and $\beta$ is the shape parameter.

When $n<1$ indicates upward concavity and $n>1$ downward concavity of the enzyme inactivation curve. The time required to achieve a number of decimal reductions, $d$, can be calculated by using the shape and scale parameters (Boekel, 2002):

$t_{d}=\alpha\left(-\ln \left(10^{-d}\right)^{\frac{1}{\beta}}\right)$

\subsection{Statistical analysis}

Statistical analyses were conducted using software Statgraphics X64. The results are presented as a mean \pm standard deviation of at least three replicates. The significance of the differences was determined based on an analysis of the variance with the Fisher's least significant method at $p$-value $\leq 0.05$.

To estimate the kinetic parameters for the different models essayed in this work, nonlinear regression was performed by using the Marquardt algorithm (Statgraphics X64). The mean relative deviation (MRD) between experimental and calculated residual activities (RA) was also evaluated:

$\operatorname{MRD}=\frac{1}{\mathrm{n}}\left(\sum_{\text {all samples }}\left|\frac{\mathrm{RA}_{\text {calc }}-\mathrm{RA}_{\exp }}{\mathrm{RA}_{\exp }}\right|\right) \cdot 100$ 


\section{Results}

\subsection{Agitation speed}

The effect of agitation on the inactivation of PPO from cloudy apple juice has been evaluated at $20 \mathrm{MPa}$ and $45^{\circ} \mathrm{C}$, at three stirring speeds, 200, 400 and $600 \mathrm{rpm}$ (Figure 1.1a). When working at higher stirring speeds, the magnetic system of agitation did not work properly in our experimental equipment; therefore stirring speeds higher than $600 \mathrm{rpm}$ were not included in this work. At any of the stirring speeds, the inactivation degree increased with increasing time.

From Figure 1.1a, it can be also observed that an increase in the stirring speed led to a higher inactivation degree. Agitation speed enhanced mass transfer rate of $\mathrm{CO}_{2}$ in the medium, facilitating $\mathrm{CO}_{2}$ solubilization and therefore the contact between $\mathrm{CO}_{2}$ and the enzyme (García-González et al., 2009). In this regard, Wang et al. (2010) also pointed out that an increase in the agitation speed can create a larger amount of bubbles that help to enzyme inactivation. These authors deduced an expression for enzyme inactivation as a function of $\mathrm{N} \cdot \mathrm{t}$ (stirred speed-time) considering an equilibrium reaction between the native and the denatured enzyme and the consequently irreversible aggregation between the denatured enzymes:

$$
\left(A_{o} / A\right)=1+\operatorname{cte}(N \cdot t)
$$

By plotting the inverse of the residual enzyme activity versus $\mathrm{N} \cdot \mathrm{t}$ a straight line should be obtained with the intercept equal to 1. Figure 1.1.b shows that for PPO inactivation in cloudy apple juice, the ratio $(\mathrm{Ao} / \mathrm{A})$ is proportional to $\mathrm{N} \cdot \mathrm{t}$ for operation times shorter than $60 \mathrm{~min}:$

$\left(A_{o} / A\right)=1+1.704 \cdot 10^{-4}(N \cdot t) \quad\left(R^{2}=0.940\right)$

At longer treatment times, residual activities for all the three stirring speeds became nearly equal and were not included. 


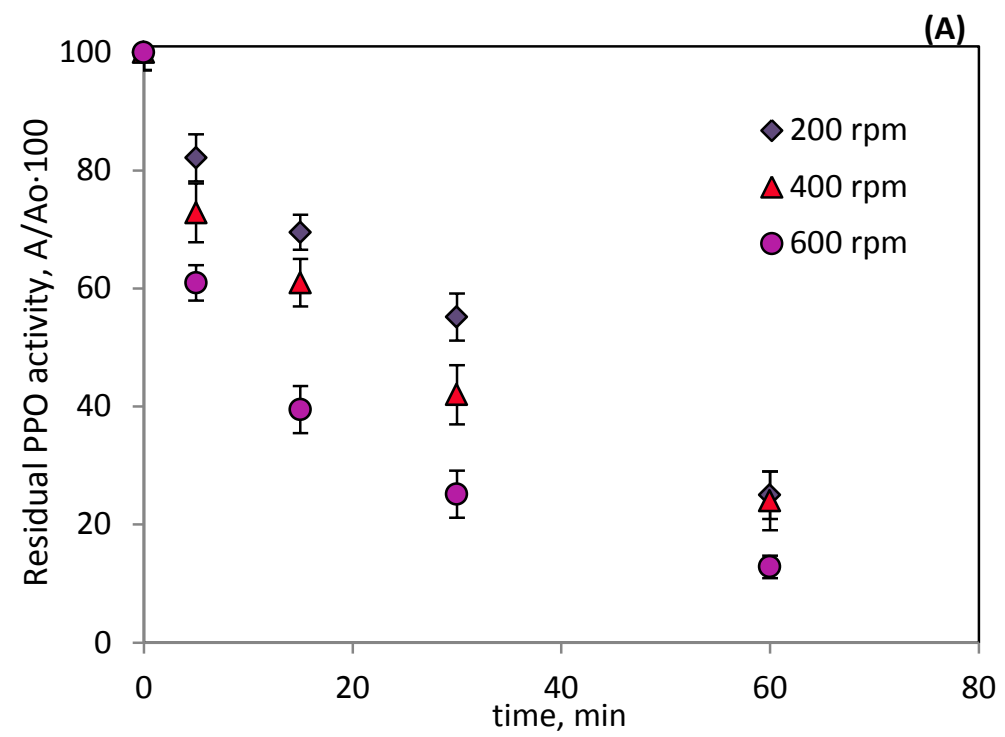

(B)

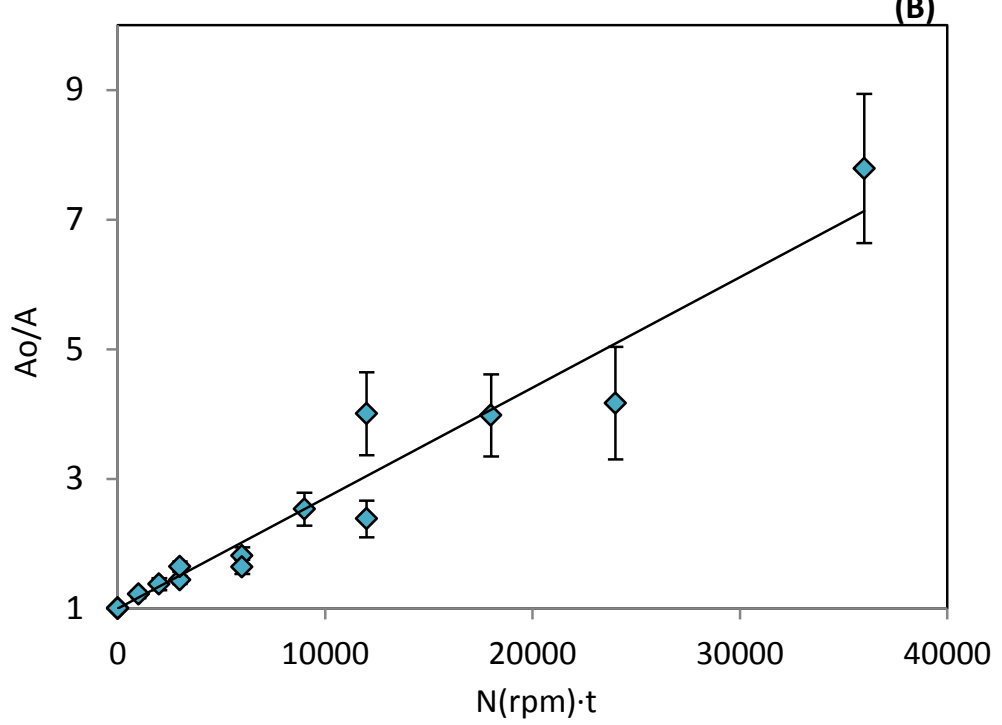

Figure 1.1 (a) Effect of stirring speed on PPO inactivation from cloudy apple juice by HPCD at $20 \mathrm{MPa}$ and $45^{\circ} \mathrm{C}$. (b) Inverse of residual activity of PPO versus the product of number of revolutions per time and treatment time $\left(\mathrm{N} \cdot \mathrm{t}\right.$ ) at $20 \mathrm{MPa}$ and $45^{\circ} \mathrm{C}$ (stirring speed range: 200 to $600 \mathrm{rpm}$ ). The continuous line corresponds to the linear fitting (Eq. 1.15) 


\subsection{Sampling procedure and number of pressurization/ depressurization cycles}

PPO activity after HPCD treatment was compared when sample was obtained after system depressurization or removed while the system was under pressure for a single cycle pressurization. HPCD treatment was carried out at $45{ }^{\circ} \mathrm{C}$ and $20 \mathrm{MPa}$ for $15 \mathrm{~min}$. No significant differences have been determined among sample RA means of different sampling procedure when applying the Fisher's least significant method at $p$-value $\leq 0.05$, with PPO RA values of $38 \pm 4 \%$ and $33 \pm 4 \%$ when sampling was withdrawn while the system was under pressure or after total depressurization, respectively.

The effect of a single cycle has been compared with a triple cycle for a total treatment time of $15 \mathrm{~min}$, that is $5 \mathrm{~min}$ of pressure-treatment each cycle, respectively $\left(t_{\text {total, treatment }}=\right.$ $t_{\text {per cycle }} \times$ number of cycles). The same effectiveness for PPO inactivation was determined when applying the Fisher's least significant method at $p$-value $\leq 0.05$, with values of $38 \pm 4 \%$ and $33 \pm 3 \%$ for one single cycle and a triple cycle for a total treatment time of 15 min, respectively.

Primo et al. (2007) studied the effect of successive cycles of pressurizationdepressurization in HPCD treatment on inactivation of PPO from mate tea leaves extracts. They observed that PPO presented a continuous loss of activity with the number of cycles at $7.05 \mathrm{MPa}, 30^{\circ} \mathrm{C}$ and $1 \mathrm{~h}$ each cycle. However, to distinguish between the effect of the number of pressurization/depressurization cycles and treatment time, comparison should have be done at the same pressure and temperature conditions but for a total treatment time equal to $t_{\text {per cycle }} \times$ number of cycles, since time plays also an important role in batch enzyme inactivation. In any case, as pointed out by $\mathrm{Hu}$ et al. (2013), the effect of pressurization/depressurization on the activity of enzymes depends on the type of enzyme, its environment, pressure, temperature and exposure time, being difficult to establish any rule. No other studies have been found in the literature about the effect of the number of cycles on enzyme inactivation by HPCD on fresh juices. 


\subsection{Effect of mild heating on PPO inactivation}

PPO inactivation kinetics was determined at atmospheric pressure in the temperature range from 35 to $45{ }^{\circ} \mathrm{C}$ (same temperature range as for HPCD treatment, Figure 1.2). The maximum reduction of PPO activity was nearly $40 \%$ after $2 \mathrm{~h}$ of heating at $45^{\circ} \mathrm{C}$, indicating that PPO of cloudy Golden delicious apple juice was rather stable under mild temperatures. Similar inactivation degrees of PPO from cloudy Fuji apple juice were obtained by Gui et al. (2007). After 1 hour of mild heating, these authors reached a maximum reduction of PPO activity of $20 \%$ at $45{ }^{\circ} \mathrm{C}$. However, Niu et al. (2010b) found that when subjecting apple slices to mild heating treatment from 25 to $45^{\circ} \mathrm{C}$ for $20 \mathrm{~min}$ and then processing them into cloudy apple juice, PPO activity increased by $22-51 \%$. Buckow et al. (2009) also found that at $45^{\circ} \mathrm{C}$, PPO activity from cloudy apple juice increased $30 \%$, attributing this behavior to the release of latent PPO.

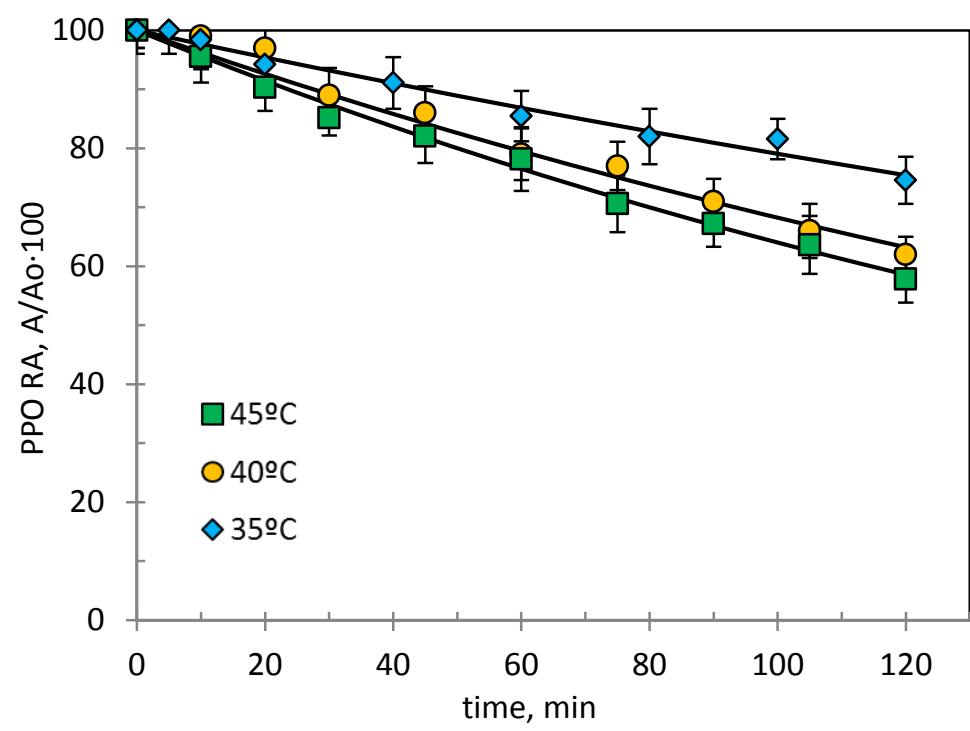

Figure 1.2 Inactivation of PPO in cloudy apple juice at atmospheric pressure at different mild temperatures. The continuous lines represent the first order model (Table 1.1).

Enzyme inactivation kinetic data under mild heating conditions and at atmospheric pressure were described by the first-order model. Parameters are collected in Table 1.1. 
Table 1.1 Kinetic parameters at $0.1 \mathrm{MPa}$ for the first order kinetic model for PPO inactivation by mild thermal heating $\left(35-45^{\circ} \mathrm{C}\right)$ and PME at $45^{\circ} \mathrm{C}$.

\begin{tabular}{ccccc}
\hline PPO & \multicolumn{4}{c}{ First order kinetic model } \\
\hline $\mathbf{T},{ }^{\circ} \mathbf{C}$ & $\mathbf{k}, \mathbf{~ m i n}^{-1}$ & $\mathbf{D}, \mathbf{m i n}$ & $\mathbf{R}^{\mathbf{2}}$ & $\mathbf{M R D}$ \\
\hline 35 & $0.00102 \pm 0.00003$ & 980 & 0.9814 & 1.6 \\
40 & $0.00166 \pm 0.00005$ & 602 & 0.9791 & 1.1 \\
45 & $0.00194 \pm 0.00003$ & 515 & 0.9993 & 1.1 \\
\hline & $\mathbf{Z}_{\mathbf{T}}=36 \pm 11^{\circ} \mathrm{C}\left(\mathbf{R}^{\mathbf{2}}=0.9188\right)$ & \\
& $\mathbf{E}_{\mathbf{a}}=53 \pm 14 \mathrm{~kJ} / \mathrm{mol}^{\left(\mathbf{R}^{2}=0.9248\right)}$ & & 0.8 \\
\hline
\end{tabular}

Inactivation rate constant, $k$, increased with the operating temperature, therefore the corresponding $D$ values decreased with temperature. The temperature sensitivity parameter, $z_{\mathrm{T}}$, and the activation energy were evaluated as $36{ }^{\circ} \mathrm{C}$ and $53 \mathrm{~kJ} / \mathrm{mol}$, respectively (see Table 1.1). Values of the same order were reported by Gui et al. (2007) for cloudy Fuji apple juice, $27.0{ }^{\circ} \mathrm{C}$ for $\mathrm{z}_{\mathrm{T}}$ and $72.0 \mathrm{~kJ} / \mathrm{mol}$, for $\mathrm{E}_{\mathrm{a}}$. Thermal stability of extracted apple PPO from Golden delicious was studied in the temperature range from 68 to $78{ }^{\circ} \mathrm{C}$ by Yemenicigly et al. (1997). These authors reported a $z_{\mathrm{T}}$ value of $9.9^{\circ} \mathrm{C}$. The higher value obtained in this work for $z_{T}$ in the temperature range from 35 to $45{ }^{\circ} \mathrm{C}$ might indicate a lower susceptibility to temperature change at temperatures lower than the one observed at pasteurization temperatures. In any case, the values of the activation energy were similar in both temperature ranges.

\subsection{Effect of HPCD treatment on PPO inactivation}

Enzyme inactivation kinetics for PPO of cloudy Golden delicious apple juice has been determined at $10 \mathrm{MPa}$ in the temperature range from 35 to $45^{\circ} \mathrm{C}$ (Figure 1.3a). By increasing temperature, enzyme inactivation rate also increased. In addition to the intrinsic effect of temperature on enzyme inactivation, by increasing temperature, although $\mathrm{CO}_{2}$ density decreased, the diffusivity of $\mathrm{CO}_{2}$ can be improved and accelerate the molecular collisions between $\mathrm{CO}_{2}$ molecules and the enzyme. Figure 1.3b shows the inactivation kinetics at $45^{\circ} \mathrm{C}$ in the pressure range from 10 to $20 \mathrm{MPa}$. 


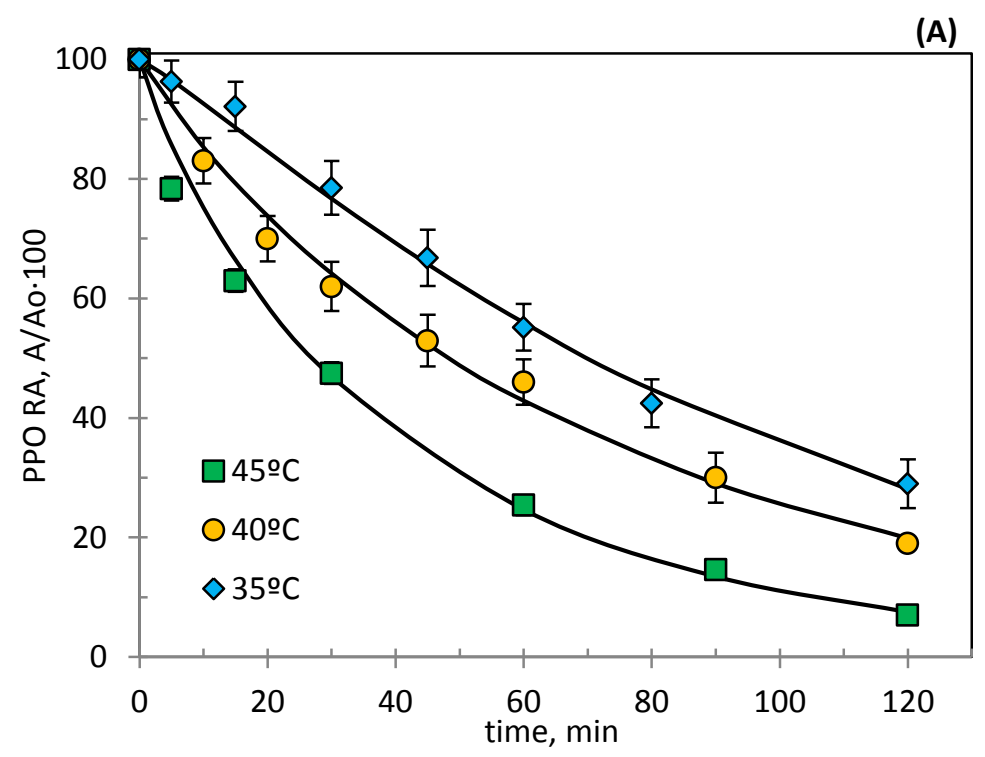

(B)

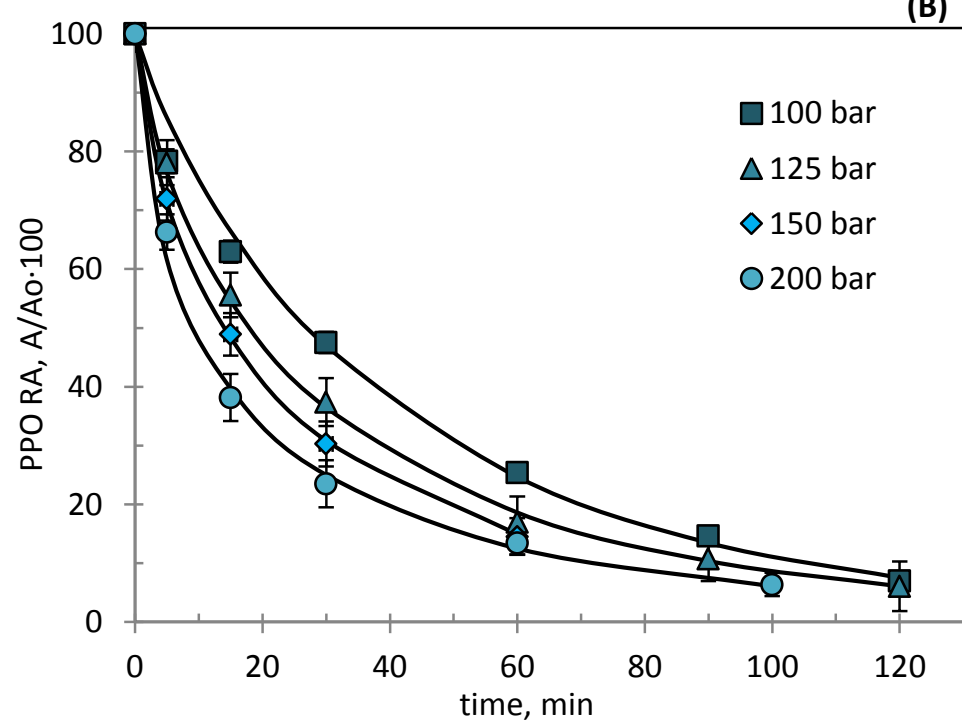

Figure 1.3 Inactivation of PPO in cloudy apple juice by HPCD (a) $10 \mathrm{MPa}$ and different temperatures. (b) $45{ }^{\circ} \mathrm{C}$ and different pressures. The continuous lines represent the Weibull model (Table 1.2a).

Higher operating pressures led to faster inactivation rates, but the fraction of the resistant form of the enzyme was nearly independent of the operating pressure, being around $6 \%$. This value was lower than the minimal residual activity of PPO from cloudy Fuji apple juice reported by Gui et al. (2007), $37 \%$, at $30 \mathrm{MPa}$ and $55{ }^{\circ} \mathrm{C}$ for $60 \mathrm{~min}$. In any case, 
comparison with other HPCD systems is difficult to establish since the inactivation reached would depend not only on the type and source of the enzyme and the experimental conditions such as pressure, temperature and treatment time but also on the agitation of the system and the ratio sample volume/cell volume since this last parameter determines the amount of $\mathrm{CO}_{2}$ injected to the system. Unfortunately in most of the studies these parameters are not detailed. PPO from cloudy Fuji apple juice was completely inactivated by a continuous HPCD system at $22 \mathrm{MPa}$ and $60{ }^{\circ} \mathrm{C}$ for $10 \mathrm{~min}$ (Xu et al., 2011). This could suggest a higher efficiency of a continuous system due to the turbulent energy, comparable with a good agitation in a discontinuous system. However, $60{ }^{\circ} \mathrm{C}$ cannot be considered as non-thermal and residual activity as high as $47 \%$ was obtained in the continuous system at $43^{\circ} \mathrm{C}$ and $25 \mathrm{MPa}$ for $2 \min$ (Xu et al., 2011).

Inactivation kinetic data by HPCD were fitted to the Weibull model (Table 1.2a) and to the first order kinetic model (Table 1.2b).

Table 1.2a Kinetic parameters for the Weibull model for PPO and PME inactivation by HPCD.

\begin{tabular}{|c|c|c|c|c|c|c|}
\hline \multicolumn{3}{|c|}{ PPO } & \multicolumn{4}{|c|}{ Weibull model } \\
\hline p, MPa & $\mathrm{T},{ }^{\circ} \mathrm{C}$ & $\alpha, \min$ & $\beta$ & $\mathrm{td}=1, \min$ & $\mathbf{R}^{2}$ & MRD \\
\hline 10 & 35 & $98 \pm 2$ & $1.13 \pm 0.06$ & 205 & 0.9940 & 2.3 \\
\hline 10 & 40 & $72 \pm 2$ & $0.93 \pm 0.04$ & 177 & 0.9939 & 3.4 \\
\hline \multirow[t]{2}{*}{10} & 45 & $41 \pm 2$ & $0.89 \pm 0.05$ & 105 & 0.9960 & 4.9 \\
\hline & & \multicolumn{5}{|c|}{$\mathbf{z}_{\mathrm{T}}^{\prime}=27 \pm 4^{\circ} \mathrm{C} ;\left(\mathbf{R}^{2}=0.9726\right)$} \\
\hline 12.5 & 45 & $30 \pm 1$ & $0.74 \pm 0.02$ & 93 & 0.9983 & 2.9 \\
\hline 15 & 45 & $23.7 \pm 0.4$ & $0.70 \pm 0.02$ & 78 & 0.9995 & 1.2 \\
\hline \multirow[t]{2}{*}{20} & 45 & $17.2 \pm 0.9$ & $0.59 \pm 0.02$ & 71 & 0.9981 & 5.9 \\
\hline & & \multicolumn{5}{|c|}{$\mathbf{z}_{\mathrm{P}}^{\prime}=27 \pm 3 \mathrm{MPa} ;\left(\mathbf{R}^{2}=0.9729\right)$} \\
\hline \multicolumn{7}{|c|}{ PME } \\
\hline $\mathrm{p}, \mathrm{MPa}$ & $\mathrm{T},{ }^{\circ} \mathrm{C}$ & $\alpha, \min$ & $\beta$ & $\mathrm{td}=1, \min$ & $\mathbf{R}^{2}$ & MRD \\
\hline 10 & 45 & $785 \pm 294$ & $0.55 \pm 0.09$ & 3576 & 0.9587 & 2.3 \\
\hline 20 & 45 & $373 \pm 74$ & $0.45 \pm 0.04$ & 2380 & 0.9940 & 1.1 \\
\hline
\end{tabular}


Although the Weibull model yielded the best fitting quality, the first order kinetic model described the inactivation curve quite well and therefore, kinetic parameters for the linear regression model have been also listed in Table $\mathbf{1 . 2 b}$ for comparison with data reported in the literature.

Table 1.2b Kinetic parameters for the first linear kinetic model for PPO and PME inactivation by HPCD.

\begin{tabular}{|c|c|c|c|c|c|}
\hline \multicolumn{2}{|c|}{ PPO } & \multicolumn{4}{|c|}{ First order kinetic model } \\
\hline $\mathrm{p}, \mathrm{MPa}$ & $\mathrm{T},{ }^{\circ} \mathrm{C}$ & $k, \min ^{-1}$ & $\mathrm{D}, \mathrm{min}$ & $\mathrm{R}^{2}$ & MRD \\
\hline 10 & 35 & $0.0044 \pm 0.0001$ & 227 & 0.9891 & 3.4 \\
\hline 10 & 40 & $0.0060 \pm 0.0001$ & 167 & 0.992 & 3.9 \\
\hline \multirow[t]{2}{*}{10} & 45 & $0.0096 \pm 0.0002$ & 104 & 0.992 & 6.8 \\
\hline & & \multicolumn{4}{|c|}{$\begin{array}{c}\mathbf{z}_{\mathrm{T}}=29 \pm 3^{\circ} \mathrm{C} ;\left(\mathbf{R}^{2}=0.9897\right) \\
\mathbf{E}_{\mathrm{a}}=64 \pm 8 \mathrm{~kJ} / \mathrm{mol} ;\left(\mathbf{R}^{2}=0.9834\right)\end{array}$} \\
\hline 12.5 & 45 & $0.015 \pm 0.001$ & 67 & 0.966 & 23.6 \\
\hline 15 & 45 & $0.019 \pm 0.001$ & 53 & 0.953 & 15.6 \\
\hline \multirow[t]{2}{*}{20} & 45 & $0.026 \pm 0.004$ & 38 & 0.965 & 44.3 \\
\hline & & \multicolumn{4}{|c|}{$\begin{array}{c}\mathbf{z}_{\mathbf{p}}=25 \pm 5 \mathrm{MPa} ;\left(\mathbf{R}^{2}=0.9226\right) \\
\mathbf{V a}=-251 \pm 48 \mathrm{~cm}^{3} / \mathrm{mol} ;\left(\mathbf{R}^{2}=0.9332\right)\end{array}$} \\
\hline \multicolumn{6}{|c|}{ PME } \\
\hline $\mathrm{p}, \mathrm{MPa}$ & $\mathrm{T},{ }^{\circ} \mathrm{C}$ & k, $\min -1$ & $D, \min$ & $\mathbf{R}^{2}$ & MRD \\
\hline 10 & 45 & $0.0015 \pm 0.0001$ & 667 & 0.9424 & 5.2 \\
\hline 20 & 45 & $0.0037 \pm 0.0006$ & 270 & 0.9181 & 8.6 \\
\hline
\end{tabular}

For the first order kinetic model, inactivation rate constant, $k$, increased with temperature and pressure. Consequently, D values decreased with increasing pressure and temperature. At each operating temperature, D values were smaller for HPCD treatment (Table 1.2b) than the corresponding values for mild heating treatment (Table 1.1) proving that HPCD treatment was more effective than thermal treatment alone. For example D was equal to $515 \mathrm{~min}$ at $45^{\circ} \mathrm{C}$ and atmospheric pressure and decreased to $104 \mathrm{~min}$ at $45^{\circ} \mathrm{C}$ and $10 \mathrm{MPa}$.

$\mathrm{z}_{\mathrm{T}}$ and activation energy values were determined as $29^{\circ} \mathrm{C}$ and $64 \mathrm{~kJ} / \mathrm{mol}$, respectively, for the first order kinetic model (see Table 1.2b). $\mathrm{z}_{\mathrm{T}}$ and activation energy values were of the 
same order as those listed for mild heating treatment (Table 1.1). This meant that the sensitivity to temperature change was similar for HPCD as for mild heating treatment in the temperature range covered in this work. The same tendency in $\mathrm{z}_{\mathrm{T}}$ and $\mathrm{E}_{\mathrm{a}}$ was found by Liu et al. (2008) in the inactivation of PPO of red beet extracts. These authors found that under mild heating treatment at atmospheric pressure $\left(35-55^{\circ} \mathrm{C}\right), \mathrm{z}_{\mathrm{T}}$ and $\mathrm{E}_{\mathrm{a}}$ were equal to $34{ }^{\circ} \mathrm{C}$ and $57 \mathrm{~kJ} / \mathrm{mol}$, respectively. After $\mathrm{HPCD}$ treatment at $37.5 \mathrm{MPa}$, in the same temperature range, they obtained values of $36^{\circ} \mathrm{C}$ and $54 \mathrm{~kJ} / \mathrm{mol}$ for $\mathrm{z}_{T}$ and $\mathrm{E}_{\mathrm{a}}$, respectively. However, Gui et al. (2007) found for PPO of cloudy Fuji apple juice that $\mathrm{z}_{\mathrm{T}}$ increased from 27 to $108{ }^{\circ} \mathrm{C}$ and activation energy decreased from 72 to $18 \mathrm{~kJ} / \mathrm{mol}$ under mild heating treatment $\left(35-55^{\circ} \mathrm{C}\right)$ and $\mathrm{HPCD}$ at $30 \mathrm{MPa}$ in the same temperature range, respectively. This increase in $z_{T}$ and decrease in $E_{a}$ found by Gui et al. (2007) would indicate that the enzyme inactivation become less temperature dependent under pressurized $\mathrm{CO}_{2}$. This behavior is difficult to understand and it has not been observed in our work. As it has been previously mentioned, in addition to the intrinsic effect of temperature on enzyme inactivation, temperature has two different effects on important properties of $\mathrm{CO}_{2}$. An increase in temperature involves an improvement of mass transport properties enhancing $\mathrm{CO}_{2}$ diffusivity and the number of collisions between the $\mathrm{CO}_{2}$ and the enzyme, but on the other hand, $\mathrm{CO}_{2}$ density and therefore $\mathrm{CO}_{2}$ solubility in the aqueous medium decreases. It seems that these effects play both an important role, since similar sensitivity to temperature was found in mild heat treatment and in HPCD.

By using equations 1.8 and 1.10, $z_{p}$ and $V_{a}$ have been determined as $25 \mathrm{MPa}$ and $-251 \mathrm{~cm}^{3} / \mathrm{mol}$, respectively for the first order kinetic model. The negative value of the activation volume indicated that PPO inactivation was favored by increasing operating pressure. Other values of activation volumes reported in the literature for PPO inactivation from different sources are of the same order, -271.7 and $-307.9 \mathrm{~cm}^{3} / \mathrm{mol}$ for the labile and stable fraction of PPO of water melon at $50{ }^{\circ} \mathrm{C}$ in the pressure range of 8 $30 \mathrm{MPa}$ (Liu et al., 2013) or $94.31 \mathrm{~cm}^{3} / \mathrm{mol}$ for PPO from cloudy Fuji apple juice at $55^{\circ} \mathrm{C}$ in the pressure range from 8 to $30 \mathrm{MPa}$ (Gui et al., 2007).

The Weibull parameters are also listed in Table 1.2a. Scale, $\alpha$, and shape, $\beta$, parameters were used to calculate the time require to inactivate $1 \log \left(t_{d=1}\right)$ of PPO. Similar to the D- 
values for the first order kinetic model, $t_{d=1}$ decreased with operating pressure and temperature. As suggested by van Boekel (2002) is important to determine the effect of temperature, and in the present work of pressure, on both parameters of the Weibull model. Scale parameter was statistically significant dependent on temperature and pressure, when tested at the $95 \%$ significance level for a linear relationship, decreasing with pressure and temperature. The shape factor, $n$, was less than 1 except for $10 \mathrm{MPa}$ and $35^{\circ} \mathrm{C}$. The concavity shape of the inactivation curve could be understood as a faster inactivation of the labile form of the enzyme and the presence of a resistant form of the enzyme to HPCD treatment (Figures 1.3a and 1.3b). The shape parameter, $\beta$, was found to be statistically significant dependent on pressure but although there seemed to be a trend in temperature dependence of $\beta$, it was not statistically significant, when tested at the $95 \%$ significance level for a linear relationship. In any case, it must be highlighted that only three temperatures have been studied to determine the effect of temperature. According to van Boekel (2002), the scale parameter, $\alpha$, could be modelled in a similar way to the classical $D$ value of the first order kinetic model, suggesting a linear dependence of the $\log \alpha$ on temperature and considering that $\beta$ did not depend on temperature:

$\log \alpha=a_{1}-b_{1} T$

$A z_{T}{ }^{\prime}$ value can be also defined:

$z_{T}^{\prime}=\frac{1}{b_{1}}$

The value of the $z_{T}^{\prime}$ is listed in Table 1.2a, together with the quality of the fitting. Although the concept of $z_{T}$ and $z_{T}^{\prime}$ is different since $z_{T}$ is obtained from the linear part, whereas $z^{\prime}{ }_{T}$ takes also into account the nonlinear part (Boekel, 2002), similar values were obtained for both parameters $\left(z_{\mathrm{T}}=29^{\circ} \mathrm{C}\right.$ and $\left.z_{T}^{\prime}=27^{\circ} \mathrm{C}\right)$.

In this work, it was also found a linear dependence of the $\log \alpha$ on pressure:

$\log \alpha=a_{2}-b_{2} p$ 
Although it was found a statistically significant linear relationship between $\beta$ and $p$, the inverse of the slope of $\log \alpha$ versus $p$ was also evaluated. Analogous to $z^{\prime}{ }_{T}$ it was defined a $z_{p}^{\prime}:$

$z_{p}^{\prime}=-\frac{1}{b_{2}}$

This value is reported in Table 1.2a and quite similar values can be observed for $z_{p}$ and $z_{p}^{\prime}$.

\subsection{Effect of HPCD treatment on PME}

To compare the HPCD resistance of PME and PPO, PME inactivation kinetics were determined for the experiments performed at $45^{\circ} \mathrm{C}$ and $10 \mathrm{MPa}$ and $20 \mathrm{MPa}$ (Figure 1.4). PME inactivation rate was also determined at atmospheric pressure and $45^{\circ} \mathrm{C}$. At atmospheric pressure, it was found that residual PME activity was still $90 \%$ after 120 min at $45^{\circ} \mathrm{C}$ (Figure 1.4).

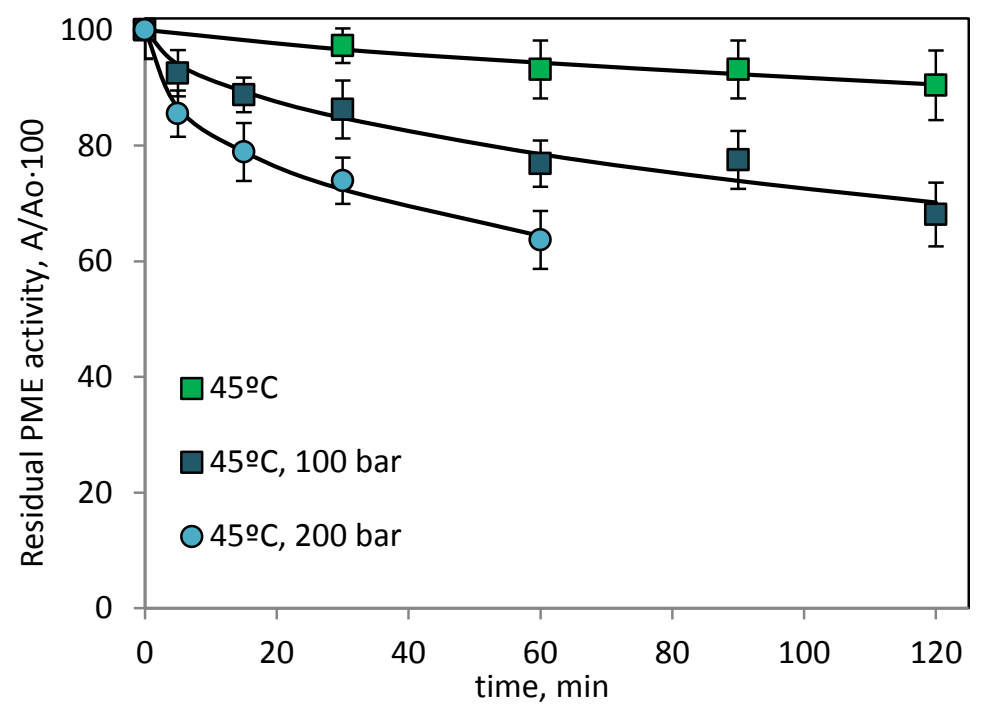

Figure 1.4. Inactivation of PME in cloudy apple juice under mild heating treatment at $45^{\circ} \mathrm{C}$ (atmospheric pressure) and by HPCD at $45^{\circ} \mathrm{C}$. The continuous lines at atmospheric pressure represent the first order kinetic model (Table 1.1), while in HPCD treatment represent the Weibull model (Table 1.2a). 
Teleszko et al. (2016) studied thermal treatment of different apple cultivars, founding that PME from cloudy Golden deliciuous apple juice was one of the apple cultivars that presented strongest thermostability (30\% of residual activity after heating $5 \mathrm{~min}$ at $100{ }^{\circ} \mathrm{C}$ ). Niu et al. (2010b) found that the RA of PME from cloudy Fuji apple juice from apple slices previously preheated for $20 \mathrm{~min}$ at the corresponding working temperature, varied between 82 to $72 \%$ at 35 and $45{ }^{\circ} \mathrm{C}$, respectively, but with error bars higher than $10 \%$ of RA at each temperature (graphical lecture).

After HPCD treatment, higher inactivation rates were observed than for mild heating treatment at the same temperature, although residual activity was still around $60 \%$ at $20 \mathrm{MPa}$ and $45^{\circ} \mathrm{C}$ after $60 \mathrm{~min}$. This indicates that PME from cloudy Golden delicious apple juice is rather stable to HPCD at operating temperatures considered as non-thermal treatment. Different HPCD inactivation values of PME from cloudy apple juice have been reported in the literature. Niu et al. (2010b) reported a minimal residual activity of $18 \%$ for PME of cloudy Fuji apple juice from apple slices treated by HPCD at $20 \mathrm{MPa}$ and $65{ }^{\circ} \mathrm{C}$ for $20 \mathrm{~min}$. In a continuous system, PME from cloudy Fuji apple juice still presented a residual activity of $40 \%$ at $22 \mathrm{MPa}$ and $60{ }^{\circ} \mathrm{C}$ for $10 \mathrm{~min}$ ( $\mathrm{Xu}$ et al., 2011). HPCD inactivation of PME extracts from apple juice was found to be more effectively inactivated at $30 \mathrm{MPa}$ for $60 \mathrm{~min}$, reaching $5 \%$ of residual activity at $55^{\circ} \mathrm{C}$ (Zhi et al., 2008). However, in this case, results are difficult to compare since an extracted enzyme suspended in a buffer solution can give different inactivation results from those obtained in an original juice.

Results obtained in this work, indicate that PME from cloudy apple juice was more resistant to HPCD than PPO in the pressure range covered in this work. In the literature, as for thermal treatment, the higher instability has been attributed to the more complex structure of PPO with three or four subunits, in higher plants, than PME, with one subunit. This structure, makes PPO more susceptible to HPCD treatment (Niu et al., 2010a). In addition, PME in fruit juices is more difficult to be effectively inactivated, since PME is bound to the plant cell wall, which contains natural stabilizing factors (Zhou et al., 2010).

PME inactivation kinetic data were described by the first order model at atmospheric pressure (Table 1.1). The decimal reduction time at $45^{\circ} \mathrm{C}$ and atmospheric pressure was 
found to be much higher than for PPO at the same conditions. HPCD inactivation data at $45^{\circ} \mathrm{C}$ and $10 \mathrm{MPa}$ and $20 \mathrm{MPa}$ were fitted to the first order kinetic model and the Weibull model (Table 1.2a and 1.2b). The Weibull model yielded the best fitting quality, but still an acceptable good fitting for the first order kinetic model was obtained. For the first order model, inactivation rate constant increased with pressure, but lower values than for PPO inactivation were obtained and therefore higher D values. Regarding the Weibull model, the scale and shape parameters, both, decreased with operating pressure at $45^{\circ} \mathrm{C}$. These parameters were used to calculate the time needed to inactivate $1 \log \left(t_{d=1}\right)$ of PME at the two pressures studied. The $t_{d=1}$ calculated by the Weibull model is much higher than the corresponding $D$ values by the first order kinetic model. Therefore, in this case, the use of the first order kinetic model could lead to an underprocessing estimation for PME inactivation.

\subsection{Effect of HPCD on different quality parameters of cloudy apple} juice

Some quality parameters have been determined right after HPCD treatment at $45^{\circ} \mathrm{C}$, $20 \mathrm{MPa}$ and $60 \mathrm{~min}$ of treatment time, and are showed in Table 1.3.

pH. Initial pH of cloudy apple juice was $3.89 \pm 0.01$ and immediately after HPCD treatment, $\mathrm{pH}$ dropped 0.15 units to $3.74 \pm 0.01$. Significant differences have been determined among sample $\mathrm{pH}$ averages before and after HPCD treatment when applying the Fisher's least significant method at p-value $\leq 0.05$ (Table 1.3). Gui et al. (2007) reported a drop of 0.3 units from 3.95 to $3.66 \pm 0.03$ for Fuji cloudy apple juice after HPCD treatment at $22 \mathrm{MPa}$ and $55^{\circ} \mathrm{C}$ for $60 \mathrm{~min}$. According to Meysammi et al. (1992), juices and beverages can be considered as an aqueous electrolyte system of multiple ions. Under pressurized $\mathrm{CO}_{2}$ a number of dissociation reactions can take place liberating some of them $\mathrm{H}^{+}$ions that could reduce the $\mathrm{pH}$ of the media. In any case, after $2 \mathrm{~h}$ after depressurization $\mathrm{pH}$ returned to a value close to its initial value $(\mathrm{pH}=3.87 \pm 0.01)$.

Hydroxymethylfurfural. Table 1.3 presents the HMF content before and after HPCD treatment. From these results, it can be concluded that non enzymatic browning reactions 
were not significant during HPCD processing, probably due to the mild temperatures employed in HPCD treatments.

Color parameters. Table 1.3 lists the $L^{*}, a^{*}, b^{*}$ parameters of cloudy apple juice before and after HPCD treatment. During browning, the $L^{*}$ values decrease, the juice's color becomes darker, while $\mathrm{a}^{*}$ and $\mathrm{b}^{*}$ values increase, with more red and yellow components (Krapfenbauer et al., 2006). After HPCD treatment, lightness ( $\left.L^{*}\right)$ presented slightly, but significant, lower values; however, $99 \%$ of the lightness was still retained. No significant difference was observed in the redness component but a significant increase of the yellowness $\left(b^{*}\right)$ value has been observed indicating more yellow components right after HPCD treatment. The change in colour, $\triangle E$ (Eq. 1.5) is also presented in Table 1.3. Slightly noticeable differences in color after HPCD treatment have been determined, $\triangle E \approx 0.51 \pm$ 0.05 (Yuk et al., 2014). Other authors found that $L^{*}, a^{*}$ and $b^{*}$ values remained almost constant after HPCD treatment at $55^{\circ} \mathrm{C}$ and different operating pressures (8-30 MPa) for 60 min (Gui et al., 2006).

Total polyphenolic compounds. Total polyphenols remained unchanged after HPCD. Gasperi et al. (2009) also found no significant differences in polyphenols content after HPCD treatment of a blend of Golden delicious and Granny Smith apple at $10 \mathrm{MPa}$ and $36^{\circ} \mathrm{C}$ for $10 \mathrm{~min}$.

Turbidity. The turbidity of the cloudy apple juice after HPCD is considerably higher than that of freshly cloudy apple juice (Table 1.3). It seems that there was a correlation between juice's turbidity and particle size distribution However, no correlation was found with PME residual activity since, after HPCD treatment, PME activity was still more than $60 \%$. 
Table 1.3 Some quality parameters before and right after HPCD treatment of cloudy apple juice at $20 \mathrm{MPa}$ and $45^{\circ} \mathrm{C}$ after $60 \mathrm{~min}$.

\begin{tabular}{|c|c|c|}
\hline Parameter & Before HPCD & After HPCD \\
\hline $\mathrm{pH}$ & $3.89 \pm 0.006^{a}$ & $3.74 \pm 0.006^{b}$ \\
\hline \multirow{3}{*}{ Color $\Delta \mathrm{E}=0.51 \pm 0.05$} & $L^{*}=37.30 \pm 0.03^{a}$ & $L^{*}=36.98 \pm 0.01^{b}$ \\
\hline & $a^{*}=1.6 \pm 0.1^{a}$ & $a^{*}=1.59 \pm 0.08^{a}$ \\
\hline & $b^{*}=7.90 \pm 0.03^{a}$ & $b^{*}=8.26 \pm 0.07^{b}$ \\
\hline Total polyphenols, mg galic/L & $456.1 \pm 13.1^{\mathrm{a}}$ & $455.4 \pm 4.3^{\mathrm{a}}$ \\
\hline \multirow{3}{*}{ ABTS, $\%$ of inhibition } & $20 \min , 49 \pm 2^{\mathrm{a}}$ & $20 \min , 52 \pm 3^{\mathrm{a}}$ \\
\hline & $60 \min , 65 \pm 2^{a}$ & $60 \min , 68 \pm 4^{a}$ \\
\hline & $120 \min , 81 \pm 3^{a}$ & $120 \min , 85 \pm 4^{a}$ \\
\hline $\begin{array}{c}\text { Non-enzimatic browning, } \\
\mathrm{mg} \mathrm{HMF} / \mathrm{L}\end{array}$ & $2 \pm 0.3^{\mathrm{a}}$ & $1.70 \pm 0.09^{a}$ \\
\hline \multirow{6}{*}{ PSD } & $\mathrm{D}(3,2)=1.7 \pm 0.07 \mu \mathrm{m}^{\mathrm{a}}$ & $D(3,2)=0.21 \pm 0.01 \mu \mathrm{m}^{b}$ \\
\hline & $\mathrm{D}(4,3)=109 \pm 3 \mu \mathrm{m}^{\mathrm{a}}$ & $\mathrm{D}(4,3)=2.4 \pm 0.2 \mu \mathrm{m}^{\mathrm{b}}$ \\
\hline & $\mathrm{d}(0,1)=0.59 \pm 0.01 \mu \mathrm{m}^{\mathrm{a}}$ & $\mathrm{d}(0,1)=0.099 \pm 0.001 \mu \mathrm{m}^{\mathrm{b}}$ \\
\hline & $\mathrm{d}(0,5)=13 \pm 1 \mu \mathrm{m}^{\mathrm{a}}$ & $\mathrm{d}(0,5)=0.265 \pm 0.006 \mu \mathrm{m}^{\mathrm{b}}$ \\
\hline & $d(0,9)=337 \pm 7 \mu m^{a}$ & $d(0,9)=1.63 \pm 0.07 \mu \mathrm{m}^{b}$ \\
\hline & Span $=26 \pm 7 \mu \mathrm{m}^{\mathrm{a}}$ & Span $=5.8 \pm 0.1 \mu \mathrm{m}^{\mathrm{b}}$ \\
\hline Turbidity, NTU & $105 \pm 2^{a}$ & $168 \pm 3^{b}$ \\
\hline \multirow{2}{*}{$\begin{array}{l}\text { Water soluble pectin } \\
\text { Oxalate soluble pectin } \\
\text { (mg galacturonic/L) }\end{array}$} & $22 \pm 2^{a}$ & $28 \pm 3^{a}$ \\
\hline & $23 \pm 4^{a}$ & $23 \pm 3^{a}$ \\
\hline$\xi$-potential & $-22.0 \pm 0.3^{a}$ & $-22.3 \pm 0.4^{a}$ \\
\hline
\end{tabular}

Antioxidant capacity. Antioxidant capacity of Golden cloudy apple juice has been determined by the ABTS tests (Table 1.3). Slightly higher values were obtained after HPCD treatment although differences before and after treatment were found to be no significant $(p \leq 0.05)$.

Particle size distribution. The particle size distribution of untreated cloudy apple juice ranged from $0.275 \mu \mathrm{m}$ to $416.87 \mu \mathrm{m}$ with three maxima at $0.63,19.96$ and $208.93 \mu \mathrm{m}$ (see Figure 1.5). After HPCD treatment, the particle range shifted to smaller particle sizes from $0.04 \mu \mathrm{m}$ to $104.71 \mu \mathrm{m}$ with one main maximum at $0.182 \mu \mathrm{m}$. Table 1.3 lists values of $D[3,2]$ and $D[4,3]$ of freshly cloudy apple juice and after HPCD treatment. 


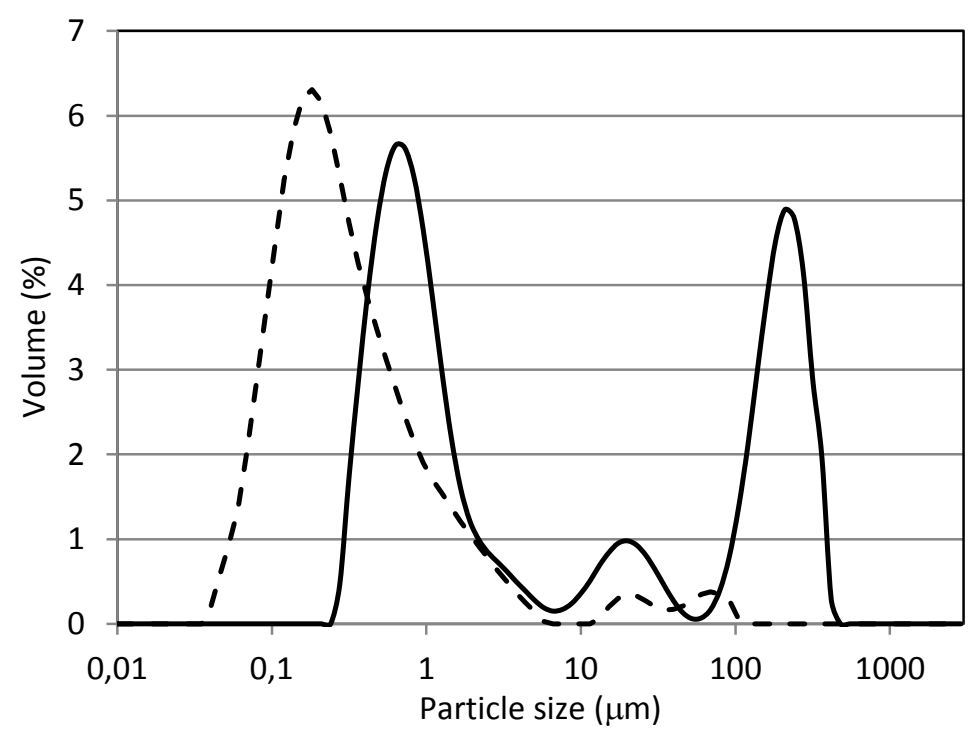

Figure 1.5 Particle size distribution (PSD) of cloudy apple juice before treatment (continuous line) and after HPCD treatment at $45^{\circ} \mathrm{C}, 20 \mathrm{MPa}$ for $60 \mathrm{~min}$ (discontinuous line).

The values after HPCD treatment were significantly lower than those of freshly cloudy apple juice. The homogenization effect of HPCD can be also observed in the values of $d(0.1), d(0.5)$ and $d(0.9)$, which correspond to the size of particle below which $10 \%, 50 \%$ and $90 \%$ of the sample lies, respectively. This homogenization effect induced by HPCD could be attributed to the explosive action and the bubbling of $\mathrm{CO}_{2}$ from the juice during decompression (Zhou et al., 2010).

For fresh cloudy apple juice, the total volume of all particles with diameter less than $5 \mu \mathrm{m}$ represented $56.5 \%$ of the total particles volume, while this number increased up to $96 \%$ after HPCD treatment. This fact is also reflected in the Span values (Table 1.3) that shows a higher degree of uniformity of the cloudy apple juice after HPCD treatment.

Pectin content. In this work, soluble pectin presented slightly higher values after HPCD (Table 1.3). HPCD treatment could result in a more dissolution of pectin in fruit cell into the juice, increasing the value of soluble pectin. In addition, according to the PSD previously reported, HPCD induced an homogenization with lower particle size diameters, which could result in a higher solubility of the pectin; since, in the literature, it has been 
reported that pectin solubility in water increases by decreasing its polymer size (Sila et al., 2009). However, no significant differences have been found at $p \leq 0.05$. No significant differences have been also determined for the oxalate-soluble pectin.

In the literature, Zhou et al. (2010) reported no change in water soluble pectin when treating peach juice by $\mathrm{HPCD}$ at $30 \mathrm{MPa}$ and $55^{\circ} \mathrm{C}$ at different treatment times, although these authors observed an increase of the large particle after HPCD treatment. However, Yu et al. (2013) observed that soluble pectin of HPCD-treated banana pulp at $20 \mathrm{MPa}$, during $30 \mathrm{~min}$ at different temperatures in the range from 45 to $60{ }^{\circ} \mathrm{C}$, was significantly lower than in the untreated pulp. These authors attributed this behavior due to interaction of pectin and protein or gelling of pectin that may occur during HPCD treatment (Yu et al., 2013).

$\xi$ potential. $\xi$ potential is an indication of colloidal stability of the juice. Both, untreated and treated apple juice presented negative values of $-22.0 \mathrm{mV}$ and $-22.3 \mathrm{mV}$, respectively. These values were within the range reported by Croak and Corredig (2006)(Croak \& Corredig, 2006) of $\xi$ potential as a function of $\mathrm{pH}$ for orange juice. Negative values of $\xi$ potential indicated that juice particles were negatively charged. The extent of this negative surface charge before and after HPCD treatment involves electrostatic charge repulsion which has been established as one of the mechanisms of cloud stabilization (Croak \& Corredig, 2006). Since no significant differences at $p$-values $\leq 0.05$ were found before and after treatment, it indicates that colloid stability is kept after HPCD treatment.

\section{Conclusions}

HPCD treatment is a valid alternative technology to process Golden delicious cloudy apple juice being more effective than mild thermal treatment in the same temperature range.

PPO and PME inactivation rate increased whit operating pressure and temperature, although PME was found to be more HPCD resistant compared to PPO. The non-linear 
Weibull model performed a better fitting of the enzyme inactivation kinetics by HPCD than the classical first order kinetic model.

However, further research is needed to have reliable data on HPCD as cold pasteurization method, since different results are found in the literature for the same fruit variety. Important variables in enzyme inactivation are usually not described in the research articles such as the way the $\mathrm{CO}_{2}$ is fed into the sample, agitation speed or the ratio juice/volume of the cell that in fact determined the ratio juice $/ \mathrm{CO}_{2}$. In this work, it was observed that the stirring speed was an important factor to take into account for enzyme inactivation, due to an improvement in $\mathrm{CO}_{2}$ diffusivity.

HPCD induced a homogenization effect on cloudy apple juice since particle size distribution was shifted to smaller particle size. Colloidal stability was not affected by HPCD treatment as well as the pectic content substances. Slightly noticeable differences in color after HPCD treatment have been determined $(\Delta \mathrm{E} \approx 0.5 \pm 0.1)$. Other quality parameters in cloudy apple juice, such as total polyphenolic compounds, antioxidant capacity or hydroxymethylfurfural content did not change after HPCD treatment. Other important aspects need also to be addressed for an industrial application such as sensory quality, shelf life studies and economic aspects. 


\section{CHAPTER 2}

Effect of thermosonication batch treatment on enzyme inactivation kinetics and other quality parameters of cloudy apple juice

Based on the article:

A.E. Illera, M. T. Sanz, O. Benito-Román, S. Varona, S. Beltrán, R. Melgosa. A. G. Solaesa (2018).

"Effect of thermosonication batch treatment on enzyme inactivation kinetics and other quality parameters of cloudy apple juice".

Innovative Food Science and Emerging Technologies, 47, 71-80. 



\title{
Capítulo 2
}

\author{
Estudio del efecto de un tratamiento de termosonicación en las cinéticas \\ de inactivación enzimáticas y en parámetros de calidad de zumo de \\ manzana no clarificado
}

\section{Resumen}

En ese capítulo se ha evaluado la tecnología de termosonicación como tratamiento alternativo al tratamiento térmico en zumo de manzana no clarificado y se comprobó su efectividad en la inactivación de la polifenoloxidasa, aunque la pectinmetilesterasa demostró ser más resistente a este tratamiento. Se consiguió aumentar la inactivación de ambas enzimas mediante un aumento en la amplitud del ultrasonido y en la cantidad de energía aplicada al zumo.

Se determinaron las cinéticas de inactivación enzimáticas a diferentes temperaturas (de 44 a $\left.67^{\circ} \mathrm{C}\right)$, y los datos de inactivación se ajustaron correctamente tanto a un modelo cinético de primer orden como al modelo de Weibull. El tratamiento de termosonicación produjo un efecto de homogenización en el zumo, reflejado por un desplazamiento de la distribución del tamaño de partícula hacia diámetros más pequeños. Se estudió también el efecto de la presencia de gases disueltos sobre la inactivación enzimática. Para ello, se desplazó el aire disuelto mediante el burbujeo de nitrógeno o dióxido de carbono antes de realizar los tratamientos de termosonicación. Tras desplazar el aire con nitrógeno se obtuvieron mejores resultados en la inactivación enzimática.

Palabras clave: Zumo de manzana no clarificado, termosonicación, inactivación enzimática, gases disueltos. 



\section{Abstract}

Cloudy apple juice has been treated by thermosonication in batch mode as an alternative processing to thermal treatment. Thermosonication was found to be effective to inactivate polyphenol oxidase; however, pectin methylesterase was found to be more resistant. An increase of the working ultrasound amplitude and the amount of energy supplied to the juice led to lower enzyme residual activities.

Enzyme inactivation kinetics was determined at different temperatures (from 44 to $67^{\circ} \mathrm{C}$ ). Inactivation data were described by the first order kinetic model and the Weibull model, both models yielding good fitting. Thermosonication treatment caused a homogenization effect reflected in the shifting of the particle size distribution towards smaller diameters. The effect of the nature of dissolved gases in the juice on enzyme inactivation was studied by displacing the air dissolved in the juice by bubbling nitrogen or carbon dioxide, previous to the thermosonication experiments. Higher inactivation rates were obtained by displacing the air with nitrogen.

Keywords: Cloudy apple juice, thermosonication, enzyme inactivation, dissolved gases. 



\section{Introduction}

Cloudy apple juice is a good source of bioactive compounds such as ascorbic acid, polyphenols and pectins. However, enzymatic browning causes serious product deterioration. One of the most important enzymes responsible for enzymatic browning is polyphenol oxidase (PPO). PPO catalyses the oxidation of phenolic compounds to quinones, which will subsequently react with other compounds to form brown pigments that reduce juice quality. Other important quality parameter in cloudy apple juice is the cloud stability. One of the most accepted theories of cloud loss in juices is based on the action of pectin methylesterase (PME). This enzyme causes pectin demethylation that could expedite pectin precipitation with calcium ions present in the juice, causing clarification and turbidity loss (Briongos et al., 2016).

Thermal treatments are widely used in the Food Industry to inactivate microorganisms and enzymes that cause deleterious effects on foods. However, consumer's demand of natural and fresh-like products has driven the Food Industry to investigate alternative technologies to replace conventional food heat treatments; which may affect food quality in terms of nutritional and physicochemical parameters. Among these technologies, ultrasonication is an attractive technology that is considered to be simple, reliable, environmentally friendly and highly effective in achieving microbial decontamination (Dias et al., 2015). Inactivation of microorganisms and enzymes by sonication is attributed to physical (cavitation, mechanical effects) and chemical (formation of free radicals) effects (Donnell et al., 2010). Inactivation of enzymes by ultrasonication has been attributed to the formation of localized hot spots upon collapse of bubbles, shear forces created by microstreaming and shock waves, as well as generation of free radicals through sonolysis of water (Kadkhodaee \& Povey, 2008). Sonochemical activity (production of radicals) is influenced by operational parameters, being the effect of frequency and gas addition the most significant (Gielen et al., 2016). Furthermore, the presence of gases (air, oxygen or an inert gas) in the solution has been reported as necessary for enzyme inactivation (Grintsevich et al., 2001). In any case, enzyme inactivation mechanisms are specific to 
each enzyme and depend on their amino acid composition and their conformational structure (Anaya-Esparza et al., 2017).

When ultrasound is combined with heating, the resulting technique, Thermosonication (TS), is usually more effective as preservation technique even when TS temperatures are lower than those used in thermal treatments. TS treatment has been found to be more efficient than thermal treatment for the inactivation of different types of enzymes responsible for deterioration of fruits and vegetable juices, among them, pectin methylesterase, polyphenol oxidase, lipoxygenases and peroxidases (Baltacioglu et al., 2017). Recently, Anaya-Esparza et al. (Anaya-Esparza et al., 2017) reviewed the advantages and limitations offered by the application of TS on different fruit and vegetable juices. In this work, the effect of TS on PPO and PME inactivation in Golden delicious cloudy apple juice has been studied. The effect on enzyme activity of different variables, such as amount of energy transmitted to the juice, expressed as power density, PD $(\mathrm{W} / \mathrm{mL})$, ultrasound amplitude, temperature and treatment time has been determined. In addition, the effect of the nature of the dissolved gas (air, nitrogen and carbon dioxide) has been evaluated on enzyme inactivation. No previous studies have been found in the literature regarding the effect of this variable on fruit juices processed by TS. Finally, enzyme inactivation by TS was compared with previous results obtained by High Pressure Carbon Dioxide (HPCD) treatment as non-thermal technology (Illera et al., 2018a), and with a thermal treatment alone in the same temperature range. The effect of TS on other quality parameters of cloudy apple juice, such as particle size distribution (PSD), color and total polyphenols and hydroxymethylfurfural content has been also determined.

\section{Materials and methods}

\subsection{Juice preparation}

Golden delicious apples were peeled, cut in cubes and submerged in a $0.3 \%$ L-ascorbic acid solution to avoid enzymatic browning during processing. Apple cubes were wiped and 
immediately squeezed with a screw juice extractor. The liqueur was filtered with 2 layers of cheesecloth. The $\mathrm{pH}$ of the juice obtained was $3.89 \pm 0.01$ and the soluble solids content was $12.5 \pm 0.1^{\circ} \mathrm{Brix}$. The juice was stored frozen at $-18^{\circ} \mathrm{C}$ until further use. Carbon dioxide (99.9\%) was supplied by Air Liquide S.A. (Spain). Nitrogen (98.5\%) was obtained by a Zefiro 25 LCMS nitrogen generator.

\subsection{Thermosonication}

A 750 W Sonics Material ${ }^{\mathrm{TM}}$ with a $13 \mathrm{~mm}$ probe was used for thermosonication. Samples were processed at a constant ultrasound frequency of $20 \mathrm{kHz}$. Cloudy apple juice was introduced in a thermostated vessel $\left(\Phi=4.8 \mathrm{~cm}, V=199 \mathrm{~cm}^{3}\right)$ and the probe was submerged in the juice at a constant depth of $2 \mathrm{~cm}$ from the bottom of the vessel. According to the manufacturer, the US amplitude is $76 \mu \mathrm{m}$ when the amplitude control is set at $100 \%$ and the $13 \mathrm{~mm}$ probe can handle volumes in the range from 50 to $150 \mathrm{ml}$.

Firstly, TS was performed in a continuous mode and fixing the amplitude at different levels (from 25 to $100 \%$ ), keeping constant the rest of operating variables: TS time (15 min), treated volume of apple juice $(80 \mathrm{ml})$ and temperature of the jacketed water $\left(40^{\circ} \mathrm{C}\right)$. This way, the effect of amplitude on PSD and PPO inactivation was first analyzed. During each TS experiment, the temperature profile was registered, and the energy input was recorded after the experiment. The ultrasonic power density, PD, was evaluated as:

$P D=\frac{E}{t \cdot V}=\frac{P}{V}$

Where $E$, is the energy input $(J), t$ is the ultrasonication time $(s), P$, the ultrasonic power $(\mathrm{J} / \mathrm{s}=\mathrm{W})$ and $\mathrm{V}$ is the sample volume $(\mathrm{ml})$.

TS experiments were also performed by varying the treated sample volume from 60 to $120 \mathrm{ml}$, in continuous and in pulse (5 s on and $5 \mathrm{~s}$ off) modes, at maximum amplitude, during $15 \mathrm{~min}$ of TS and keeping constant the temperature of the jacketed water at $40{ }^{\circ} \mathrm{C}$. By varying the sample volume at fixed amplitude, the power density was also varied (see equation 2.1) and its effect on PPO inactivation was analyzed. 
Enzyme inactivation kinetics for PME and PPO were determined at maximum amplitude for a treated sample volume of $80 \mathrm{ml}$ at different TS temperatures, by varying the temperature of the jacketed water from 20 to $50{ }^{\circ} \mathrm{C}$. Previous to the TS treatment, cloudy apple juice was preheated (90 s (Sulaiman et al., 2015)) to the initial temperature of TS (temperature of the jacketed water) in all the experiments, then temperature was continuously recorded during treatment.

No enzyme inactivation was observed during the preheating time (90 s) at the initial TS temperatures essayed in this work, from 20 to $50{ }^{\circ} \mathrm{C}$.

The effect of the nature of the dissolved gas in the juice was also considered. Previous to the thermosonication experiments, air dissolved in the juice was displaced by bubbling nitrogen or carbon dioxide in the sample at atmospheric pressure until oxygen concentration was below $0.4 \mathrm{mg} / \mathrm{L}$ (YSI ProODO optical dissolved oxygen meter). After that, TS experiments were performed as previously described.

\subsection{Physical-chemical analysis}

\subsubsection{Determination of enzyme activity}

Polyphenol oxidase. PPO activity was determined by adding $100 \mu \mathrm{l}$ of apple juice into $2.9 \mathrm{ml}$ of substrate solution consisting of a $0.05 \mathrm{M}$ catechol (Sigma Aldrich) solution prepared in a $0.1 \mathrm{M}$ phosphate buffer $(\mathrm{pH} 6.5)$. Oxidation of catechol was determined immediately by the absorbance increase at $420 \mathrm{~nm}$ by using a Jasco V-750 spectrophotometer equipped with a Peltier thermostated cell holder at $30^{\circ} \mathrm{C}$. The PPO activity was determined by using the very first linear part of the reaction curve (Illera et al., 2018a).

Pectin methylesterase. Samples were analyzed by using an automatic titrator system (Metrohm $\AA$ Titrando). A pectin solution (1\%) (Alfa Aesar $\AA$ pectin citrus) was prepared in $\mathrm{NaCl}(0.3 \mathrm{M})$. This solution was used as substrate. $50 \mathrm{ml}$ of pectin solution were mixed with $1 \mathrm{ml}$ of cloudy apple juice and $\mathrm{pH}$ was adjusted to 7.5 with $\mathrm{NaOH} 0.005 \mathrm{~N}$. During 
pectin hydrolysis at $30{ }^{\circ} \mathrm{C}, \mathrm{pH}$ was maintained at 7.5 by adding $\mathrm{NaOH} 0.005 \mathrm{~N}$. The amount of $\mathrm{NaOH}$ added for 15 min was recorded. One PME activity unit (UPE) is defined as the micromoles of carboxylic groups produced per minute and $\mathrm{ml}$ of juice, at $\mathrm{pH} 7.5$ and $30^{\circ} \mathrm{C}$ (Briongos et al., 2016).

Relative residual activities of PPO and PME were evaluated as:

Residual activity $(\%)=\frac{\text { Enzyme specific activity after TS treatment }}{\text { Enzyme specific activity before TS treatment }} \cdot 100$

As previously explained, during the preheating time (90 s) no inactivation was observed, therefore the enzyme activity right before TS treatment was considered to be the enzyme activity of the untreated juice.

\subsubsection{Determination of hydrogen peroxide, nitrate and nitrite formation}

One of the mechanisms proposed on enzyme inactivation by US is the formation of free radicals. In the literature, hydrogen peroxide $\left(\mathrm{H}_{2} \mathrm{O}_{2}\right)$ formation has been determined as an estimation of cavitation intensity (Raviyan et al., 2005). However, $\mathrm{H}_{2} \mathrm{O}_{2}$ generation during an ultrasound treatment in a food system is complicated due to the presence of ions and other colloidal components (Raviyan et al., 2005). Therefore, in this work, $\mathrm{H}_{2} \mathrm{O}_{2}$ generation during TS has been determined in a citrate buffer solution at the same $\mathrm{pH}$ as the one of the apple juice $(\mathrm{pH}=3.9)$. Formation of nitrite and nitrate in citrate buffer solutions was also determined, since its sonochemical formation in water has been known for a long time (Supeno \& Kruus, 2000).

Different citrate buffer solutions $(\mathrm{pH}=3.9)$ in the presence of dissolved air, nitrogen or carbon dioxide, prepared as indicated in section 2.2, were thermosonicated $(80 \mathrm{ml}$ of solution at $60^{\circ} \mathrm{C}$ ) for 20 minutes. Samples were collected at different time intervals, to determine the $\mathrm{H}_{2} \mathrm{O}_{2}$, nitrate and nitrite formation during the sonication process.

$\mathrm{H}_{2} \mathrm{O}_{2}$ was determined spectrophotometrically by a colorimetric method based on the one described by Mead et al. (Mead et al., 1976). $1 \mathrm{ml}$ of solution A [1 g NaOH, $33 \mathrm{~g} \mathrm{Kl}$, and 
$0.1 \mathrm{~g}\left(\mathrm{NH}_{4}\right)_{6} \mathrm{Mo}_{7} \mathrm{O}_{2} 4 \mathrm{H}_{2} \mathrm{O}$ in $500 \mathrm{ml} \mathrm{H} \mathrm{H}_{2} \mathrm{O}$ ] was mixed with $1 \mathrm{ml}$ of solution $\mathrm{B}\left[10 \mathrm{~g} \mathrm{C}_{8} \mathrm{H}_{5} \mathrm{O}_{4} \mathrm{~K}\right.$ in $500 \mathrm{ml} \mathrm{H} \mathrm{H}_{2} \mathrm{O}$ ] and subsequently mixed with $2 \mathrm{ml}$ of the thermosonicated buffer solution taken at different time intervals. Absorbance at $350 \mathrm{~nm}$ was registered with time and it was found that 45 min was time enough not to observe any further change in the reaction medium color. Citrate buffer solution, not subjected to thermosonication, was used as a blank. The concentration of $\mathrm{H}_{2} \mathrm{O}_{2}$ was calculated based on a standard curve at different $\mathrm{H}_{2} \mathrm{O}_{2}$ concentrations.

Nitrate and nitrite analysis were performed by using Dr. Lange Küvetten-Test analysis kits and a Hach Lange DR2800 spectrophotometer. LCK 339 kit was used for measuring nitrates. This measurement is based on the reaction of nitrate ion with 2,6dimethylphenol that causes the formation of 2,6-dimethyl-4-nitrophenol. For measuring nitrites, LCK $341 \mathrm{kit}$, which is based on the reaction of nitrite with aromatic primary amines, producing the formation of an azo dye, was used.

\subsubsection{Particle size distribution}

Particle size distribution of cloudy apple juice was determined by laser diffraction at $750 \mathrm{~nm}$ with a Mastersizer 2000 (Malvern ${ }^{\circledR}$ Inst., MA). Particle size distribution was calculated by the Fraunhofer model. Size distributions (volume fractions against particle size) before and after thermosonication treatment were calculated and the weightaverage sizes expressed as:

The equivalent surface area mean diameter:

$$
\mathrm{D}(3,2)=\sum \mathrm{n}_{\mathrm{c}} \mathrm{d}_{\mathrm{lc}}^{3} / \sum \mathrm{n}_{\mathrm{c}} \mathrm{d}_{\mathrm{lc}}^{2}
$$

The equivalent volume mean diameter:

$$
\mathrm{D}(4,3)=\sum \mathrm{n}_{\mathrm{c}} \mathrm{d}_{\mathrm{lc}}^{4} / \sum \mathrm{n}_{\mathrm{c}} \mathrm{d}_{\mathrm{lc}}^{3}
$$

Where $d_{l c}$ is the diameter of the particle and $n_{c}$ is the percentage of particles. 
Other useful parameters $D_{v, 0.9}, D_{v, 0.1}$ and $D_{v, 0.5}$ correspond to the particle size bellow which, $90 \%, 10 \%$ and $50 \%$ of the particles lie respectively.

\subsubsection{Color, hydroxymethylfurfural content and total polyphenol content}

The cloudy apple juice color was determined by using a Beckman DU-650 spectrophotometer with diode-array of UV-vis (Beckman Instruments). Following the CIE recommendations, illuminant D65 (daylight source) and a $10^{\circ}$ standard observer (perception of a human observer) were used. $L^{*}, a^{*}$ and $b^{*}$ values were obtained representing brightness, red to green color and yellow to blue color respectively.

Color difference $(\Delta \mathrm{E})$ and chroma $(\mathrm{C})$ were evaluated as:

$$
\begin{aligned}
& \Delta \mathrm{E}=\sqrt{\left(\mathrm{L}_{\mathrm{before}}^{*}-\mathrm{L}_{\mathrm{after}}^{*}\right)^{2}+\left(\mathrm{a}_{\mathrm{before}}^{*}-\mathrm{a}_{\mathrm{after}}^{*}\right)^{2}+\left(\mathrm{b}_{\mathrm{before}}^{*}-\mathrm{b}_{\mathrm{after}}^{*}\right)^{2}} \\
& C=\sqrt{\left(a^{*}\right)^{2}+\left(b^{*}\right)^{2}}
\end{aligned}
$$

Non enzymatic browning in the juice has been measured as hydroxymethylfurfural (HMF) content (Queiroz et al., 2011). $0.7 \mathrm{ml}$ of juice were mixed with $0.7 \mathrm{ml}$ of ethanol in a $1.5 \mathrm{ml}$ Eppendorf tube. The mixture was centrifuged at $12000 \mathrm{~g}$ for $10 \mathrm{~min}$. After that, $1 \mathrm{ml}$ of the supernatant was mixed with $1 \mathrm{ml}$ of a trichloroacetic acid solution (734 mM) and $1 \mathrm{ml}$ of a thiobarbituric acid solution $(25 \mathrm{mM})$ in a closed recipient. Samples were incubated at $40{ }^{\circ} \mathrm{C}$ during $50 \mathrm{~min}$ in an agitated batch and absorbance was measured at $443 \mathrm{~nm}$. A blank was also prepared with distilled water instead of juice. A calibration curve was prepared using different concentrations of HMF from $0.5 \mathrm{mg} / \mathrm{L}$ to $10 \mathrm{mg} / \mathrm{L}$.

Total phenolic compounds were determined by using the Folin-Ciocalteau reagent (VWR). $100 \mu \mathrm{l}$ of the juice were mixed with $2.8 \mathrm{ml}$ of water, and subsequently with $100 \mu \mathrm{l}$ of the Folin-Ciocalteau reagent. After that, $2 \mathrm{ml}$ of sodium carbonate $7.5 \%(\mathrm{w} / \mathrm{v})$ were added and the reaction started. Absorbance was measured after 60 minutes of reaction at $750 \mathrm{~nm}$. A blank was also prepared using water instead of juice. A calibration curve was prepared with standard solutions of gallic acid by following the same colorimetric method. 


\subsection{Kinetic data analysis}

The inactivation kinetic data at different TS conditions were fitted to the first-order kinetic model and the non-linear Weibull model. The first-order kinetic model can be written as:

$\log A / A_{o}=-\mathrm{kt}$

Where $A_{o}$ is the initial activity of the enzyme, $A$ is the residual activity at different treatment times, $\mathrm{k}$ is the inactivation rate constant at the operating conditions $\left(\mathrm{min}^{-1}\right)$ and $\mathrm{t}$ is the treatment time ( $\mathrm{min})$.

From the inactivation rate constant, the decimal reduction time ( $D$ : time needed to achieve a $90 \%$ reduction of enzyme activity) can be evaluated. $\mathrm{z}_{\mathrm{T}}$, defined as the temperature increase needed for a $90 \%$ reduction of the $D$ value, was determined as the negative reciprocal slope of the regression line of $\log D$ as function of $T$ :

$\log \left[D_{1} / D_{2}\right]=\left(T_{2}-T_{1}\right) / z_{T}$

Furthermore, the dependence of the inactivation constant on temperature can be expressed through Arrhenius equation:

$\ln \left(k_{1} / k_{2}\right)=\left(E_{a} / R T\right)\left(1 / T_{2}-1 / T_{1}\right)$

Where $T_{2}$ and $T_{1}$ are temperatures corresponding to the decimal reduction times $D_{1}$ and $D_{2}$ or constant $k_{1}$ and $k_{2}$, respectively. $R$ is the universal gas constant and $E_{a}$, the activation energy $(\mathrm{kJ} / \mathrm{mol})$.

The non-linear Weilbull model can be written in the power-law form (Boekel, 2002):

$\log \left(A / A_{o}\right)=-(1 / 2.303)(t / \alpha)^{\beta}$

Where $\alpha$ is the scale parameter (a characteristic time) and $\beta$ is the shape parameter. The time required to achieve a number of decimal reductions, $d$, can be calculated by using the shape and scale parameters (Boekel, 2002): 
$t_{d}=\alpha\left(-\ln \left(10^{-d}\right)^{\frac{1}{\beta}}\right)$

\subsection{Statistical analysis}

Statistical analyses were conducted using the software Statgraphics X64. The results are presented as a mean \pm standard deviation of at least three replicates. The significance of the differences was determined based on an analysis of the variance with the Tukey's honestly significant difference (HSD) method at $p$-value $\leq 0.05$.

To estimate the kinetic parameters of the different models essayed in this work, nonlinear regression was performed by using the Marquardt algorithm (Statgraphics X64).

\section{Results and discussion}

\subsection{Temperature profile}

Figure 2.1 shows the temperature profile for a $15 \mathrm{~min}$ TS treatment in a continuous mode at a fixed amplitude of $76 \mu \mathrm{m}(100 \%)$, for a temperature of the jacketed water of $40{ }^{\circ} \mathrm{C}$, at different volumes of treated apple juice $(60,80,100$ and $120 \mathrm{ml})$, which are equivalent to power densities of 1.57, 1.36, 1.21 and $1.09 \mathrm{~W} / \mathrm{mL}$, respectively (equation 2.1). The temperature profile was similar for all the treated volumes; although, the power density increased by decreasing the treated volume. A sharp temperature increase was observed during the first three minutes of TS, then, it reached a plateau with a mean value of $60 \pm 1{ }^{\circ} \mathrm{C}$. Similar temperature profiles were obtained for the other temperatures essayed of the jacketed water, $20,30,45$ and $50^{\circ} \mathrm{C}$, reaching temperatures in the plateau region of $44 \pm 1,52 \pm 1,64 \pm 1$ and $67 \pm 1^{\circ} \mathrm{C}$, respectively (data not shown). 


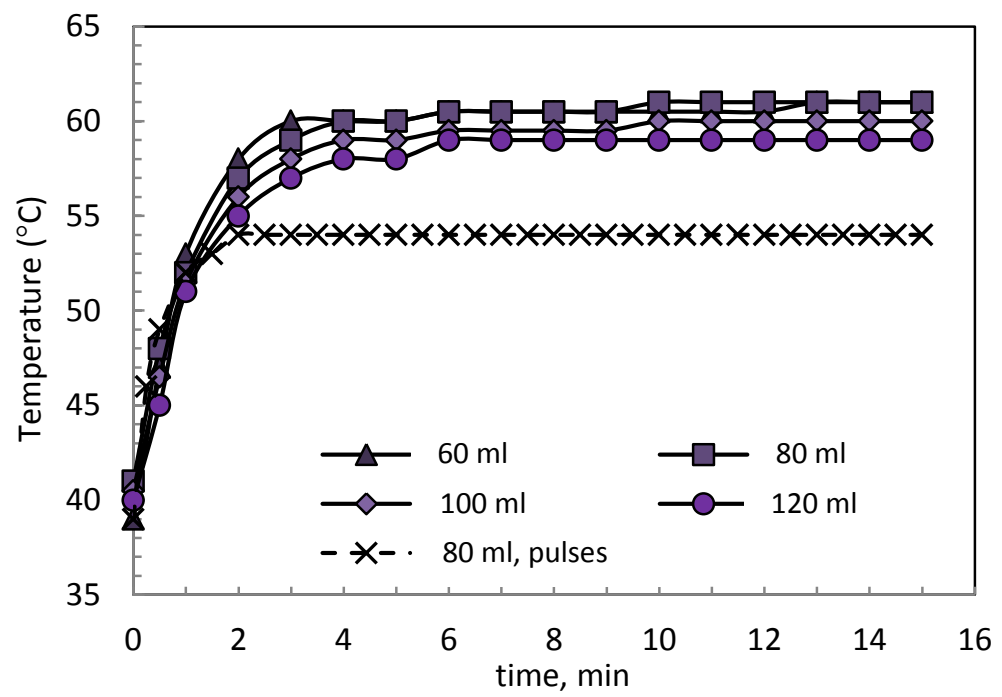

Figure 2.1 Temperature profile of cloudy apple juice during thermosonication of different volumes of cloudy apple juice in a continuous mode and pulse mode, $100 \%$ US amplitude $(76 \mu \mathrm{m})$ and $40^{\circ} \mathrm{C}$ of the jacketed water.

Figure 2.1 also shows the temperature profile for a pulse treatment. Total treatment time under pulse mode, $t_{p}$, was determined as:

$t_{p}=t_{c}(1+(1 / R))$

Where $t_{c}$ is the corresponding time of exposure in a continuous experiment, $15 \mathrm{~min}$, and $\mathrm{R}$ is the ratio on/off, in this work equal to 1 . Experiments under pulse mode were carried out at the same amplitude $(76 \mu \mathrm{m})$, temperature of the jacketed water $\left(40{ }^{\circ} \mathrm{C}\right)$ and amount of treated apple juice $(80 \mathrm{ml})$, equivalent to a power density of $1.18 \mathrm{~W} / \mathrm{mL}$, as the continuous experiments. Power density in the pulse mode was determined by considering only the effective sonication time (tc), although total treatment time (tp) was $30 \mathrm{~min}$, including the interval length. Likewise to a continuous mode, a sharp initial increase in the temperature was observed and then, the temperature remained constant. However, the temperature increase observed in the pulse mode is lower than in a continuous mode. 


\subsection{Effect of the amplitude}

The effect of the TS amplitude was studied in the range of 25 to $100 \%$ (19 to $76 \mu \mathrm{m}$ ) in a continuous mode. These experiments were carried out with $80 \mathrm{ml}$ of cloudy apple juice treated for $20 \mathrm{~min}$ at a temperature of the jacketed water of $40{ }^{\circ} \mathrm{C}$ (Figure 2.2). A linear increase with amplitude was observed for both, power density and final temperature reached during TS $(P D(W / m L)=0.020 \cdot$ Amplitude $(\mu \mathrm{m})-0.238), \quad R^{2}=0.986$; $\mathrm{T}\left({ }^{\circ} \mathrm{C}\right)=0.258 \cdot$ Amplitude $\left.(\mu \mathrm{m})+42, \mathrm{R}^{2}=0.994\right)$.

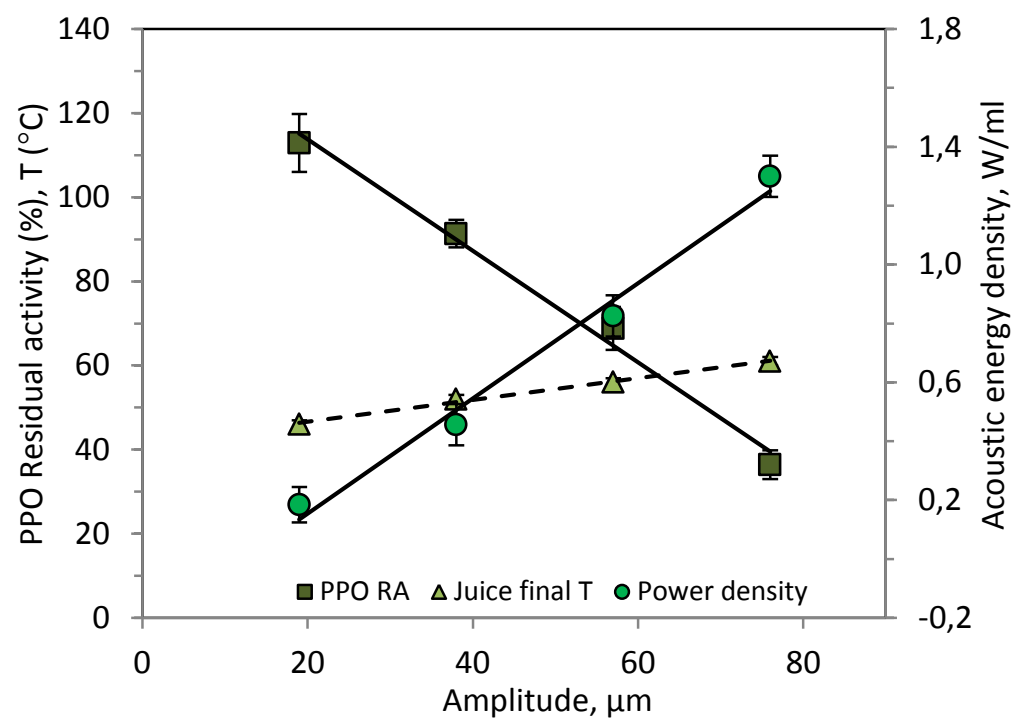

Figure 2.2 Effect of the amplitude on PPO residual activity, final temperature of the juice and power density, $\mathrm{W} / \mathrm{mL}$, for a treated volume of $80 \mathrm{ml}$ and $40{ }^{\circ} \mathrm{C}$ of the jacketed water. Lines represent the linear regression.

PPO residual activity decreased linearly with amplitude, obtaining the lowest residual activity, $36 \pm 3 \%$, at the maximum amplitude (PPO RA $(\%)=-1.326 \cdot$ Amplitude $(\mu \mathrm{m})+140$ $\left.R^{2}=0.990\right)$. It was observed that, at the lowest amplitude essayed in this work, PPO activity after TS treatment was higher than in the untreated sample, indicated by a residual activity value higher than $100 \%$, as determined by equation 2.2. This behavior has been attributed to the homogenization of the juice, due to the acoustic energy that could cause the release of the enzymes usually bound to cell walls (Başlar \& Ertugay, 2013). The increase of the ultrasound effects by increasing amplitude has been also related to the 
increase of the effective size of the zone of liquid undergoing cavitation and the range of sizes of bubbles that undergo cavitation at higher amplitudes (Raso et al., 1999). Baltacioglu et al. (2017) also found that residual enzyme activity decreased with increasing amplitude when studying the inactivation of the mushroom PPO by ultrasonication.

The effect of the amplitude on the particle size distribution of cloudy apple juice is shown in Figure 2.3 Particle size distribution of untreated cloudy apple juice ranged from $0.5 \mu \mathrm{m}$ to $550 \mu \mathrm{m}$ with three maxima at 0.8, 30 and $240 \mu \mathrm{m}$ (see Figure 2.3).

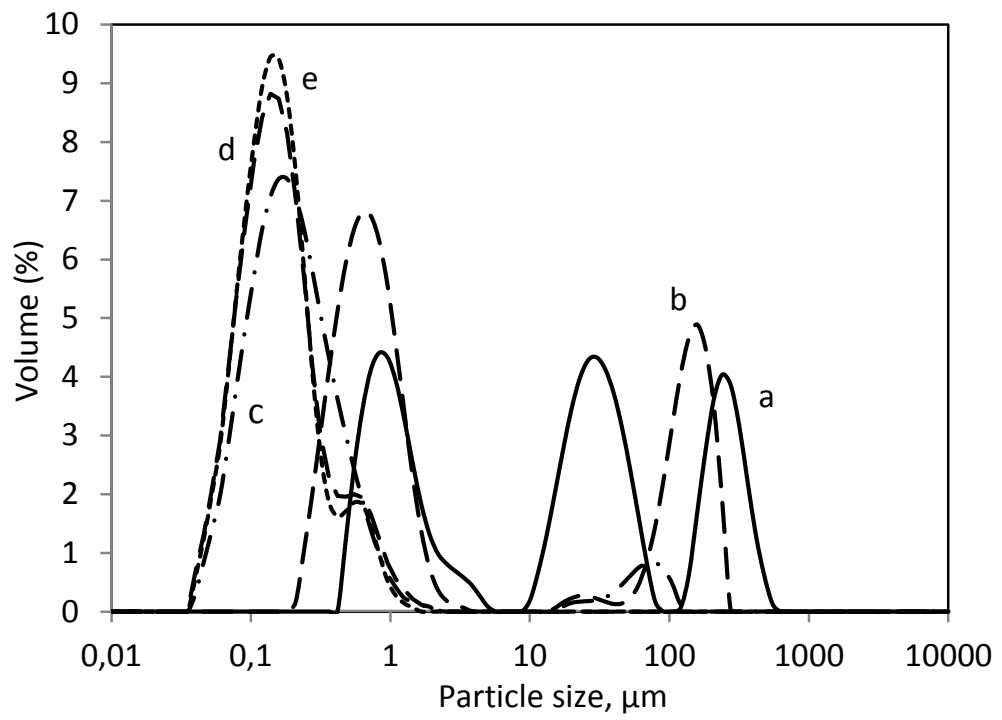

Figure 2.3 Particle size distribution of fresh cloudy apple juice (a) and treated by TS at $40{ }^{\circ} \mathrm{C}$ and different amplitudes $19 \mu \mathrm{m}$ ( $25 \%$ of maximum amplitude, (b), $38 \mu \mathrm{m}$ (50\% of maximum amplitude, (c), $57 \mu \mathrm{m}$ (75\% of maximum amplitude, (d), $76 \mu \mathrm{m}$ (100\% of maximum amplitude, (e). Treated volume was $80 \mathrm{ml}$.

After TS treatment under different amplitudes, the particle range moved towards smaller particle sizes with two main peaks at the lowest amplitude essayed (19 $\mu \mathrm{m})$ at 0.6 and 159 $\mu \mathrm{m}$, one main peak at $0.17 \mu \mathrm{m}$ for $50 \%$ of amplitude $(38 \mu \mathrm{m})$ and at $0.14 \mu \mathrm{m}$ at the two highest amplitude essayed (57 and $76 \mu \mathrm{m}$ ). Based on these results it can be concluded that TS reduces the size of juice particles leading to a better uniformity and stability, especially at high working amplitude. Ertugay \& Baslar (2014) related cloud stability of apple juice to the size of the juice particles. These authors reported that particle size 
above $0.5-0.65 \mu \mathrm{m}$ in apple juice are unstable and settle down, whereas those below 0.5 $\mu \mathrm{m}$ are held in suspension by Brownian motion and do not settle. Therefore, by working at higher amplitude, lower residual activity was reached and also cloud stability was improved. Cheng et al. (Cheng et al., 2007) concluded in their study of sonication of guava juice that, due to the high shearing effect that occurs during cavitation, TS can fragment colloidal pectin molecules that would be more stable in the colloidal system.

Table 2.1 lists the values of $D[3,2]$ and $D[4,3]$ of fresh cloudy apple juice and after TS treatment at different amplitudes. These values indicate that TS treatment promotes dissociation, since they were significantly lower after TS than before treatment. This effect can also be observed in the values of $d(0.1), d(0.5)$ and $d(0.9)$ in Table 2.1.

Table 2.1 Effect of amplitude in the thermosonication treatment on the particle size distribution $(\mu \mathrm{m})$ of cloudy apple juice

\begin{tabular}{|c|c|c|c|c|c|}
\hline & $\mathrm{D}[3,2]$ & $D[4,3]$ & $d(0.1)$ & $d(0.5)$ & $d(0.9)$ \\
\hline Cloudy apple juice & $\begin{array}{l}2.24 \pm \\
0.04^{d}\end{array}$ & $70 \pm 2^{d}$ & $\begin{array}{c}0.690 \pm \\
0.003^{d}\end{array}$ & $20.9 \pm 0.8^{c}$ & $249 \pm 4^{c}$ \\
\hline $19 \mu \mathrm{m}(25 \%)$ & $\begin{array}{c}0.82 \pm \\
0.02^{c}\end{array}$ & $44 \pm 2^{c}$ & $\begin{array}{c}0.36 \pm \\
0.01^{c}\end{array}$ & $\begin{array}{l}0.88 \pm \\
0.01^{b}\end{array}$ & $158 \pm 4^{b}$ \\
\hline $38 \mu \mathrm{m}(50 \%)$ & $\begin{array}{c}0.168 \pm \\
0.003^{b}\end{array}$ & $\begin{array}{l}4.66 \pm \\
0.06^{b}\end{array}$ & $\begin{array}{c}0.086 \pm \\
0.003^{b}\end{array}$ & $\begin{array}{c}0.202 \pm \\
0.003^{a}\end{array}$ & $\begin{array}{c}0.70 \pm \\
0.06^{\mathrm{a}}\end{array}$ \\
\hline $57 \mu \mathrm{m}(75 \%)$ & $\begin{array}{c}0.140 \pm \\
0.001^{\mathrm{a}}\end{array}$ & $\begin{array}{c}0.238 \pm \\
0.001^{a}\end{array}$ & $\begin{array}{c}0.077 \pm \\
0.000^{a}\end{array}$ & $\begin{array}{c}0.164 \pm \\
0.001^{a}\end{array}$ & $\begin{array}{c}0.513 \pm \\
0.001^{a}\end{array}$ \\
\hline $76 \mu \mathrm{m}(100 \%)$ & $\begin{array}{c}0.138 \pm \\
0.001^{\mathrm{a}}\end{array}$ & $\begin{array}{c}0.217 \pm \\
0.001^{\mathrm{a}}\end{array}$ & $\begin{array}{c}0.078 \pm \\
0.001^{a}\end{array}$ & $\begin{array}{c}0.160 \pm \\
0.001^{\mathrm{a}}\end{array}$ & $\begin{array}{c}0.434 \pm \\
0.001^{\mathrm{a}}\end{array}$ \\
\hline
\end{tabular}

Data: mean \pm SD ( $n=3)$. Different letters in a column indicate significant differences by the Tukey's honestly significant difference (HSD) method at $p$-value $\leq 0.05$.

Based on these results, further TS experiments were performed at $100 \%$ amplitude. In any case, it must be highlighted that probe erosion, as an unavoidable side effect of sonication, is faster when working at higher amplitudes. 


\subsection{Effect of power density on enzyme inactivation at different operating temperatures.}

Figures 2.4a and 2.4b show PPO and PME residual activity, respectively, after 15 min of TS in the temperature range from 52 to $67{ }^{\circ} \mathrm{C}$ (temperature of the plateau, see Figure 2.1), for different treated juice volumes $(60,80,100$ and $120 \mathrm{ml})$, which correspond to different power densities, in continuous mode and in pulse mode.

Comparing both figures, it can be observed that PME is more resistant to TS treatment than PPO. At $60^{\circ} \mathrm{C}$, no PME inactivation was observed at any of the treated volumes (power density ranged from 1.21 to $1.57 \mathrm{~W} / \mathrm{ml}$ ), even a slight increase was found, probably due to the release of enzyme bound to cell walls (Baslar \& Ertugay, 2014). The greater stability of PME compared to PPO has been also found in thermal treatments and other non-thermal treatments such as HPCD (Illera et al., 2018a) and it has been attributed to the more complex structure of PPO, with three or four subunits in higher plants, that makes it more susceptible to inactivation. Additionally, PME in fruit juices is more difficult to be effectively inactivated, since PME is bound to the plant cell wall, which contains natural stabilizing factors (Zhou et al., 2010).

For PPO, at the highest temperature $\left(67^{\circ} \mathrm{C}\right)$, nearly complete inactivation $(3 \pm 1 \%)$ was obtained when working at power density values greater than $1.15 \mathrm{~W} / \mathrm{mL}$. Figure $\mathbf{2 . 4 a}$ shows that to reach a certain inactivation degree, lower values of power density are needed when working at higher temperatures.

A linear relationship between enzyme residual activity and $P D(W / m L)$ was found at the different working temperatures (for PPO at $52^{\circ} \mathrm{C}: \mathrm{RA}=-77 \cdot \mathrm{PD}+181, \mathrm{R}^{2}=0.990$; at $60^{\circ} \mathrm{C}$ : $R A=-166 \cdot P D+278, R^{2}=0.987 ;$ at $67^{\circ} \mathrm{C}: R A=-332 \cdot P D+396 R^{2}=1$ (only two points); for $\mathrm{PME}$ at $\left.67^{\circ} \mathrm{C} \mathrm{RA}=-43 \cdot \mathrm{PD}+110, \mathrm{R}^{2}=0.920\right)$. The values of these slopes indicate a greater effect of the power density in enzyme inactivation when working at higher temperatures. This suggests that the synergic effect between temperature and ultrasound is more effective when working at high temperatures. 

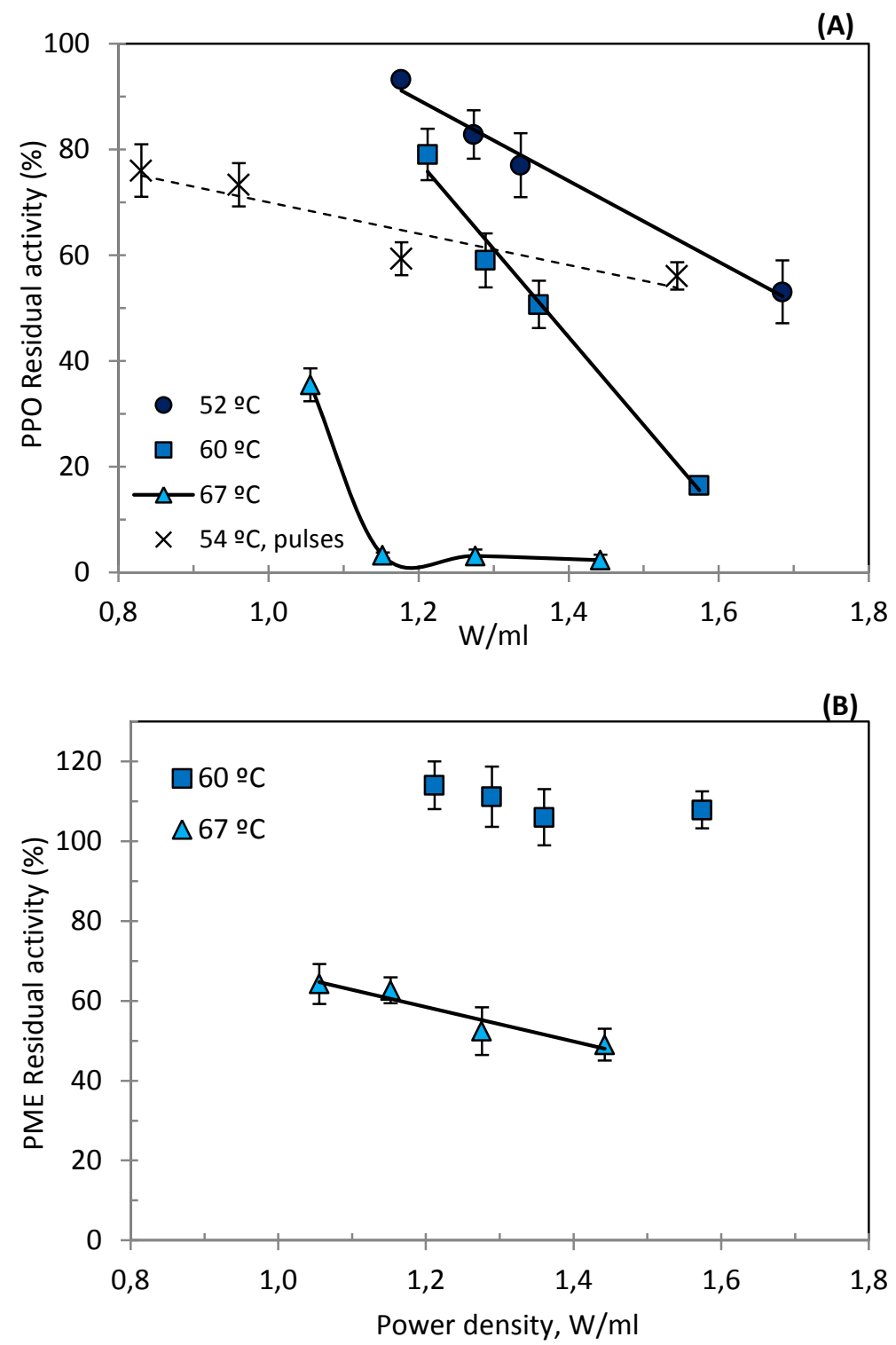

Figure 2.4 Enzyme residual activity after $15 \mathrm{~min}$ of thermosonication at $100 \%$ of amplitude $(76 \mu \mathrm{m})$ and different temperatures in a continuous mode and in pulse mode at $54{ }^{\circ} \mathrm{C}$ ( $\mathrm{T}$ of the plateau) as a function of power density, W/ml (a) PPO (b) PME. Lines represent the linear relationship (continuous mode - , pulse mode - -).

Figure 2.4a also shows that when working in a pulse mode, the effect of power density on PPO enzyme inactivation is lower than when working in a continuous mode $\left(R A=30 \cdot A E D+100, R^{2}=0.867\right)$. Although pulse ultrasound can be considered as an energy 
saving operational mode (Al-Juboori et al., 2015), in this study, it has been found to be less effective than continuous mode for PPO inactivation.

Other values have been found in the literature for PPO and PME inactivation in apple juice. Values of PPO inactivation in Golden delicious apple juice by TS treatment, with a $22 \mathrm{~mm}$ diameter probe $(24 \mathrm{kHz})(200 \mathrm{ml}$ of apple juice in a $250 \mathrm{ml}$ vessel) in a pulse mode ( $50 \%$ and $100 \%$ of cycle), were reported by Baslar and Ertugay in 2013 (Başlar \& Ertugay, 2013). These authors observed that the inactivation degree increased sharply with amplitude and temperature, observing an increase in the inactivation degree from $5 \%$ to $30 \%$ when amplitude increased from 50 to $100 \mu \mathrm{m}$ at $50{ }^{\circ} \mathrm{C}$, for $10 \mathrm{~min}$ of TS and pulse 1:1. At $60^{\circ} \mathrm{C}$, these authors reported much higher inactivation degrees, reaching values of $30 \%$ and $80 \%$ at 50 and $100 \mu \mathrm{m}$ of amplitude respectively for $10 \mathrm{~min}$ of TS and pulse 1:1. Sulaiman et al. (Sulaiman et al., 2015) reported values of PPO residual activity, around $17 \%$, for PPO of Royal Gala apple puree when treated by TS for $15 \mathrm{~min}$ at $58{ }^{\circ} \mathrm{C}$ and $210 \mu \mathrm{m}$ of amplitude in a continuous mode, with a $3 \mathrm{~mm}$ diameter probe, which corresponds to $1.3 \mathrm{~W} / \mathrm{g}$ ( $25 \mathrm{~g}$ apple puree in a $34.4 \mathrm{ml}$ vessel). These authors found that, under these conditions, nearly complete inactivation of PPO was reached at temperatures of $72-73^{\circ} \mathrm{C}$. Abid et al. (Abid et al., 2014) studied the TS of Fuji (Malus domestica) variety apple juice ( $80 \mathrm{ml}$ of apple juice in a $100 \mathrm{ml}$ vessel), with a 0.5 inch probe at $20 \mathrm{kHz}$, and a value of the power density of $0.3 \mathrm{~W} / \mathrm{ml}$ in a pulse mode ( $5 \mathrm{~s}$ on and $5 \mathrm{~s}$ off). No value of the amplitude was reported. They reported residual activities of 97,53 and $6 \%$ for PPO at 20,40 and $60^{\circ} \mathrm{C}$, respectively after 10 minutes of TS. For PME, these authors reported similar values of residual activities 97,52 and $7 \%$ at 20,40 and $60^{\circ} \mathrm{C}$, respectively after 10 minutes of TS.

In this work, lower inactivation degree, i.e. higher residual activity, was obtained for PME of Golden delicious, reaching the lowest residual activity of $50 \%$ at $67{ }^{\circ} \mathrm{C}$ after $15 \mathrm{~min}$ of TS at $76 \mu \mathrm{m}$ of amplitude and $1.44 \mathrm{~W} / \mathrm{mL}$. In this regard, it must be highlighted that PME from cloudy Golden delicious apple juice was found to be one of the apple cultivars presenting strongest thermostability (30\% of residual activity after heating 5 min at $100{ }^{\circ} \mathrm{C}$ ) (Teleszko et al., 2016), although mechanism of TS and thermal treatment is probably different. Regarding PPO activity, higher residual activities have been also 
obtained compared to the results found in the literature. This could be attributed to the lower working amplitude, $76 \mu \mathrm{m}$ (maximum amplitude reported by the supplier for this type of probes). The variety of data on PPO inactivation from apple juice indicates that enzyme inactivation depends on many factors such as source, sub-type, environmental and physicochemical conditions ( $\mathrm{pH}$, temperature) (Cheng et al., 2013). Islam et al. (Islam et al., 2014) reviewed the inactivation mechanisms and factors affecting the enzyme inactivation by ultrasound; however, further investigation is needed to understand the specific mechanism by which the different enzymes in apple juice are inactivated.

TS treatment was compared with thermal treatment by heating the cloudy apple juice during $15 \mathrm{~min}$ in the same temperature range as for the TS process, $52 \pm 1,60 \pm 1$ and $67 \pm 1{ }^{\circ} \mathrm{C}$. Heating the juice at the lowest temperatures essayed in TS experiments, $52^{\circ} \mathrm{C}$ and $60^{\circ} \mathrm{C}$ did not cause any loss of enzyme activity but even a significant increase $(p \leq 0.05)$, compared to the untreated juice (RA for PPO: $114 \pm 12,106 \pm 16$, RA for PME: $135 \pm 10,157 \pm 8$ at $52{ }^{\circ} \mathrm{C}$ and $60^{\circ} \mathrm{C}$, respectively). At the highest temperature essayed, $67^{\circ} \mathrm{C}$, a significant decrease $(p \leq 0.05)$ in enzyme activity by $24 \pm 4 \%$ for PPO $(\mathrm{RA}=76 \pm 4 \%)$ and $9 \pm 2 \%$ for PME (RA = $91 \pm 2 \%)$ was observed. These results prove that TS significantly improved the inactivation of PPO and PME.

\subsection{Inactivation kinetics of PPO at different operating} temperatures.

The TS inactivation kinetics of PPO was determined in the temperature range from to 52 to $67^{\circ} \mathrm{C}$ final TS temperature. PPO of cloudy apple juice was inactivated faster by increasing operating temperature (Figure 2.5).

First order kinetic model has been successfully used in the literature to correlate thermosonication inactivation kinetic data (Terefe et al., 2014). In this work, kinetic data were fitted to the first order kinetic model and the Weibull model. The corresponding kinetic parameters are listed in Table $\mathbf{2 . 2 a}$ and $\mathbf{2 . 2 b}$, together with the quality of the fitting. 


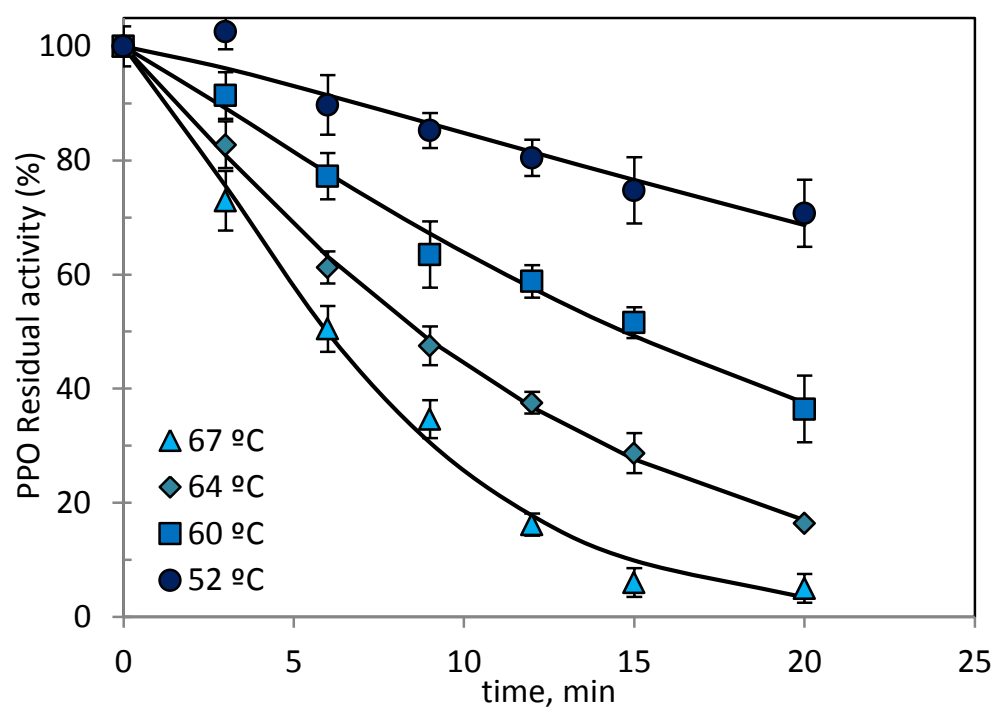

Figure 2.5 PPO inactivation kinetics during TS treatment at $100 \%$ of amplitude $(76 \mu \mathrm{m})$ at different operating temperatures. Treated volume was $80 \mathrm{ml}$. Continuous lines represent the Weibull model.

Table 2.2a First order kinetic model parameters for TS inactivation at different operating temperatures. Sensitivity temperature parameters, $\mathrm{z}_{\mathrm{T}}$ and $\mathrm{E}_{\mathrm{a}}$.

\begin{tabular}{cccc}
\hline \multicolumn{4}{c}{ First order kinetic model } \\
\hline $\mathbf{T}\left({ }^{\circ} \mathbf{C}\right)$ & $\mathbf{k}, \mathbf{~ m i n}^{-1}$ & $\mathbf{R}^{\mathbf{2}}$ & $\mathbf{D}, \mathbf{m i n}$ \\
\hline 52 & $0.0077 \pm 0.0006$ & 0.9542 & 130 \\
60 & $0.0201 \pm 0.0008$ & 0.9862 & 50 \\
64 & $0.036 \pm 0.001$ & 0.9943 & 28 \\
67 & $0.056 \pm 0.004$ & 0.9795 & 18 \\
\hline \multicolumn{4}{c}{$\mathbf{z}_{\mathbf{T}}=17.5 \pm 0.8{ }^{\circ} \mathbf{C}\left(\mathbf{R}^{2}=0.9962\right)$} \\
$\mathbf{E}_{\mathbf{a}}=123 \pm 4 \mathrm{~kJ} / \mathrm{mol}\left(\mathbf{R}^{2}=0.9976\right)$ \\
\hline
\end{tabular}

For the first order kinetic model, the inactivation rate constant, k, increased with temperature; therefore, D-values for PPO inactivation decreased with temperature from $130 \mathrm{~min}$ at $52{ }^{\circ} \mathrm{C}$ to $18 \mathrm{~min}$ at $67^{\circ} \mathrm{C}$. Başlar and Ertugay (Başlar \& Ertugay, 2013) reported lower D values for PPO of Golden delicious apple juice, 146, 66.4 and 12.9 min at 40, 50 and $60{ }^{\circ} \mathrm{C}$ respectively when working at $100 \mu \mathrm{m}$ of amplitude by ultrasound. $\mathrm{D}$ values for PPO of Malus domestica cv Royal Gala apple juice ranged from 49 to $4 \mathrm{~min}$ at 33 and $72{ }^{\circ} \mathrm{C}$, respectively, at $1.3 \mathrm{~W} / \mathrm{g}, 210 \mu \mathrm{m}$ of amplitude (Sulaiman et al., 2015). The 
temperature sensitive parameters, $\mathrm{z}_{\mathrm{T}}$ and $\mathrm{E}_{\mathrm{a}}$, were evaluated through the slopes of plotting equations 2.8 and 2.9 , respectively, yielding $17.5 \pm 0.8^{\circ} \mathrm{C}$ and $123 \pm 4 \mathrm{~kJ} / \mathrm{mol}$, respectively. Both sensitivity parameters values show that the inactivation of PPO by TS is rather temperature sensitive. Process with high activation energy values are very temperature sensitive (Levenspiel, 1999) as well as processes with low $\mathrm{z}_{\mathrm{T}}$ values.

In the literature, values of the same order were obtained for PPO inactivation of mushroom crude extract in the temperature range from 55 to $75^{\circ} \mathrm{C}$, with $\mathrm{z}_{\mathrm{T}}=13.8^{\circ} \mathrm{C}$ and $E_{a}=183 \pm 32 \mathrm{~kJ} / \mathrm{mol}$ (Cheng et al., 2013). Baslar and Ertugay (2013) reported a similar value of $\mathrm{z}_{\mathrm{T}}$ of $19^{\circ} \mathrm{C}$ for PPO inactivation by thermosonication of Golden delicious apple juice, same variety as in this work. These authors did not report a value for $E_{a}$; however, as previously mentioned, these authors reported $D$ values in the temperature range from 40 to $60^{\circ} \mathrm{C}$ and the activation energy could be easily evaluated through Arrhenius equation by using the inverse of the $D$-values $(D=1 / k)$, obtaining a value of $105 \mathrm{~kJ} / \mathrm{mol}$, similar to this work. On the contrary, other values reported for PPO of Malus domestica cv. Royal Gala apple puree inactivation by TS showed lower temperature sensitivity at $1.3 \mathrm{~W} / \mathrm{g}$, with values for activation energy and $\mathrm{z}_{\mathrm{T}}$ of, $52 \mathrm{~kJ} / \mathrm{mol}$ and $39^{\circ} \mathrm{C}$ respectively, in the temperature range from 33 to $72{ }^{\circ} \mathrm{C}$ (Sulaiman et al., 2015).

The Weibull parameters are also listed in Table $\mathbf{2 . 2 b}$. Scale, $\alpha$, and shape, $\beta$, parameters were used to calculate the time required to inactivate $1 \log \left(t_{d=1}\right)$ of PPO. Similar to the Dvalues for the first order kinetic model, $t_{d=1}$ decreased with temperature. The $t_{d=1}$ calculated by the Weibull model were lower than the corresponding $D$ values obtained by the first order kinetic model. Therefore, in this case, the use of the first order kinetic model could lead to an overprocessing estimation for PPO inactivation. According to Boekel (2002), the dependence on temperature of both parameters was analyzed. It was found that the scale parameter, $\alpha$, was statistically significant dependent on temperature, when tested at the $95 \%$ significance level for a linear relationship. The shape factor, $\beta$, was higher than 1 indicating a downward concavity of the enzyme inactivation curve (Boekel, 2002), but it was not statistically significant dependent on temperature, when tested at the $95 \%$ significance level for a linear relationship. According to Boekel (2002), the scale parameter, $\alpha$, could be modelled in a similar way to the classical $D$ value of the 
first order kinetic model, suggesting a linear dependence of the log $\alpha$ on temperature and considering that $\beta$ did not depend on temperature:

$\log \alpha=a_{1}-b_{1} T$

$A z_{T}{ }^{\prime}$ value can be also defined:

$z_{T}^{\prime}=1 / b_{1}$

Table 2.2b Weibull model kinetic parameters for TS inactivation at different operating temperatures. Sensitivity temperature parameter, $z^{\prime}{ }_{T}$

\begin{tabular}{cccc}
\hline \multicolumn{4}{c}{ Weibull model } \\
\hline $\boldsymbol{\alpha}, \min$ & $\boldsymbol{\beta}$ & $\mathbf{R}^{\mathbf{2}}$ & $\mathbf{t d = 1 , \mathbf { m i n }}$ \\
\hline $46 \pm 10$ & $1.2 \pm 0.2$ & 0.9378 & 92 \\
$20.3 \pm 0.9$ & $1.13 \pm 0.08$ & 0.9911 & 42 \\
$12.0 \pm 0.2$ & $1.12 \pm 0.04$ & 0.9981 & 25 \\
$7.9 \pm 0.3$ & $1.31 \pm 0.09$ & 0.9944 & 15 \\
\hline \multicolumn{4}{c}{$\mathbf{z}^{\prime}=20 \pm 1^{\circ} \mathrm{C}\left(\mathbf{R}^{\mathbf{2}}=0.9935\right)$} \\
\\
\multicolumn{4}{c}{$\left(\mathbf{R}^{2}=0.9908\right)$} \\
\hline
\end{tabular}

The value of the $z_{T}{ }^{\prime}$ is given in Table $\mathbf{2 . 2 b}$, together with the quality of the fitting. Although the concept of $z_{T}$ and $z_{T}^{\prime}$ is different since $z_{T}$ is obtained from the linear part, whereas $z^{\prime}{ }_{T}$ takes also into account the nonlinear part (Boekel, 2002), similar values were obtained for both parameters $\left(z_{T}=17.5 \pm 0.8^{\circ} \mathrm{C}\right.$ and $\left.z_{T}^{\prime}=20 \pm 1^{\circ} \mathrm{C}\right)$. An Arrhenius type equation was also considered to relate the inverse of the scale parameter, $1 / \alpha$, with temperature. Although $1 / \alpha$ cannot be considered a kinetic constant, the value obtained from the slope was found to be close to the $E_{a}$ obtained by applying the first order kinetic model, being $107 \pm 6 \mathrm{~kJ} / \mathrm{mol}$.

\subsection{Effect of the nature of dissolved gases}

The effect of the nature of dissolved gases on PPO inactivation kinetics is shown in

Figure 2.6a at three different thermosonication temperatures, 44,52 and $60^{\circ} \mathrm{C}$ 
(temperature of the plateau, see Figure 2.1) when treating $80 \mathrm{ml}$ of apple juice at $100 \%$ of amplitude.
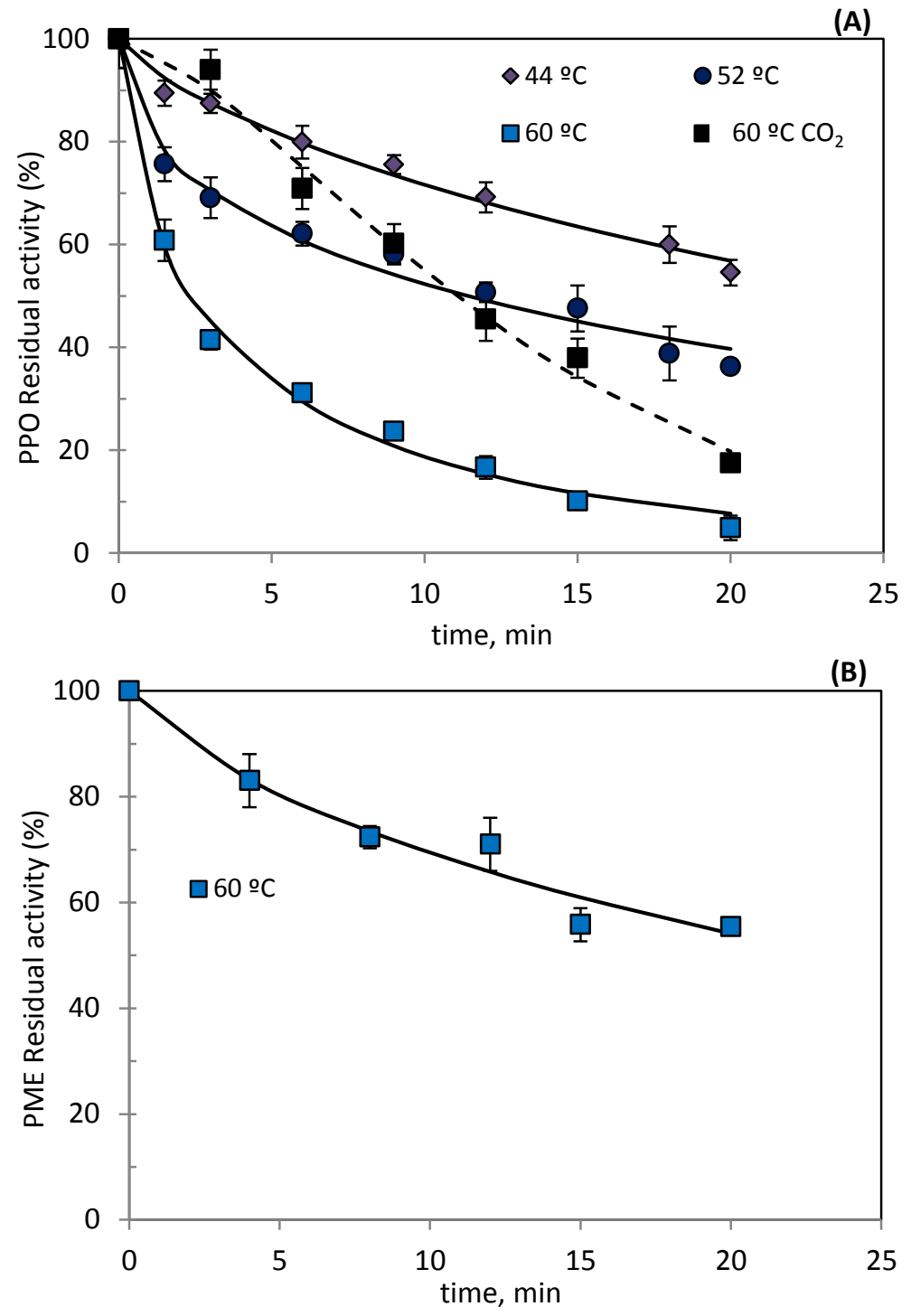

Figure 2.6 PPO (a) and PME (b) inactivation kinetics during TS treatment at $100 \%$ of amplitude $(76 \mu \mathrm{m})$ at different operating temperatures in presence of nitrogen and carbon dioxide. Treated volume was $80 \mathrm{ml}$. Lines represent the Weibull model. 
Regarding the effect of nitrogen, faster inactivation kinetics was obtained compared to the inactivation kinetics in the presence of dissolved air in the apple juice at the same thermosonication temperature. The effect of dissolved carbon dioxide was studied only at $60{ }^{\circ} \mathrm{C}$. In this case, initial inactivation reaction rates (initial slope of the curve) in the presence of $\mathrm{CO}_{2}$ was of the same order as in the presence of air (Figure 2.5), however, faster reaction rates were obtained at longer TS times and therefore, lower residual activity after 20 min of TS was reached in presence of $\mathrm{CO}_{2}, 18 \pm 2 \%$, than in the presence of air, $36 \pm 5 \%$ at the same operating conditions. Nevertheless, the best results in terms of inactivation rate and final RA were obtained when the air was displaced by nitrogen, reaching a RA of $5 \pm 2 \%$ at $60{ }^{\circ} \mathrm{C}$ for $20 \mathrm{~min}$ of TS.

Figure 2.6b shows the PME inactivation kinetics at $60^{\circ} \mathrm{C}$ (temperature of the plateau) when dissolved air was displaced by nitrogen. After 20 min of TS, a minimal RA of $55 \%$ was reached while no inactivation of PME was observed at the same temperature when TS was performed in presence of air (Figure 2.4b). However, at these conditions, results obtained with $\mathrm{CO}_{2}$ did not bring any improvement in the inactivation process of PME compared with the results obtained in the presence of air and inactivation was neither observed.

PPO and PME inactivation kinetic data obtained displacing the air by $\mathrm{N}_{2}$ or $\mathrm{CO}_{2}$ were also fitted to the first order kinetic model and the Weibull model (Table 2.3). In general, a better fitting was obtained by the Weibull model. For the first order kinetic model, Dvalues were evaluated. It can be clearly observed that by displacing the dissolved air by previously bubbling nitrogen into the apple juice, D- values were lower than those reported in Table 2.2. At $60{ }^{\circ} \mathrm{C}$, in the presence of air, the D-value for PPO was $50 \mathrm{~min}$, while it decreased down to $11 \mathrm{~min}$ in the presence of nitrogen and to $36 \mathrm{~min}$ in the presence of carbon dioxide. The temperature sensitive parameters, $z_{T}$ and $E_{a}$, in the presence of nitrogen were evaluated through the slopes of plotting equations $\mathbf{2 . 8}$ and 2.9, respectively, yielding $20 \pm 4{ }^{\circ} \mathrm{C}$ and $106 \pm 18 \mathrm{~kJ} / \mathrm{mol}$ respectively. Regarding the Weibull model, the time required to achieve one decimal reduction, $t_{d=1}$, was calculated by using the shape and scale parameters (Table 2.3). 
Table 2.3 TS kinetic inactivation parameters at different operating temperatures and with different dissolved gases. Sensitivity temperature parameters, $Z_{T}$ and $E_{a}$.

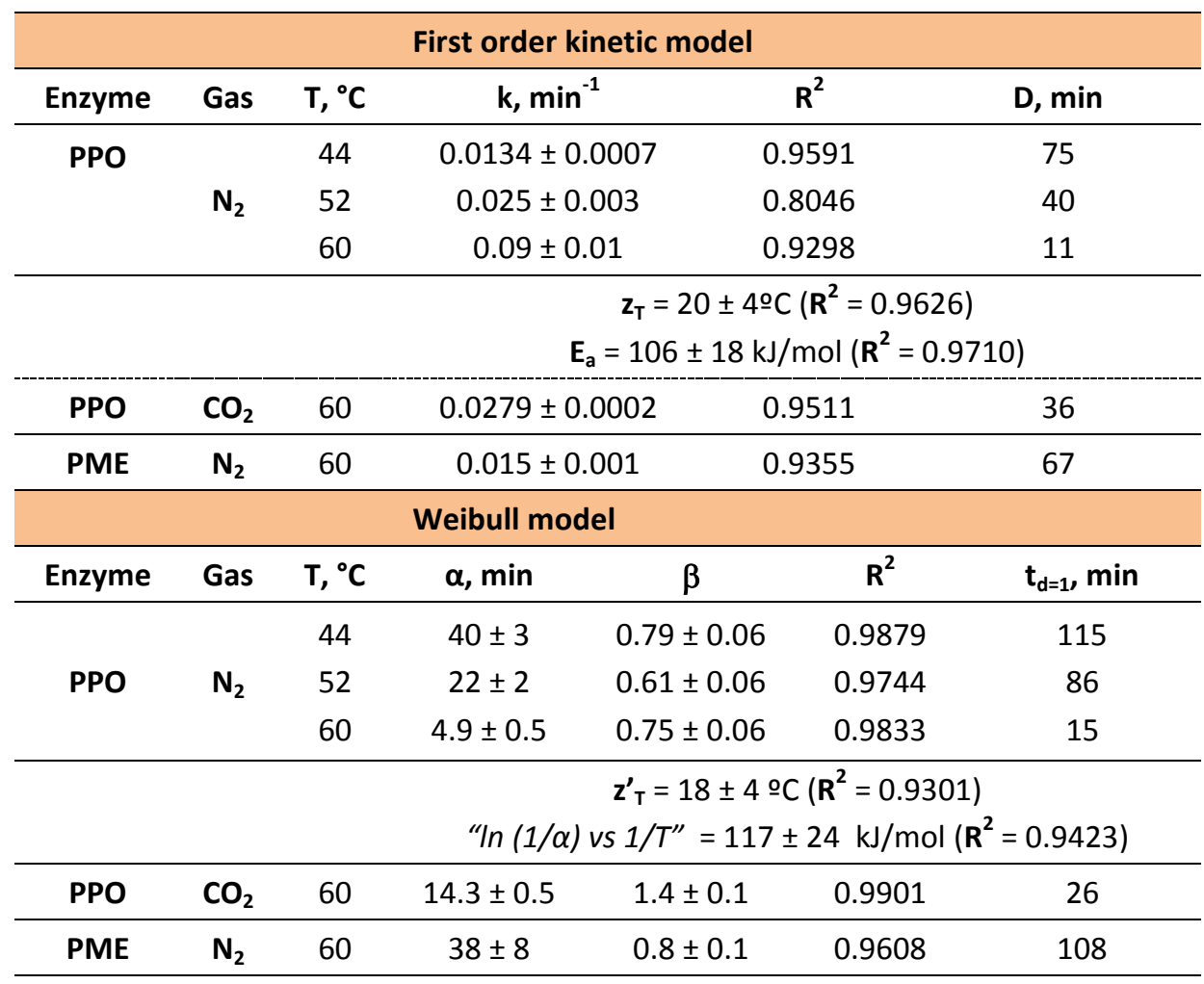

Displacing the air by nitrogen led to lower values of $t_{d=1}$, compared to the values reported in the presence of air. It was found that the scale parameter, $\alpha$, was statistically significant dependent on temperature, when tested at the $95 \%$ significance level for a linear relationship; but the shape factor, $\beta$ was not. According to equations 2.13 and 2.14, $\mathrm{z}_{\mathrm{T}}{ }^{\prime}$ for the Weibull model was evaluated as $18 \pm 4{ }^{\circ} \mathrm{C}$, being similar to $\mathrm{z}_{\mathrm{T}}$ for the first order kinetic model. An Arrhenius type equation was also considered to relate the inverse of the scale parameter, $1 / \alpha$, with temperature. From the slope, a value close to the activation energy obtained by applying the first order kinetic model was obtained, $117 \pm 24 \mathrm{~kJ} / \mathrm{mol}$. These results indicated that the nature of the dissolved gas in the apple juice played an important role in enzyme inactivation. 
The effect of the nature of dissolved gases on enzyme inactivation has not been frequently studied in the literature. Cheng et al. (Cheng et al., 2007) studied the sonication process on guava juice quality with previous carbonation of the sample. These authors proposed that dissolved carbon dioxide could reduce surface tension and could create more nuclei cavitation. However, they found that after sonication or a combination of carbonation + sonication, PPO showed higher activity than the untreated sample.

Gielen et al. (Gielen et al., 2016) discussed the different effect of the dissolved gases on sonochemistry considering the solubility and thermal properties of the gases as well as the different radical production. In this work, the $\mathrm{H}_{2} \mathrm{O}_{2}$ rate production was determined in a citrate buffer solutions at the same $\mathrm{pH}$ as apple juice $(\mathrm{pH}=3.9)$ at $60{ }^{\circ} \mathrm{C}, 100 \%$ of amplitude, $80 \mathrm{ml}$ of treated volume during $20 \mathrm{~min}$. $\mathrm{H}_{2} \mathrm{O}_{2}$ rate formation was determined in three types of citrate solutions with dissolved air and by displacing the air by bubbling nitrogen or carbon dioxide previous to TS experiments. $\mathrm{No}_{2} \mathrm{O}_{2}$ production was observed during the first five minutes of TS in the presence of nitrogen or air, according to our analytical method. After that, it was found that the $\mathrm{H}_{2} \mathrm{O}_{2}$ production as a function of time followed a linear relationship, with a $\mathrm{H}_{2} \mathrm{O}_{2}$ rate production of $(3.6 \pm 0.2) \cdot 10^{-8} \mathrm{~mol} /(\mathrm{Lmin})$ $\left(R^{2}=0.994\right)$ in air, and $(3.78 \pm 0.05) \cdot 10^{-8} \mathrm{~mol} /(\operatorname{Lmin})\left(R^{2}=0.999\right)$ for nitrogen. In the presence of $\mathrm{CO}_{2}$, no $\mathrm{H}_{2} \mathrm{O}_{2}$ formation was observed after 15 min of TS; subsequently, $\mathrm{H}_{2} \mathrm{O}_{2}$ formation rate was similar to that obtained with nitrogen and air $\left(3.81 \cdot 10^{-8} \mathrm{~mol} /(\mathrm{Lmin})\right.$, from $15 \mathrm{~min}$ to $20 \mathrm{~min}$ ). In any case, these results indicated that $\mathrm{CO}_{2}$ partially inhibited the formation of $\mathrm{H}_{2} \mathrm{O}_{2}$ during TS. These results agreed partially with the radical yield formation obtained by Gielen et al. (2016) in the presence of different gases in water at $24 \pm 2{ }^{\circ} \mathrm{C}$. These authors also found, that $\mathrm{CO}_{2}$, although being a highly soluble gas $(39.2 \mathrm{mmol} / \mathrm{L}$ versus 0.85 and $0.71 \mathrm{mmol} / \mathrm{L}$ for air and nitrogen respectively, at $293 \mathrm{~K}$ and $1 \mathrm{~atm}$ ), inhibited radical formation due to low bubble temperature attributed to its lower polytropic index and a higher thermal conductivity compared to air and nitrogen (Gielen et al., 2016). The similar $\mathrm{H}_{2} \mathrm{O}_{2}$ rate production for air and nitrogen obtained in this work could be then attributed to their similar thermal properties. However, Gielen et al. (Gielen et al., 2016) found that nitrogen reduced radical yield by the production of radical scavengers and a lower bubble volume. In any case, no relation can be established between $\mathrm{H}_{2} \mathrm{O}_{2}$ production rate in presence of the different dissolved gases and enzyme 
inactivation, since higher inactivation rates were determined when nitrogen displaced the dissolved air of the apple juice.

Nitrate and nitrite rate production was also determined during TS for the three buffer solutions at the same operating conditions. The highest nitrate rate production was obtained when nitrogen was previously dissolved in the buffer, $\left(2.6 \pm 0.2 \cdot 10^{-7}\right) \mathrm{mol} /(\mathrm{Lmin})$ $\left(R^{2}=0.982\right)$ and the same value was obtained for $\mathrm{CO}_{2}$ and air, $1.8 \pm 0.210^{-7} \mathrm{~mol} /(\mathrm{Lmin})$, $\mathrm{R}^{2}=0.910$ and 0.960 respectively. Nitrite rate formation was lower than nitrate for all the gases being $3.2 \pm 0.2 \cdot 10^{-8}, 3.3 \pm 0.4 \cdot 10^{-8}$ and $1.5 \pm 0.2 \cdot 10^{-8} \mathrm{~mol} /(\mathrm{Lmin})$, for nitrogen, air and $\mathrm{CO}_{2}\left(\mathrm{R}^{2}=0.993,0.960,0.967\right)$ respectively. These results could partially explain the higher inactivation rate for PPO and PME found by displacing the air with nitrogen. However, further studies are needed to understand the effect of the nature of the dissolved gas on enzyme inactivation by TS.

\subsection{Comparison with HPCD}

Among the different non-thermal technologies, the use of High Pressure Carbon Dioxide (HPCD) treatment is having also growing attention to inactivate certain microorganisms and enzymes. Typically, operating pressure does not exceed $50 \mathrm{MPa}$ and temperature ranges between 20 and $50{ }^{\circ} \mathrm{C}$ (Briongos et al., 2016), being lower than the temperature employed in this work in TS. Figure 2.7 compares the PPO inactivation kinetics by TS at $44{ }^{\circ} \mathrm{C}$, temperature of the plateau, $(\mathrm{V}=80 \mathrm{ml}$ and $100 \%$ of amplitude) in the presence of air and by displacing the air with nitrogen, with results obtained in a previous study on inactivation kinetic of PPO from apple juice at $45^{\circ} \mathrm{C}$ by HPCD at $20 \mathrm{MPa}$ (Illera et al., 2018a). At $44{ }^{\circ} \mathrm{C}$, in the presence of air, short treatment times of TS led to an increase of PPO activity. As indicated in section 3.2, this increase in enzyme activity has been attributed to the release of enzymes bond to cell walls due to the acoustic shock waves (Başlar \& Ertugay, 2013) or to the activation of PPO latent forms at low intensities and short treatment times. In any case, at longer treatment times, PPO was inactivated. Figure 2.7 shows that, at the same operating temperature, HPCD treatment at $20 \mathrm{MPa}$ led to lower PPO residual activity values. This indicates a different enzyme inactivation mechanism for these two non-thermal technologies. 


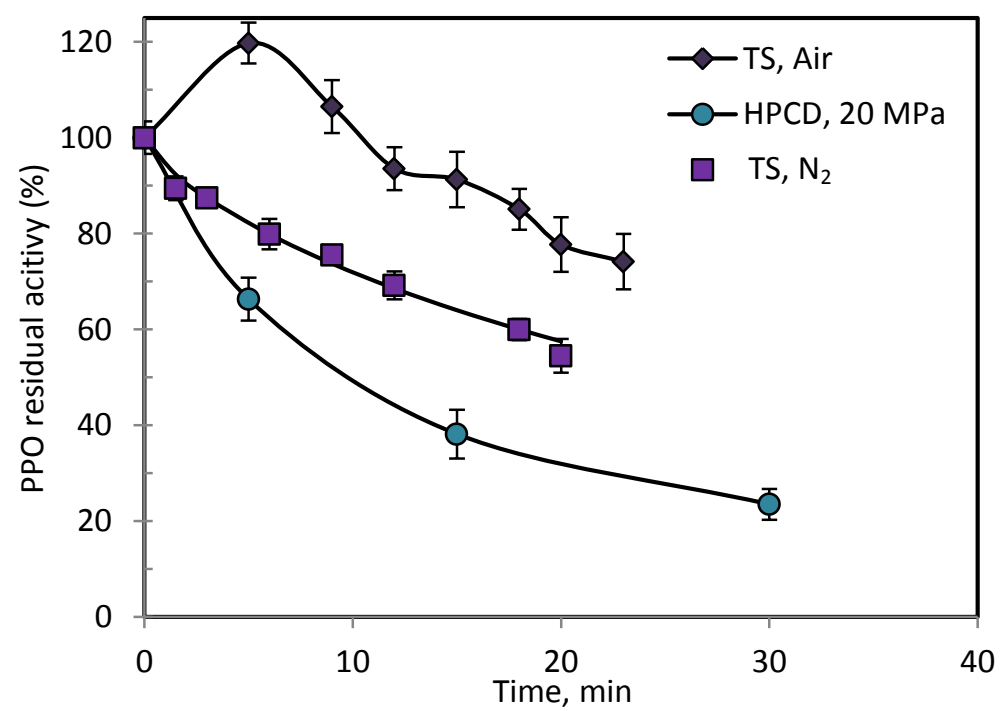

Figure 2.7 Comparison of PPO inactivation kinetics at $44-45^{\circ} \mathrm{C}$ for different non-thermal treatments.

\subsection{Effect of thermosonication on different quality parameters of} cloudy apple juice

Some quality parameters have been determined right after TS treatment at $60{ }^{\circ} \mathrm{C}$ (final TS temperature), $100 \%$ of amplitude, $15 \mathrm{~min}$ of treatment time and $80 \mathrm{ml}$ treated volume of apple juice.

Color parameters. Table $\mathbf{2 . 4}$ lists the $L^{*}, a^{*}, b^{*}$ parameters of cloudy apple juice before and after different TS treatments. As general trend, there were significant differences in all color attributes after TS. The lightness (L*) slightly increased, while the red and yellow components decreased compared to the untreated juice. The increase in lightness after TS has been previously reported in the literature and it has been attributed to a homogenization effect of sonication (Tiwari et al., 2008). A decrease in $a^{*}$ and $b^{*}$ parameters has been also observed in different juices, such as orange juice (Tiwari et al., 2008) or soursop juice (Dias et al., 2015). 
Table 2.4 Effect of thermosonication on color parameters, total polyphenolic compounds (TPCs) and hydroxymethyl furfural content (HMF).

\begin{tabular}{|c|c|c|c|c|c|c|c|c|}
\hline $\begin{array}{c}\mathrm{V}-\mathrm{PD}^{1} \\
\mathrm{ml}-\mathrm{W} / \mathrm{ml}\end{array}$ & $\begin{array}{c}\mathrm{T} \\
\left({ }^{\circ} \mathrm{C}\right)\end{array}$ & $\mathrm{L}^{*}$ & $a^{*}$ & $\mathbf{b}^{*}$ & $\Delta \mathrm{E}$ & Chroma & $\begin{array}{c}\text { TPCs } \\
\text { mg GAE/L }\end{array}$ & $\begin{array}{l}\mathrm{HMF} \\
\mathrm{mg} / \mathrm{L}\end{array}$ \\
\hline $\begin{array}{l}\text { Untreated } \\
\text { apple juice }\end{array}$ & & $37.1 \pm 0.2^{\mathrm{a}, \mathrm{b}}$ & $1.7 \pm 0.1^{\mathrm{e}}$ & $7.8 \pm 0.1^{d}$ & & $7.9 \pm 0.1^{d}$ & $407 \pm 20^{a}$ & $1.9 \pm$ \\
\hline $60-1.58$ & 60 & $38.9 \pm 0.2^{d}$ & $0.07 \pm 0.05^{c}$ & $7.0 \pm 0.2^{c}$ & $2.5 \pm 0.3^{b}$ & $7.0 \pm 0.2^{c}$ & $419 \pm 27^{a}$ & $2.0 \pm 0.1^{a, b}$ \\
\hline $80-1.30$ & 60 & $37.9 \pm 0.6^{b, c}$ & $0.47 \pm 0.02^{d}$ & $6.9 \pm 0.1^{c}$ & $1.7 \pm 0.3^{\mathrm{a}}$ & $6.9 \pm 0.1^{c}$ & $459 \pm 3^{a, b}$ & $1.7 \pm 0.1^{a, b}$ \\
\hline $100-1.21$ & 60 & $39.2 \pm 0.2^{\mathrm{d}, \mathrm{e}}$ & $-0.5 \pm 0.1^{b}$ & $7.1 \pm 0.2^{c}$ & $3.1 \pm 0.1^{c}$ & $7.1 \pm 0.2^{c}$ & $478 \pm 35^{b}$ & $1.2 \pm 0.1^{a, b}$ \\
\hline $80-1.43^{*}$ & 60 & $38.0 \pm 0.2^{c}$ & $0.48 \pm 0.02^{d}$ & $5.9 \pm 0.1^{b}$ & $2.3 \pm 0.1^{b}$ & $6.0 \pm 0.1^{b}$ & $508 \pm 13^{b}$ & $2.2 \pm 0.1^{b}$ \\
\hline $60-1.51$ & 67 & $37.1 \pm 0.2^{\mathrm{a}}$ & $-0.85 \pm 0.01^{\mathrm{a}}$ & $4.5 \pm 0.1^{\mathrm{a}}$ & $4.1 \pm 0.1^{d}$ & $4.6 \pm 0.1^{a}$ & $482 \pm 15^{b}$ & $1.6 \pm 0.2^{\mathrm{a}, \mathrm{b}}$ \\
\hline $80-1.28$ & 67 & $40.3 \pm 0.2^{f}$ & $-0.45 \pm 0.04^{b}$ & $8.4 \pm 0.2^{\mathrm{e}}$ & $3.8 \pm 0.2^{d}$ & $8.5 \pm 0.2^{\mathrm{e}}$ & $483 \pm 10^{b}$ & $1.1 \pm 0.1^{\mathrm{a}}$ \\
\hline $100-1.15$ & 67 & $39.9 \pm 0.1^{\mathrm{e}, \mathrm{f}}$ & $-0.03 \pm 0.03^{c}$ & $7.9 \pm 0.1^{d}$ & $3.2 \pm 0.1^{c}$ & $7.9 \pm 0.1^{d}$ & $498 \pm 9^{b}$ & $1.6 \pm 0.1^{\mathrm{a}, \mathrm{b}}$ \\
\hline
\end{tabular}

${ }^{1}$ Treated volume and power density. Different letters in the same column indicates significant differences by applying the Tukey's honestly procedure. *Nitrogen was used instead of air. 
Color difference, $\Delta \mathrm{E}$, (Equation 2.4) is also listed in Table 2.4. In all TS experiments, a color difference was observed compared to the untreated juice. According to Yuk et al. (Yuk et al., 2014), the color difference could be estimated to be not noticeable (0-0.5), slightly noticeable (0.5-1.5), noticeable (1.5-3), well visible (3-6) and great visible (6-12). Based on this classification, at $60^{\circ} \mathrm{C}$, the change in color was noticeable $(1.5-3)$ while at $67^{\circ} \mathrm{C}$ was well visible (3-6). According to color parameters, the chroma value presented the lowest value at $67{ }^{\circ} \mathrm{C}$ and the lowest treated volume, $60 \mathrm{ml}$ (higher power density) Therefore, although higher TS temperatures led to higher inactivation rates, change in color was more visible.

Color changes during TS have been attributed to Maillard reactions that may occur at long treatment time and high temperature, as well as to cavitation, that involves various physical, chemical and biological reactions (Anaya-Esparza et al., 2017).

Total polyphenolic compounds. Total polyphenolic compounds (TPCs) slightly increased after TS compared to the untreated apple juice. Significant differences of the total polyphenolic compounds were found at 60 and $67^{\circ} \mathrm{C}$ and in the apple juice treated by previously displacing the air with nitrogen (Table 2.4). This TPCs increase after TS has been attributed to the enhanced disruption of cell walls that might lead to the release of some chemically bound phenolic compounds (Bhat et al., 2011). However, as pointed out by Bhat et al. (Bhat et al., 2011), this disruption cell wall process may cause a series of other oxidation reactions that might involve changes in color as it has been observed by determining the color parameters. Abid et al. (Abid et al., 2014) reported a significant increase of chlorogenic acid, caffeic acid, epicatechin and phloridzin content in sonicated Malus domestic cv. Fuji apple juice in an ultrasound bath at $20{ }^{\circ} \mathrm{C}(60 \mathrm{ml}$ in a $100 \mathrm{ml}$ thermostated vessel, $70 \%$ of amplitude and $25 \mathrm{kHz}$ frequency).

Different results on TPC after TS of different juices have been previously reported in the literature. Some authors observed an increase of TPC after TS of pineapple and pear juices at 54 and $78{ }^{\circ} \mathrm{C}$, respectively (Costa et al., 2013; Zafra-Rojas et al., 2013), while a reduction between 15-30\% was observed after TS of cantaloupe melon (Fonteles et al., 2012). 
Hydroxymethylfurfural. Table $\mathbf{2 . 4}$ also lists the HMF content after TS treatment of cloudy apple juice. It can be observed that the HMF value remains constant around $2 \mathrm{mg} \mathrm{HMF/L}$ for all the TS conditions used in this work, indicating that non-enzymatic browning reactions were not significant during TS processing.

\section{Conclusions}

The present study reports the effect of different operating variables of the thermosonication process on enzyme inactivation and other important quality parameters of cloudy apple juice.

It has been observed that working US amplitude increased enzyme inactivation and significantly enhanced the particle size distribution of cloudy apple juice by shifting the particle size towards lower particle diameters compared to the untreated juice.

The nature of the dissolved gas in the cloudy apple juice has been found to play an important role on enzyme inactivation, observing faster inactivation kinetics when nitrogen displaced the air dissolved in the juice.

Total phenolic compounds increased after TS, and color change was noticeable. Hydroxymethylfurfural content did not change after different TS treatments.

Further investigations are needed to elucidate the enzyme inactivation mechanism and reach a better understanding and optimization of the TS process. 



\section{CHAPTER 3}

Enzyme inactivation and other properties of cloudy apple juice after High Pressure Carbon Dioxide (HPCD) and Thermosonication (TS) treatments and during refrigerated storage

Based on the article:

A.E. Illera, M. T. Sanz, S. Beltrán

"Enzyme inactivation and other properties of cloudy apple juice after High Pressure Carbon Dioxide (HPCD) and Thermosonication (TS) treatments and during refrigerated storage"

(Submitted to Journal of Food Processing and Preservation). 



\section{Capítulo 3}

Efecto de un tratamiento de $\mathrm{CO}_{2}$ a alta presión (HPCD) y termosonicación (TS) sobre la inactivación enzimática y propiedades de calidad de zumo de manzana no clarificado y durante su almacenamiento en refrigeración

\section{Resumen}

En este capítulo se trató zumo de manzana no clarificado mediante las dos tecnologías no térmicas estudiadas en los anteriores capítulos (HPCD y TS) con el fin de comparar su efecto tras el tratamiento y durante un almacenamiento a $4{ }^{\circ} \mathrm{C}$ durante 28 días. Se evaluó la inactivación enzimática de la polifenoloxidasa (PPO) y de la pectinmetilesterasa (PME), así como diferentes parámetros de calidad del zumo de manzana. Las condiciones de tratamiento se eligieron según los resultados obtenidos en los capítulos anteriores. En el caso del tratamiento HPCD las condiciones fueron $20 \mathrm{MPa}$ y $45^{\circ} \mathrm{C}$ durante 60 minutos, y en el tratamiento TS $20 \mathrm{kHz}, 62{ }^{\circ} \mathrm{C}$ y $100 \%$ amplitud durante 20 minutos. Ambos tratamientos mostraron un gran impacto en la inactivación de la PPO, y su actividad residual continuó disminuyendo progresivamente durante el almacenamiento a $4{ }^{\circ} \mathrm{C}$. Sin embargo, la PME mostró mucha más resistencia a los tratamientos. En general tras ambos tratamientos se observó un efecto de homogenización en el zumo debido a un desplazamiento en la distribución del tamaño de partícula hacia diámetros más pequeños, reflejado en un aumento de la 'nube' de los zumos tras los tratamientos y durante el almacenamiento. La capacidad antioxidante y el contenido en polifenoles mantuvieron niveles altos tras ambos tratamientos y durante el estudio de almacenamiento del zumo.

Palabras clave: Zumo de manzana no clarificado, tratamiento no térmico, inactivación enzimática, parámetros de calidad, almacenamiento refrigerado. 



\section{Abstract}

High Pressure Carbon Dioxide (HPCD) and Thermosonication (TS) technologies were applied to cloudy apple juice to determine their effect on polyphenol oxidase (PPO) and pectin methylesterase (PME) enzymatic inactivation and other quality parameters right after treatment and during storage at $4{ }^{\circ} \mathrm{C}$ during 28 days. Treatment conditions were chosen based on previous studies, being $20 \mathrm{MPa}$ and $45^{\circ} \mathrm{C}$ for 60 minutes and $20 \mathrm{kHz}$, $62{ }^{\circ} \mathrm{C}$ and $100 \%$ amplitude for 20 min, for HPCD and TS treatments, respectively. Both treatments showed a great impact on PPO inactivation and its residual activity steadily decreased during storage at $4{ }^{\circ} \mathrm{C}$. On the contrary, PME was found to be more resistant to the treatments. In general, after both treatments, a homogenization effect was observed, due to a shifting of the particle size distribution to smaller diameters, what was also reflected in an increase in the cloud value of the juices after the treatments, kept during storage. Antioxidant capacity and total polyphenol content kept high levels during storage after both treatments.

Keywords: Cloudy apple juice, non-thermal treatment, enzymatic inactivation, quality parameters, refrigerated storage. 



\section{Introduction}

Apple juice is usually consumed as a clear juice, but there is a growing market for natural cloudy apple juice since it is more beneficial to human health than the clear one (Oszmianski et al., 2007). The main problem with cloudy apple juice is related to the assurance of color and cloud stability during its processing and storage. Changes of these properties of the juice are caused by the action of two different enzymes, polyphenol oxidase (PPO) and pectin methylesterase (PME), which produce the browning and the clarification of the juice respectively. Traditionally, thermal treatments have been used to ensure the safety of the juices and to extent their shelf life by the inactivation of microorganisms and enzymes that can deteriorate the quality of the product, but nutritional quality of the juice can be greatly reduced due to the processing intensity. This is the reason why different non-thermal emerging technologies are proposed as alternatives.

A recent study concluded that HPCD (High Pressure Carbon Dioxide) treatment was a valid alternative technology to process cloudy apple juice, since it was more effective than mild thermal treatment, in the same temperature range, in the inactivation of PPO and PME (Illera et al., 2018a). Some other studies can be found in the literature regarding the effect of other non-thermal technologies in the processing of cloudy apple juice. Illera et al. (Illera et al., 2018b), found that a high inactivation degree of PPO could be achieved by Thermosonication. However, the literature is reduced when dealing with storage of fruit juices after non-thermal treatments and only a few quality parameters are determined along storage time (Abid et al., 2015; Ferrentino et al., 2009; Gui et al., 2006) .In this work, some quality properties of cloudy apple juice from Golden delicious apples, such as PPO and PME activity, particle size distribution, color, pectin content and antioxidant capacity among others have been measured before and right after HPCD and TS treatment. Other physical properties of treated samples were studied during storage at $4{ }^{\circ} \mathrm{C}$ for 28 days. The results obtained for both technologies have been compared, as well as with other results found in the literature. 


\section{Materials and methods}

\subsection{Juice preparation}

Golden delicious apple juice was prepared according to Illera et al. (Illera et al., 2018a) and analyzed right after preparation. There were two different control samples (untreated juices), one for each treatment, since HPCD and TS studies were not carried out at the same time. Some parameters could be different between both controls since experiments were performed in different seasons of the year and apple quality parameters can change.

\subsection{Equipment and processing}

\subsubsection{High Pressure Carbon Dioxide (HPCD)}

The experimental procedure has been described in detail in the literature (Briongos et al., 2016; Illera, et al., 2018c). Briefly, $40 \mathrm{ml}$ of juice were charged into a stainless steel (SS316) HPCD cell, which was immersed in a thermostatic water bath at the operating temperature. The system was then pressurized up to the operating pressure by using a syringe pump with a pressure controller (ISCO 260 D). Conditions were chosen based on the results obtained in previous work for PPO inactivation in cloudy apple juice by HPCD at $20 \mathrm{MPa}$ and $45^{\circ} \mathrm{C}$ during 60 minutes (Illera et al., 2018a).

\subsubsection{Thermosonication}

A $750 \mathrm{~W}$ ultrasonic processor (Sonics Materials ${ }^{\mathrm{TM}}$ ) with a $13 \mathrm{~mm}$ probe was used for sonication. The experimental procedure can be found elsewhere (Illera et al., 2018b). $80 \mathrm{ml}$ of cloudy apple juice were placed in a thermostated vessel and treated for $20 \mathrm{~min}$ at $62{ }^{\circ} \mathrm{C}$ in a continuous mode at $100 \%$ amplitude. The selection of the amplitude and operating temperature was done taking into account previous results on enzyme inactivation by TS (Illera et al., 2018b). 


\subsection{Physico-chemical analysis}

Treated cloudy apple juices were analyzed right after treatments and then, stored at $4{ }^{\circ} \mathrm{C}$ and periodically analyzed every 7 days up to 28 days.

\subsubsection{Determination of enzymatic activity}

Polyphenol oxidase (PPO): PPO activity was determined spectrophotometrically by using a $0.05 \mathrm{M}$ catechol (Sigma Aldrich) solution prepared in a $0.1 \mathrm{M}$ phosphate buffer (pH 6.5) as substrate. Samples were analyzed by mixing $100 \mu \mathrm{l}$ of the apple juice with $2.9 \mathrm{ml}$ of substrate solution. Oxidation of catechol was determined by the increase of absorbance at $420 \mathrm{~nm}$ by using a Jasco V-750 spectrophotometer equipped with a Peltier thermostated cell holder and water pump to keep the temperature constant at $30^{\circ} \mathrm{C}$. PPO activity was taken as the very first linear part of the reaction curve.

Pectin methylesterase (PME): PME activity was determined by using an automatic titrator

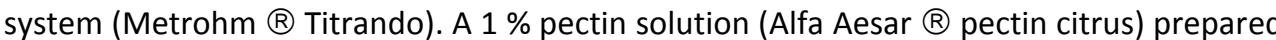
in $\mathrm{NaCl} 0.3 \mathrm{M}$ was used as substrate for the enzyme. For the determination, $50 \mathrm{ml}$ of the pectin solution were mixed with $1 \mathrm{ml}$ of cloudy apple juice and $\mathrm{pH}$ was adjusted to 7.5 with $\mathrm{NaOH} 0.005 \mathrm{~N}$. During pectin hydrolysis at $30^{\circ} \mathrm{C}, \mathrm{pH}$ was maintained at 7.5 by adding $\mathrm{NaOH} 0.005 \mathrm{~N}$. The amount of $\mathrm{NaOH}$ added during 15 min was recorded (Briongos et al., 2016).

Relative residual activities of PPO and PME were evaluated as:

Residual activity $(\%)=\frac{\text { Enzyme specific activity in the processed juice }}{\text { Enzyme specific activity in the untreated juice }} \cdot 100$

\subsubsection{Determination of $\mathrm{pH}$, color and non-enzymatic browning}

pH of cloudy apple juice was determined with a pH-meter (Crison ${ }^{\circledR}$ pH \& Ion-Meter GLP

22) at room temperature $\left(21 \pm 1^{\circ} \mathrm{C}\right)$. 
Non-enzymatic browning was measured as hydroxymethylfurfural (HMF) concentration according to Queiroz et al. (Queiroz et al., 2011) with slight modifications; $0.7 \mathrm{ml}$ of juice was mixed with $0.7 \mathrm{ml}$ of ethanol in a $1.5 \mathrm{ml}$ Eppendorf tube. The mixture was centrifuged at $12000 \mathrm{~g}$ for $10 \mathrm{~min} .1 \mathrm{ml}$ of the supernatant was mixed with $1 \mathrm{ml}$ of a trichloroacetic acid solution (734 mM) and $1 \mathrm{ml}$ of a thiobarbituric acid solution ( $25 \mathrm{mM}$ ). Samples were incubated at $40{ }^{\circ} \mathrm{C}$ during $50 \mathrm{~min}$, and then, absorbance was measured at $443 \mathrm{~nm}$. Concentration was determined by using a calibration curve of HMF. Some studies refer changes in non-enzymatic browning after thermal treatment as the ratio $\mathrm{HMF} / \mathrm{HMF}_{0}$ where $\mathrm{HMF}$ is the concentration after the treatment and $\mathrm{HMF}_{0}$ is the concentration in the untreated sample. In fresh juices, the amount of HMF is practically null, but its concentration tends to rise because of heating processes or long-term storage (Queiroz et al., 2011).

Color was measured at room temperature using a Beckman DU-560 spectrophotometer (Beckman Instruments, EEUU). Color parameters, L* (lightness), a* (redness) and $b^{*}$ (yellowness), were expressed in the CIELAB system. Total change in color $(\Delta E)$ was expressed as the difference between each color parameter in the untreated sample (control) and the treated one (Eq. 3.2).

$\Delta \mathrm{E}=\sqrt{\left(\mathrm{L}_{\text {control }}^{*}-\mathrm{L}_{\text {treated }}^{*}\right)^{2}+\left(\mathrm{a}_{\text {control }}^{*}-\mathrm{a}_{\text {treated }}^{*}\right)^{2}+\left(\mathrm{b}_{\text {control }}^{*}-\mathrm{b}_{\text {treated }}^{*}\right)^{2}}$

Depending on the value of $\Delta E$, the color difference could be estimated as not noticeable (0-0.5), slightly noticeable (0.5-1.5), noticeable (1.5-3), well visible (3-6) and great visible (6-12) (Yuk et al., 2014).

\subsubsection{Cloud value, cloud stability and particle size distribution.}

Cloud value was measured according to Versteeg et al. (Versteeg et al., 1980) with slight modifications. $4 \mathrm{ml}$ of juice were centrifuged at $760 \mathrm{~g}$ during 10 minutes at $4{ }^{\circ} \mathrm{C}$ and the absorbance of the supernatant was then measured at $660 \mathrm{~nm}$. 
Cloud stability was determined using the method of Baslar \& Ertugay (Baslar \& Ertugay, 2014). $4 \mathrm{ml}$ of juice were centrifuged at $4200 \mathrm{~g}$ for 15 minutes, and the absorbance of the supernatant was measured at $625 \mathrm{~nm}$. Cloud stability was calculated according to equation 3.3:

$C S(\%)=\frac{A_{C}}{A_{0}} * 100$

Where $A_{c}$ is the absorbance after centrifugation and $A_{0}$ is the absorbance before centrifugation

Particle size distribution (PSD) was determined by laser diffraction with a Mastersizer 2000 (Malvern ${ }^{\circledR}$ Inst., MA). The system uses a laser light at $750 \mathrm{~nm}$ wavelength to size particles from 0.4 to $2000 \mu \mathrm{m}$ by light diffraction. Size distribution (volume fractions against particle size) was calculated and the weight-average sizes were expressed as the equivalent surface area mean diameter, $D(3,2)$ and the equivalent volume mean diameter, $D(4,3)$.

The Span value was also evaluated:

Span $=\frac{d_{\mathrm{v}, 0.9}-d_{\mathrm{v}, 0.1}}{d_{\mathrm{v}, 0.5}}$

Where $d_{v, 0.9}, d_{v, 0.1}$ and $d_{v 0.5}$ are the particle size bellow which, $90 \%, 50 \%$ and $10 \%$ of the particles lies, and it describes distribution width.

\subsubsection{Determination of pectic substances}

Water soluble pectin was determined according to the procedure described by lllera et al. (Illera et al., 2018a). Spectrophotometric data measurements were taken at the highest absorbance instead of at a certain reaction time. A calibration curve was also prepared with standard solutions of D-galacturonic acid (Sigma Aldrich). 


\subsubsection{Total phenolic compounds and antioxidant capacity}

Total phenolic compounds were determined by using the Folin-Ciocalteau reagent (VWR). First, $100 \mu \mathrm{l}$ of the juice were mixed with $2.8 \mathrm{ml}$ of water and subsequently $100 \mu \mathrm{l}$ of the Folin-Ciocalteau reagent. After that, $2 \mathrm{ml}$ of sodium carbonate $7.5 \%(\mathrm{w} / \mathrm{v})$ were added to the mixture and the reaction started. Color was measured at $750 \mathrm{~nm}$ after $60 \mathrm{~min}$ of reaction. A calibration curve was prepared with standard solutions of gallic acid.

Antioxidant capacity was determined by the ABTS assay. ABTS method is based on the decolorization of the radical cation 2,2'-azinobis-(3-ethylbenzothiazoline-6-sulfonic acid) $\left(\mathrm{ABTS}^{++}\right)$when it is reduced to ABTS'. The ABTS ${ }^{+}$solution was diluted with ethanol to reach an absorbance value between 0.7 and 0.9 at $734 \mathrm{~nm}$.

The reaction took place when $300 \mu$ of diluted (1:10) cloudy apple juice where mixed with $3 \mathrm{ml}$ of $\mathrm{ABTS}^{+}+$solution. Absorbance was registered along time at $734 \mathrm{~nm}$, since antioxidant activity depends on the selected time point (Re et al., 1999). All the spectrophotometric measurements were carried out at $21^{\circ} \mathrm{C}$ in a Jasco V-750 spectrophotometer and expressed as inhibition percentage of the radical after 60 minutes of reaction.

\subsection{Statistical analysis}

Statistical analysis was conducted using software Statgraphics X64. The results are presented as the mean \pm standard deviation of at least three replicates. The significance of the differences was determined based on an analysis of the variance with the Tukey's honestly significant difference (HSD) method at $p$-value $\leq 0.05$. 


\section{Results and discussion}

\subsection{Effect of HPCD and TS treatments on enzymatic inactivation}

Table 3.1 shows the residual activity of PPO and PME after treatment and along storage at $4{ }^{\circ} \mathrm{C}$. Right after HPCD treatment, PPO residual activity was only $8.7 \pm 0.5 \%$. This result was of the same order as the one previously found by Illera et al. (Illera et al., 2018a), that reported a PPO residual activity of $15 \%$ at the same operation conditions $\left(20 \mathrm{MPa}, 45^{\circ} \mathrm{C}\right.$, 60 minutes). During storage, PPO activity decreased until it was completely inactivated after 14 days. This decrease could be attributed to the remaining dissolved $\mathrm{CO}_{2}$ in the juice after treatment, which could have a further effect on enzyme inactivation. Storage bottles were made of glass and they were totally filled up with juice, with no remaining head space, therefore, some amount of $\mathrm{CO}_{2}$ could be still dissolved in the juice during storage. Although the exact mechanism for enzyme inactivation by HPCD is not still clear, different approaches such as $\mathrm{pH}$ lowering due to $\mathrm{CO}_{2}$ dissolution and dissociation, conformational changes of the enzyme by the action of $\mathrm{CO}_{2}$ and the formation of different complex with $\mathrm{CO}_{2}$ molecules can be found in literature (Hu et al., 2013).

Regarding Thermosonication, PPO residual activity was $12.7 \pm 0.8 \%$ after TS treatment. Possible mechanisms of enzyme inactivation are the generation of free radicals and the mechanical effect of cavitation, due to the formation and collapsing of micro sized bubbles (Sulaiman et al., 2017). During storage of the juice, PPO residual activity decreased continuously with a nearly complete inactivation after 28 days of storage $(0.3 \pm 0.1 \%)$. No literature has been found regarding the time that the radicals previously mentioned remain in the juice after treatment; although Illera et al. (Illera et al., 2018b) found production of hydrogen peroxide, nitrate and nitrites after TS in a citrate buffer solution at the same $\mathrm{pH}$ as the apple juice. In this regard, Julák et al. (Julák et al., 2018) referred to nitrate and hydrogen peroxide as long-lived chemical products, since after 7 days, these radicals were still present in their plasma treated samples. This could explain the decrease in PPO activity during storage. Sulaiman et al. (Sulaiman et al., 2017) obtained similar 
results after thermosonication treatment of cloudy apple juice, with a residual activity of $14.9 \pm 1.3 \%$ after 10 minutes at $58{ }^{\circ} \mathrm{C}$ and a slightly decrease in PPO activity after storage.

Table 3.1 Residual activity of PPO and PME in untreated samples and HPCD and TS treated samples during shelf life study at $4{ }^{\circ} \mathrm{C}$.

\begin{tabular}{cccc}
\hline Sample & Time (days) & PPO (RA\%) & PME (RA\%) \\
\hline HPCD untreated & 0 & $100.0 \pm 4.4^{\mathrm{a}}$ & $100.0 \pm 1.4^{\mathrm{a}}$ \\
\hline \multirow{2}{*}{ HPCD treated } & 0 & $8.7 \pm 0.46^{\mathrm{b}}$ & $101.5 \pm 0.5^{\mathrm{a}}$ \\
& 7 & $1.0 \pm 0.02^{\mathrm{c}}$ & $116.6 \pm 0.1^{\mathrm{b}}$ \\
& 21 & $0.0 \pm 0.01^{\mathrm{c}}$ & $131.4 \pm 0.8^{\mathrm{c}}$ \\
\hline TS untreated & 28 & $0.0 \pm 0.01^{\mathrm{c}}$ & $151.2 \pm 1.0^{\mathrm{d}}$ \\
\hline \multirow{3}{*}{ TS treated } & 0 & $0.0 \pm 0.01^{\mathrm{c}}$ & $169.0 \pm 12.5^{\mathrm{e}}$ \\
& 0 & $100 \pm 2.3^{\mathrm{a}}$ & $100 \pm 2.9^{\mathrm{a}}$ \\
\hline & 14 & $12.7 \pm 0.8^{\mathrm{b}}$ & $93.1 \pm 0.9^{\mathrm{a}}$ \\
& 21 & $2.9 \pm 1.3^{\mathrm{cd}}$ & $113.6 \pm 2.2^{\mathrm{b}}$ \\
& 28 & $3.9 \pm 1.3^{\mathrm{c}}$ & $121.5 \pm 3.7^{\mathrm{c}}$ \\
& $1.9 \pm 0.4^{\mathrm{cd}}$ & $121.0 \pm 7.8^{\mathrm{c}}$ \\
& 21 & $0.3 \pm 0.1^{\mathrm{d}}$ & $123.4 \pm 1.4^{\mathrm{c}}$ \\
\hline
\end{tabular}

Values with different letters in each column, and each treatment are significantly different when applying the Tukey's honestly significant difference (HSD) method at $p$-value $\leq 0.05$.

On the contrary, PME was not successfully inactivated by any of these technologies. PME activity remained constant after HPCD treatment and it increased continuously during storage up to $169 \pm 12 \%$ after 28 days (Table 3.1). Xu et al. (Xu et al., 2011) also observed an increase of PME activity up to $110 \%$ in HPCD treated apple juice at $25 \mathrm{MPa}$ during 2 minutes at $43^{\circ} \mathrm{C}$. They attributed this behavior to the fragmentation of the cell wall during HPCD processing, as PME is bounded to this wall, an increase in apparent PME activity can occur. After thermosonication treatment, PME residual activity was slightly reduced to $93.1 \pm 0.9 \%$ (Table 3.1), but it also increased during storage. 


\subsection{Effect of HPCD and Thermosonication on $\mathrm{pH}$, color and non- enzymatic browning}

\section{$3.2 .1 \mathrm{pH}$}

After both treatments, $\mathrm{pH}$ value decreased, although not in the same extent (Table 3.2). HPCD treatment is supposed to decrease $\mathrm{pH}$ due to the dissolution of $\mathrm{CO}_{2}$ in the juice. In this study, $\mathrm{pH}$ decreased significantly from $3.76 \pm 0.01$ to $3.67 \pm 0.01$ after HPCD treatment, and very small changes were detected during storage, reaching a final value of $3.65 \pm 0.01$ after 28 days of storage. The maintenance of a lower $\mathrm{pH}$ value during the storage could be related to the remaining dissolved $\mathrm{CO}_{2}$ in the juice. Ferrentino et al. (Ferrentino et al., 2009) obtained a similar trend to the one observed in this work, with a significant decrease in $\mathrm{pH}$ (3.56 to 3.52) after treatment at $16 \mathrm{MPa}, 60^{\circ} \mathrm{C}$ and 50 minutes, and, after 4 weeks of storage at $4{ }^{\circ} \mathrm{C}, \mathrm{pH}$ remained unchanged.

After Thermosonication treatment, pH decreased from $3.71 \pm 0.01$ to $3.66 \pm 0.01$ (Table 3.2), and a significant decrease was observed during storage, being the $\mathrm{pH}$ value after 28 days of $3.54 \pm 0.01$. Amaral et al. (Amaral et al., 2015) also observed a decrease of pH after TS treatment when treating fresh potatoes ( $40 \mathrm{kHz}, 200 \mathrm{~W}, 10$ minutes), and a significant decrease during storage, being the initial pH value 5.97, and around 5.4 after 12 days at $3{ }^{\circ} \mathrm{C}$. However, no significant changes after TS were obtained by other authors in apple and lime juice respectively (Abid et al., 2013; Bhat et al., 2011).

\subsubsection{Non enzymatic browning}

After HPCD treatment, no significant change in HMF concentration was observed, and after TS treatment, the amount of HMF significantly increased from 0.75 to 1.3 (Table 3.2), which could be related with the oxygen availability in the juice and the temperature used in TS treatment for PPO inactivation (Illera et al., 2018b). The ratio $\mathrm{HMF} / \mathrm{HMF}_{0}$ was 1.3 and 1.7 for the HPCD and TS treated samples respectively. Similar values were found by Rattanathanalerk et al. (Rattanathanalerk et al., 2005), who studied HMF formation in 
pineapple juice after thermal processing. For example, after treating the juice at $55{ }^{\circ} \mathrm{C}$ during 60 minutes (similar to HPCD treatment conditions) the $\mathrm{HMF} / \mathrm{HMF}_{0}$ value was 1.25 and after treatment at $65{ }^{\circ} \mathrm{C}$ during 20 minutes (similar to TS treatment conditions), the $\mathrm{HMF} / \mathrm{HMF}_{0}$ value was around 1.1. Other non-thermal technologies, such as pulsed electric fields applied to strawberry juice, have shown that, after treatment, the content of HMF increased from $0.744 \pm 0.012 \mathrm{mg} / \mathrm{L}$ to $1.371 \pm 0.022 \mathrm{mg} / \mathrm{L}$ (Aguiló-aguayo et al., 2009)

During storage, for both HPCD and TS samples, HMF slightly increased after 7 days at $4{ }^{\circ} \mathrm{C}$ and, then, it remained unchanged during the rest of the storage time (Table 3.2). Abid et al. (Abid et al., 2015) observed a similar trend in their sonicated apple juice; nonenzymatic browning, expressed as absorbance at $420 \mathrm{~nm}$, changed from $0.37 \pm 0.02$ to $0.8 \pm 0.02$ after a TS treatment at $90 \%$ amplitude and $20 \mathrm{kHz}$ during 3 minutes. This value increased continuously during storage, reaching a value of $1.31 \pm 0.04$ after 30 days at $4{ }^{\circ} \mathrm{C}$.

Table $3.2 \mathrm{pH}$ and non-enzymatic browning values of untreated samples and HPCD and TS treated samples during storage time at $4{ }^{\circ} \mathrm{C}$.

\begin{tabular}{cccc}
\hline Sample & Time (days) & pH & mg HMF/L \\
\hline HPCD untreated & 0 & $3.76 \pm 0.01^{\mathrm{a}}$ & $0.34 \pm 0.09^{\mathrm{a}}$ \\
\hline \multirow{2}{*}{ HPCD treated } & 0 & $3.67 \pm 0.01^{\mathrm{cd}}$ & $0.44 \pm 0.06^{\mathrm{a}}$ \\
& 7 & $3.71 \pm 0.0^{\mathrm{b}}$ & $0.90 \pm 0.01^{\mathrm{b}}$ \\
& 21 & $3.69 \pm 0.0^{\mathrm{bc}}$ & $0.88 \pm 0.01^{\mathrm{b}}$ \\
\hline TS untreated & 28 & $3.69 \pm 0.01^{\mathrm{bc}}$ & $0.88 \pm 0.02^{\mathrm{b}}$ \\
\hline \multirow{2}{*}{ TS treated } & 0 & $3.71 \pm 0.01^{\mathrm{a}}$ & $0.75 \pm 0.02^{\mathrm{a}}$ \\
\hline & 0 & $3.66 \pm 0.01^{\mathrm{b}}$ & $1.30 \pm 0.05^{\mathrm{b}}$ \\
& 7 & $3.67 \pm 0.01^{\mathrm{b}}$ & $2.95 \pm 0.13^{\mathrm{c}}$ \\
& 14 & $3.64 \pm 0.0^{\mathrm{c}}$ & $2.97 \pm 0.01^{\mathrm{c}}$ \\
& 21 & $3.56 \pm 0.01^{\mathrm{d}}$ & $2.99 \pm 0.02^{\mathrm{c}}$ \\
& 28 & $3.54 \pm 0.01^{\mathrm{e}}$ & $3.02 \pm 0.04^{\mathrm{c}}$ \\
\hline
\end{tabular}

Values with different letters in each column, and each treatment are significantly different when applying the Tukey's honestly significant difference (HSD) method at $p$-value $\leq 0.05$. 
Anyway, common industry practice for acceptable HMF concentration of a high-quality thermally processed apple juice is below $5 \mathrm{mg} / \mathrm{kg}$ (Cohen et al., 1998), so the treated juices in this work are below this maximum value.

\subsubsection{Color}

After HPCD treatment, lightness $\left(L^{*}\right)$ presented a slightly but significant lower value, from $41.36 \pm 0.03$ to $41.01 \pm 0.01$. This value decreased continuously during storage to a value of $39.14 \pm 0.06$ in the 28 th day (Figure 3.1a). After HPCD treatment, redness $\left(a^{*}\right.$ ) value did not change significantly compared to the untreated sample (Figure 3.1b), but during storage it showed a significant increase, especially in the first week, where a* value changed from $0.68 \pm 0.03$ to $1.54 \pm 0.05$. This increase in redness means that the juice suffered browning. During the following weeks, it remained more or less constant (Figure 3.1b). On the contrary, yellowness $\left(b^{*}\right)$ value suffered a continuous decrease in the juice during the storage (Figure 3.1c). Ferrentino et al. (2009) also observed a slightly decrease in lightness of apple juice after HPCD treatment (16 MPa, $60{ }^{\circ} \mathrm{C}, 50$ minutes) from 49.17 to 48.77 , although its value was constant during storage with a small decrease in the last weeks. Redness significantly decreased after 28 days from 0.9 to 0.7 approximately. Regarding yellowness, ( $b^{*}$ value) these authors found, that after 4 weeks of storage, it decreased from 2.77 to 2.5 approximately. Total color change (Figure $\mathbf{3 . 2}$ ) was only $0.532 \pm 0.03$ right after the HPCD treatment, but this value increased continuously during the storage time, being the final value of $3.971 \pm 0.06$ after four weeks of storage. According to the classification by Yuk et al. (Yuk et al., 2014), the change in color was slightly noticeable after the treatment and well visible after 4 weeks of storage. 

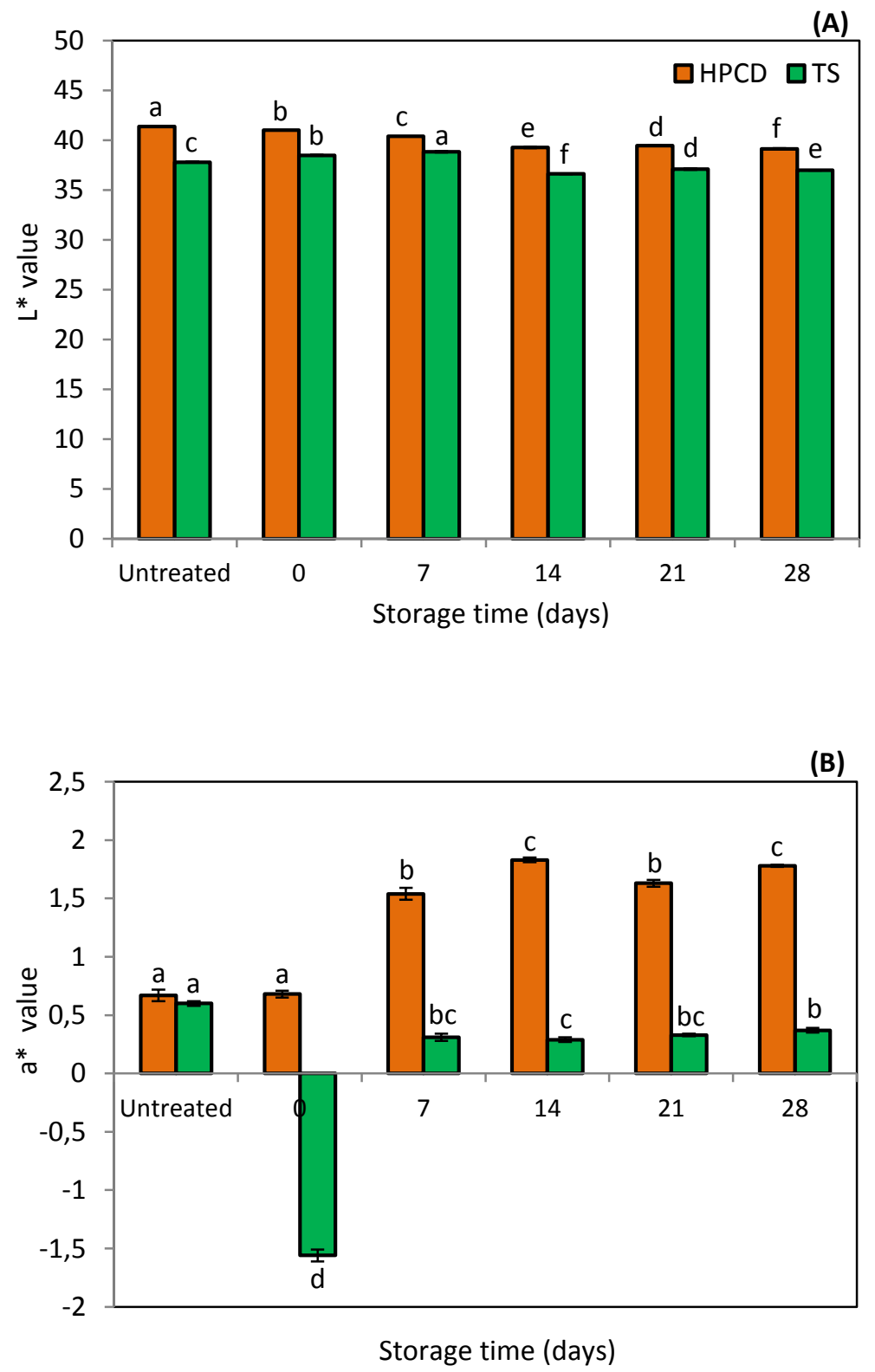


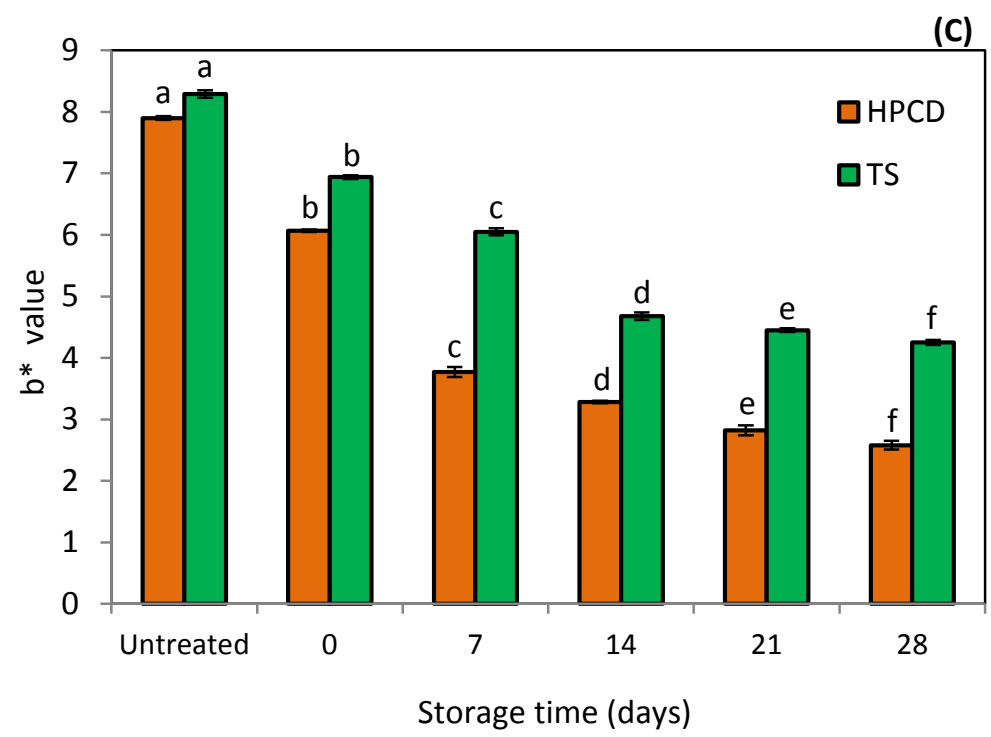

Figure 3.1 Color parameters (a) $\mathrm{L}^{*},(\mathbf{b}) \mathrm{a}^{*}$ and (c) b* of untreated samples and after HPCD treatment ( $20 \mathrm{MPa}, 45^{\circ} \mathrm{C}$ and $60 \mathrm{~min}$ ) and TS treatment $\left(100 \%\right.$ amplitude, $40{ }^{\circ} \mathrm{C}$ and 20 min) during storage at $4{ }^{\circ} \mathrm{C}$. Values with different letters in each figure and for each treatment are significantly different when applying the Tukey's honestly significant difference (HSD) method at $p$-value $\leq 0.05$.

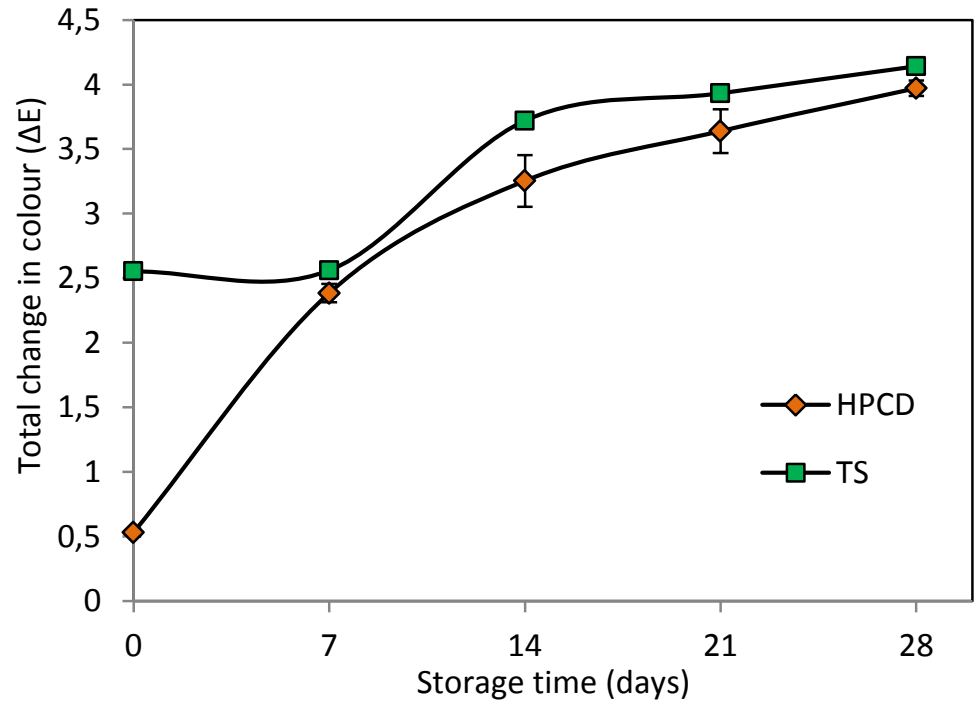

Figure 3.2 Total change in color of the juices during storage at $4{ }^{\circ} \mathrm{C}$ after HPCD treatment (20 MPa, $45^{\circ} \mathrm{C}$ and $60 \mathrm{~min}$ ) and TS treatment (100\% amplitude, $62{ }^{\circ} \mathrm{C}$ and $20 \mathrm{~min}$ ). 
After TS treatment, lightness significantly increased from $37.8 \pm 0.05$ to $38.49 \pm 0.05$ (Figure 3.1a). Redness and yellowness values, $a^{*}$ and $b^{*}$, decreased after thermosonication treatment, especially $a^{*}$, which changed from $0.6 \pm 0.02$ to $-1.56 \pm 0.05$. During storage, a* value increased reaching values slightly lower than the control sample (Figure 3.1b). The lightness increase could be appreciated by an untrained viewer. Abid et al. (Abid et al., 2015) explained that the increase in $L^{*}$ value after the treatment might be due to the increase in the cloud value of juice under the effect of sonication, producing an improved homogenization. They also observed an increase in lightness of apple juice from $18.75 \pm 0.19$ to $24.05 \pm 0.7$ after TS treatment ( $90 \%$ amplitude, $20 \mathrm{kHz}, 3 \mathrm{~min}$ ). After TS treatment, total change in color value was $2.55 \pm 0.03$, in this case, produced by a lighter color of the samples. Figure $\mathbf{3 . 2}$ shows the change in color during storage for both treatments. Differences can be observed after each treatment, however, after the 7 th day of storage a nearly parallel increase in color change was observed for both technologies.

\subsection{Cloud value, cloud stability and particle size distribution}

Initial cloud value of the juice before HPCD treatment was $0.524 \pm 0.06$ and it did not change significantly after treatment $(0.532 \pm 0.02)$, although it slowly increased during the refrigerated storage. On the contrary, cloud stability remained more or less constant during storage time, being the initial value $8.6 \pm 0.3 \%$ and $7.7 \pm 0.5 \%$ after 28 days of storage (Figure 3.3a). Cloud stability after HPCD can be related with the Span values (Table 3.3), since the lower the Span, the narrower the distribution width is, and Span changed from $26 \pm 2$ to $5.8 \pm 0.1$ after HPCD treatment. Therefore, there is a higher stability as a consequence of a homogenization of the juice. This can be also observed in the decrease of $D[4,3]$ from $109 \pm 3 \mu \mathrm{m}$ to $2.4 \pm 0.01 \mu \mathrm{m}$ after HPCD (Table 3.3) and also in Figure 3.4a. After HPCD treatment, the peak corresponding to the larger particles nearly disappeared and the peak of the smallest particles increased and was shifted to smaller sizes. PSD didn't significantly change during storage (Figure 3.4a). 

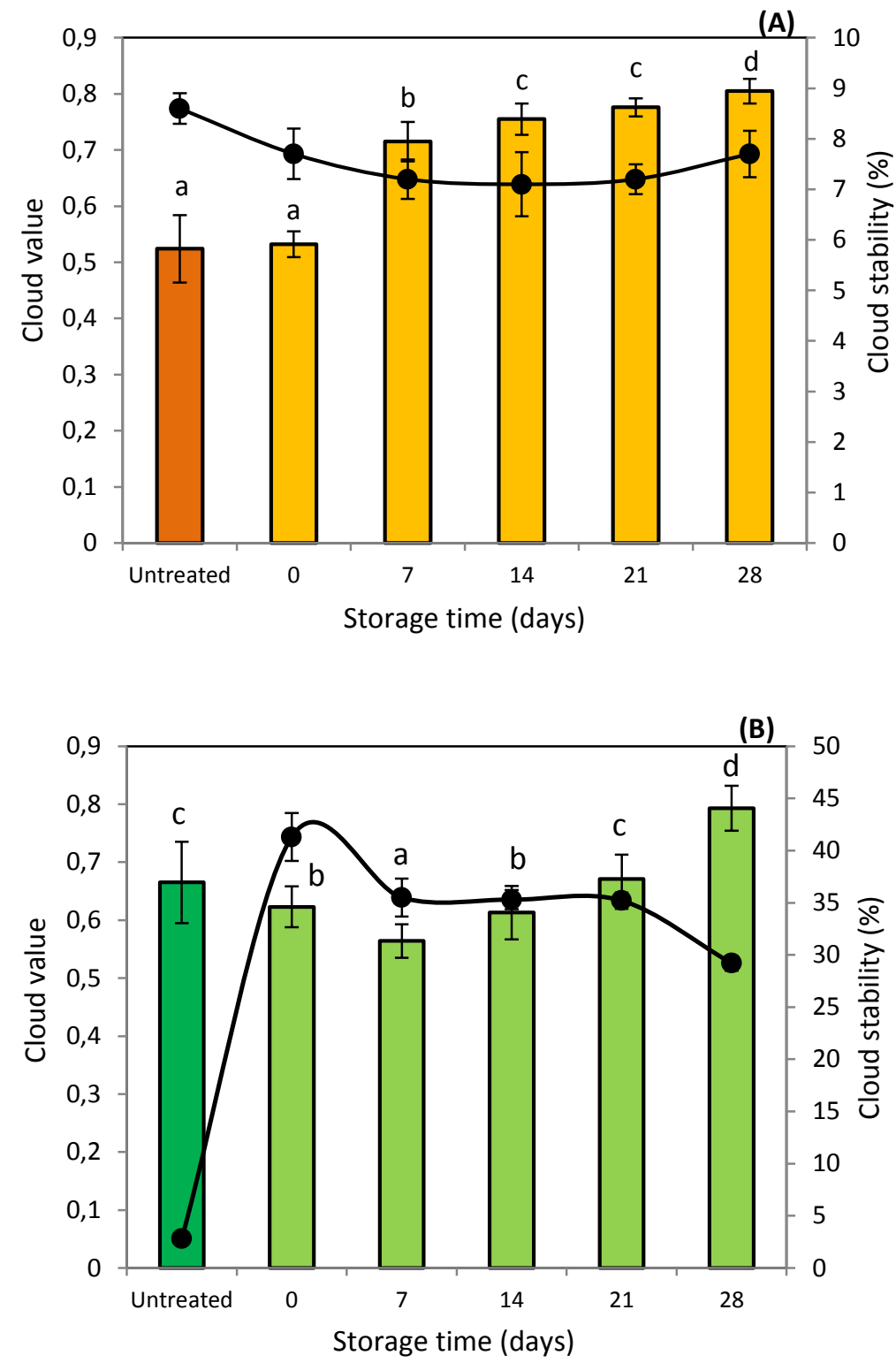

Figure 3.3 Cloud value and cloud stability of untreated samples, (a) HPCD treated samples (20 MPa, $45^{\circ} \mathrm{C}$ and $60 \mathrm{~min}$ ) (b) TS treated samples (100\% amplitude, $62{ }^{\circ} \mathrm{C}$ and $20 \mathrm{~min}$ ) after each treatment and during storage at $4{ }^{\circ} \mathrm{C}$. Bars represent cloud value and symbols represent cloud stability values. Values with different letters in each figure are significantly different when applying the Tukey's honestly significant difference (HSD) method at p-value $\leq 0.05$. 

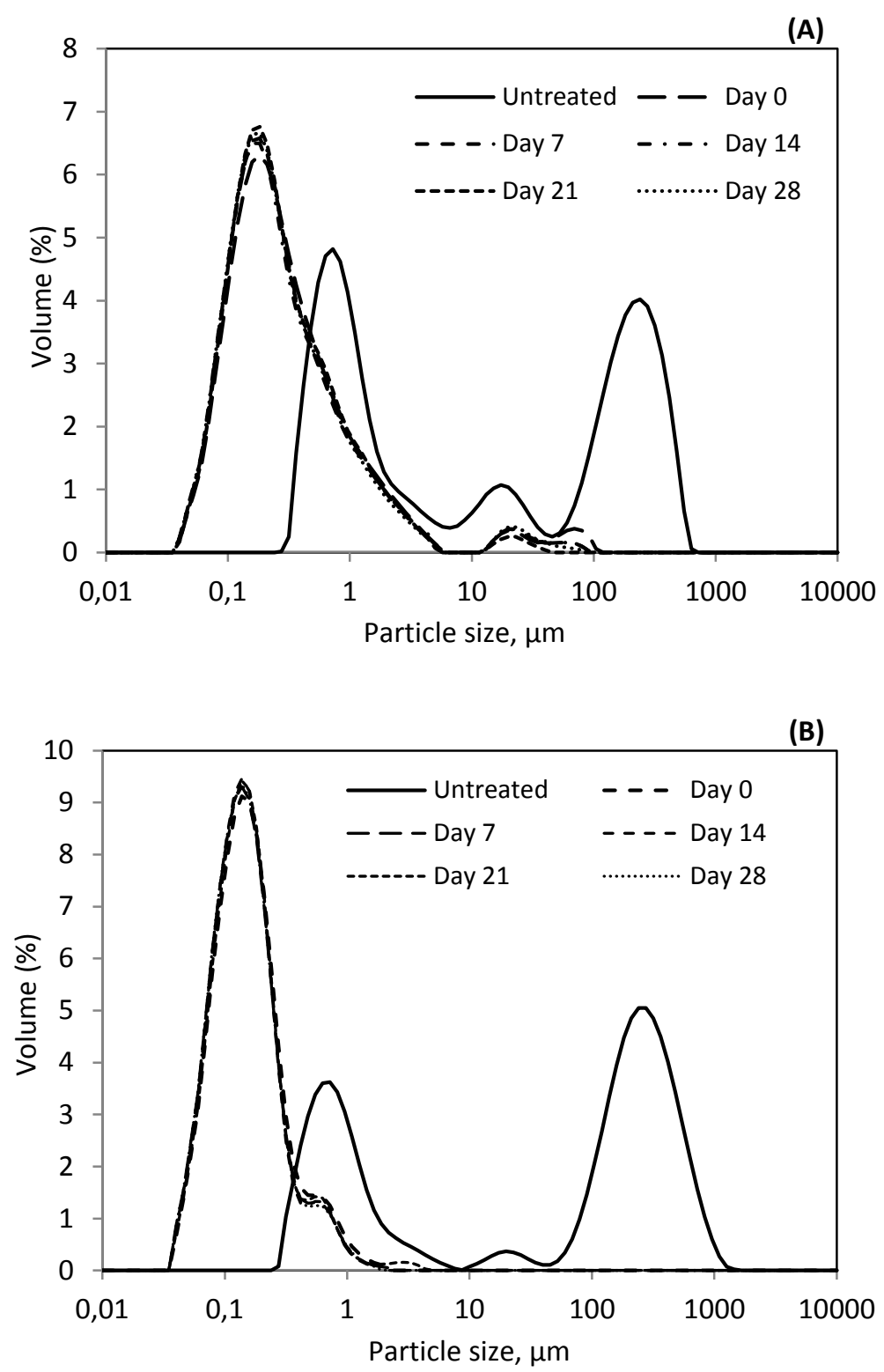

Figure 3.4 Particle size distribution (PSD) of cloudy apple juice before treatment and after (a) HPCD treatment at $20 \mathrm{MPa}, 45^{\circ} \mathrm{C}$ and 60 minutes (b) TS treatment at $100 \%$ amplitude, $40{ }^{\circ} \mathrm{C}, 20 \mathrm{kHz}$ and 20 minutes, and during storage; 7, 14, 21 and 28 days. 
Table 3.3 PSD values of untreated samples and HPCD and TS treated samples during storage time at $4{ }^{\circ} \mathrm{C}$.

\begin{tabular}{cccccccc}
\hline Sample & Time (days) & $\mathbf{D}[\mathbf{3 , 2}]$ & $\mathbf{D}[\mathbf{4 , 3}]$ & $\mathbf{d}(\mathbf{0 . 1})$ & $\mathbf{d}(\mathbf{0 . 5})$ & $\mathbf{d}(\mathbf{0 . 9})$ & Span \\
\hline HPCD untreated & 0 & $1.8 \pm 0.02^{\mathrm{a}}$ & $109 \pm 3^{\mathrm{a}}$ & $0.6 \pm 0.01^{\mathrm{a}}$ & $13.3 \pm 1.2^{\mathrm{a}}$ & $337 \pm 7^{\mathrm{a}}$ & $26 \pm 2^{\mathrm{a}}$ \\
\hline \multirow{3}{*}{ HPCD treated } & 0 & $0.21 \pm 0.03^{\mathrm{b}}$ & $2.4 \pm 0.01^{\mathrm{b}}$ & $0.1 \pm 0.01^{\mathrm{b}}$ & $0.27 \pm 0.01^{\mathrm{b}}$ & $1.6 \pm 0.07^{\mathrm{b}}$ & $5.8 \pm 0.1^{\mathrm{b}}$ \\
& 7 & $0.20 \pm 0.01^{\mathrm{b}}$ & $1.5 \pm 0.02^{\mathrm{b}}$ & $0.1 \pm 0.01^{\mathrm{b}}$ & $0.25 \pm 0.01^{\mathrm{b}}$ & $1.4 \pm 0.05^{\mathrm{b}}$ & $5.3 \pm 0.2^{\mathrm{b}}$ \\
& 14 & $0.20 \pm 0.01^{\mathrm{b}}$ & $1.6 \pm 0.09^{\mathrm{b}}$ & $0.1 \pm 0.01^{\mathrm{b}}$ & $0.25 \pm 0.01^{\mathrm{b}}$ & $1.4 \pm 0.02^{\mathrm{b}}$ & $5.4 \pm 0.1^{\mathrm{b}}$ \\
& 21 & $0.20 \pm 0.01^{\mathrm{b}}$ & $1.0 \pm 0.04^{\mathrm{b}}$ & $0.1 \pm 0.01^{\mathrm{b}}$ & $0.24 \pm 0.01^{\mathrm{b}}$ & $1.3 \pm 0.01^{\mathrm{b}}$ & $4.8 \pm 0.1^{\mathrm{b}}$ \\
TS untreated & 28 & $0.20 \pm 0.01^{\mathrm{b}}$ & $1.2 \pm 0.06^{\mathrm{b}}$ & $0.1 \pm 0.01^{\mathrm{b}}$ & $0.24 \pm 0.01^{\mathrm{b}}$ & $1.3 \pm 0.01^{\mathrm{b}}$ & $4.9 \pm 0.1^{\mathrm{b}}$ \\
\hline \multirow{3}{*}{ TS treated } & 0 & $2.0 \pm 0.01^{\mathrm{a}}$ & $197 \pm 2^{\mathrm{a}}$ & $0.6 \pm 0.01^{\mathrm{a}}$ & $14.6 \pm 1.5^{\mathrm{a}}$ & $505 \pm 6^{\mathrm{a}}$ & $34 \pm 3^{\mathrm{a}}$ \\
\hline & 0 & $0.14 \pm 0.01^{\mathrm{b}}$ & $0.22 \pm 0.01^{\mathrm{b}}$ & $0.08 \pm 0.001^{\mathrm{b}}$ & $0.16 \pm 0.01^{\mathrm{b}}$ & $0.42 \pm 0.01^{\mathrm{b}}$ & $2.2 \pm 0.01^{\mathrm{b}}$ \\
& 7 & $0.13 \pm 0.00^{\mathrm{b}}$ & $0.21 \pm 0.00^{\mathrm{b}}$ & $0.07 \pm 0.001^{\mathrm{b}}$ & $0.15 \pm 0.01^{\mathrm{b}}$ & $0.37 \pm 0.01^{\mathrm{b}}$ & $2.0 \pm 0.01^{\mathrm{b}}$ \\
& 14 & $0.13 \pm 0.00^{\mathrm{b}}$ & $0.21 \pm 0.00^{\mathrm{b}}$ & $0.07 \pm 0.001^{\mathrm{b}}$ & $0.15 \pm 0.01^{\mathrm{b}}$ & $0.36 \pm 0.01^{\mathrm{b}}$ & $2.0 \pm 0.01^{\mathrm{b}}$ \\
& 21 & $0.13 \pm 0.00^{\mathrm{b}}$ & $0.23 \pm 0.00^{\mathrm{b}}$ & $0.08 \pm 0.001^{\mathrm{b}}$ & $0.16 \pm 0.01^{\mathrm{b}}$ & $0.40 \pm 0.01^{\mathrm{b}}$ & $2.0 \pm 0.01^{\mathrm{b}}$ \\
& 28 & $0.13 \pm 0.01^{\mathrm{b}}$ & $0.20 \pm 0.01^{\mathrm{b}}$ & $0.07 \pm 0.001^{\mathrm{b}}$ & $0.15 \pm 0.01^{\mathrm{b}}$ & $0.36 \pm 0.02^{\mathrm{b}}$ & $2.0 \pm 0.07^{\mathrm{b}}$
\end{tabular}

Values with different letters in each column, and each treatment are significantly different when applying the Tukey's honestly significant difference (HSD) method at $p$-value $\leq 0.05$. 
Thermosonication treatment produced a significant decrease in the cloud value of the juice, which changed from $0.66 \pm 0.07$ to $0.62 \pm 0.07$ and then it reached a minimum value in the 7 th day of storage at 0.564 although then steadily increased up to 0.793 in the 28th day (Figure 3.3b). On the contrary, Abid et al. (Abid et al., 2015) studied the cloud value of cloudy apple juice after TS treatment ( $90 \%$ amplitude, $20{ }^{\circ} \mathrm{C}, 20 \mathrm{kHz}, 3$ minutes), finding that cloud value increased significantly from $0.28 \pm 0.02$ to $0.86 \pm 0.03$ probably due to high-pressure gradient by cavitation that causes the breakdown of macromolecules to smaller ones and make the juice to be homogenized and more consistent, although it decreased during storage. This fact agrees with the significant reduction of particle size after TS (Table 3.3) since D[4,3] value decreased from $197 \pm 2 \mu \mathrm{m}$ to $0.22 \pm 0.01 \mu \mathrm{m}$. It can also be observed in Figure 3.4b that the peak corresponding to larger particles completely disappeared and the maximum peak of the smallest particles drastically decreased from 0.724 to $0.138 \mu \mathrm{m}$. PSD didn't significantly change during storage (Figure $\mathbf{3 . 4 b}$ ).

Cloud stability after TS treatment showed a big increase, from $2.8 \pm 0.1 \%$ to $41.3 \pm 2.3 \%$ (Figure 3.3b), during storage this value steadily decreased, although it was still higher than the initial one. As for HPCD treatment, cloud stability can be related with the trend observed in the Span value (Table 3.3), Span value decreased from $34 \pm 3$ to $2.2 \pm 0.1$ and then it remained constant along time. The cloud stability value for thermosonication was much higher than the cloud stability obtained in the HPCD treated sample. This could be attributed to the fact that sonication can produce a more stabilized colloid system because of smaller particle size. After sonication, $D[4,3]$ was lower than $0.5 \mu \mathrm{m}$, what make particles stay in suspension and do not settle. This behavior could be visually observed since, during storage, the samples treated by sonication looked homogeneous and there was no phase separation during the 28 days period evaluated, although PME activity was not reduced. This agrees with results reported in the literature concluding that reduction of particle size was more dependent on the ultrasound amplitude than the inactivation of PME (Fonteles et al., 2012). 


\subsection{Determination of pectic substances}

Pectin results are listed in Table 3.4. After HPCD treatment, water soluble pectin content was $31.9 \pm 0.1 \mathrm{mg} / \mathrm{L}$, higher than the value for the control $(25.9 \pm 0.3)$. However, it continuously decreased during storage to $27.9 \pm 0.3$ after 28 days at $4{ }^{\circ} \mathrm{C}$. Similar results were previously found by Illera et al. (Illera et al., 2018a). Similar to HPCD treatment, water soluble pectin increased after thermosonication treatment from $14.7 \pm 0.2$ to $19.8 \pm$ 2.3 , and it did not significantly change during storage.

The increase observed in water soluble pectin content after HPCD and TS treatment, agrees with the decrease in PSD described in Figures 3.4a and 3.4b, since, according to Sila et al. (Sila et al., 2009), when polymer size decreases, pectin solubility in water is increased. The cloud of the juice contains significant quantities of pectin, and soluble pectin supports cloud stability, thus, since soluble pectin has increased after treatments, cloud stability has also improved in the treated juices.

\subsection{Total phenolic compounds and antioxidant capacity}

Table 3.4 shows the evolution of total polyphenolic compounds (TPC) after both treatments. TPC did not change significantly after HPCD treatment (from $449 \pm 8$ to $453 \pm$ $0.1 \mathrm{mg}$ galic/L) and slightly increased during storage time, up to a concentration of $518 \pm 4$ $\mathrm{mg}$ galic/L after 28 days. Similar results can be found in the literature. Gasperi et al. (Gasperi et al., 2009) also found no significant differences in polyphenols content after HPCD treatment (10 MPa, $36^{\circ} \mathrm{C}, 10$ minutes) of apple juice, from $580 \pm 143$ to $622 \pm 242$.

Regarding thermosonication treatment, according to Fonteles et al. (Fonteles et al., 2012), cavitation effect during sonication could liberate into the juice the phenolic compounds that are bond to the cell wall. In this work, TPC significantly increased in TS apple juice, from $711 \pm 10$ to $740 \pm 2 \mathrm{mg}$ galic/L, but steadily decreased during storage which could be attributed to the presence of oxygen in the medium. 
TPC is closely related to antioxidant capacity. After HPCD treatment, apple juice didn't show a significant change of ABTS inhibition percentage after 60 minutes of reaction (from $99.7 \pm 0.3$ to $99.4 \pm 0.1$ ) and during storage a slight decrease was observed despite of the increase in polyphenol content. Thermosonication treatment showed an increase in the antioxidant activity, from $94.4 \pm 0.5$ to $99.7 \pm 0.1$. In this regard, thermosonication can enhance the extractability of different antioxidant compounds due to the disruption of cell walls. Antioxidant activity remained constant during storage. Abid et al. (Abid et al., 2015) observed an increase in the antioxidant capacity, from $297.93 \pm 2.34$ to $359.23 \pm 3.37 \mu \mathrm{g}$ ascorbic acid/mL, after a TS treatment (90\% amplitude, $20 \mathrm{kHz}, 20^{\circ} \mathrm{C}, 3 \mathrm{~min}$ ). As it can be observed in Table 3.4, after 28 days, the ABTS inhibition (\%) is still quite high in the two samples, being slightly lower in the HPCD treated one, $87.8 \pm 0.1$, compared to the TS sample, $98.3 \pm 0.8$.

\section{Conclusions}

HPCD and TS treatments have been shown as valid alternative technologies for treating cloudy apple juice. Both technologies were able to inactivate PPO with no reactivation during storage. PME was found to be more resistant to the treatments, and an increase in its activity was observed during storage.

Both treatments also had a homogenization effect in the juice. This effect was more evident after thermosonication treatments, where cloud stability increased in a big extent. Related to this decrease in particle size distribution, water soluble pectin also increased after treatments.

Color significantly changed after both treatments, but it was more significant in thermosonicated juice, where juice increased lightness and maintained that color during storage. HPCD and TS treatments also showed to have a good effect on total polyphenol content or antioxidant capacity not decreasing these values, and no changing the nutritional properties of the juice 
Table 3.4 Water soluble pectin content $(\mathrm{mg} / \mathrm{L})$, polyphenol content (mg galic/L) and antioxidant capacity $\left(\%\right.$ inhibition of radical ABTS ${ }^{+}$after 60 minutes of reaction) of untreated samples and HPCD and TS treated samples during storage time at $4{ }^{\circ} \mathrm{C}$.

\begin{tabular}{ccccc}
\hline Samples & Time (days) & Water soluble pectin $(\mathrm{mg} / \mathrm{L})$ & mg galic/L & ABTS inhibition (\%) \\
\hline HPCD untreated & 0 & $25.9 \pm 0.3^{\mathrm{a}}$ & $449 \pm 8^{\mathrm{a}}$ & $99.7 \pm 0.3^{\mathrm{a}}$ \\
\hline \multirow{3}{*}{ HPCD treated } & 0 & $31.9 \pm 0.1^{\mathrm{d}}$ & $453 \pm 0.1^{\mathrm{a}}$ & $99.4 \pm 0.1^{\mathrm{a}}$ \\
& 7 & $28.0 \pm 0.1^{\mathrm{b}}$ & $464 \pm 0.5^{\mathrm{ab}}$ & $91.8 \pm 1.2^{\mathrm{b}}$ \\
& 21 & $27.5 \pm 0.8^{\mathrm{b}}$ & $481 \pm 2^{\mathrm{b}}$ & $89.7 \pm 0.9^{\mathrm{b}}$ \\
\hline TS untreated & 28 & $29.0 \pm 0.4^{\mathrm{c}}$ & $514 \pm 1^{\mathrm{c}}$ & $89.2 \pm 1.4^{\mathrm{bc}}$ \\
\hline \multirow{3}{*}{ TS treated } & 0 & $27.9 \pm 0.3^{\mathrm{b}}$ & $518 \pm 4^{\mathrm{c}}$ & $87.8 \pm 0.1^{\mathrm{c}}$ \\
\hline & 0 & $14.7 \pm 0.2^{\mathrm{a}}$ & $711 \pm 10^{\mathrm{b}}$ & $94.4 \pm 0.5^{\mathrm{a}}$ \\
\hline & 14 & $19.8 \pm 2.3^{\mathrm{b}}$ & $740 \pm 2^{\mathrm{a}}$ & $99.7 \pm 0.1^{\mathrm{b}}$ \\
& 21 & $19.3 \pm 1.2^{\mathrm{b}}$ & $674 \pm 5^{\mathrm{c}}$ & $99.0 \pm 0.9^{\mathrm{b}}$ \\
& 28 & $22.0 \pm 2.0^{\mathrm{b}}$ & $629 \pm 5^{\mathrm{d}}$ & $99.2 \pm 0.2^{\mathrm{b}}$ \\
\hline
\end{tabular}

Values with different letters in each column, and each treatment are significantly different when applying the Tukey's honestly significant difference (HSD) method at $p$-value $\leq 0.05$. 



\section{CHAPTER 4}

Effect of Cold Plasma on polyphenol oxidase inactivation in cloudy apple juice and on the quality parameters of the juice during storage

Based on the article:

A.E. Illera, S. Chaple, M.T. Sanz, S. Ng, P. Lu, J. Jones, E. Carey, P. Bourke

"Effect of Cold Plasma on polyphenol oxidase inactivation in cloudy apple juice and on the quality parameters of the juice during storage".

(Submitted to Food Chemistry). 



\title{
Capítulo 4
}

\author{
Efecto de la tecnología de plasma frío en la inactivación de \\ polifenoloxidasa en zumo de manzana no clarificado y en sus parámetros \\ de calidad durante el almacenamiento
}

\section{Resumen}

En este capítulo se ha estudiado el efecto de otra tecnología no térmica sobre el zumo de manzana no clarificado. En concreto se ha estudiado el efecto de un tratamiento directo de plasma frío con el objetivo de mantener y mejorar la calidad de zumo de manzana fresco. Se estudiaron diversas variables de proceso, entre ellas el tipo de descarga del plasma, el voltaje o el tiempo de tratamiento, y al igual que en los anteriores capítulos, se estudió su efecto en la inactivación de polifenoloxidasa (PPO), la distribución del tamaño de partícula y el color entre otras propiedades de calidad importantes en zumo de manzana no clarificado de la variedad Golden delicious. Las mejores condiciones de tratamiento fue un tratamiento de plasma de tipo 'spark' durante 5 minutos a $10.5 \mathrm{kV}$, mediante el que se prácticamente se consiguió la inactivación completa de la PPO (16\% actividad residual), aunque tras el tratamiento de 4 minutos también se obtuvo un alto porcentaje de inactivación (más del 70 \%). Esta inactivación se mantuvo durante el estudio de almacenamiento del zumo, así como las propiedades de calidad del zumo. El cambio más notable se produjo en el color, el cual tomó un tono más verde y más atractivo. El contenido en polifenoles totales aumentó un 69 y $64 \%$ tras 4 y 5 minutos de tratamiento respectivamente.

Palabras clave: Zumo de manzana no clarificado, plasma frío, descarga 'spark', inactivación PPO, parámetros de calidad, vida útil. 



\section{Abstract}

Direct cold plasma treatment has been investigated as an alternative non thermal technology as a means of maintaining and improving quality of fresh cloudy apple juice. Process variables studied included type of plasma discharge, input voltage and treatment time on polyphenol oxidase (PPO) inactivation. Spark discharge plasma at $10.5 \mathrm{kV}$ during 5 minutes was found to be the best treatment, with near total inactivation of PPO achieved, although good PPO inactivation degree were also obtained at shorter treatment times, being residual activity (RA) 16 and $27.6 \%$ after 5 and 4 minutes of treatment. This PPO inactivation was maintained throughout storage trials and even decreased, being this change more noticeable in the short time treated samples. Plasma treatment also improved many key quality parameters of Golden delicious cloudy apple juice, with retention during extended storage trials. Color was the most noticeable change, which turned to a greener and more attractive color. Also an increase of 69 and $64 \%$ was obtained in the total phenolic content after 4 and 5 minutes of treatment, respectively. Therefore, cold plasma showed to be a good alternative to traditional heat treatments for the treatment of fresh cloudy apple juice and its storage.

Keywords: Cloudy apple juice, Cold Plasma, Spark discharge, PPO inactivation, quality parameters, shelf life study. 



\section{Introduction}

Fruit juices are rich in bioactive compounds and meet the consumer's demand for healthy, tasty and practical foods, what makes that these products are consumed by a big part of the population (Faria et al., 2017). Apple juice is one of the most consumed one and some studies show that consuming cloudy apple juice can be more beneficial to health than consuming the clear one, since cloudy apple juice is a good source of bioactive and prebiotic compounds such as ascorbic acid, polyphenols, and pectin (Oszmianski et al., 2007; Fonteles \& Rodrigues, 2018). For cloudy apple juice, the most important factor responsible for quality degradation is enzymatic browning, which is catalysed by polyphenol oxidase (PPO) through the oxidation of naturally present polyphenols. The production of juices with fresh-like characteristics and stable quality during processing and storage remains a challenge for the food industry (Rodríguez et al., 2017). In last decades, the development of emerging technologies has been one of the most important aims of food technology research. As thermal processing is the most prevalent technology, studies have been usually based on the removal of heat. Some of these non thermal technologies are cold plasma, pressurized fluid processes, ultrasonication and high-pressure applications among others (Misra et al., 2017). The effect of HPCD on PPO and other enzymes has been extensively studied on different fruit juices by Briongos et al. (2016), Illera et al. (2018a \& 2018b) and Zhou et al. (2009) among others. Thermosonication has also emerged as an alternative for enzymatic inactivation (Abid et al., 2015; Illera et al., 2018b), as well as Pulsed Electric Fields (Aguiló-aguayo et al., 2009; Yang et al., 2004).

Plasma is known as the fourth state of matter, consisting of an ionized gas composed of electrons, ions, radicals and atoms which are both in ground and excited states (Tappi et al., 2014) and is considered a promising non thermal process technology. Plasma can be generated in any neutral gas by providing enough energy for its ionization (Pankaj \& Keener, 2017b). Cold plasma is generated at $30-60{ }^{\circ} \mathrm{C}$ and it does not present thermodynamic equilibrium (Coutinho et al., 2018). 
Some advantages of this technology are short treatment times and reduced thermal effects, which makes it suitable for treating heat sensitive food (Mandal et al., 2018). When air is used as working gas, the formation of reactive oxygen species (ROS) and reactive nitrogen species (RNS) occurs, and they can interact with different compounds present in the food, altering their properties (Ramazzina et al., 2016). Very few studies have evaluated or understood the effect of cold plasma on enzymatic inactivation. Furthermore, existing studies were mainly focused on solid foods, specially fruits such as tomato (Ma et al., 2015; Misra et al., 2014), kiwifruit (Ramazzina et al., 2015) or melon (Tappi et al., 2016), although treatment of fruit juices is starting to be more common, including apple juice (Liao et al., 2018, 2017; Rodríguez et al., 2017; Surowsky et al., 2014).

Thus, we addressed the gap identified in relation to quality retention of high value fresh cloudy apple juice and optimized a cold plasma process using air as the inducer gas. A custom built system that allows control of key plasma reactive species through changing mode of discharge was employed. Direct treatment to liquid was employed, and two different discharges modes were used, corona glow discharge and spark discharge, for comparing their effect on PPO inactivation. The effect of cold plasma on inactivation of enzymes depends on gas composition, electrical input, exposure mode, treatment time and food composition (Coutinho et al., 2018; Liao et al., 2017). In the present study, these variables were studied for PPO inactivation in cloudy apple juice with quality parameter responses of color, cloud stability, polyphenol content and antioxidant activity evaluated after plasma treatments and during 28 days of storage at $4{ }^{\circ} \mathrm{C}$, what up to the literature found in bibliography has not been carried out to the moment. 


\section{Materials and methods}

\subsection{Sample preparation}

\subsubsection{Cloudy apple juice}

Golden delicious apples were peeled and cut in cubes. To avoid enzymatic browning during processing, apple cubes were submerged in a $0.3 \%$ of L-ascorbic acid solution during 5 minutes and then they were wiped and immediately squeezed with a juicer (Breville JE3). The juice was filtered and analyzed right after preparation and it was considered as untreated sample (control). Cloudy apple juice was stored frozen $\left(-18^{\circ} \mathrm{C}\right)$ in $25 \mathrm{ml}$ tubes until required.

\subsubsection{Pure PPO solution}

In order to compare PPO inactivation between a pure enzymatic solution and in apple juice, a pure polyphenol oxidase solution was prepared. The enzyme used was tyrosinase from mushroom (Sigma-Aldrich ${ }^{\circledast}$ ). Following the manufacturer's recommendation, the enzyme was diluted in a $0.1 \mathrm{M}$ sodium phosphate buffer $\mathrm{pH}=6.5$ (enzyme optimum $\mathrm{pH}=6-7$ ). Final enzyme concentration was $0.04 \mathrm{mg} / \mathrm{ml}$. Activity of PPO was measured right after preparation and considered as untreated sample. Enzyme solution was frozen until further use $\left(-18^{\circ} \mathrm{C}\right)$.

\subsection{Cold plasma treatments}

Two types of electrical discharge configuration were investigated in order to compare their effect on PPO inactivation on cloudy apple juice. Namely spark and glow discharge, both treatments are direct cold plasma treatments, and mechanisms are similar but present some differences. When glow discharge is used, usually short time treatment or pulses are used for maintaining the stability of the discharge. According to Shao et al. 
(Shao et al., 2013), when treatment time is increased, the transition to a spark discharge occurs, being this one more instable. The main difference between these discharges is the way in which plasma channels are described. In a spark mode, the gas gap is bridged by a large current, and in the glow mode, a diffuse discharge is observed. In both setups, described elsewhere (Lu et al., 2017), a stainless-steel needle served as the high voltage (HV) electrode and was fixed perpendicular to the apple juice surface. The distance between the HV needle tip and the juice surface was fixed to $5 \mathrm{~mm}$ in all experiments. For each treatment of the juice or model enzyme solution, $10 \mathrm{ml}$ of the liquid sample were accurately added into a plastic petri dish (55 $\mathrm{mm}$ inner dimeter) via a pipette, which corresponded to a liquid layer of about $4.2 \mathrm{~mm}$ depth. To carry out the different discharge modes, the ground electrode connection was adjusted in two setups. For spark discharge, the plastic petri dish was placed on a stainless-steel plate which was connected to the ground; for glow discharge a thin ground electrode rod was submerged into juice contained in the petri dish. Both discharges were operated in open air. The light from the plasma discharges was focused by a fiber optic lens mounted on a post placed at an angle of $45^{\circ}$ with respect to the $\mathrm{HV}$ electrode axis.

The effect of input power in spark discharge was evaluated in apple juice using a voltage range from 7.9375 to $10.875 \mathrm{kV}$ to determine the optimum voltage. Using the optimum voltage, the effect of treatment time was then also studied from 1 to 5 minutes in both cloudy apple juice and in pure enzyme solution. Measurement of PPO activity and physical-chemical analysis of samples were carried out immediately after each treatment.

\subsection{Physical-chemical analysis}

\subsubsection{Determination of polyphenol oxidase (PPO) activity}

The activity of PPO was determined spectrophotometrically. It was analyzed by mixing $100 \mu \mathrm{l}$ of sample with $2.9 \mathrm{ml}$ of substrate solution, which was a $0.05 \mathrm{M}$ catechol (Sigma Aldrich ${ }^{\circledR}$ ) solution prepared in a $0.1 \mathrm{M}$ phosphate buffer $(\mathrm{pH} 6.5)$, which was kept at $30^{\circ} \mathrm{C}$ in a water bath. Oxidation of catechol was determined immediately by the increase of 
absorbance at $420 \mathrm{~nm}$ during 120 seconds by using a spectrophotometer (DR6000 Hach Lange). The solution of catechol was used as blank. PPO activity was taken as the very first linear part of the reaction curve (Illera et al., 2018a).

Relative residual activity of PPO was expressed as:

Residual activity $(\%)=\frac{\text { Enzyme specific activity in the processed juice }}{\text { Enzyme specific activity in the untreated juice }} \cdot 100$

\subsubsection{Determination of $\mathrm{pH}$, color and non-enzymatic browning}

pH of cloudy apple juice was determined with a pH-meter (Eutech ${ }^{\mathrm{TM}} \mathrm{pH} 700$ ) at room temperature $\left(21 \pm 1^{\circ} \mathrm{C}\right)$.

Color was measured at room temperature $\left(21 \pm 1^{\circ} \mathrm{C}\right)$ using an UltraScan PRO colorimeter (Hunterlab, Inc.). The observation angle was $10^{\circ}$, equal to the perception of a human observer, and illuminant D65 was used (daylight source), following the CIE recommendations. For calibration, a white reference standard was used before the measurements. An appropriate cell was filled with $20 \mathrm{ml}$ of cloudy apple juice and color was measured. Color parameters obtained were $L^{*}$ (lightness), $a^{*}$ (redness) and $b^{*}$ (yellowness) and the CIE $\mathrm{L}^{*}, \mathrm{a}^{*}, \mathrm{~b}^{*}$ parameters were used to report the total change in $\operatorname{color}(\Delta \mathrm{E})$ (Eq. 4.2).

$\Delta \mathrm{E}=\sqrt{\left(\mathrm{L}_{\text {untreated }}^{*}-\mathrm{L}_{\text {treated }}^{*}\right)^{2}+\left(\mathrm{a}_{\text {untreated }}^{*}-\mathrm{a}_{\text {treated }}^{*}\right)^{2}+\left(\mathrm{b}_{\text {untreated }}^{*}-\mathrm{b}_{\text {treated }}^{*}\right)^{2}}$

Depending on the value of $\Delta E$, differences in perceivable color can be analytically classified as very distinct $(\Delta E>3)$, distinct $(1.5<\Delta E<3)$ and small difference $(\Delta E<1.5)$ (Misra et al., 2014).

Non-enzymatic browning (NEB) was determined spectrophotometrically. For its determination, the method described by Queiroz et al. (2011) was applied with slight modifications; $0.7 \mathrm{ml}$ of apple juice was mixed with $0.7 \mathrm{ml}$ of ethanol in a $1.5 \mathrm{ml}$ Eppendorf tube. The mixture was centrifuged at $12000 \mathrm{~g}$ for $10 \mathrm{~min}$ (Legend Micro 21R, 
Thermo Scientific $\left.{ }^{\mathrm{TM}}\right)$. Supernatant was recovered and $1 \mathrm{ml}$ was mixed with $1 \mathrm{ml}$ of a trichloroacetic acid solution (734 $\mathrm{mM}$ ) and $1 \mathrm{ml}$ of a thiobarbituric acid solution ( $25 \mathrm{mM})$. Samples were incubated at $40{ }^{\circ} \mathrm{C}$ during $50 \mathrm{~min}$, and then, absorbance was measured at $443 \mathrm{~nm}$ at room temperature $\left(21 \pm 1^{\circ} \mathrm{C}\right)$. A blank was also prepared with distilled water instead of juice. Non enzymatic browning of juice was expressed as the absorbance value at $443 \mathrm{~nm}$.

2.3.3 Determination of cloud value, cloud stability and particle size distribution (PSD)

Cloud value was measured according to the method described by Versteeg et al (Versteeg et al., 1980) with slight modifications. $4 \mathrm{ml}$ of juice were centrifuged at $760 \mathrm{~g}$ during 10 minutes in a thermostatic centrifuge at $4{ }^{\circ} \mathrm{C}$, then the supernatant was collected and its absorbance was measured at $660 \mathrm{~nm}$.

Cloud stability was determined using the method of Ertugay and Baslar (2014). $4 \mathrm{ml}$ of juice were centrifuged at $4200 \mathrm{~g}$ for 15 minutes, and the absorbance of the supernatant was measured at $625 \mathrm{~nm}$. Cloud stability was calculated according to Eq. 4.3:

$\operatorname{CS}(\%)=\frac{A_{c}}{A_{0}} * 100$

Where $A_{c}$ and $A_{0}$ are the absorbance after and before centrifugation respectively. In both determinations, a spectrophotometer (DR6000 Hach Lange) was used for the measurements and distilled water was used as blank.

Particle size distribution (PSD) was determined by laser diffraction with a Mastersizer Hydro-2000S (Malvern ${ }^{\circledR}$ Inst., MA). The system uses a laser light to size particles from 0.02 to $2000 \mu \mathrm{m}$ by light diffraction. Particle size distribution was calculated by the Fraunhofer model. Size distributions (volume fractions against particle size) were calculated and the weight-average sizes expressed as:

The equivalent surface area mean diameter: $\mathrm{D}(3,2)=\sum \mathrm{n}_{\mathrm{c}} \mathrm{d}_{\mathrm{lc}}^{3} / \sum \mathrm{n}_{\mathrm{c}} \mathrm{d}_{\mathrm{lc}}^{2}$ 
The equivalent volume mean diameter: $\mathrm{D}(4,3)=\sum \mathrm{n}_{\mathrm{c}} \mathrm{d}_{\mathrm{lc}}^{4} / \sum \mathrm{n}_{\mathrm{c}} \mathrm{d}_{\mathrm{lc}}^{3}$

where $d_{l c}$ is the diameter of the particle and $n_{c}$ is the percentage of particles.

The Span value was also evaluated:

Span $=\frac{d_{\mathrm{v}, 0.9}-d_{\mathrm{v}, 0.1}}{d_{\mathrm{v}, 0.5}}$

where $d_{v, 0.9}, d_{v, 0.1}$ and $d_{v 0.5}$ are the particle size bellow which, $90 \%, 10 \%$ and $50 \%$ of the particles lies respectively, and it describes distribution width.

\subsubsection{Determination of total phenolic content and antioxidant capacity}

Total phenolic content (TPC) was determined by using the Folin-Ciocalteau method. First, $100 \mu \mathrm{l}$ of juice were mixed with $2.8 \mathrm{ml}$ of water and subsequently with $100 \mu \mathrm{l}$ of the FolinCiocalteau reagent (VWR), in that order. After that, $2 \mathrm{ml}$ of sodium carbonate $7.5 \%(\mathrm{w} / \mathrm{v})$ were added to the mixture and the reaction immediately started. Color was measured spectrophotometrically at $750 \mathrm{~nm}$ after $60 \mathrm{~min}$ of reaction at room temperature $\left(21 \pm 1^{\circ} \mathrm{C}\right)$. A blank was also prepared using water instead of juice. Total phenolic content retention of juice was expressed as:

Total phenolic content retention $(\%)=\frac{A b s(750 \mathrm{~nm}) \text { in the treated juice }}{A b s(750 \mathrm{~nm}) \text { in the untreated juice }} \cdot 100$

Antioxidant capacity was determined by the DPPH assay. It is based on the discoloration of the radical 2,2-diphenil-1-picrylhydrazyl, which occurs in presence of an oxidant agent. DPPH was prepared in advance, consisting of $50.7 \mu \mathrm{M}$ DPPH in methanol and kept in the dark for a minimum of 4 hours before use. For the antioxidant test, juice samples were diluted 1:10 with deionized water. The reaction took place when $300 \mu$ of diluted cloudy apple juice were mixed with $3 \mathrm{ml}$ of DPPH solution. Absorbance was measured at $517 \mathrm{~nm}$ at room temperature after 60 minutes of reaction in the dark. Results were expressed as inhibition percentage of the radical. 


\subsection{Shelf life study}

Physical-chemical parameters and PPO activity were analyzed in apple juice directly after cold plasma treatments. Then, they were stored at $4{ }^{\circ} \mathrm{C}$ and periodically analyzed every 7 days up to 28 days to determine their evolution. PPO activity of pure enzyme solution was studied immediately after the treatments and 24 hours later $\left(4^{\circ} \mathrm{C}\right)$.

\subsection{PPO inactivation kinetics}

Different kinetic models were tested to fit the evolution of the residual enzymatic activity as a function of time:

\subsubsection{Weibull model}

The non-linear Weilbull model can be written in the power-law form as (Boekel, 2002):

$\log _{10}\left(\frac{A}{A_{0}}\right)=-b t^{n}$

where $A_{0}$ is the initial activity of the enzyme, $A$ is the residual activity at different treatment times, $\mathrm{b}$ is the non-linear rate parameter and $\mathrm{n}$ is the shape factor.

\subsubsection{Two-fraction kinetic model}

This model takes into account the existence of several isoenzymes of PPO in apple juice, grouped into two fractions, a labile and a stable fraction. Both enzymes were considered to be inactivated according to first-order kinetics, but independently of each other (Briongos et al., 2016):

$A=A_{L} \exp \left(-k_{L} t\right)+A_{S} \exp \left(-k_{S} t\right)$ 
where $A_{L}$ and $A_{S}\left(A_{S}=1-A_{L}\right)$ are the activity of the labile and stable fractions respectively and $k_{L}$ and $k_{S}\left(\min ^{-1}\right)$ the inactivation rate constants of both the labile and stable fractions respectively.

\subsection{Statistical analysis}

All analysis were conducted using software Statgraphics X64. The results are presented as a mean \pm standard deviation of at least three replicates. The significance of the differences was determined based on an analysis of the variance with the Tukey's honestly significant difference (HSD) method at $p$-value $\leq 0.05$.

To estimate the kinetic parameters for the different models tested in this work, non-linear regression was performed by using the Marquardt algorithm (Statgraphics X64). The mean relative deviation (MRD) between experimental and calculated residual activities was also evaluated:

$M R D=\frac{1}{n}\left(\sum_{\text {all samples }}\left|\frac{R A_{\text {calc }}-R A_{\text {exp }}}{R A_{\text {exp }}}\right|\right) * 100$

\section{Results and discussion}

\subsection{Effect of plasma treatment on PPO activity}

After preliminary studies using PPO inactivation as the indicator, spark discharge mode was found to be more effective for PPO inactivation of cloudy apple juice than glow discharge configuration. No significant difference was found after 1 minute of treatment, since RA was $85.9 \pm 1.4$ and $82.9 \pm 3.7$ after glow and spark treatments respectively, but after a treatment of 5 minutes the difference was much higher, being in this case RA $55.5 \pm 2.5$ and $16.6 \pm 2.2$. This difference can be explained because spark discharge energy efficiency is much higher than in corona discharge (Gao et al., 2018), what would affect in a higher level to PPO, due to the higher energy applied. Also Lu et al. (Lu et al., 2017) 
explained that in a spark discharge, a higher concentration of $\mathrm{H}_{2} \mathrm{O}_{2}$ and $\mathrm{NO}_{3}{ }^{-}$was produced than in glow discharge, what would produce a higher enzyme inactivation due to the inactivation effect of these species (Illera et al., 2018b). Therefore, the following experiments were performed using the spark discharge mode.

\subsubsection{Effect of input power}

The effect of input power (voltage and frequency) was the first variable evaluated. Eight different spark plasma treatments using voltages values from 7.9375 to $10.875 \mathrm{kV}$ were carried out, with treatment times of 5 minutes. PPO residual activity for each treatment is presented in Figure 4.1a Higher input voltage is linearly related to greater inactivation efficacy of Cold Plasma on PPO (PPO residual activity $=-23.871 \cdot$ Voltage +267.15 ; $\left.\mathrm{R}^{2}=0.9905\right)$. Although the highest voltage applied $(10.875 \mathrm{kV})$ produced the best inactivation results, reaching a final residual activity of $6 \pm 5 \%$, it was not significantly different to the one obtained at $10.5 \mathrm{kV}(16 \pm 0.8 \%)$ at $p$-value $\leq 0.05$. Temperatures of the juices after the treatments were 41 and $50{ }^{\circ} \mathrm{C}$ for 10.5 and $10.875 \mathrm{kV}$ respectively, therefore, $10.5 \mathrm{kV}$ was chosen as the best input voltage for the following experiments.

\subsubsection{Effect of treatment time}

As can be observed in Figure 4.1b, increasing treatment time increases PPO inactivation. Best results were found after longer treatment times, where final PPO activity in cloudy apple juice was $27.6 \pm 2.9$ and $16 \pm 0.8 \%$ after 4 and 5 minutes respectively, although this difference is significant. When treatment time increased, an increase in the final temperature of the juice was also observed (Figure 4.1b). In order to know if the higher inactivation at longer treatment times was attributable to this increase in temperature, independent heating treatments were also performed on apple juice. No inactivation was observed after heat treatments in the time range from 1 to 5 minutes; however, some enzyme activation was observed, so it can be concluded that inactivation of the enzyme was due to the effects of plasma treatment. 

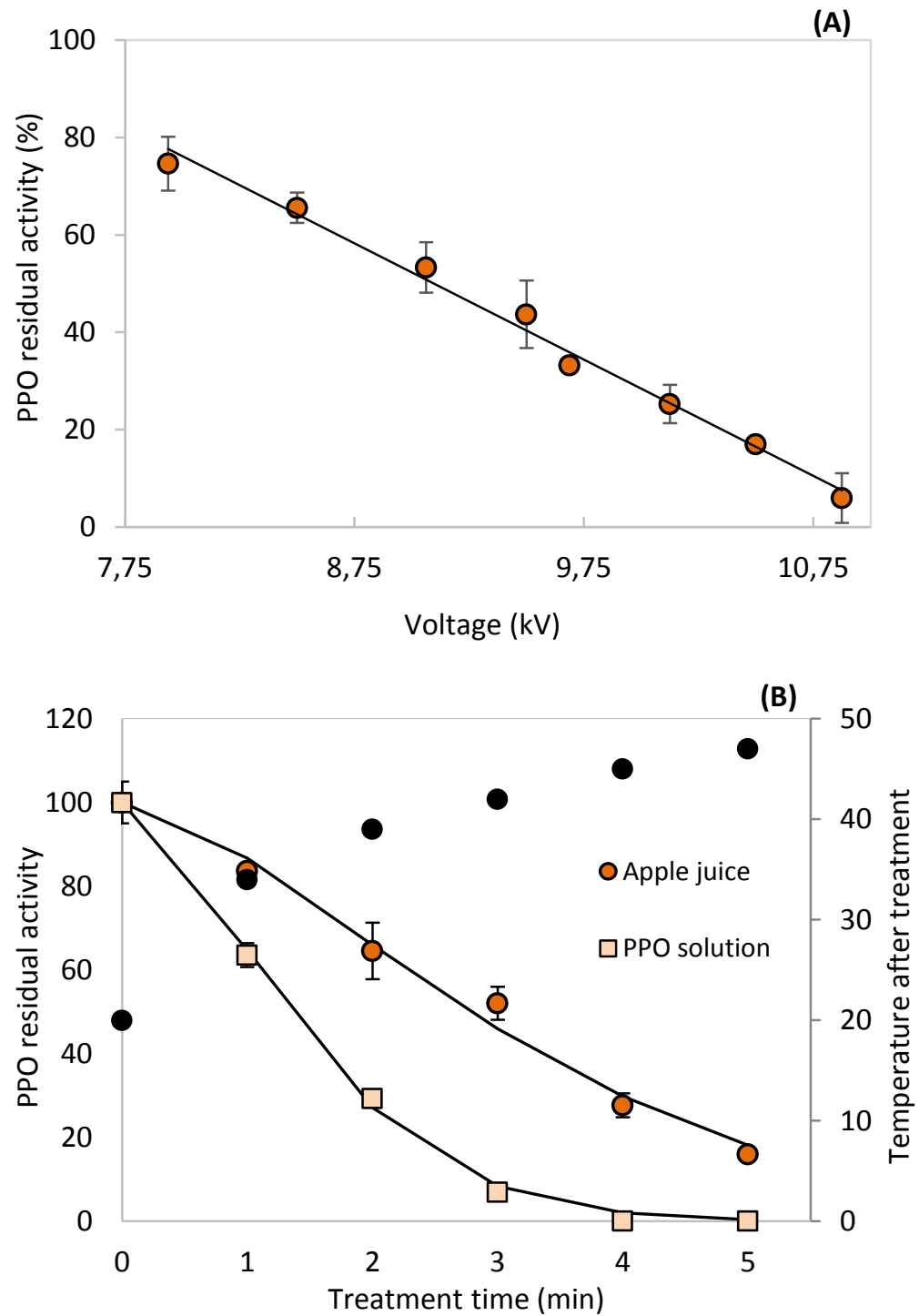

Figure 4.1 Effect of (a) input voltage. Continuous line represents linear adjustment (b) treatment time on PPO inactivation of cloudy apple juice and PPO solution $(\mathrm{pH}=6.5)$ after plasma treatment. Continuous line represents Weibull model (Apple juice $R^{2}=98.9 ;$ PPO solution $R^{2}=99.8$ ). Filled spots represent final temperature after plasma treatments.

Tappi et al. (2014) treated fresh-cut apples using Dielectric Barrier Discharge (DBD) plasma, and observed that increasing treatment time significantly decreased PPO activity, where after 10 minutes treatment, residual activity of PPO was still $88 \%$, which decreased to $42 \%$ after 30 minutes treatment. In comparison, in the present study, higher PPO 
inactivation and in significantly less time was achieved by the use of spark plasma. Pankaj et al. (2013) studied the kinetics of isolated tomato peroxidase inactivation by in package DBD plasma, where they obtained low inactivation after 1 minute of treatment (30\%) and nearly total inactivation after 3 minutes.

In the present study, different treatment times were also applied on pure enzyme solution $(\mathrm{pH}=6.5)$, and the same trend was observed (Figure $\mathbf{4 . 1 b})$, but in this case, total inactivation was reached after 4 minutes of plasma treatment, and higher inactivation rates were observed, showing that inactivation is easier and faster when enzyme was isolated than when it was present in a complex food matrix. For both cloudy apple juice and the pure enzyme solution data, the Weibull model fitted very well (for apple juice: $b=3.5 \pm 0.1, n=1.5 \pm 0.2, R^{2}=98.9$; for pure PPO solution: $b=1.7 \pm 0.1, n=1.6 \pm 0.1$, $\left.R^{2}=99.8\right)$. It can be seen that the shape value, $n$, is very similar in both samples, but $b$, value of pure PPO solution, is the half of the value for apple juice, due to higher inactivation rates. Surowsky et al. (2013) also treated polyphenol oxidase (PPO) from mushroom and they observed that its inactivation depended greatly on the plasma exposure time. Inactivation kinetics were very similar to the ones of the present study, after 4 minutes of treatment, final residual activity was around $90 \%$, although they employed argon as working gas. Employing air as a working gas provides ease of operation and cost effectiveness to the process.

\subsubsection{PPO activity during storage}

Treated apple juices were stored during 28 days at $4{ }^{\circ} \mathrm{C}$, and PPO activity was measured just after the treatment and $24 \mathrm{~h}$ later, and then weekly for up to four weeks. During the first day of storage, a significant decrease in PPO activity was observed. Juice that had been treated for just one minute experienced a decrease from $83.7 \pm 0.5$ to $35.6 \pm 0.8 \%$ of residual PPO activity after only $24 \mathrm{~h}$ storage. Juice that had been treated for 4 or 5 minutes had minimal PPO activity $24 \mathrm{~h}$ post treatment, and no residual activity was found after 7 days up to the end of the storage study (Figure 4.2a). 

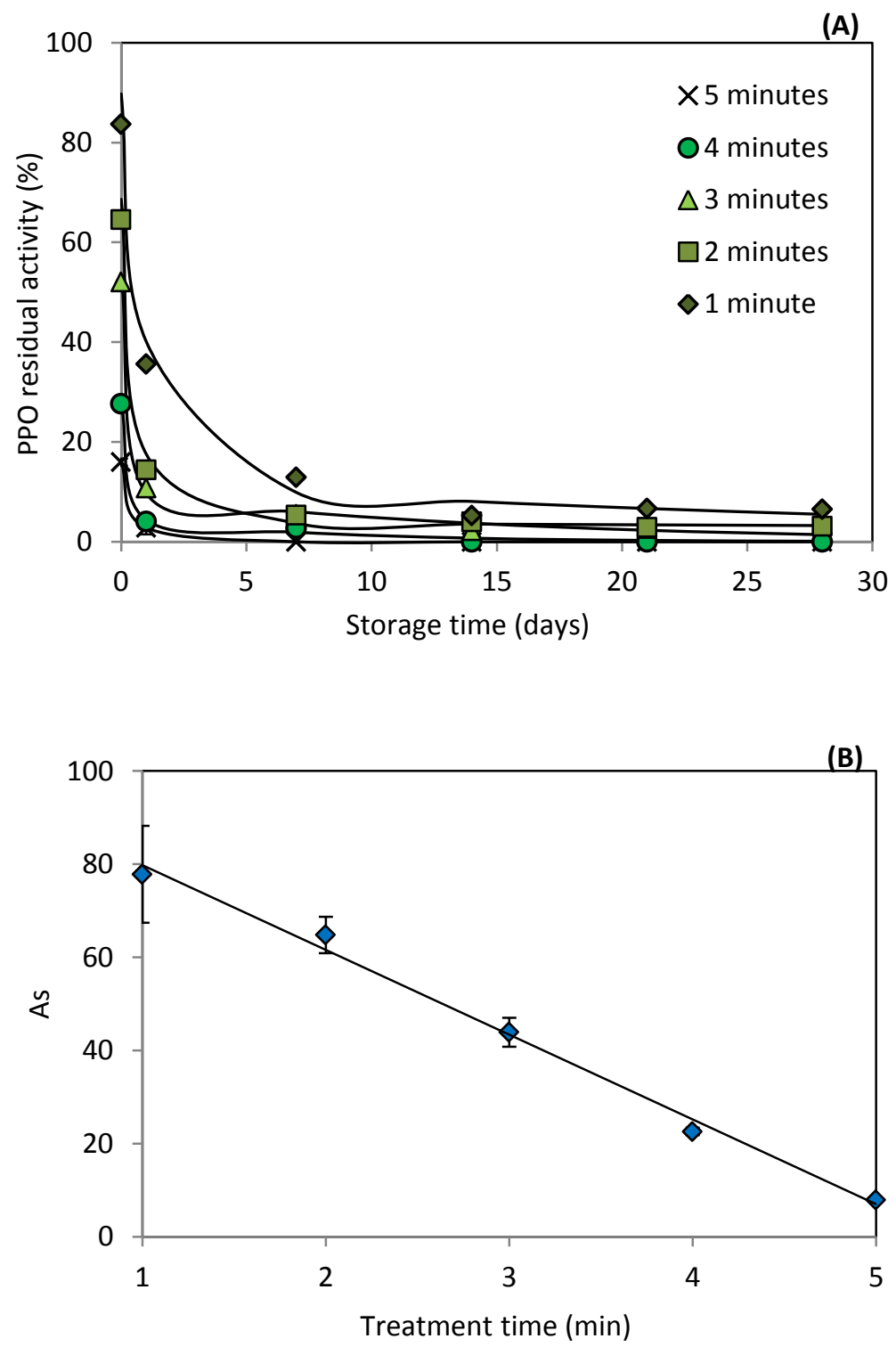

Figure 4.2 (a) PPO residual activity in cloudy apple juice just after different plasma treatments of $1,2,3,4$ and 5 minutes and during storage at $4{ }^{\circ} \mathrm{C}$. Solid symbols represent the experimental inactivation values obtained, and continuous lines represent the two fraction kinetic model data, (b) $A_{s}$ values from the two fraction kinetic model after different treatment times. Continuous line represents linear adjustment. 


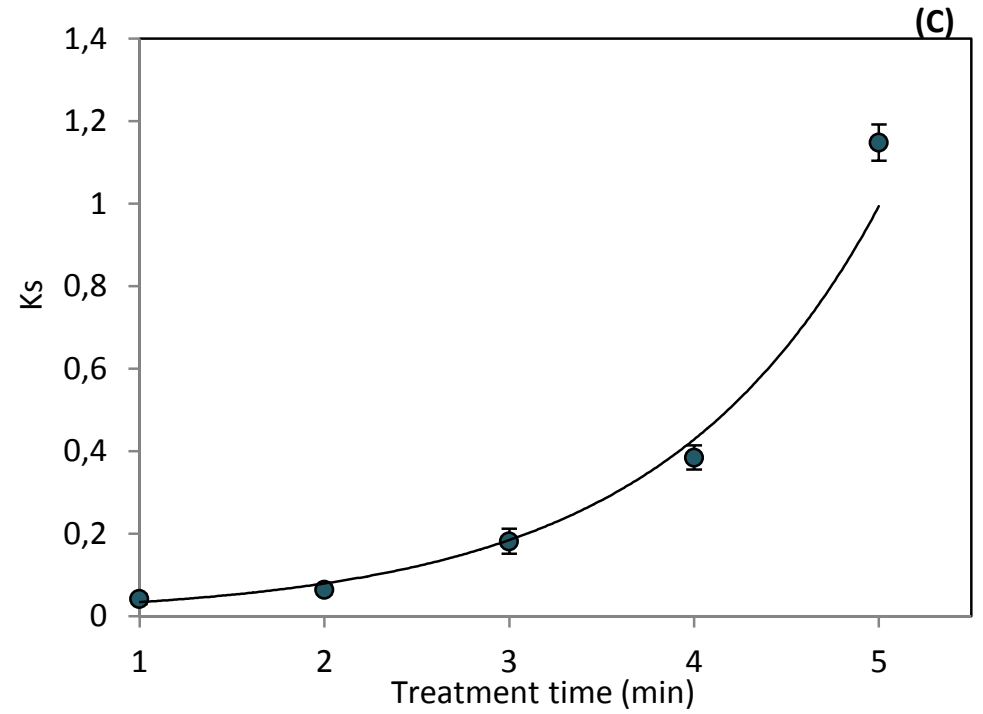

Figure 4.2 (c) $\mathrm{K}_{\mathrm{s}}$ values from the two fraction kinetic model after different treatment times. Continuous line represents exponential adjustment.

Table 4.1 Weibull and two-fraction kinetic model parameters for different treatment time PPO kinetics of cloudy apple juice during storage.

\begin{tabular}{ccccccc}
\hline & Parameter & $\mathbf{1}^{\prime}$ & $\mathbf{2}^{\prime}$ & $\mathbf{3}^{\prime}$ & $\mathbf{4}^{\prime}$ & $\mathbf{5}^{\prime}$ \\
\hline $\begin{array}{c}\text { Weibull } \\
\text { model }\end{array}$ & $\mathbf{b}$ & $25.1 \pm 4.1$ & $17.7 \pm 1.8$ & $10.9 \pm 2.3$ & $4.9 \pm 0.8$ & $5.9 \pm 0.3$ \\
& $\mathbf{n}$ & $3.4 \pm 2.6$ & $1.4 \pm 0.2$ & $0.7 \pm 0.1$ & $0.5 \pm 0.1$ & $0.4 \pm 0.1$ \\
& $\mathbf{R}^{2}$ & 95.6 & 98.7 & 96.8 & 97.9 & 99.9 \\
\hline $\begin{array}{c}\text { Two- } \\
\text { fraction } \\
\text { kinetic } \\
\text { model }\end{array}$ & $\mathbf{A}_{\mathbf{L}}$ & $11.9 \pm 10.2$ & $3.9 \pm 3.7$ & $9.8 \pm 2.6$ & $5.0 \pm 0.6$ & $8.0 \pm 0.1$ \\
& $\mathbf{k}_{\mathrm{L}}$ & $1.2 \cdot 10^{-3} \pm$ & $2.6 \cdot 10^{-4} \pm$ & $2.9 \cdot 10^{-3} \pm$ & $5.7 \cdot 10^{-3} \pm$ & $4.3 \cdot 10^{-2} \pm$ \\
& $2.5 \cdot 10^{-3}$ & $2.1 \cdot 10^{-4}$ & $1.4 \cdot 10^{-4}$ & $1.5 \cdot 10^{-3}$ & $1.1 \cdot 10^{-3}$ \\
& $\mathbf{K}_{\mathbf{S}}$ & $0.042 \pm$ & $0.064 \pm$ & $0.2 \pm 0.03$ & $0.4 \pm 0.03$ & $1.1 \pm 0.05$ \\
& $\mathbf{R}^{2}$ & 0.012 & 0.011 & & & \\
\hline
\end{tabular}


No reactivation was observed in any of the treated juices over the storage trial as well as in the pure PPO solution, although this one was only measured until $24 \mathrm{~h}$ after treatment. After $24 \mathrm{~h}$ post treatment, there was still residual activity in the juices that had been treated for 1, 2 and 3 minutes, but this was very low, e.g. residual activity in the 2 minutes treated juice changed from $64.5 \pm 2.8$ just after the treatment to $14.4 \pm 0.6$ after 24 hours of storage. Many studies propose that enzymatic inactivation by plasma treatments is produced by ROS (Reactive Oxygen Species) and RNS (Reactive Nitrogen Species) formed, and their effect on conformational changes and structure changes of the enzyme (Misra et al., 2016; Surowsky et al., 2013; Takai et al., 2012). Although formation of these species has not been studied during storage time, according to Surowsky et al. (2014), $\mathrm{H}_{2} \mathrm{O}_{2}$ formed during plasma treatment and in container during storage time has a longer halflife than other reactive species, and could remain active in the treated juice post plasma treatment, which could cause a further inactivation of PPO in the juice during prolonged storage. PPO residual inactivation kinetics during storage was fitted to the Weibull and to the two fractional kinetic models (Table 4.1). Inactivation data during storage fitted quite well to both models, although the two fractional kinetic model fitted better, especially for short plasma treatments. At the one minute plasma treatment time, inactivation kinetic data fitting during storage was $R^{2}=95.6$ for the Weibull model and $R^{2}=98.6$ for the two fraction one (Table 4.1).

The activity $\left(A_{S}\right)$ and the inactivation rate constant $\left(K_{S}\right)$ of the stable fraction of the enzyme showed a decrease and increase, respectively, when increasing treatment time, and are plotted in Figure $\mathbf{4 . 2 b}$ and $\mathbf{4 . 2 c}$. As can be observed, the activity of the stable fraction of PPO decreased linearly $\left(A_{S}=-18.2 \cdot\right.$ treatment time $\left.+98 ; R^{2}=0.9934\right)$ when treatment time was increased, decreasing from $77.8 \pm 10.4$ ( 1 minute treatment) to $7.9 \pm 0.1 \%$ (5 minutes treatment). In the same way, the constant that refers to the inactivation rate of the enzyme increased after longer treatments, showing a noticeable increase after 5 minutes of treatment (Figure 4.2c). 


\subsection{Effect of spark plasma on physical-chemical properties of the} juice

\subsection{1 pH, color and non-enzymatic browning}

A significant decrease in the $\mathrm{pH}$ value of all the plasma treated samples was observed, and this decreasing trend was aligned to treatment time. After 4 and 5 minutes of treatment, $\mathrm{pH}$ changed from 3.73 to 3.58 and 3.59 respectively (Table 4.2). After 28 days of storage, the $\mathrm{pH}$ value of the juice was similar to that measured immediately after the treatment. After a DBD treatment of just 2 minutes, Xiang et al. (2018) found that $\mathrm{pH}$ of commercial apple juice decreased from $3.96 \pm 0.01$ to $3.34 \pm 0.01$. Liao et al. (2018) also observed a pH decrease after a $30 \mathrm{kV}$ DBD treatment, where $\mathrm{pH}$ of commercial apple juice changed from approximately 3.71 to 3.66 after just 40 seconds of treatment. Thirumdas et al. (2018) explained that this effect is produced due to the formation of chemical species by the action of plasma, such as hydrogen peroxides, that contribute to the acidity of liquid samples.

Color parameters of different samples are plotted in Figure 4.3. Total change in color $(\Delta E)$ has been calculated (Eq. 4.2) and is also represented. This value is the total change in color between the treated samples during storage compared to the untreated juice. After plasma treatment, significant changes in color parameters can be observed depending on the duration of the treatment applied to each juice. Lightness $(L)$ of the juice only decreased after 1 minute of plasma treatment, and after longer treatments, this value was maintained and even increased in juice treated for 4-5 minutes. The optimal value was obtained after the 5 minutes treatment, where $L$ value significantly increased from $39.5 \pm 0.1$ (untreated sample) to $43.9 \pm 0.6$, and, although this value was not maintained over storage, it was still higher than the value in the untreated juice, at $40.3 \pm 0.4$ after 21 days. Similar values can be seen for the 4 minute treated sample. In untreated and 1 minute treated samples lightness of the juice significantly decreased during storage time, pointing that juice had suffered severe browning, which could also be probed visually. Another important value related to browning in the juice is redness ( $a^{*}$ value), and 
usually, an increase in this value is related to browning. In Figure 4.3b, the difference of this value between different treated samples is evident, the longer the plasma treatment, the lower the value, which means that the juice has gone to a greener color and has not browned. During storage this value increased in all the samples, but at the highest treatment times it was more or less constant over storage. This value is correlated with the $b^{*}$ values obtained, indicating that the longer the plasma treatment, the higher yellowness the juice, and the values were generally maintained during storage (Figure 4.3c). With the changes observed in color parameters, it can be said that plasma treatment effect on color is treatment time dependent, and the best results for color quality were obtained at 4 and 5 minutes treatment were juice is more green and yellow, and lightness increased. In Figure 4.3d, total color change of the samples is represented, and it can be clearly seen that juices with longer treatments suffered a bigger change after the treatment due to lightening, but stability was maintained during the storage. In all cases, $\Delta \mathrm{E}$ value during storage was higher than 3 , so the change in color was very distinct (Misra et al., 2014), and clearly appreciable visually. No studies of the effect of plasma on color of fresh juice have been found in the literature, but there are some studies of color changes on commercial apple juices after plasma treatments (Dasan \& Boyaci, 2018; Liao et al., 2018). In these studies, apple juice was treated during very short times (2 minutes or lower) with a plasma jet device and DBD plasma respectively. After both treatments, juice was brown due to an increase in $a^{*}$ and $b^{*}$ values and a decrease in lightness. Also total color change was higher than that obtained in this work. It can be observed that spark plasma discharge using air, and the associated chemistry has a better effect on the color properties of the juice than other plasma devices. 
$\square$ Untreated $\square 1$ minute $\square 2$ minute $\square 3$ minute $\square 4$ minute $\square 5$ minute
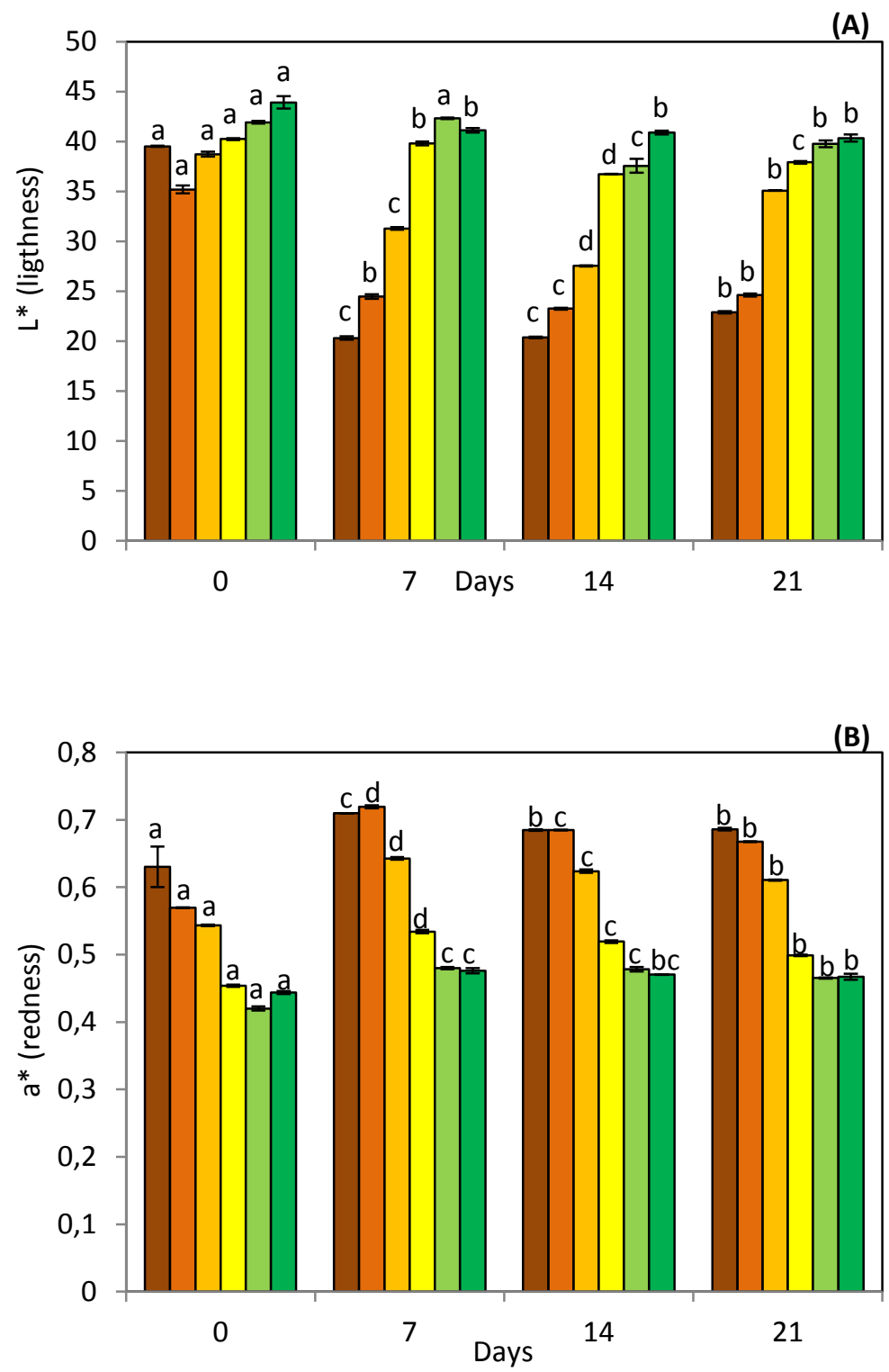

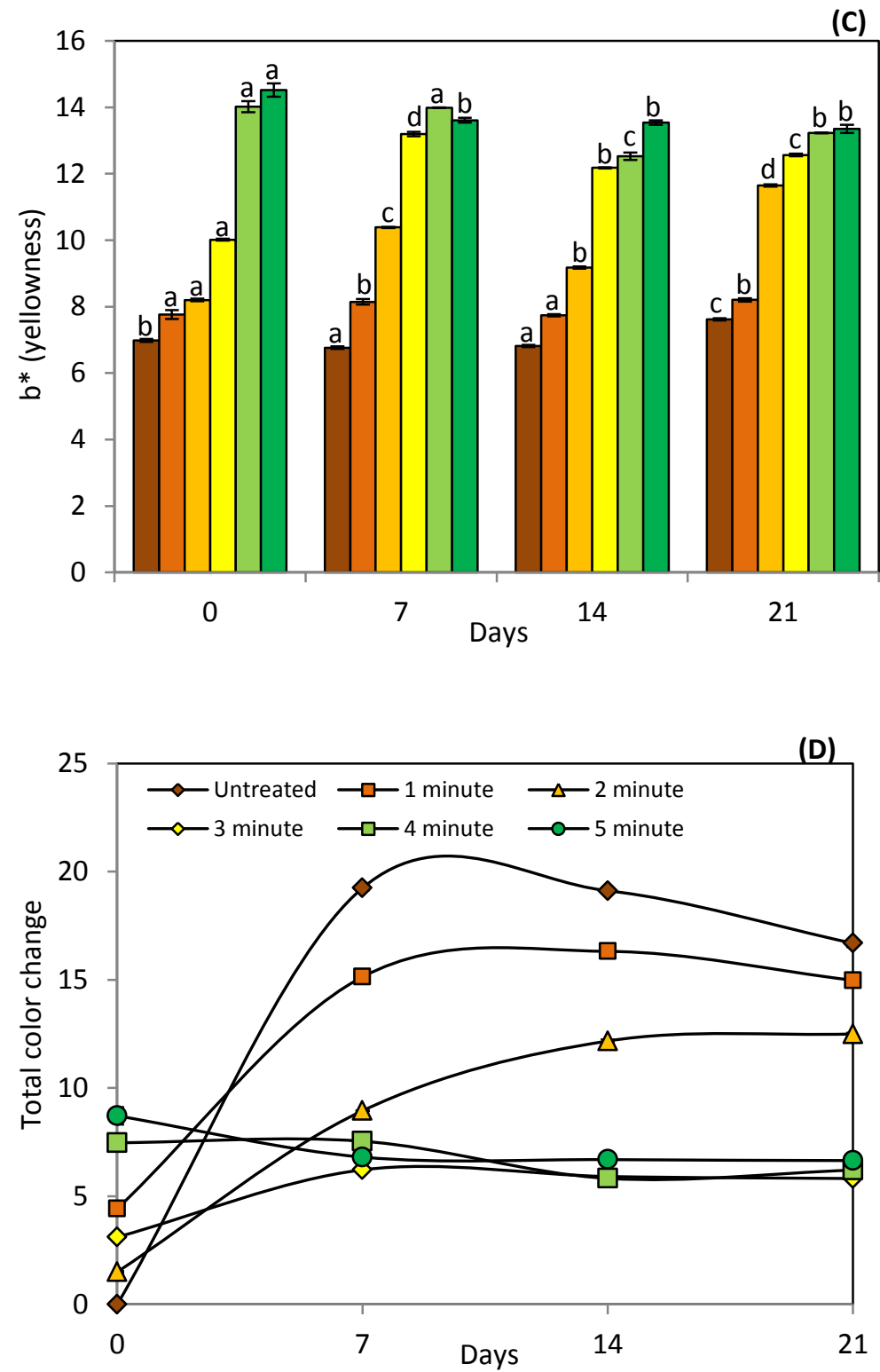

Figure 4.3 Color parameters (a) $\mathrm{L}^{*}$ (b) $\mathrm{a}^{*}$ and (c) b* of untreated samples and plasma treated samples after $1,2,3,4,5$ minutes and during storage at $4{ }^{\circ} \mathrm{C}$ for 21 days. Values with different letters in each figure are significantly different for each treatment time when applying the Tukey's honestly significant difference (HSD) method at $p$-value $\leq 0.05$. (d) Total color change during storage of untreated juice and after plasma treatment of 1 , 2, 3, 4 and 5 minutes. 
Table 4.2 Non enzymatic browning (NEB), cloud value, cloud stability (\%), pH, total polyphenolic content retention (\%) and DPPH (\% inhibition) values of apple juice after plasma treatment (AT) at $10.5 \mathrm{kV}$ during 5 minutes and during storage at $4{ }^{\circ} \mathrm{C}$.

\begin{tabular}{|c|c|c|c|c|c|c|c|}
\hline Sample & Time (days) & $\mathrm{pH}$ & NEB & Cloud value & Cloud stability & TPC & DPPH \\
\hline \multirow{5}{*}{ Untreated juice } & AT & $3.73 \pm 0.00^{b}$ & $0.12 \pm 0.01^{\mathrm{a}}$ & $0.44 \pm 0.02^{\mathrm{a}}$ & $8.57 \pm 0.10^{\mathrm{a}}$ & $100 \pm 7^{\mathrm{a}}$ & $79.4 \pm 0.8^{\mathrm{a}}$ \\
\hline & 7 & $3.76 \pm 0.01^{\mathrm{a}}$ & $0.09 \pm 0.01^{b}$ & $0.38 \pm 0.01^{b}$ & $8.33 \pm 0.19^{\mathrm{a}}$ & $88 \pm 5^{b}$ & $57.2 \pm 0.3^{b}$ \\
\hline & 14 & $3.76 \pm 0.01^{\mathrm{a}}$ & $0.10 \pm 0.01^{\mathrm{ab}}$ & $0.31 \pm 0.01^{c}$ & $5.72 \pm 0.05^{b}$ & $96 \pm 1^{\mathrm{ab}}$ & $58.5 \pm 0.5^{b}$ \\
\hline & 21 & $3.69 \pm 0.01^{c}$ & $0.10 \pm 0.01^{\mathrm{ab}}$ & $0.32 \pm 0.01^{c}$ & $5.60 \pm 0.04^{b}$ & $90 \pm 3^{\mathrm{ab}}$ & $61.6 \pm 3.5^{b}$ \\
\hline & 28 & $3.70 \pm 0.01^{c}$ & - & $0.30 \pm 0.01^{c}$ & $3.25 \pm 0.12^{c}$ & $86 \pm 3^{b}$ & - \\
\hline \multirow{5}{*}{1 minute treated } & AT & $3.69 \pm 0.00^{c}$ & $0.20 \pm 0.01^{a}$ & $0.37 \pm 0.01^{\mathrm{a}}$ & $8.83 \pm 0.15^{\mathrm{a}}$ & $111 \pm 10^{a}$ & $78.4 \pm 0.3^{a}$ \\
\hline & 7 & $3.74 \pm 0.01^{\mathrm{a}}$ & $0.14 \pm 0.01^{b}$ & $0.37 \pm 0.01^{\mathrm{a}}$ & $7.46 \pm 0.06^{b}$ & $101 \pm 3^{\mathrm{a}}$ & $60.0 \pm 0.1^{b}$ \\
\hline & 14 & $3.71 \pm 0.01^{b}$ & $0.13 \pm 0.01^{b}$ & $0.33 \pm 0.01^{b}$ & $5.18 \pm 0.10^{c}$ & $114 \pm 2^{\mathrm{a}}$ & $61.6 \pm 0.1^{b}$ \\
\hline & 21 & $3.66 \pm 0.01^{d}$ & $0.12 \pm 0.01^{b}$ & $0.07 \pm 0.01^{c}$ & $2.19 \pm 0.05^{d}$ & $101 \pm 4^{a}$ & $60.7 \pm 0.2^{b}$ \\
\hline & 28 & $3.67 \pm 0.01^{d}$ & - & $0.06 \pm 0.01^{c}$ & $1.88 \pm 0.03^{d}$ & $101 \pm 5^{\mathrm{a}}$ & - \\
\hline \multirow{5}{*}{2 minutes treated } & AT & $3.65 \pm 0.00^{b}$ & $0.23 \pm 0.01^{\mathrm{a}}$ & $0.31 \pm 0.01^{c}$ & $8.93 \pm 0.06^{\mathrm{a}}$ & $136 \pm 2^{b}$ & $85.0 \pm 0.2^{\mathrm{a}}$ \\
\hline & 7 & $3.70 \pm 0.01^{\mathrm{a}}$ & $0.13 \pm 0.01^{c}$ & $0.37 \pm 0.01^{\mathrm{a}}$ & $7.22 \pm 0.21^{b}$ & $134 \pm 5^{b}$ & $68.8 \pm 0.8^{b}$ \\
\hline & 14 & $3.68 \pm 0.01^{\mathrm{a}}$ & $0.16 \pm 0.01^{b}$ & $0.34 \pm 0.01^{b}$ & $5.47 \pm 0.17^{c}$ & $147 \pm 2^{a}$ & $68.9 \pm 1.1^{b}$ \\
\hline & 21 & $3.63 \pm 0.01^{c}$ & $0.13 \pm 0.01^{c}$ & $0.09 \pm 0.01^{d}$ & $2.04 \pm 0.04^{d}$ & $123 \pm 5^{c}$ & $68.1 \pm 0.1^{b}$ \\
\hline & 28 & $3.63 \pm 0.01^{c}$ & - & $0.06 \pm 0.01^{\mathrm{e}}$ & $1.16 \pm 0.03^{\mathrm{e}}$ & $124 \pm 1^{c}$ & - \\
\hline
\end{tabular}

Values with different letters in each column, and each treatment time (a,b) are significantly different when applying the Tukey's honest significant difference (HSD) method at $p$-value $\leq 0.05$ 
Table 4.2 Continued

\begin{tabular}{|c|c|c|c|c|c|c|c|}
\hline Sample & Time (days) & $\mathrm{pH}$ & NEB & Cloud value & Cloud stability & TPC & DPPH \\
\hline \multirow{5}{*}{3 minutes treated } & AT & $3.63 \pm 0.00^{c}$ & $0.23 \pm 0.01^{a}$ & $0.39 \pm 0.01^{c}$ & $8.12 \pm 0.05^{a}$ & $146 \pm 1^{a}$ & $92.9 \pm 0.3^{a}$ \\
\hline & 7 & $3.70 \pm 0.01^{a}$ & $0.14 \pm 0.01^{c}$ & $0.44 \pm 0.01^{\mathrm{a}}$ & $8.22 \pm 0.08^{\mathrm{a}}$ & $117 \pm 1^{c}$ & $74.2 \pm 0.9^{b}$ \\
\hline & 14 & $3.66 \pm 0.01^{b}$ & $0.18 \pm 0.01^{b}$ & $0.42 \pm 0.01^{b}$ & $6.98 \pm 0.20^{b}$ & $128 \pm 6^{b}$ & $74.5 \pm 1.2^{b}$ \\
\hline & 21 & $3.61 \pm 0.01^{d}$ & $0.15 \pm 0.01^{c}$ & $0.09 \pm 0.01^{d}$ & $2.26 \pm 0.05^{c}$ & $136 \pm 3^{b}$ & $72.0 \pm 0.4^{c}$ \\
\hline & 28 & $3.62 \pm 0.01^{c}$ & - & $0.05 \pm 0.01^{e}$ & $1.22 \pm 0.06^{d}$ & $135 \pm 4^{b}$ & - \\
\hline \multirow{5}{*}{4 minutes treated } & AT & $3.59 \pm 0.00^{c}$ & $0.22 \pm 0.01^{a}$ & $0.42 \pm 0.01^{\mathrm{a}}$ & $7.66 \pm 0.14^{a}$ & $169 \pm 1^{a}$ & $93.4 \pm 1.5^{a}$ \\
\hline & 7 & $3.66 \pm 0.01^{a}$ & $0.14 \pm 0.01^{c}$ & $0.43 \pm 0.01^{a}$ & $7.39 \pm 0.01^{\mathrm{ab}}$ & $143 \pm 6^{b}$ & $75.9 \pm 0.5^{c}$ \\
\hline & 14 & $3.64 \pm 0.01^{b}$ & $0.18 \pm 0.01^{b}$ & $0.38 \pm 0.01^{b}$ & $7.06 \pm 0.25^{b}$ & $151 \pm 12^{b}$ & $78.3 \pm 0.3^{b}$ \\
\hline & 21 & $3.58 \pm 0.01^{c}$ & $0.14 \pm 0.01^{c}$ & $0.22 \pm 0.01^{c}$ & $3.81 \pm 0.08^{c}$ & $145 \pm 1^{b}$ & $74.4 \pm 0.6^{c}$ \\
\hline & 28 & $3.59 \pm 0.01^{c}$ & - & $0.05 \pm 0.01^{d}$ & $1.05 \pm 0.02^{d}$ & $145 \pm 1^{b}$ & - \\
\hline \multirow{5}{*}{5 minutes treated } & AT & $3.58 \pm 0.00^{b}$ & $0.22 \pm 0.01^{a}$ & $0.45 \pm 0.01^{a}$ & $9.41 \pm 0.23^{a}$ & $164 \pm 1^{a}$ & $92.8 \pm 0.2^{a}$ \\
\hline & 7 & $3.63 \pm 0.01^{a}$ & $0.14 \pm 0.01^{c}$ & $0.43 \pm 0.01^{\mathrm{ab}}$ & $8.75 \pm 0.01^{b}$ & $166 \pm 1^{\mathrm{a}}$ & $76.4 \pm 0.4^{c}$ \\
\hline & 14 & $3.62 \pm 0.01^{a}$ & $0.13 \pm 0.01^{b}$ & $0.42 \pm 0.01^{b}$ & $7.80 \pm 0.23^{c}$ & $159 \pm 2^{b}$ & $78.2 \pm 0.5^{b}$ \\
\hline & 21 & $3.57 \pm 0.01^{b}$ & $0.17 \pm 0.01^{c}$ & $0.35 \pm 0.02^{c}$ & $7.18 \pm 0.14^{d}$ & $158 \pm 2^{b}$ & $73.3 \pm 1.0^{d}$ \\
\hline & 28 & $3.58 \pm 0.01^{b}$ & - & $0.18 \pm 0.01^{d}$ & $1.03 \pm 0.06^{\mathrm{e}}$ & $143 \pm 2^{c}$ & - \\
\hline
\end{tabular}

Values with different letters in each column, and each treatment time (a,b) are significantly different when applying the Tukey's honest significant difference (HSD) method at $p$-value $\leq 0.05$ 


\subsubsection{Cloud value, cloud stability and particle size distribution}

Both cloud value and cloud stability are two parameters of great interest in fresh juices and cloudy apple juices. Initial cloud value of untreated apple juice was $0.44 \pm 0.02$ (Table 4.2). Although cloud value did not change to a great extent post plasma treatments, the worst results were found after 2 minutes of treatment, where cloud value was $0.31 \pm 0.01$. After 4 and 5 minutes cloud value was maintained post treatment. During storage, all samples showed a decrease in the cloud value, with a faster decline in the case of samples treated for a short time. The optimal values were obtained in the 5 minutes treated juice, where cloud value was $0.18 \pm 0.01$ after 28 days of storage, although it was lower than in the untreated sample after the same storage time $(0.30 \pm 0.01)$. Cloud stability results are in accordance with cloud value results, where after 5 minutes of plasma treatment, cloud stability of the juice increased from $8.57 \pm 0.10$ to $9.41 \pm 0.23$ (Table 4.2), although, as it happened in cloud values, the stability significantly decreased during storage. All cloud stability values after 28 days of storage were similar and lower than the cloud value of untreated samples.

The main components responsible for the desirable cloud appearance of apple juice are proteins, pectin and polyphenols (Zhao et al., 2008), and the different interactions that can occur between them during and after plasma treatments will determine its stability. Cloud stability of the juice is usually related to the diameters of the particles present in the juice, homogenization occurs when particle size decreases, and therefore, cloud stability increases. According to Beveridge (2002), particle sizes above $0.5 \mu \mathrm{m}$ to $0.65 \mu \mathrm{m}$ are unstable and settle out, while the particles below this range are held in suspension and do not settle.

Particle size distribution results are shown in Table 4.3 and plotted in Figure 4.4a. Particle size was not measured during the storage study; results correspond to the juices right after different treatment times. As it can be observed in $D[4,3]$ values, particle size did not change in a great extent, although a significant decrease was observed after 4 and 5 minutes treatments, where it changed from $8.53 \pm 0.05$ to $7.00 \pm 0.02$ and $6.85 \pm 0.02$ respectively. In contrast, after the one minute treatment, the $D[4,3]$ value significantly 
increased to $13.34 \pm 0.06$. Obtained values for $d(0.1)$ and $d(0.5)$ parameters were also practically unchanged after plasma treatment, but a bigger change was seen in $d(0.9)$ values. This parameter indicates the size where $90 \%$ of the particles are below it. As seen in Table 4.3, after a treatment of one minute, particle size in the juice increased, since $d(0.9)$ increased from $28.2 \pm 1.2$ to $45.5 \pm 2$, which may have been caused by coagulation of particles. After longer treatments, $d(0.9)$ value decreased, therefore, increasing treatment time decreased the particle size. After 5 minutes treatment, $d(0.9)$ was $7.8 \pm 0.1$, which is lower than the value for the untreated juice, but it is still high enough for a stable juice. This can be seen in Figure 4.4a, where in the particle size range between 0.1 and $1 \mu \mathrm{m}$, there is an increase in the volume (\%) of the treated samples compared to the untreated one, as well as a decrease in the particles between 10 and $100 \mu \mathrm{m}$ (except for 1 minute treated). This change is clearly visible in Span values, which also increased after 1 minute, but decreased thereafter with longer treatments. As expected, the lowest Span value was obtained after 5 minutes treatment, decreasing from $106 \pm 7$ in the untreated sample to $28 \pm 2$ in the treated one. Span value represents the distribution width, so this decrease indicates a homogenization of the juice, which should contribute to its cloud stability. Although particles are much higher than $0.5 \mu \mathrm{m}$ and cloud stability was low, no phase separation was observed in the juices that had been treated during 4 and 5 minutes during the shelf life study. One possible explanation of the cloud maintenance in these juices is the inactivation of another enzyme that is usually present in apple juice and which activity has not been measured in this study, pectin methylesterase (PME). This enzyme causes pectin demethylation that can precipitate with calcium ions present in the juice, producing clarification and loss of turbidity (Illera et al., 2018a). Based on the good results obtained in PPO inactivation after these treatments of 4 and 5 minutes, total or partial inactivation of PME could have happened. Zhao et al. (2008) also explained that an important factor for cloud stability could be the electrostatic repulsion by negative charges present in the partly de-methylated pectin, which would avoid aggregation 

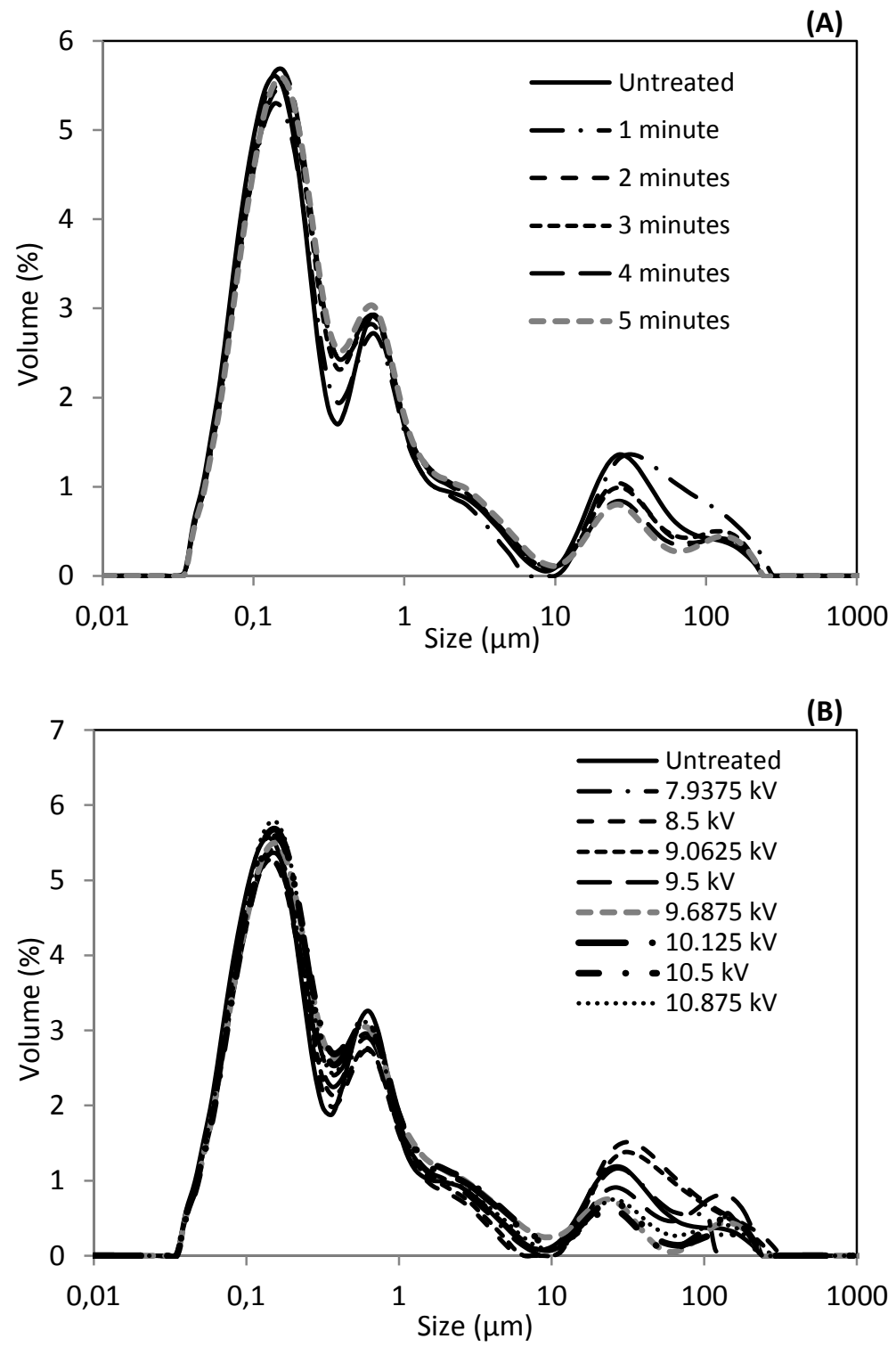

Figure 4.4 Particle size distribution of (a) Untreated and treated cloudy apple juice at different treatment times (b) Untreated and treated juices at different voltages input.

Particle size distribution of the juices treated at different voltages is plotted in Figure 4.4b. The distribution did not change to a great extent, but some differences can be found especially in the bigger size range, where lower voltage treatments produced an increase in the volume of big particles sizes. 
Table 4.3 PSD values of untreated and plasma treated juices after different treatment times.

\begin{tabular}{ccccccc}
\hline Sample & $D[3,2]$ & $D[4,3]$ & $d(0.1)$ & $d(0.5)$ & $d(0.9)$ & Span* \\
\hline Untreated & $0.19 \pm 0.01^{\mathrm{a}}$ & $8.53 \pm 0.05^{\mathrm{b}}$ & $0.084 \pm 0.001^{\mathrm{a}}$ & $0.26 \pm 0.01^{\mathrm{a}}$ & $28.2 \pm 1.2^{\mathrm{b}}$ & $106 \pm 7^{\mathrm{b}}$ \\
\hline 1 minute & $0.21 \pm 0.02^{\mathrm{c}}$ & $13.34 \pm 0.06^{\mathrm{a}}$ & $0.087 \pm 0.001^{\mathrm{b}}$ & $0.30 \pm 0.02^{\mathrm{c}}$ & $45.5 \pm 2^{\mathrm{a}}$ & $152 \pm 8^{\mathrm{a}}$ \\
2 minutes & $0.20 \pm 0.01^{\mathrm{b}}$ & $7.53 \pm 0.05^{\mathrm{d}}$ & $0.088 \pm 0.001^{\mathrm{b}}$ & $0.28 \pm 0.01^{\mathrm{b}}$ & $21.1 \pm 0.8^{\mathrm{c}}$ & $75 \pm 5^{\mathrm{c}}$ \\
3 minutes & $0.20 \pm 0.01^{\mathrm{b}}$ & $8.23 \pm 0.03^{\mathrm{c}}$ & $0.088 \pm 0.001^{\mathrm{b}}$ & $0.28 \pm 0.01^{\mathrm{b}}$ & $22.5 \pm 0.6^{\mathrm{c}}$ & $81 \pm 7^{\mathrm{c}}$ \\
4 minutes & $0.20 \pm 0.01^{\mathrm{b}}$ & $7.00 \pm 0.02^{\mathrm{e}}$ & $0.087 \pm 0.001^{\mathrm{b}}$ & $0.26 \pm 0.01^{\mathrm{a}}$ & $13.9 \pm 0.1^{\mathrm{d}}$ & $53 \pm 5^{\mathrm{d}}$ \\
5 minutes & $0.20 \pm 0.01^{\mathrm{b}}$ & $6.85 \pm 0.02^{\mathrm{f}}$ & $0.089 \pm 0.001^{\mathrm{b}}$ & $0.27 \pm 0.01^{\mathrm{b}}$ & $7.8 \pm 0.1^{\mathrm{e}}$ & $28 \pm 2^{\mathrm{e}}$ \\
\hline
\end{tabular}

Values with different letters in each column, and each treatment $(a, b)$ are significantly different when applying the Tukey's honestly significant difference (HSD) method at $p$-value $\leq 0.05$. $\left({ }^{*}\right)$ Span has no units. 


\subsubsection{Total phenolic content and antioxidant capacity}

Table 4.2 shows the evolution of total phenolic compounds retention after plasma treatments and during the shelf life study at $4{ }^{\circ} \mathrm{C}$. Total phenolic compounds (TPC) retention, expressed as percentage of the initial value, increased after all plasma treatments, and it was significantly higher when treatment time increased, reaching the highest values in the 4 and 5 minutes treated juices, where TPC increased by $69 \%$ and $64 \%$ respectively. During storage, all samples suffered a decrease in TPC content, but after 28 days, these values were still higher than in the untreated juice. Rodríguez et al. (2017) observed the same trend, the TPC showed a significantly higher increase with increasing the treatment time. They observed an increment of $114 \%$ in TPC of cashew apple juice after 5 minutes of plasma treatment. The same increase was obtained by Dasan \& Boyaci (2018) after a DBD treatment of 2 minutes on commercial apple juice. Both studies explained that the increase in phenolic compounds is probably caused by an increase in cell membrane breakdown, where these compounds are located. The energy applied by the plasma treatment and also the degradation of the cell membrane by the action of plasma reactive species could produce this breakdown and enhance the phenolic extraction. Ramazzina et al. (2015) studied TPC in processed kiwifruit and they also obtained a decrease of around $5 \%$ after storage of 4 days.

The determination of phenolic content is related to antioxidant capacity of the sample (Muhammad et al., 2018), as it can be observed in DPPH inhibition results (Table 4.2). A very similar trend to the changes observed in TPC can be seen, with an increase in antioxidant capacity with treatment time, although in this case, the 3 minutes treatment was as effective as 4 and 5 minutes. In these samples, DPPH \% inhibition increased from $79.4 \pm 0.8 \%$ to approximately $93 \%$. As happened with TPC, despite this initial increase, antioxidant capacity decreased during storage, although from day seven onwards, antioxidant capacity remained constant until the end of the shelf life study. This overall decrease of antioxidant capacity can be explained by the ability of antioxidant compounds present in the juice to scavenge the free radicals generated with plasma, which would decrease their concentration in the juice (Dasan \& Boyaci, 2018). This explanation also includes phenolic compounds, and explains their decrease during storage, although 
according to Muhammad et al., (2018), further work is needed to clarify the reaction chemistry between plasma and antioxidants in food.

\section{Conclusions}

Cold plasma treatment using spark discharge to liquid was an effective alternative for the treatment and quality preservation of cloudy apple juice. The optimal conditions of treatment were a power input of $10.5 \mathrm{kV}$ and a treatment time of 5 minutes. Enzyme inactivation and physical-chemical properties were dependent on treatment time. Very high PPO inactivation was achieved after 5 minutes of treatment, and after 24 hours it was totally inactivated. No reactivation of PPO was found in any sample. pH significantly decreased after plasma treatments due to the formation of reactive species. Color of juice was improved after long treatments, being lighter than the untreated sample right after treatment, and it was maintained during storage. Antioxidant capacity of the sample was also increased, as well as polyphenols content, and, although cloud stability didn't show high values and particle size distribution didn't significantly change, the juice quality was stable during storage in samples after long treatments. 



\section{CHAPTER 5}

High pressure $\mathrm{CO}_{2}$ solubility in food model solutions and fruit juices

Based on the article:

A.E. Illera, M. T. Sanz, S. Beltrán, R. Melgosa (2019).

"High pressure $\mathrm{CO}_{2}$ solubility in food model solutions and fruit juices"

The Journal of Supercritical Fluids, 143, 120-125. 



\section{Capítulo 5}

Solubilidad de $\mathrm{CO}_{2}$ presurizado en soluciones modelo de alimentos y en zumos de frutas

\section{Resumen}

Dada la importancia de conocer en profundidad la acción del $\mathrm{CO}_{2}$ sobre los alimentos tratados, en este capítulo se ha estudiado su solubilidad en función de la composición del medio en el que se aplica. Se llevaron a cabo mediciones de la solubilidad de $\mathrm{CO}_{2}$ en agua pura, en una solución modelo de tampón citrato a diferentes valores de $\mathrm{pH}$ y con diferentes cantidades de azúcares que simulaba las condiciones del medio de un zumo, y finalmente en zumos reales de manzana y de zanahoria. Se determinó la solubilidad en un rango de presiones de 8 a $20 \mathrm{MPa}$ y en un rango de temperaturas de 35 a $45^{\circ} \mathrm{C}$. La solubilidad del $\mathrm{CO}_{2}$ en la solución tampón de citrato a $\mathrm{pH}=3.8$ y $\mathrm{pH}=6.2$ era ligeramente menor que la solubilidad en agua pura. Para ajustar los datos de solubilidad del $\mathrm{CO}_{2}$ en el agua pura y en las soluciones modelo se empleó una ecuación de tipo Chrastil. En dicha ecuación se introdujo un nuevo término para tener en cuenta el descenso en la solubilidad del $\mathrm{CO}_{2}$ en el medio líquido en presencia de azúcar.

Palabras clave: Solubilidad del $\mathrm{CO}_{2}$, contenido de azúcar, zumos de manzana y zanahoria, ecuación de Chrastil. 



\section{Abstract}

Measurements of $\mathrm{CO}_{2}$ solubility were performed in different media, pure water, model citrate buffer solutions at different $\mathrm{pH}$ values, in the presence of different sugar content and in real apple and carrot juices. Solubility was determined in the pressure range from 8 to $20 \mathrm{MPa}$ and in the temperature range from 308 to $318 \mathrm{~K}$. $\mathrm{CO}_{2}$ solubility in citrate buffer solutions at $\mathrm{pH}=3.8$ and $\mathrm{pH}=6.2$ was slightly lower than $\mathrm{CO}_{2}$ solubility in pure water. $\mathrm{A}$ Chrastil-type equation according to Fornari's approach was used to fit $\mathrm{CO}_{2}$ solubility data in pure water and model solutions. A new term was introduced in this equation to account for the decrease in solubility of $\mathrm{CO}_{2}$ in the presence of sugar in the liquid media.

Keywords: $\mathrm{CO}_{2}$ solubility, sugar content, apple and carrot juices, Chrastil's equation. 



\section{Introduction}

Thermal treatments are usually employed in the Food Industry as a preservation technique, however, they cause undesirable changes in several physical parameters and can also destroy heat-sensitive nutritional components. Non-thermal technologies have gained interest and acceptance as food processing methods due to the consumer demand for fresh-like products. Among them, High Pressure Carbon Dioxide (HPCD) has been proposed as an alternative non-thermal pasteurization technique for foods. In HPCD treatments, operating temperatures do not exceed $60{ }^{\circ} \mathrm{C}$ and pressures are usually below $50 \mathrm{MPa}$. The use of HPCD in the Food Industry is very attractive since $\mathrm{CO}_{2}$ is non-toxic, chemically inert, and ready available. HPCD has been used to inactivate some microorganism and enzymes that cause deleterious effects in fruit and vegetable juices (Briongos et al., 2016; Damar \& Balaban, 2006; Illera et al., 2018a).

The mechanism of pressurized $\mathrm{CO}_{2}$ on microorganism and enzyme inactivation is not yet fully understood. Knowledge of $\mathrm{CO}_{2}$ solubility in liquid foods is of interest for a better understanding of the action of $\mathrm{CO}_{2}$ as pasteurizing agent. Additionally, the amount of $\mathrm{CO}_{2}$ employed in HPCD processes could be optimized by knowing the solubility of $\mathrm{CO}_{2}$ at different operating pressures and temperatures and the process would be more economical (Ferrentino et al., 2010b).

In the literature, there are a few studies dealing with the determination of $\mathrm{CO}_{2}$ solubility in liquid foods or in model media containing different food components. Dohrn et al. (Dohrn, et al., 1993) determined the phase equilibria for ternary and quaternary systems of glucose, water, $\mathrm{CO}_{2}$ and ethanol. They observed that the solubility of glucose in the vapor phase was very small, and it increased with pressure and ethanol in the medium, while the $\mathrm{CO}_{2}$ solubility in the aqueous solution decreased when glucose was in the medium at a concentration of 15 wt. \%. Calix et al. (Calix et al., 2008) determined the $\mathrm{CO}_{2}$ solubility at $40{ }^{\circ} \mathrm{C}$ in different model aqueous solutions with ascorbic or citric acid (0.01 wt.\%) and different sugars, from 11.5 to 13 wt. \% and in commercial orange and apple juices in the pressure range from 7.58 to $15.86 \mathrm{MPa}$. These authors also found that $\mathrm{CO}_{2}$ solubility 
decreased in the presence of solutes compared with pure water. Following the previous work of Calix et al. (Calix et al., 2008), Ferrentino et al. (Ferrentino et al., 2010a) determined $\mathrm{CO}_{2}$ solubility in ternary and quaternary mixtures with malic acid (from 0.01 to 2.68 wt. \%) and glucose (from 4 to $12 \mathrm{wt}$ \%) in the pressure and temperature range from 7.5 to $15.0 \mathrm{MPa}$ and 308 to $333 \mathrm{~K}$, respectively. These authors observed that organic acids hardly affected $\mathrm{CO}_{2}$ solubility while the $\mathrm{CO}_{2}$ solubility significantly decreased with glucose concentration. These authors also found that $\mathrm{CO}_{2}$ solubility decreased with the presence of sodium phosphate monobasic concentrations (Ferrentino et al., 2010a).

In this work, $\mathrm{CO}_{2}$ solubility was determined in two different citrate buffer solutions at $\mathrm{pH}$ of 3.8 and 6.2 , similar to the $\mathrm{pH}$ of apple and carrot juices, respectively. The effect on $\mathrm{CO}_{2}$ solubility of different sugars (glucose, sucrose and fructose) found in apple and carrot juices was also determined in citrate buffer solutions. $\mathrm{CO}_{2}$ solubility in model buffer solutions has been compared with pure water and with $\mathrm{CO}_{2}$ solubility in real apple and carrot juices. $\mathrm{CO}_{2}$ solubility data have been fitted to an empirical equation based on the Chrastil's equation (Chrastil, 1982) according to Fornari's approach (Fornari et al., 2009) that correlates $\mathrm{CO}_{2}$ solubility in different media with the density of the $\mathrm{CO}_{2}$ at the operating pressure and temperature. The effect of sugar concentration, by determining oBrix of the liquid mixture, was also considered in the Chrastil-type equation proposed in this work.

\section{Materials and methods}

\subsection{Equipment for the measurement of $\mathrm{CO}_{2}$ solubility}

The high pressure equipment used for measurement of $\mathrm{CO}_{2}$ solubility has been previously described for fluid phase equilibrium measurements (Melgosa et al., 2017a). The equipment was built by Eurotechnica GmbH (Germany) and consists of an equilibrium cell made of stainless steel (SS-316) and equipped with a sapphire window for observing the content of the cell during measurements. The maximum specifications of the apparatus 
are $\mathrm{p}=32 \mathrm{MPa}$ and $\mathrm{T}=393 \mathrm{~K}$. Internal volume of the cell ranges from 40 to $70 \mathrm{ml}$, adjustable through a manual screw piston. The cell includes a pressure transducer and an immersed thermocouple. Both of them calibrated and connected to a Data Acquisition System (DAS). Overall standard uncertainties in the equilibrium measurements were $u(p)= \pm 0.15 \mathrm{MPa}, u(T)= \pm 0.1 \mathrm{~K}$

The equipment was placed inside an oven that allowed temperature control of the system. Once the operating temperature was achieved, the system was purged with low pressure $\mathrm{CO}_{2}$ and $25 \mathrm{ml}$ of the liquid media were introduced into the cell. Using the manual screw piston, the volume of the cell was adjusted to $50 \mathrm{ml}$. A certain amount of $\mathrm{CO}_{2}$ was then charged into the cell by using a high-pressure syringe pump (ISCO 260D) and measured by a Coriolis mass flow meter (Rheonik RHE015). The desired pressure was adjusted by actuating the manual screw piston. Mixing of the components of the system was achieved by continuously recirculating the vapour phase through the liquid phase by means of a gear pump (Micropump IDEX). First, the speed of the pump was set to the maximum during $30 \mathrm{~min}$ in order to achieve a convenient mixture. Then, speed was set to a lower value for at least $1 \mathrm{~h}$ to assure equilibrium. The system was then let to stand for $30 \mathrm{~min}$ at constant temperature and pressure. Samples from the liquid phase were taken by a micro-metering valve connected to the bottom of the equilibrium cell through a $1 / 16^{\prime \prime}$ capillary. Pressure drop during sampling was compensated with the manual screw piston.

Samples were decompressed to atmospheric pressure and released $\mathrm{CO}_{2}$ was measured using an upturned burette and a thermal mass flow meter (Bronkhorst F-110C). The liquid separated from $\mathrm{CO}_{2}$, was collected in an ice-cooled glass trap and the vials weighed in a precision analytical balance (accurate to $\pm 0.0001 \mathrm{~g}$ ). The ratio between the grams of $\mathrm{CO}_{2}$ and the grams of liquid gave the solubility value, expressed in grams of $\mathrm{CO}_{2}$ per $100 \mathrm{~g}$ of noncarbonated solution (Ferrentino et al., 2010a). 


\subsection{Effect of different components on $\mathrm{CO}_{2}$ solubility}

$\mathrm{CO}_{2}$ solubility was determined in different liquid media at different temperatures, from 308 to $328 \mathrm{~K}$, in the pressure range from 8 to $20 \mathrm{MPa}$. This pressure and temperature range was chosen based on previous studies of enzyme inactivation by HPCD in cloudy juice from Golden delicious apples (Illera et al., 2018a).

First, $\mathrm{CO}_{2}$ solubility was determined in pure water at $318 \mathrm{~K}$ to verify the reliability of the solubility data obtained with the equipment.

In liquid foods, many components such as amino acids and organic acids can exert buffer action (Yoshimura et al., 2002). Therefore, the solubility of $\mathrm{CO}_{2}$ was determined in different citrate buffer solutions to study the effect of a buffer action on $\mathrm{CO}_{2}$ solubility. Solubility was determined at two different values of $\mathrm{pH}$ in the citrate buffer, according to the natural $\mathrm{pH}$ values of apple and carrot juices, $\mathrm{pH}=3.8$ and $\mathrm{pH}=6.2$, respectively.

The effect of the main sugars present in fruits on solubility of $\mathrm{CO}_{2}$ was also determined in a citrate buffer solution at $\mathrm{pH}=3.8 . \mathrm{CO}_{2}$ solubility was determined in pseudo-ternary mixtures, considering the citrate buffer as one component, of glucose-citrate buffer- $\mathrm{CO}_{2}$, sucrose-citrate buffer- $\mathrm{CO}_{2}$ and fructose-citrate buffer- $\mathrm{CO}_{2}$. The concentration of glucose, fructose and sucrose in the buffer solution was 2.91 wt. \%, 2.51 wt. \% and 5.85 wt. \%, respectively. The sugar content was taken from Wu et al. (Wu et al., 2007) as determined for apple fruit of Golden delicious cultivar. Further solubility measurements were carried out in a multicomponent mixture formed by glucose-sucrose-fructose-citrate buffer- $\mathrm{CO}_{2}$, at the same sugar content as the reported above. Finally, $\mathrm{CO}_{2}$ solubility was also determined in a more complex mixture formed by all the sugars and pectin.

The effect of sugars on solubility of $\mathrm{CO}_{2}$ was also carried out at a $\mathrm{pH}$ value of the citrate buffer of 6.2 , similar to the $\mathrm{pH}$ of carrot juice. Although sugar content of carrot juice is lower than the previously reported values for apple juice (USDA, 2015), the same sugar content was kept to compare with the data determined at $\mathrm{pH} 3.8$. 
Finally, solubility of $\mathrm{CO}_{2}$ was determined in real apple and carrot juices. Cloudy apple juice was prepared from Golden delicious apples. Apples were peeled and cut in cubes and then added to a 0.3 wt. \% of L-ascorbic acid solution to avoid enzymatic browning. Apple cubes were wiped and immediately squeezed with a screw juice extractor. Carrot juice was prepared from fresh carrots (Daucus carota cv. Natesa). Carrots were washed, peeled and the juice was extracted by an electronic juicer (Moulinex ${ }^{\circledR}$ Junior 864). Both liquors, apple and carrot juices, were filtered with 2 layers of cheesecloth. The $\mathrm{pH}$ of apple and carrot juice was 3.72 and 6.34 , respectively.

oBrix of all the liquid media employed in this work were measured with a Milton Roy refractometer at $25^{\circ} \mathrm{C}$ (Model 334610) and are reported in Table 5.1.

Table $5.1{ }^{\circ}$ Brix of the different citrate buffer solutions and apple and carrot juices employed in this work.

\begin{tabular}{ccccc}
\hline pH & Glucose (\%) & Fructose (\%) & Sucrose (\%) & oBrix \\
3.8 & 2.91 & - & - & $3.60 \pm 0.08$ \\
3.8 & - & - & 2.51 & $3.23 \pm 0.1$ \\
3.8 & - & 5.85 & - & $6.17 \pm 0.06$ \\
3.8 & 2.91 & 5.85 & 2.51 & $11.17 \pm 0.06$ \\
6.2 & 2.91 & - & - & $3.73 \pm 0.06$ \\
6.2 & 2.91 & 5.85 & 2.51 & $11.63 \pm 0.06$ \\
\hline \multicolumn{5}{r}{ Apple juice } \\
Carrot juice
\end{tabular}

\section{$2.3 \mathrm{CO}_{2}$ solubility data correlation}

In this work, $\mathrm{CO}_{2}$ solubility data were correlated to an empirical equation based on the Chrastil's equation traditionally employed to correlate the solubility of a compound in a supercritical fluid with the density of the supercritical gas (Chrastil, 1982). Fornari et al. (Fornari et al., 2009) demonstrated that the liquid phase composition could be also related with the density of the supercritical fluid and they successfully correlated solubility (S) of different supercritical gases in different liquids: 
$\ln S\left(\mathrm{gCO}_{2} / 100 \mathrm{~g}\right.$ liquid $)=k \cdot \ln \left(\rho_{\mathrm{SC}-\mathrm{CO}_{2}}\right)+c \quad$ at constant temperature

According to Fornari et al. (Fornari et al., 2009) this equation establishes a Chrastil-type relationship between the composition of the liquid phase and the density of the $\mathrm{SC}-\mathrm{CO}_{2}$.

When $\mathrm{CO}_{2}$ solubility data were obtained at different temperatures, the following equation, based on the one proposed by Chrastil (Chrastil, 1982), was used:

$\ln S\left(\mathrm{gCO}_{2} / 100 \mathrm{~g}\right.$ liquid $)=k \cdot \ln \left(\rho_{\mathrm{SC}-\mathrm{CO}_{2}}\right)+a / T(K)+c$

In the present work, Fornari's model has been extended to multicomponent mixtures, due to the nature of the components present in the liquid phase. Components such as sugar, salts an citric acid can be considered almost insoluble in $\mathrm{SC}-\mathrm{CO}_{2}$ (Raventós et al., 2002; Shishikura et al., 1992).

\subsection{Statistical analysis}

Statistical analysis were conducted using the software Statgraphics X64. The results are presented as a mean \pm standard deviation of $\mathrm{CO}_{2}$ solubility in the liquid phase by sampling three times. The significance of the differences was determined based on an analysis of the variance with the Fisher's least significant method at $p$-value $\leq 0.05$.

The mean relative deviation (MRD) between experimental and calculated solubility of $\mathrm{CO}_{2}$ was evaluated:

$\operatorname{MRD}=\frac{1}{\mathrm{n}}\left(\sum_{\text {all samples }}\left|\frac{\mathrm{S}_{\mathrm{calc}}-\mathrm{S}_{\exp }}{\mathrm{S}_{\exp }}\right|\right) \cdot 100$

Where the subscripts exp and calc are experimental and calculated values and $\mathrm{n}$ is the number of experimental solubility data. 


\section{Results and discussion}

\subsection{Validation of the equipment, $\mathrm{CO}_{2}$ solubility in water}

In order to check the reliability of the apparatus and the experimental procedure, $\mathrm{CO}_{2}$ solubility in water was determined at $318 \mathrm{~K}$ in the pressure range from 8 to $20 \mathrm{MPa}$ (Table 5.3). Figure 5.1 shows that solubility data obtained in this work at $318 \mathrm{~K}$ lie between data obtained from literature at $308 \mathrm{~K}$ and $328 \mathrm{~K}$ (Bamberger et al., 2004; Wiebe \& Gaddy, 1940) proving that the apparatus can provide reliable values of solubility being of the order of previous published results. For instance, at $10 \mathrm{MPa}$ Bamberger et al. (Bamberger et al., 2004) reported a solubility value of $5.11 \mathrm{~g} \mathrm{CO}_{2} / 100 \mathrm{~g}$ water at $323 \mathrm{~K}$, while $5.46 \mathrm{~g} \mathrm{CO}_{2} / 100 \mathrm{~g}$ water was reported by Wiebe et al. (Wiebe \& Gaddy, 1940) at $313 \mathrm{~K}$. In this work, at the same pressure and $313 \mathrm{~K}$, the solubility was $5.33 \mathrm{~g} \mathrm{CO}_{2} / 100 \mathrm{~g}$, lying between both temperatures. In the literature, graphical representations of $\mathrm{CO}_{2}$ solubility as a function of temperature at different pressures can be found, and solubility data at $45^{\circ} \mathrm{C}$ can be easily obtained, having values similar to this work (Dodds et al., 1956; Wiebe \& Gaddy, 1940).

$\mathrm{CO}_{2}$ solubility data in pure water were fitted to equation 5.1. Parameters are reported in Table 5.2 and represented in Figure 5.1, yielding a good fitting quality $\left(R^{2}>0.94\right)$.

\section{$3.2 \mathrm{CO}_{2}$ solubility in citrate buffer solutions}

The effect of the $\mathrm{pH}$ on $\mathrm{CO}_{2}$ solubility was assessed by means of a citrate buffer solution at two different values of $\mathrm{pH}, 3.8$ and 6.2 , in the pressure and temperature range from 8 to $20 \mathrm{MPa}$ and from 318 to $328 \mathrm{~K}$, respectively (Figure $\mathbf{5 . 2}$ and Table 5.3). For each liquid medium, it can be observed that $\mathrm{CO}_{2}$ solubility depends on pressure and temperature. At a constant temperature, an increase in pressure led to an increase in solubility of $\mathrm{CO}_{2}$ while solubility at a constant pressure, increased by decreasing temperature. 


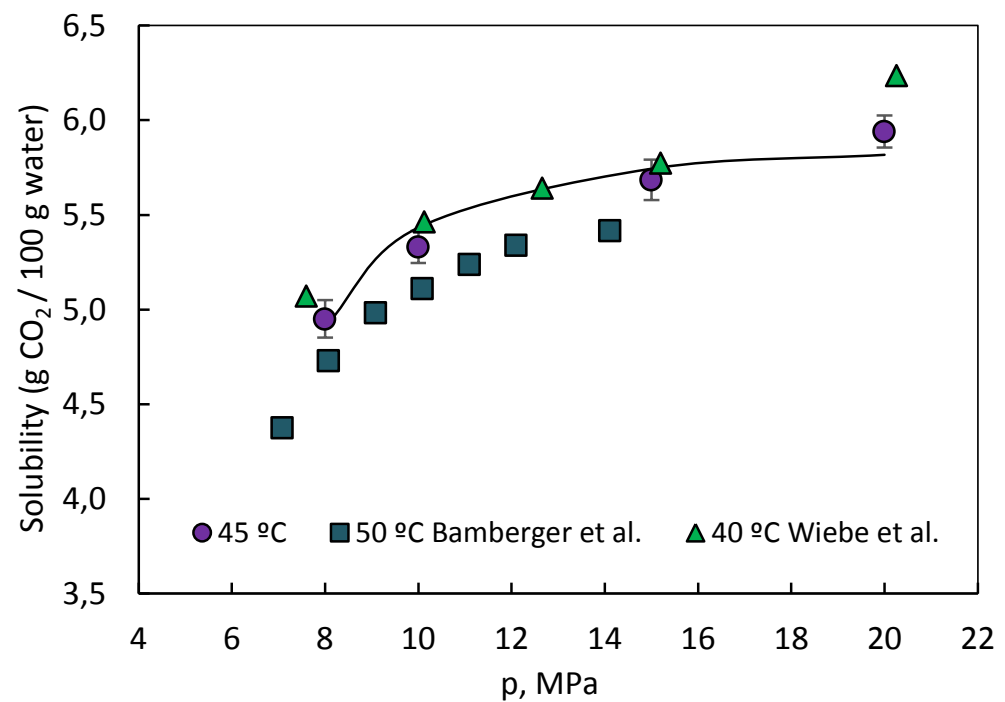

Figure 5.1 Solubility of $\mathrm{CO}_{2}$ in pure water at different temperatures: $45^{\circ} \mathrm{C}, 50{ }^{\circ} \mathrm{C}$ (Bamberger et al., 2004) and $40^{\circ} \mathrm{C}$ (Wiebe \& Gaddy, 1940). Continuous line corresponds to Eq. 5.1, parameters are listed in Table 5.2.

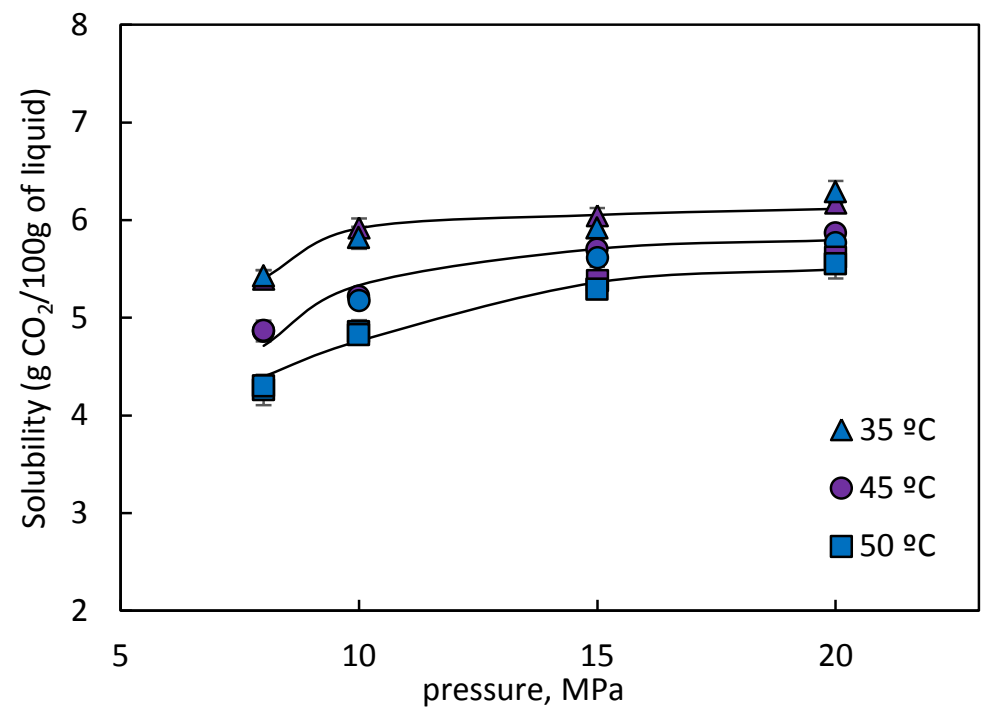

Figure 5.2 Solubility of $\mathrm{CO}_{2}$ in citrate buffer solutions at two values of $\mathrm{pH}, 3.8$ (purple symbols) and 6.2 (blue symbols) at different temperatures. Continuous lines correspond to Eq. 5.2, parameters are listed in Table 5.2. 
Results obtained with pure water at $318 \mathrm{~K}$ are also listed for a better comparison of the effect of the buffer capacity of the media on $\mathrm{CO}_{2}$ solubility. Slightly differences can be observed in $\mathrm{CO}_{2}$ solubility for pure water and the two buffer systems with the highest values obtained in pure water and the lowest in the citrate buffer solution at $\mathrm{pH}=6.2$. Although, according to the Fisher's least significant method, no differences were observed in $\mathrm{CO}_{2}$ solubility in the different liquid media for each pressure. The small differences observed in $\mathrm{CO}_{2}$ solubility in the different liquid media, especially at the highest pressures, can be related with the composition of the liquid media. The concentration of citric acid and sodium citrate salt at $\mathrm{pH}=3.8$ and 6.2 were 0.74 wt. $\%$ and 0.15 wt. $\%$ of citric acid and 0.39 wt. \% and 1.10 wt. \% of sodium citrate, respectively.

In this regard, Ferrentino et al. (Ferrentino et al., 2010) reported $\mathrm{CO}_{2}$ solubility data in a water-malic acid system, at $313 \mathrm{~K}$ in the pressure range from 7.5 to $15 \mathrm{MPa}$, finding no significant dependence of the $\mathrm{CO}_{2}$ solubility value on the malic acid concentration in the solutions, in the range from $0 \mathrm{~g}$ to $2.68 \mathrm{~g}$ of malic acid in a $100 \mathrm{~g}$ solution. Based on these results, in this work, it was assumed that the citric acid concentration would not play an important role on the values of $\mathrm{CO}_{2}$ solubility. In a different study, Ferrentino et al. (Ferrentino et al., 2010a) also determined $\mathrm{CO}_{2}$ solubility in the system water-sodium phosphate monobasic solutions at different salt concentration in the range from 0.24 to $4.8 \mathrm{~g}$ of sodium phosphate monobasic in $100 \mathrm{~g}$ of water. These authors found that an increase in the amount of the solute decreased solubility of the $\mathrm{CO}_{2}$. For instance, at $313 \mathrm{~K}$ and $10.34 \mathrm{MPa}, \mathrm{CO}_{2}$ solubility decreased from values of $5.32 \pm 0.19 \mathrm{~g} \mathrm{CO}_{2} / 100 \mathrm{~g}$ in pure water to values of $5.16 \pm 0.03$ and $4.61 \pm 0.06 \mathrm{~g} \mathrm{CO}_{2} / 100 \mathrm{~g}$ for a sodium phosphate monobasic concentration of $0.240 \mathrm{~g} / 100 \mathrm{~g}$ water and $4.8 \mathrm{~g} / 100 \mathrm{~g}$ water, respectively. These results agree with the trend in the $\mathrm{CO}_{2}$ solubility data obtained in this work, since the lowest solubility values were obtained at $\mathrm{pH}$ value of 6.2 , corresponding with the highest sodium citrate concentration. Similar trend was observed for the other two isotherms, at 308 and $328 \mathrm{~K}$, for each operating pressure. 
Table 5.2 Parameters of Eq. 5.1, $\mathbf{5 . 2}$ and $\mathbf{5 . 4}$ for different $\mathrm{CO}_{2}+$ liquid media systems, $\mathrm{n}$ number of experimental data fitted, MRD, mean relative deviation Eq. 5.3.

\begin{tabular}{ccccccccc}
\hline Liquid media & Equation & $\mathbf{k}$ & $\mathbf{a}$ & $\mathbf{b}$ & $\mathbf{c}$ & $\mathbf{R}^{\mathbf{2}}$ & $\mathbf{n}$ & $\mathbf{M R D}$ \\
\hline Water & 5.1 & $0.139 \pm 0.023$ & & & $0.82 \pm 0.14$ & 0.9484 & 4 \\
$\begin{array}{c}\text { Citrate buffer solutions } \\
\text { (pH = 3.8 and 6.2) }\end{array}$ & 5.2 & $0.170 \pm 0.009$ & $422 \pm 55$ & & $-0.71 \pm 0.16$ & 0.9669 & 24 & $1.54 \%$ \\
$\begin{array}{c}\text { Citrate buffer solutions + } \\
\text { sugars }\end{array}$ & 5.4 & $0.140 \pm 0.008$ & $446 \pm 96$ & $0.366 \pm 0.042$ & $-0.74 \pm 0.30$ & 0.9391 & 25 & $1.42 \%$ \\
\hline
\end{tabular}


Table 5.3 Solubility of $\mathrm{CO}_{2}$ ( $\mathrm{g} \mathrm{CO}_{2} / 100 \mathrm{~g}$ sample) in pure water at $318 \mathrm{~K}$ and two different citrate buffer solutions at $\mathrm{pH}$ values of 3.8 and 6.2 in the temperature range from 308 to $328 \mathrm{~K}$ and pressure range from 8 to $20 \mathrm{MPa}$

\begin{tabular}{ccccc}
\hline $\mathbf{p , ~ M P a}$ & T, K & water & $\mathbf{p H}=3.8$ & $\mathbf{p H}=6.2$ \\
\hline 8 & 308 & & $5.40 \pm 0.05^{\mathrm{a}}$ & $5.43 \pm 0.05^{\mathrm{a}}$ \\
10 & 308 & & $5.94 \pm 0.11^{\mathrm{b}, \mathrm{c}}$ & $5.85 \pm 0.11^{\mathrm{b}}$ \\
15 & 308 & & $6.05 \pm 0.08^{\mathrm{c}, \mathrm{d}}$ & $5.92 \pm 0.08^{\mathrm{b}, \mathrm{c}}$ \\
20 & 308 & & $6.18 \pm 0.05^{\mathrm{d}, \mathrm{e}}$ & $6.29 \pm 0.11^{\mathrm{e}}$ \\
\hline 8 & 318 & $4.95 \pm 0.10^{\mathrm{a}}$ & $4.86 \pm 0.07^{\mathrm{a}}$ & $4.87 \pm 0.13^{\mathrm{a}}$ \\
10 & 318 & $5.33 \pm 0.08^{\mathrm{b}}$ & $5.22 \pm 0.04^{\mathrm{b}}$ & $5.18 \pm 0.07^{\mathrm{b}}$ \\
15 & 318 & $5.69 \pm 0.11^{\mathrm{c}}$ & $5.70 \pm 0.11^{\mathrm{c} . d}$ & $5.62 \pm 0.11^{\mathrm{c}}$ \\
20 & 318 & $5.94 \pm 0.08^{\mathrm{e}}$ & $5.87 \pm 0.02^{\mathrm{d}, \mathrm{e}}$ & $5.77 \pm 0.03^{\mathrm{c}, \mathrm{d}}$ \\
\hline 8 & 328 & & $4.27 \pm 0.23^{\mathrm{a}}$ & $4.30 \pm 0.07^{\mathrm{a}}$ \\
10 & 328 & & $4.86 \pm 0.12^{\mathrm{b}}$ & $4.83 \pm 0.04^{\mathrm{b}}$ \\
15 & 328 & & $5.38 \pm 0.07^{\mathrm{c}}$ & $5.29 \pm 0.06^{\mathrm{c}}$ \\
20 & 328 & & $5.62 \pm 0.03^{\mathrm{d}}$ & $5.55 \pm 0.15^{\mathrm{c.d}}$ \\
\hline
\end{tabular}

For each isotherm $(308,318$ and $328 \mathrm{~K})$, same letters in the same raw and column mean no significant difference according to LSD test at $p$-value $\leq 0.05$.

Based on the results presented in Table 5.3, $\mathrm{CO}_{2}$ solubility data in the citrate buffer solutions at both $\mathrm{pH}$ values were fitted all together to equation 5.2, in the temperature and pressure range from 308 to $328 \mathrm{~K}$ and from 8 to $20 \mathrm{MPa}$, respectively. Parameters are listed in Table 5.2. Based on the quality of the fitting, it can be concluded that a Chrastiltype relationship can be successfully applied to fit $\mathrm{CO}_{2}$ solubility data in buffer aqueous solution, according to Fornari's approach (Fornari et al., 2009).

\section{$3.3 \mathrm{CO}_{2}$ solubility in different sugars solutions}

Solubility of $\mathrm{CO}_{2}$ in the liquid system citrate buffer-glucose was measured at $318 \mathrm{~K}$, in the pressure range from 8 to $20 \mathrm{MPa}$ at the two values of $\mathrm{pH}, 3.8$ and 6.2. The weight fraction of glucose in the liquid feed was $2.91 \mathrm{wt}$. \% (Wu et al., 2007). The experimental results for the citrate buffer at $\mathrm{pH}=3.8$ are listed in Table 5.4. $\mathrm{CO}_{2}$ solubility increased with increasing pressure at constant temperature. For the citrate buffer at $\mathrm{pH}=6.2$ and same 
glucose concentration, no significant differences were obtained with the values reported in Table 5.4 at $\mathrm{pH}=3.8$ for each operating pressure $(4.78 \pm 0.04,5.10 \pm 0.05,5.36 \pm 0.01$ and $5.57 \pm 0.09 \mathrm{~g} / 100 \mathrm{~g}$ of liquid mixture at $8,10,15$ and $20 \mathrm{MPa}$, respectively). The presence of glucose led to a decrease in $\mathrm{CO}_{2}$ solubility compared to the corresponding buffer solution, also listed in Table $\mathbf{5 . 4}$ for a better comparison. This fact has been also observed in the literature for water + glucose $+\mathrm{CO}_{2}$ systems (Dohrn et al., 1993; Ferrentino et al., 2010b) . Dohrn et al. observed a decrease in $\mathrm{CO}_{2}$ solubility of $6.2 \%$ and $8.9 \%$ per gram of glucose at $323 \mathrm{~K}$ at 10 and $20 \mathrm{MPa}$, respectively, compared with pure water. In this work, a decrease of the same order was obtained for $\mathrm{CO}_{2}$ solubility, 5.2 wt. \% and 7.4 wt. \% per gram of glucose at $313 \mathrm{~K}$ at 10 and $20 \mathrm{MPa}$, respectively, compared with the citrate buffer solution (at $\mathrm{pH}$ value of 3.8 ).

Table $5.4 \mathrm{CO}_{2}$ solubility in citrate buffer solutions at $\mathrm{pH}=3.8$ in the presence of different sugars: glucose (2.91 wt. \%), sucrose (2.51 wt. \%), fructose (5.85 wt. \%) and a mixture of all.

\begin{tabular}{cccccc}
\hline p, MPa & Citrate buffer & Glucose & Sucrose & Fructose & All sugars \\
\hline 8 & $4.86 \pm 0.07^{\mathrm{b}}$ & $4.75 \pm 0.09^{\mathrm{b}}$ & $4.73 \pm 0.09^{\mathrm{b}}$ & $4.46 \pm 0.03^{\mathrm{a}}$ & $4.33 \pm 0.02^{\mathrm{a}}$ \\
10 & $5.22 \pm 0.04^{\mathrm{d}}$ & $5.07 \pm 0.06^{\mathrm{c}}$ & $5.05 \pm 0.04^{\mathrm{c}}$ & $4.84 \pm 0.01^{\mathrm{b}}$ & $4.66 \pm 0.01^{\mathrm{a}}$ \\
15 & $5.70 \pm 0.11^{\mathrm{c}}$ & $5.41 \pm 0.01^{\mathrm{b}}$ & $5.39 \pm 0.06^{\mathrm{b}}$ & $5.27 \pm 0.08^{\mathrm{b}}$ & $4.97 \pm 0.10^{\mathrm{a}}$ \\
20 & $5.87 \pm 0.02^{\mathrm{d}}$ & $5.65 \pm 0.08^{\mathrm{c}}$ & $5.66 \pm 0.04^{\mathrm{c}}$ & $5.47 \pm 0.05^{\mathrm{b}}$ & $5.26 \pm 0.05^{\mathrm{a}}$ \\
\hline
\end{tabular}

For each pressure, same letters in the same raw mean no significant difference according to LSD test at $\mathrm{p}$-value $\leq 0.05$.

The effect of other sugars, such as sucrose and fructose on $\mathrm{CO}_{2}$ solubility was only determined in the citrate buffer solution at $\mathrm{pH}=3.8$, at $318 \mathrm{~K}$ in the pressure range from 8 to $20 \mathrm{MPa}$. Sucrose and fructose concentration was fixed at $2.51 \mathrm{wt}$ \% and $5.85 \mathrm{wt}$. \%, respectively ( $\mathrm{Wu}$ et al., 2007). $\mathrm{CO}_{2}$ solubility was also determined in the citrate buffer solutions at $\mathrm{pH}=3.8$ in presence of all sugars: $2.91 \mathrm{wt}$. \% of glucose, $2.51 \mathrm{wt}$. \% of sucrose and 5.85 wt. \% of fructose. Results are collected in Table $\mathbf{5 . 4}$ and plotted in Figure 5.3. For each pressure, an increase in sugar concentration led to a decrease in $\mathrm{CO}_{2}$ solubility with significant differences among the sugar concentration for each pressure when applying the LSD test $(p \leq 0.05)$. 
Figure $\mathbf{5 . 3}$ clearly shows that, the higher the sugar content, the lower the solubility of $\mathrm{CO}_{2}$. $\mathrm{CO}_{2}$ solubility at $318 \mathrm{~K}$ and the ${ }^{\circ}$ Brix of the corresponding sugar feed solutions has been plotted in Figure $\mathbf{5 . 4}$ for each operating pressure. A linear relationship can be observed for each pressure, the corresponding linear regressions have been listed in Table 5.5, together with the quality of the fitting. An ANOVA was performed to test the statistical significance of the terms in the regression model and it was found no significant differences among the slope for the various values of pressure at $90 \%$ or higher confidence level. Based on this finding, $\mathrm{CO}_{2}$ solubility data obtained in the presence of sugars were fitted to an equation similar to Eq. 5.2, but taking also into account the effect of sugar content, expressed as ${ }^{\circ}$ Brix of the solution, in a similar way as the effect of temperature on $\mathrm{CO}_{2}$ solubility:

$\ln S\left(\mathrm{gCO}_{2} / 100 \mathrm{~g}\right.$ liquid $)=k \cdot \ln \left(\rho_{S C-\mathrm{CO}_{2}}\right)+a / T(K)+b / \stackrel{\mathrm{o}}{B}$ Brix $+c$

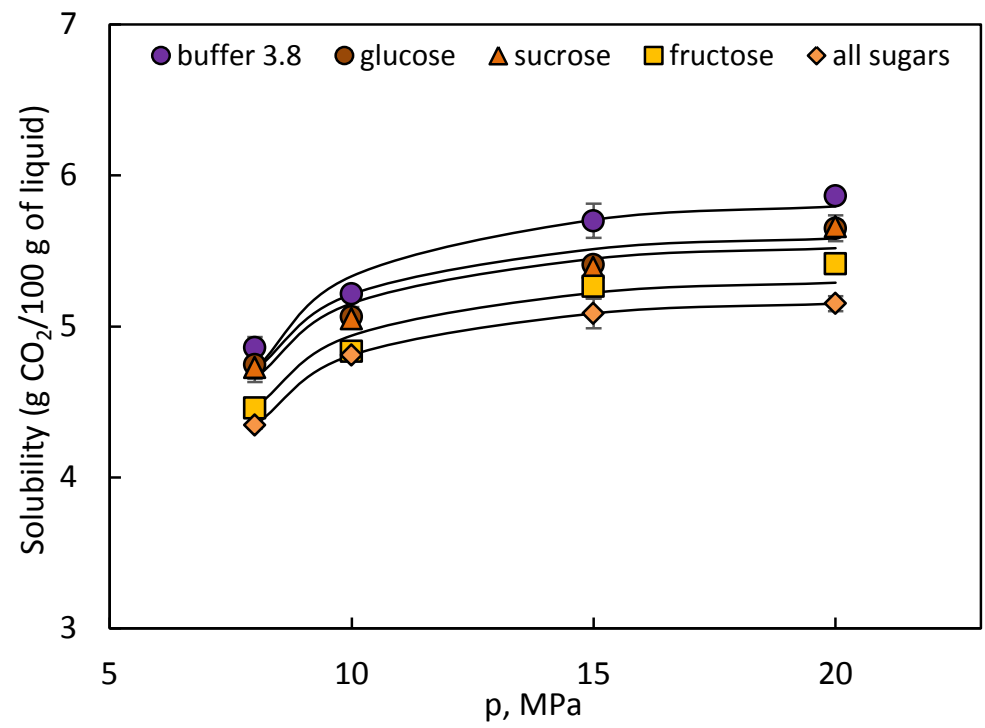

Figure $5.3 \mathrm{CO}_{2}$ solubility at $318 \mathrm{~K}$ in a buffer citrate solution $(\mathrm{pH}=3.8)$ and in the same buffer with different sugars in the medium. Continuous lines correspond to Eq. $\mathbf{5 . 2}$ (buffer solution) and Eq. $\mathbf{5 . 4}$ (in the presence of sugars), parameters are listed in Table 5.2. 


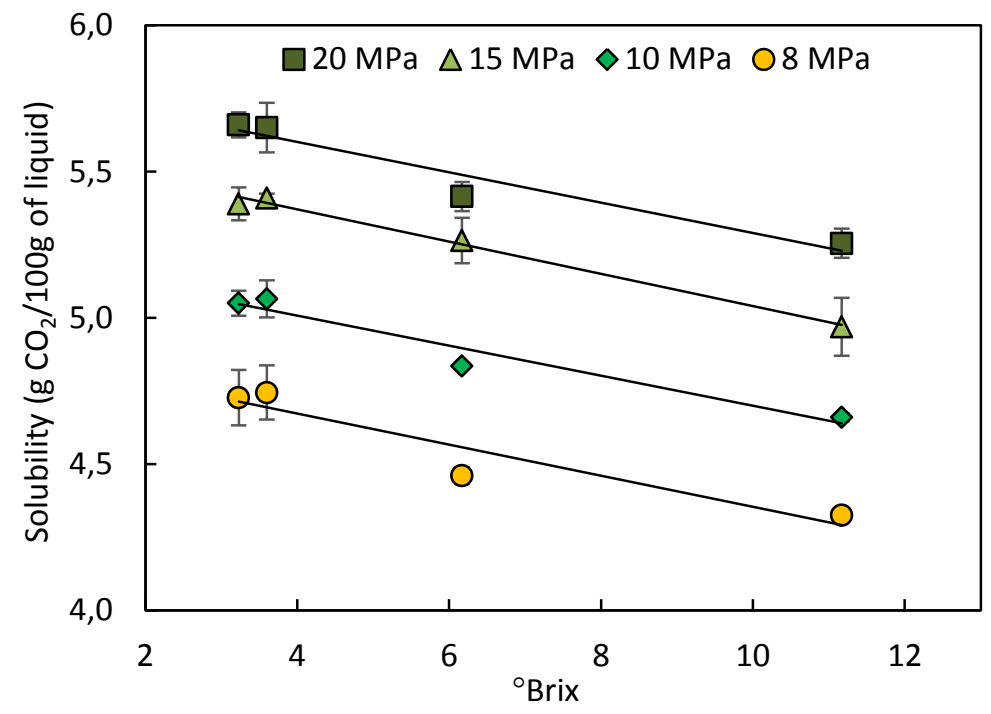

Figure $5.4 \mathrm{CO}_{2}$ solubility at $318 \mathrm{~K}$ as a function of ${ }^{\circ} \mathrm{Brix}$ of different sugar solutions (see Table 5.1) in a citrate buffer solution at $\mathrm{pH}=3.8$. at different operating pressure. Continuous lines correspond to the linear regression of solubility with ${ }^{\circ}$ Brix (Table 5.6).

Table 5.5 Terms of the linear regression model of $\mathrm{CO}_{2}$ solubility as a function of ${ }^{\circ} \mathrm{Brix}$ at $318 \mathrm{~K}$ at different operating pressures

\begin{tabular}{cccc}
\hline Pressure, $\mathbf{M P a}$ & Intercept & Slope* & $\mathbf{R}^{\mathbf{2}}$ \\
\hline 8 & $4.886 \pm 0.091$ & $-0.0532 \pm 0.0134$ & 0.9423 \\
10 & $5.213 \pm 0.057$ & $-0.0514 \pm 0.0083$ & 0.9749 \\
15 & $5.592 \pm 0.025$ & $-0.0552 \pm 0.0036$ & 0.9957 \\
20 & $5.808 \pm 0.064$ & $-0.0519 \pm 0.0095$ & 0.9681 \\
\hline
\end{tabular}

$(*)$ The ANOVA performed for variables in the order fitted determined no significant differences among the slope at the $90 \%$ (or higher) confidence level.

At the highest pressure studied in this work, $20 \mathrm{MPa}, \mathrm{CO}_{2}$ solubility has been also determined at 308 and $328 \mathrm{~K}$ in the citrate buffer solution for the two $\mathrm{pH}$ values of 3.8 and 6.2 in presence of all sugars ( 2.91 wt. \% of glucose, 2.51 wt. \% of sucrose and 5.85 wt. \% of fructose). Results are plotted in Figures 5.5a and 5.5b. As previously described, $\mathrm{CO}_{2}$ solubility decreased with temperature and, for each temperature, no significant differences $(\mathrm{p} \leq 0.05)$ were found between both values of $\mathrm{pH}$, although, in general, slightly lower values were obtained at $\mathrm{pH}=6.2$ (Table 5.6). Solubility data obtained at these two 
temperatures were also fitted to Eq. $\mathbf{5 . 4}$ together with the previous data at different sugar concentration. Fitted parameters are listed in Table $\mathbf{5 . 2}$ and good fitting can be observed.

Table $5.6 \mathrm{CO}_{2}$ solubility in citrate buffer solutions at $\mathrm{pH}=3.8$ and $\mathrm{pH}=6.2$ in the presence of glucose (2.91 wt. \%), sucrose (2.51 wt. \%) and fructose (5.85 wt. \%) at $20 \mathrm{MPa}$ and different temperatures.

\begin{tabular}{ccc}
\hline $\mathbf{p H}$ & Temperature, $\mathrm{K}$ & $\mathbf{g ~ C O}_{2} / \mathbf{1 0 0} \mathbf{g}$ of liquid \\
\hline 3.8 & 308 & $5.43 \pm 0.01^{\mathrm{c}}$ \\
6.2 & 308 & $5.46 \pm 0.08^{\mathrm{c}}$ \\
\hline 3.8 & 318 & $5.26 \pm 0.05^{\mathrm{b}}$ \\
6.2 & 318 & $5.15 \pm 0.06^{\mathrm{b}}$ \\
\hline 3.8 & 328 & $4.93 \pm 0.02^{\mathrm{a}}$ \\
6.2 & 328 & $4.85 \pm 0.03^{\mathrm{a}}$ \\
\hline
\end{tabular}

Same letters in the solubility column mean no significant difference according to LSD test at $p$-value $\leq 0.05$.

Finally, the effect of the presence of pectin on $\mathrm{CO}_{2}$ solubility was also determined in a complex mixture of citrate buffer at $\mathrm{pH}=3.8$ in presence of all the sugars $(2.91 \mathrm{wt}$. \% of glucose, 2.51 wt. \% of sucrose and 5.85 wt. \% of fructose) and for a pectin concentration similar to the pectin content of apple juice, $22 \mathrm{mg} / \mathrm{L}$ expressed as D-galacturonic acid (Illera et al., 2018a). $\mathrm{CO}_{2}$ solubility was determined for that mixture at $20 \mathrm{MPa}$ and $318 \mathrm{~K}$ obtaining a value of $5.27 \pm 0.04 \mathrm{~g} / 100 \mathrm{~g}$ of liquid mixture, finding no significant difference with the value of solubility for the same mixture in the absence of pectin ( $p \leq 0.05)$.

\section{$3.4 \mathrm{CO}_{2}$ solubility in real apple and carrot juice}

$\mathrm{CO}_{2}$ solubility was finally determined in real apple and carrot juices at $20 \mathrm{MPa}$ in the temperature range from 308 to $328 \mathrm{~K}$. Results are plotted in Figure 5.5a and 5.5b together with the results obtained for the corresponding citrate buffer in presence of all sugars for a better comparison. Surprisingly, $\mathrm{CO}_{2}$ solubility is higher in the real juices than in the model solutions in presence of all sugars. This result could be attributed to the ${ }^{\circ}$ Brix of the real juices compared to the ${ }^{\circ}$ Brix of the corresponding model solutions at both $\mathrm{pH}$ values. 


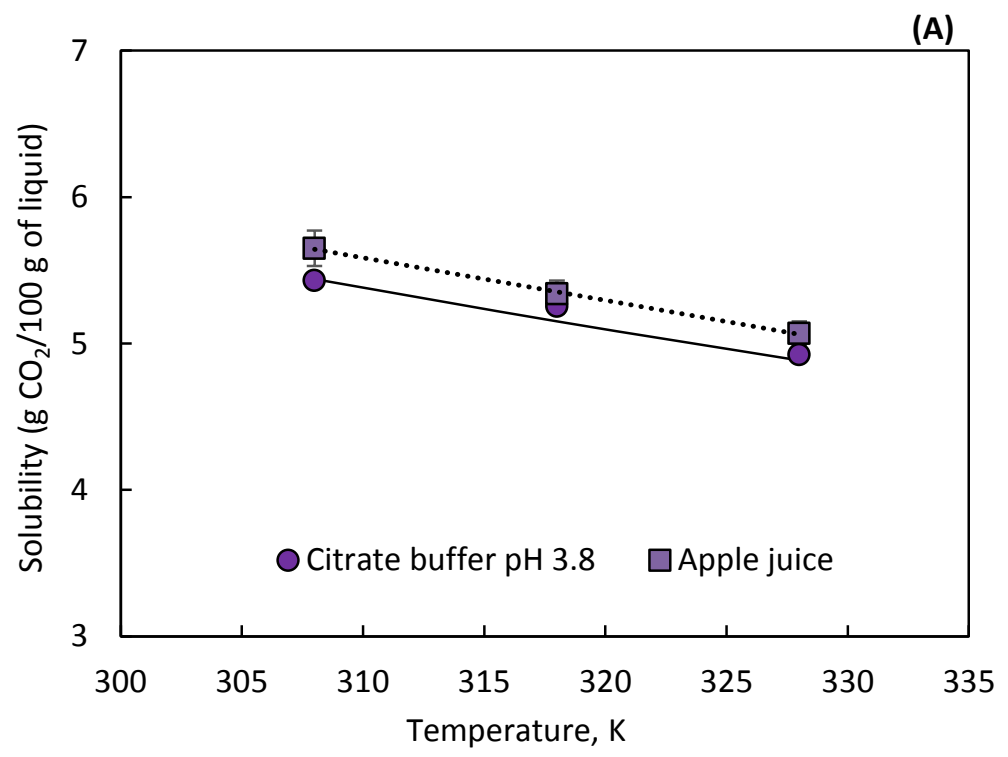

(B)

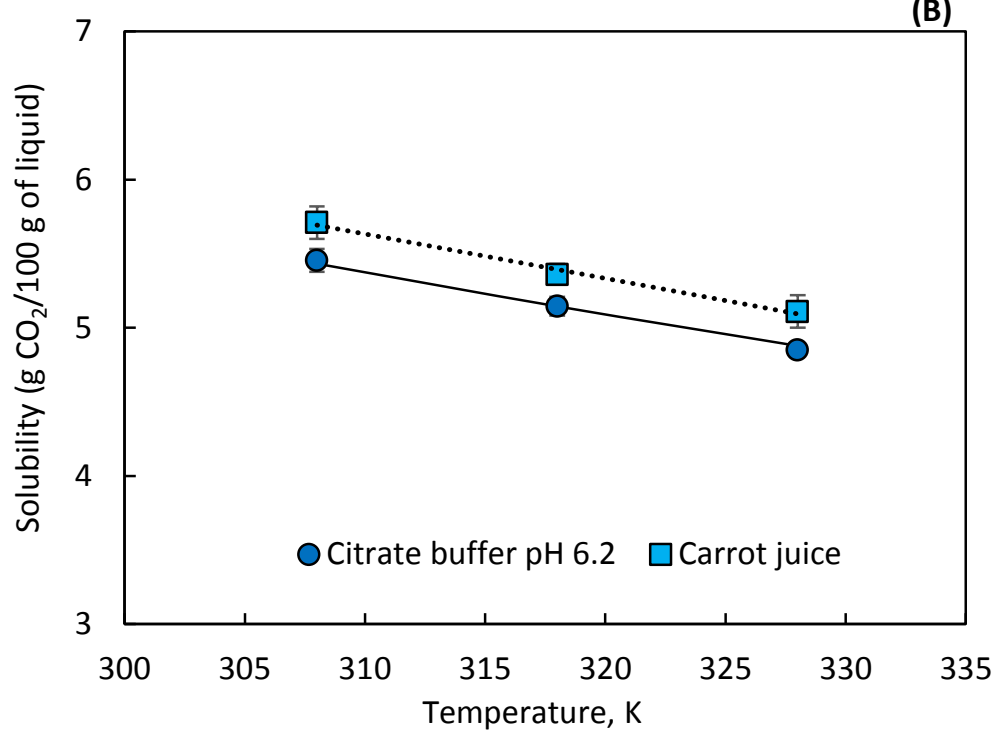

Figure $5.5 \mathrm{CO}_{2}$ solubility at $20 \mathrm{MPa}(\mathrm{a})$ In a citrate buffer solution $\mathrm{pH}=3.8$ with all the sugars and in real apple juice (b) In a citrate buffer solution $\mathrm{pH}=6.2$ with all the sugars and real carrot juice. Continuous lines represent the fitting to Eq. $\mathbf{5 . 4}$ and parameters are listed in Table 5.2. Discontinuous lines are to guide the eye.

Apple juice presented a value of $10.83^{\circ}$ Brix while the citrate buffer solution with all the sugars at $\mathrm{pH}=3.8$ presented a slightly higher value, $11.17^{\circ}$ Brix. The same behavior was determined for carrot juice, with a ${ }^{\circ} \mathrm{Brix}$ value of 9.06 while the ${ }^{\circ} \mathrm{Brix}$ of the model solution at $\mathrm{pH}=6.2$ were higher, 11.63 . As it was explained in the experimental section 2.2 , higher 
sugar content than the usual found in carrot juice was chosen at $\mathrm{pH}$ close to the carrot juice, to compare the $\mathrm{CO}_{2}$ solubility at different $\mathrm{pH}$ values. In any case, differences could be also attributed to the presence of minor components present in the real juices that could exert an effect on $\mathrm{CO}_{2}$ solubility.

\section{Conclusions}

$\mathrm{CO}_{2}$ solubility in aqueous solutions depends on the composition of the solutions. Slightly lower values, but not significant different according to LSD test, of $\mathrm{CO}_{2}$ solubility in citrate buffer solutions were obtained compared to water, probably due to presence of sodium citrate salt. Sugars present in fruit or vegetable juices, such as sucrose, glucose or fructose led to significant lower values of $\mathrm{CO}_{2}$ solubility. The presence of other minor components such as pectin did not affect the solubility values.

$\mathrm{CO}_{2}$ solubility data were successfully fitted to a Chrastil type equation, according to Fornari's approach to relate the liquid phase composition with the density of the supercritical fluid. In this work, an additional term was added, to account for the decrease in solubility of $\mathrm{CO}_{2}$ in the presence of sugars taking into account the ${ }^{\circ} \mathrm{Brix}$ of the aqueous solutions, obtaining a good fitting.

Solubility of real apple and carrot juices did not fit to the proposed model, since minor components present in natural juices could affect the $\mathrm{CO}_{2}$ solubility. 



\section{CHAPTER 6}

Optimization of polyphenol oxidase concentration by cationic reversed micellar extraction of Golden delicious apple: High Pressure Carbon Dioxide and Thermosonication enzyme inactivation

Based on the article:

A.E. Illera, S. Beltrán, M. T. Sanz

"Optimization of polyphenol oxidase concentration by cationic reversed micellar extraction of Golden delicious apple: High Pressure Carbon Dioxide and Thermosonication enzyme inactivation"

(Submitted to Scientific Reports) 



\title{
Capítulo 6
}

\author{
Optimización de la concentración de polifenoloxidasa en extractos \\ proteicos de manzanas Golden delicious mediante extracción por micelas \\ reversas: Inactivación enzimática por $\mathrm{CO}_{2}$ presurizado y termosonicación
}

\section{Resumen}

Con el objetivo de comprender en mayor profundidad el efecto de los tratamientos HPCD y TS sobre la polifenoloxidasa (PPO), en este capítulo se extrajo PPO de manzana y se purificó parcialmente mediante una extracción de micelas reversas. Las condiciones para las extracciones se optimizaron usando bromuro de dodecil trimetil amonio (DTAB) como surfactante catiónico. Se estudió el efecto de los parámetros de la extracción en las fases acuosa y orgánica y también el aumento en la concentración de PPO para optimizar el proceso de extracción a partir del extracto crudo obtenido y utilizando AG2-X8 como adsorbente de compuestos fenólicos y Triton X-100. Utilizando las mejores condiciones, la actividad de PPO recuperada fue del 99 \% y el número de veces en que la concentración de la enzima se enriqueció fue 17. Se eliminaron algunas impurezas mediante un proceso de ultrafiltración centrífuga y el extracto de proteína se trató con $\mathrm{CO}_{2}$ presurizado (HPCD) y termosonicación (TS), obteniendo un valor de actividad residual de $16 \pm 3$ y $9 \pm 1$, respectivamente. Se realizaron pruebas de 'quenching' utilizando yoduro potásico en los extractos tratados y sin tratar, y como resultado se obtuvo que la fracción proteica había sufrido cambios conformacionales debido a la gran exposición que se observó entre el fluoróforo y el 'quencher'.

Palabras clave: PPO de manzana, extracción por micelas reversas, tecnologías no térmicas, análisis de fluorescencia. 



\begin{abstract}
Polyphenol oxidase (PPO) was extracted and further concentrated from apple by cationic reversed micellar extraction. Forward and reverse extraction conditions were optimized by using dodecyl trimethyl ammonium bromide (DTAB) as cationic surfactant. The effect of parameters in the aqueous and organic phases on activity recovery and concentration fold of PPO was studied to optimize the extraction process from a crude extract obtained using AG2-X8 as adsorbent of phenolic compounds and Triton X-100. Under optimum conditions, PPO recovered activity and purification fold were $99 \%$ and 17 , respectively, showing that reverse micellar extraction was a good technique to initially concentrate a targeted enzyme. After removing some impurities by centrifuge ultrafiltration, this protein extract with PPO activity was treated by High Pressure Carbon Dioxide (HPCD) and Thermosonication (TS), achieving residual PPO activity values of $16 \pm 3$ and $9 \pm 1 \%$, respectively. Quenching experiments by potassium iodide performed in the non-treated extract and in the HPCD and TS treated extracts revealed conformational changes of this protein fraction reflected in the greater exposure of the fluorophore to the quencher.
\end{abstract}

Keywords: PPO-apple, reverse micellar extraction, non-thermal technologies, fluorescence analysis. 



\section{Introduction}

Consumers demand fresh and minimally processed products without chemical preservatives. Traditionally, thermal treatments have been used to prevent microbial spoilage as well as for the inactivation of some enzymes that cause deleterious effects on foods. However, thermal treatments can cause undesirable changes in physical and nutritional parameters. Therefore, in the last years, the Food Industry is searching for new processing and preservation methods. Some of these technologies include the use of high pressure, such as High Pressure Processing (HPP) or High Pressure Carbon Dioxide (HPCD), electric fields, and ultrasounds (US) among others (Briongos et al., 2016). In previous works, HPCD and Thermosonication (TS) have been applied to inactivate some of the enzymes that cause negative effects on cloudy apple juice from Golden delicious, such as polyphenol oxidase (PPO) and pectin methylesterase (PME). PPO is responsible for the enzymatic browning since it catalyzes the oxidation of phenolic compounds to quinones that can polymerize into brown pigments. When using HPCD to inactive PPO, a residual activity of $13.4 \%$ at $20 \mathrm{MPa}, 45^{\circ} \mathrm{C}$ and 60 min was achieved (Illera et al., 2018a) However, application of moderate temperatures $\left(50-67^{\circ} \mathrm{C}\right)$ was necessary when using the TS technology to reach low residual activity of PPO, $71 \%$ and $5 \%$ at 50 and $67{ }^{\circ} \mathrm{C}$, respectively during 20 min of continuous thermosonication (Illera et al., 2018b).

The knowledge of the mechanism of enzyme inactivation is of great importance for the optimization of these new preservation methods. Mechanism for enzyme inactivation by $\mathrm{HPCD}$ is not still clear, conformational changes, formation of different complex with $\mathrm{CO}_{2}$ molecules or decomposition of the enzyme by $\mathrm{CO}_{2}$ have been reviewed by $\mathrm{Hu}$ et al. (Hu et al., 2013). Recently, Illera et al. (Illera et al., 2019) determined $\mathrm{CO}_{2}$ solubility in different fruit juices for a better understanding of $\mathrm{CO}_{2}$ as pasteurizing agent. Regarding enzyme inactivation by TS, inactivation of enzymes has been attributed to the formation of localized hot spots upon collapse of bubbles, shear forces created by microstreaming and shock waves, as well as generation of free radicals through sonolysis of water (Kadkhodaee \& Povey, 2008). Characterization of PPO structure in its original matrix is complicated since many other compounds present in the juice can interfere (sugar, pectin, 
polyphenols and other proteins). In this work, polyphenol oxidase has been partially concentrated from Golden delicious apple in order to obtain a protein extract with PPO activity that has been treated by two non-thermal technologies, HPCD and TS.

Reverse micellar extraction has been selected as separation and concentration method of PPO from Golden delicious apple, based on previous studies on partial purification of PPO from apple skin by cationic reversed micellar extraction (Imm \& Kim, 2009). In a reverse micellar extraction process, a target protein is transferred from the initial aqueous phase to the reverse micelles (forward extraction) and then stripped into a fresh aqueous phase stripping solution (backward extraction) (Mathew \& Juang, 2007). The distribution of proteins between a micellar organic phase and an aqueous solution is determined by the parameters in the aqueous phase $(\mathrm{pH}$, ionic strength, type of salt) and in the organic phase (type and concentration of surfactant, presence of co-surfactant and type of solvent), as well as by changes in temperature (Pires \& Cabral, 1996). Reverse micellar extraction is an attractive extraction method to recover different biochemical compounds without losing their native activity. In addition, it offers a low interfacial tension, it is easy to scale-up and it can operate in a continuous mode (Mathew \& Juang, 2007). However, this separation technique must be considered as a first separation step since pure enzymes cannot be isolated.

In this work, reverse micellar extraction has been optimized as a first step for PPO purification from apple, following a similar procedure as the one proposed by $1 \mathrm{~mm}$ and Kim (2009) for apple skin. The parameters of forward and backward extraction were studied to optimize activity recovery and purification fold of PPO. The protein extract with the highest PPO activity recovery and purification fold, was treated by High Pressure Carbon Dioxide and Thermosonication. PPO inactivation in the extract was compared with previously data obtained in its natural media in the juice. Conformational changes of the protein extract with PPO activity were determined by quenching experiments of the extract by fluorescence after treatment. 


\section{Materials and methods}

\subsection{Crude PPO extracts preparation}

The extraction procedure of PPO was performed according to Zhou et al. (Zhou et al., 1993) for apple skin with some modifications. The anion exchange resin AG2-X8 (Bio Rad Laboratories) was used as adsorbent of phenolic compounds during the extraction to avoid PPO inactivation during extraction. Additionally, the detergent Triton X100 was employed to facilitate solubilization of the membrane bound-PPO (Rocha \& Morais, 2001). The unseeded apple was grounded with liquid nitrogen in a glass blender to decompose cell membranes. Sodium phosphate buffer, $\mathrm{pH}=7.2$, with different amounts of AG2-X8 (0 to 2:1, g resin:g apple) and Triton $\mathrm{X} 100$ (from 0 to $0.15 \mathrm{wt}$. \%) was mixed with the grounded apple at the ratio $1.7 \mathrm{ml}$ of buffer/g apple, as the optimum ratio determined by Rocha and Morais (2001) for PPO extraction from apple (cv. Jonagored). The mixture was kept in the fridge at $4{ }^{\circ} \mathrm{C}$ for $1 \mathrm{~h}$. Afterwards, the extract was filtered and centrifuged for $30 \mathrm{~min}$ at $5000 \mathrm{~g}$ and $4{ }^{\circ} \mathrm{C}$. The supernatant for the optimum amount of AG2-X8 and Triton $\mathrm{X} 100$ was used as a crude extract for further purification by reverse micellar extraction.

\subsection{Reverse micellar extraction}

\subsubsection{Forward extraction}

The distribution of the protein between a micellar organic phase and an aqueous solution is determined by the $\mathrm{pH}$ and the ionic strength of the aqueous phase among other factors (Pires \& Cabral, 1996). The $\mathrm{pH}$ was adjusted by using two different types of buffers to obtain the aqueous extract, a citrate buffer, $100 \mathrm{mM} \mathrm{pH}=4-6$, and sodium phosphate buffer, $100 \mathrm{mM} \mathrm{pH}=7-8$. $\mathrm{KCl}$ concentration was varied from 0 to $100 \mathrm{mM}$ to adjust the ionic strength. The organic phase was constituted by the cationic surfactant dodecyl trimethyl ammonium bromide (DTAB), at different concentrations (50 - $200 \mathrm{mM}$ ) dissolved 
in isooctane mixed with hexanol as co-surfactant at the ratio 5:1 (v/v), according to Imm and Kim (2009). When using a cationic surfactant, very small micelles are formed and the addition of a co-surfactant, such as an alcohol, makes the micelles grow, improving water uptake and solubility capacity of the organic phase (Mathew \& Juang, 2007; Noh \& Imm, 2005). The forward extraction was carried out by mixing thoroughly equal volumes of the organic phase and the crude extract, at the different $\mathrm{pH}$ of extraction and ionic strength, for $20 \mathrm{~min}$ at $4{ }^{\circ} \mathrm{C}$. Phase separation was performed by centrifugation at $4{ }^{\circ} \mathrm{C}$ and $2800 \mathrm{~g}$. Forward extraction was also carried out at different temperatures in the range from 4 to $25^{\circ} \mathrm{C}$, since change in temperature can also affect the protein solubilization (Pires \& Cabral, 1996). The upper organic phase was formed by the reverse micellar phase that contained the extracted PPO and was collected for the backward extraction.

\subsubsection{Backward extraction}

The protein reverse micellar phase from the forward extraction was mixed with an equal volume of the stripping solution that consisted in sodium phosphate buffer at $\mathrm{pH}=6$ containing $1 \mathrm{M} \mathrm{KCl}$ and $10 \% \mathrm{v} / \mathrm{v}$ of ethanol. The mixture was centrifuged at $4{ }^{\circ} \mathrm{C}$ and $2800 \mathrm{~g}$ for $90 \mathrm{~min}$ to separate the phases. This stripping solution was used in all the experiments where forward extraction was optimized. The effect of different ionic strength in the backward extraction, $\mathrm{KCl}$ from 0.05 to $1 \mathrm{M}$, was also studied. The effect of the presence or absence of ethanol in the stripping solution was also analyzed. Forward and backward experiments were performed at the same extraction temperature. The lower aqueous phase was collected to determine the activity recovery and the purification fold of the reverse micellar extraction process.

\subsubsection{Centrifuge ultrafiltration}

The optimum extract obtained by reverse micellar extraction with the highest activity recovery and purification factor was treated by centrifuge ultrafiltration by using Amicon Ultra centrifugal filters (15 ml, NMWL:3000) with a regenerate cellulose membrane of the filters that allowed a high PPO activity recovery. The final retentate volume was brought 
to the initial treated volume with the same sodium phosphate buffer as the one used in the backward extraction.

\subsection{Parameters to determine the efficiency of the reverse micellar process}

\subsubsection{Protein content in the aqueous phase}

Total protein content in the crude extract and in the aqueous phase after backward extraction was determined by using the kit $R C D C^{\mathrm{TM}}$ (Bio Rad Laboratories). This assay is based on the Lowry protocol and it allows protein determination in the presence of reducing agents and detergents such as Triton X100. Bovine serum albumin was used as standard.

\subsubsection{Determination of PPO activity}

The activity of PPO was determined spectrophotometrically by using a $0.05 \mathrm{M}$ catechol (Sigma Aldrich) solution prepared in a $0.1 \mathrm{M}$ phosphate buffer $(\mathrm{pH} 6.5)$ as substrate. Samples were analyzed by adding $100 \mu \mathrm{l}$ of PPO extract into $2.9 \mathrm{ml}$ substrate solution. Oxidation of catechol was determined immediately by the increase in absorbance at $420 \mathrm{~nm}$ by using a Jasco V-750 spectrophotometer equipped with a Peltier thermostated cell holder and a water pump to keep the temperature constant at $30^{\circ} \mathrm{C}$. The PPO activity was taken as the very first linear part of the reaction curve. One unit of PPO activity was defined as the amount of enzyme required for $0.001 / \mathrm{min}$ absorbance increase under the reaction conditions.

\subsubsection{Determination of peroxidase activity}

Peroxidase (POD) activity was determined spectrophotometrically according to Soysal et al. (2004). Reaction started when mixing $2.7 \mathrm{ml}$ of $0.01 \mathrm{M}$ acetate buffer (pH 5), $0.1 \mathrm{ml}$ of $0.1 \%(\mathrm{v} / \mathrm{v}) \mathrm{H}_{2} \mathrm{O}_{2}, 0.4 \mathrm{ml}$ of $0.05 \%(\mathrm{w} / \mathrm{v})$ o-dianisidine in methanol and $0.1 \mathrm{ml}$ of protein 
extract. Right after mixing, absorbance was measured at $460 \mathrm{~nm}$ during 120 seconds by using a Jasco V-750 spectrophotometer. The POD activity was taken as the linear part of the reaction curve.

\subsubsection{Activity recovery and purification fold}

Percentage of activity recovery (AR) is defined as

$A R(\%)=A_{b} / A_{i} \cdot 100$

Purification fold (PF) is defined as

$P F=\left(A_{b} / C_{b} V_{b}\right) \cdot\left(C_{i} V_{i} / A_{i}\right)$

where $A$ is the PPO activity, $V(\mathrm{ml})$ volume and C concentration of protein $(\mathrm{mg} / \mathrm{L})$ and subscripts $i$ and $b$ denote initial crude PPO extract and backward extraction aqueous phase, respectively (Imm \& Kim, 2009; Liu et al., 2006).

\subsection{Treatment of PPO extract by HPCD and TS}

The optimum protein extract in terms of PPO activity recovery and purification fold, was treated by HPCD and TS. Residual activity after treatment was determined as well as conformational changes by quenching of enzyme extract with $\mathrm{KI}$ by fluorescence spectroscopy.

HPCD treatment. The experimental set up has been previously described in detail (Illera et al., 2018a). It consists of a $\mathrm{CO}_{2}$ reservoir and a high pressure syringe pump (260D Teledyne ISCO). In a HPCD experiment, $40 \mathrm{ml}$ of PPO extract were charged in a stainless steel high pressure batch stirred reactor with an internal volume of, approximately, $80 \mathrm{ml}$, submerged in a thermostatic water bath. Pressurized $\mathrm{CO}_{2}$ was bubbled directly into the enzyme solution. Based on previous inactivation studies on PPO inactivation from Golden 
delicious cloudy apple juice, operating pressure and temperature were fixed at $20 \mathrm{MPa}$ and $45{ }^{\circ} \mathrm{C}$ respectively, and treatment time was 60 min (Illera et al., 2018a).

TS treatment. A $750 \mathrm{~W}$ ultrasonic processor (Sonics and Materials ${ }^{\mathrm{TM}}$ ) with a $13 \mathrm{~mm}$ probe was used for sonication. $80 \mathrm{ml}$ of PPO extract were treated for $20 \mathrm{~min}$ in a continuous mode at $100 \%$ amplitude. Medium temperature treatment was $64{ }^{\circ} \mathrm{C}$ (Illera et al., 2018b).

PPO activity was determined before and after treatment and residual activity for both, HPCD and TS treatment, was evaluated as the ratio between PPO activity after treatment and PPO activity before treatment.

\subsection{Fluorescence Spectroscopy}

The tertiary structure of the protein extract before and after HPCD and TS treatment was determined by fluorescence spectroscopy using a FLS980 photoluminescence spectrometer (Edinburgh Instruments, Livingstone, UK). The sample was excited at a $\lambda_{\mathrm{em}}=280 \mathrm{~nm}$ and the emission spectra were recorded in the range from 290 to $400 \mathrm{~nm}$. A $1 \mathrm{~cm}$ path length cell was used and the emission and excitation slits were set at 2 and $1 \mathrm{~nm}$, respectively.

Conformational changes of protein extract with PPO activity induced by HPCD and TS treatments were confirmed by tryptophan fluorescence quenching experiments. A stock solution of potassium iodide $(\mathrm{KI}, 2 \mathrm{M})$ containing $0.1 \mathrm{M}$ sodium thiosulfate, to prevent the formation for triiodide, was used as quencher. Small aliquots of the quencher stock solution were added to the PPO extract and fluorescence spectra were recorded after each addition. The quenching process of the tryptophan fluorescence was analyzed by using the Stern-Volmer equation:

$I_{o} / I=1+K_{S V} Q$

Where $I_{0}$ and $I$ are the fluorescence intensities in the absence and presence of a given concentration of quencher, $Q$ is the quencher concentration and $K_{S V}$ is the Stern-Volmer constant. This constant describes the accessibility of the quencher to the fluorophore 
(tryptophan). If the tryptophan residue is located on the protein surface, the emission will be strongly affected by the addition of the quencher; on the other hand, if the tryptophan residue is buried, its emission will be less affected after the addition of the quencher (Möller \& Denicola, 2002).

\subsection{Statistical analysis}

Statistical analysls were conducted using software Statgraphics Centurion (Version 17.3.02, 64-bit) by Statpoint Technologies, Inc. The results are presented as a mean \pm standard deviation of at least three replicates. The significance of the differences was determined based on an analysis of the variance with the Tukey's honestly significant difference (HSD) method at $p$-value $\leq 0.05$. An ANOVA was performed to test the statistical significance of the slope in the equation of Stern Vollmer, $\mathrm{K}_{\mathrm{sV}}$ for the untreated protein extract and HPCD and TS treated extract.

\section{Results and discussion}

\subsection{Optimization of crude PPO extract}

AG2-X8 and Triton X100 concentration were varied in the range of 0 to 2:1 (g resin: g apple), and 0 to 0.15 wt. \%, respectively. Table 6.1 presents the PPO activity for the crude extracts for all the experiments performed. When neither resin nor Triton $\mathrm{X} 100$ was employed in the extraction, the PPO activity of the crude extract presented the lowest value. PPO extraction significantly improved with the presence of the resin due to its ability to adsorb endogenous phenolic compounds from the extraction medium (Zhou et al., 1993). A ratio of $0.5: 1$ (g resin: $g$ apple) was found to be the optimum, since higher ratios did not bring any increase in PPO activity. Triton X100 also induced an increase in PPO activity. 
Table 6.1 Influence of AG2-X8 and Triton X100 concentration on PPO activity of the crude extract by using phosphate buffer, $\mathrm{pH}=7.2$

\begin{tabular}{cccc}
\hline Resin (g) & Apple (g) & Triton X100 (\%) & Apple (U/g) \\
\hline 0 & 0 & 0 & $326 \pm 30^{\mathrm{a}}$ \\
\hline 0 & 1 & 0.15 & $1214 \pm 134^{\mathrm{b}}$ \\
0.5 & 1 & 0.15 & $1900 \pm 90^{\mathrm{c,d}}$ \\
1 & 1 & 0.15 & $1821 \pm 20^{\mathrm{c}}$ \\
2 & 1 & 0.15 & $1379 \pm 101^{\mathrm{b}}$ \\
\hline 0.5 & 1 & 0 & $1205 \pm 119^{\mathrm{b}}$ \\
0.5 & 1 & 0.02 & $1819 \pm 103^{\mathrm{c}}$ \\
0.5 & 1 & 0.05 & $1920 \pm 105^{\mathrm{c}, \mathrm{d}}$ \\
0.5 & 1 & 0.1 & $2166 \pm 74^{\mathrm{d}}$ \\
0.5 & 1 & 0.15 & $1900 \pm 90^{\mathrm{c,d}}$ \\
\hline
\end{tabular}

Values with different letters in each column, and each treatment are significantly different when applying the Tukey's honestly significant difference (HSD) method at $p$-value $\leq 0.05$.

At a ratio of $0.5 \mathrm{~g}$ resin: $1 \mathrm{~g}$ apple PPO activity sharply increased with the addition of 0.02 wt. \% of Triton $\mathrm{X} 100$, reaching a plateau up to the highest concentration essayed in this work, 0.15 wt. \%. Janovitz-Klapp et al. (Janovitz-Klapp et al., 1989) also found that PPO activity increased rapidly up to 0.5 wt. \% of Triton X100, reaching also a plateau in the extraction from Red delicious apple. Based on these results, further PPO extractions will be carried out adding $0.5 \mathrm{~g}$ resin: $1 \mathrm{~g}$ apple and $0.02 \mathrm{wt}$. \% Triton X100 to the corresponding extraction buffer.

\subsection{Purification by reverse micellar extraction}

\subsubsection{Forward extraction}

Effect of pH. Figure 6.1 shows a strong influence of the $\mathrm{pH}$ of the extraction medium on the activity recovery and purification fold, with no $\mathrm{KCl}$ added to the extraction medium and at a DTAB concentration of $100 \mathrm{mM}$. Buffer extraction media at $\mathrm{pH}=6$ and 7.2 yielded the highest purification factor, although slightly higher values of activity recovery were obtained at $\mathrm{pH}=7.2$. 


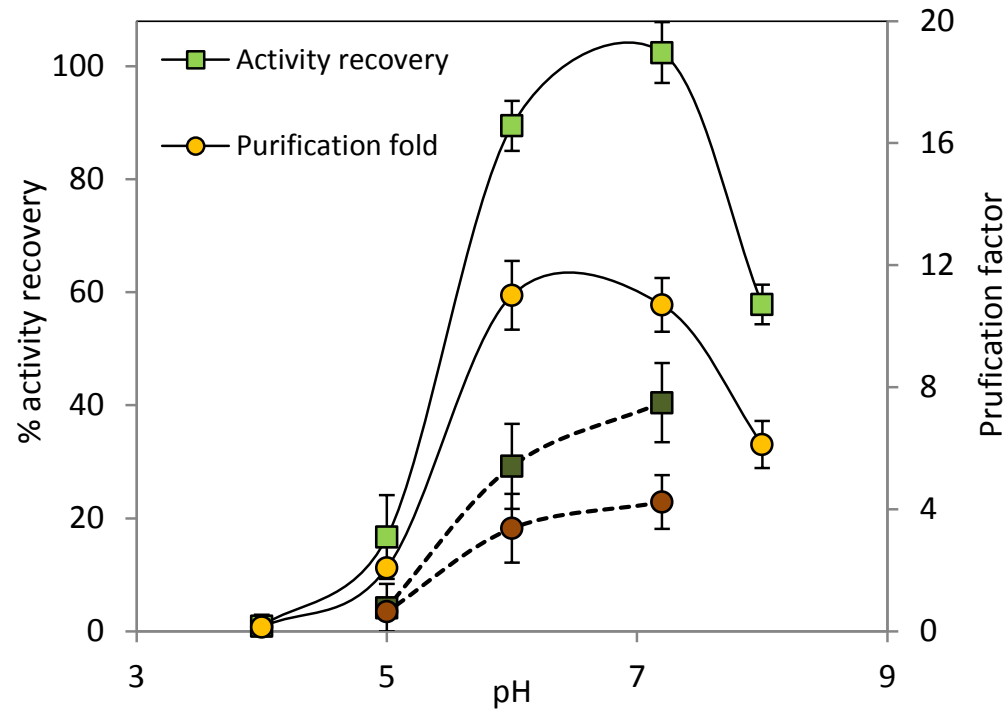

Figure 6.1 Effect of $\mathrm{pH}$ of the initial aqueous phase on activity recovery and purification fold of PPO. Lighter symbols correspond when Triton X-100 was added to obtain the initial crude extract.

For cationic surfactants, such as DTAB, solubilization of the protein in the reverse micellar phase is favored at $\mathrm{pH}$ above its isoelectric point (Qiang et al., 1998). According to the literature, the reported isoelectric point of PPO from Red delicious apple was 4.5 - 4.8 (Imm \& Kim, 2009). At pH above its isoelectric point, PPO presents a net negative charge that favors electrostatic interactions with the cationic surfactant. In any case, it must be highlighted that not only electrostatic interactions play an important role on protein solubilization but also hydrophobic interactions (Pires \& Cabral, 1996). Rocha \& Morais (Rocha \& Morais, 2001) reported two maxima in the extraction pH vs. activity curve, at 5.0 and 7.5 at $20^{\circ} \mathrm{C}$ from PPO extracted from Jonagored apple, corresponding to PPO from chloroplasts and from mitochondria, respectively. According to the optimum $\mathrm{pH}$ of PPO, it seems to be a chloroplasmic enzyme, although, the use of detergents may affect either the cytoplasm or the mitochondrial enzyme. At pH above 7.2, both, activity recovery and purification fold dropped probably due to enzyme inactivation. Imm and Kim (2009) reported an optimum $\mathrm{pH}$ of 6 for PPO extraction from apple skin by reverse micellar extraction with DTAB, although activity recovery was less than $50 \%$ with purification fold slightly above 10 . These authors, at $\mathrm{pH}=7$, obtained similar purification fold, but the 
activity recovery was less than 20 wt. \%. In this work, a similar protocol as the one proposed by these authors was used to extract and concentrate PPO, but higher activity recoveries were obtained. These differences could be attributed to the way the crude extract was obtained. Imm and Kim (2009) employed double-deionized water containing the resin as extracting medium to obtain the crude extract with no addition of Triton $\mathrm{X} 100$. As described in the previous section, the effect of Triton X100 was positive to increase the activity of PPO in the crude extract. To study the effect of Triton X100 in the reverse micellar process extraction and purification process, experiments were performed in the $\mathrm{pH}$ range from 5 to 7.2 without adding Triton $\mathrm{X} 100$ to obtain the crude extract.

Figure 6.1 shows that activity recovery and purification fold was significantly lower when no Triton X100 was added to the process.

Effect of ionic strength. Forward extraction was performed at the optimum pH of 7.2 and $100 \mathrm{mM}$ of DTAB under different concentrations of $\mathrm{KCl}$, from 0 to $100 \mathrm{mM}$. The effect of ionic strength on PPO activity recovery and purification fold is shown in Figure 6.2.

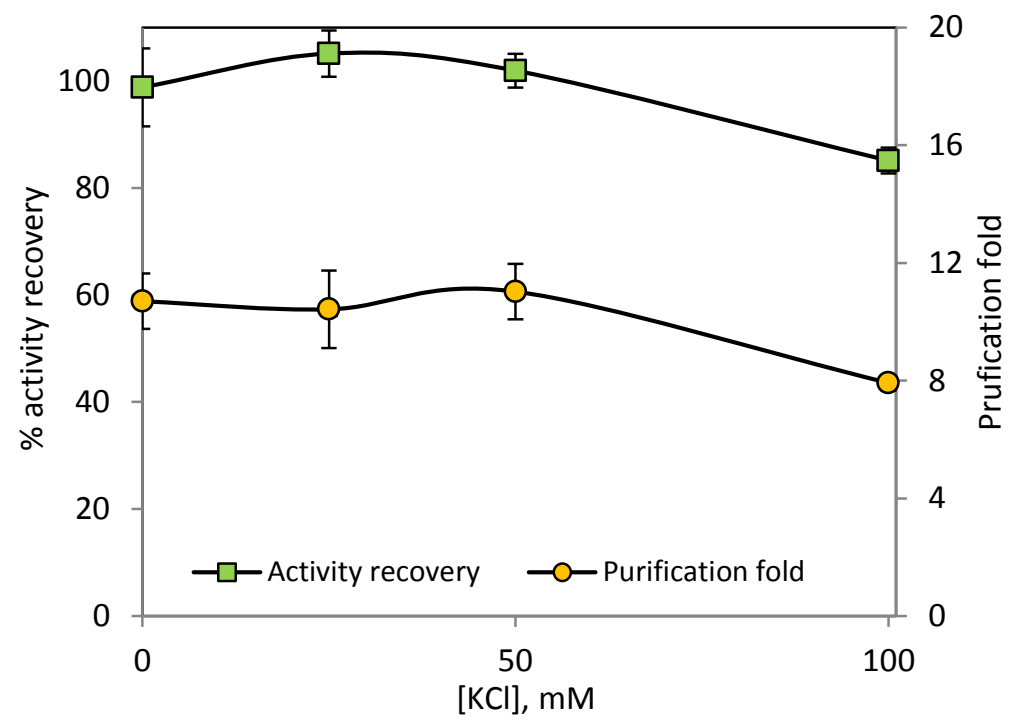

Figure 6.2 Effect of ionic strength in the forward extraction on activity recovery and purification fold of PPO. 
The activity recovery and purification fold did not change up to $50 \mathrm{mM}$ of $\mathrm{KCl}$, while a decrease was observed at the highest concentration of $\mathrm{KCl}$ essayed in this work, $100 \mathrm{mM}$. At this concentration, the solubilization capacity of the organic phase for water and the protein decreased. At high ionic strength of the aqueous phase, electrostatic interactions between protein and surfactant decreased due to the Debye screening effect caused by the presence of mobile charge carriers (Pires \& Cabral, 1996). In the literature it has been reported that a certain ionic strength is needed to form reverse micelles and phase separation. In this work, when no $\mathrm{KCl}$ was added, a good performance was observed. This could be attributed to the use of a buffered aqueous solutions that can supply enough ionic strength (Pires \& Cabral, 1996). Imm and Kim (2009) obtained also the best results when no $\mathrm{KCl}$ was added to the extraction medium, with $43 \%$ of activity recovery and a value of 13 for the purification fold.

Effect of temperature. Reverse micellar extraction was carried out at three different temperatures, 4,18 and $25^{\circ} \mathrm{C}$, at $\mathrm{pH}=7.2$, DTAB concentration of $100 \mathrm{mM}$ and no $\mathrm{KCl}$ added to the aqueous phase. Figure 6.3 shows that when temperature increased, both activity recovery and purification fold of PPO decreased.

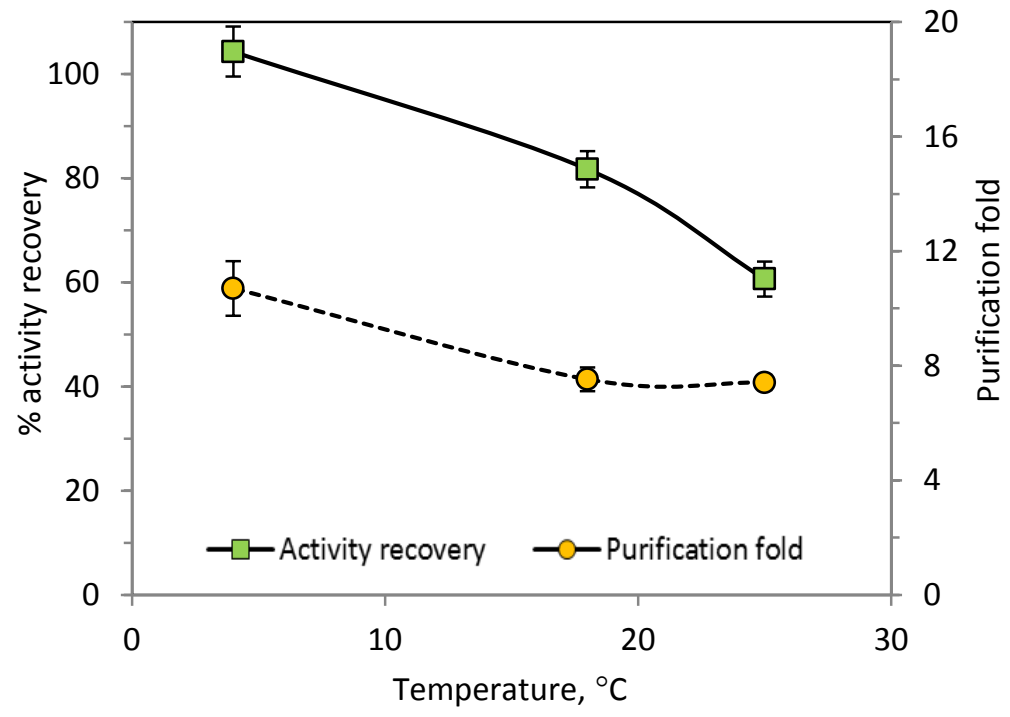

Figure 6.3 Effect of extraction temperature on activity recovery and purification fold of PPO. 
In this regard, the effect of temperature on reverse micellar extraction is still unclear, since phase behavior and mass transfer phenomena are involved. According to Liu et al. (Liu et al., 2006), an increase in temperature involves a decrease of the migration time for protein transfer through the interface and an enhanced diffusion, but also a decrease in the partition coefficient. By increasing extraction temperature, enzyme inactivation could also happen. However, in the temperature range covered in this work, during the extraction time, it was proved that no PPO inactivation took place. According to Figure 6.3, an increase of temperature seemed to decrease the protein partition coefficient, decreasing activity recovery and purification fold.

Effect of surfactant concentration. The nature and concentration of surfactant are important factors that determine enzyme solubilization. According to Imm and Kim (2009), DTAB was found to be an adequate surfactant to extract PPO from apple skin. In this work, DTAB was the only surfactant essayed and its concentration was varied between 50 to $200 \mathrm{mM}$ at $4{ }^{\circ} \mathrm{C}, \mathrm{pH}=7.2$ and no $\mathrm{KCl}$ added. In the concentration range covered in this work, no significant change in activity recovery and purification fold of PPO was observed as concentration of DTAB incrased from 50 to $200 \mathrm{mM}$ (Figure 6.4). Other authors observed a maximum activity recovery around $40 \%$ and purification fold of 12 at $100 \mathrm{mM}$ (Imm \& Kim, 2009). By increasing the surfactant concentration, protein solubilization in the organic phase is favored (Pires \& Cabral, 1996). In this work, $50 \mathrm{mM}$ seems to be enough to assure total protein mass transfer. A negative effect at the highest concentration, $200 \mathrm{mM}$, was not observed and probably, at this concentration, micellar interaction is still not taking place. 


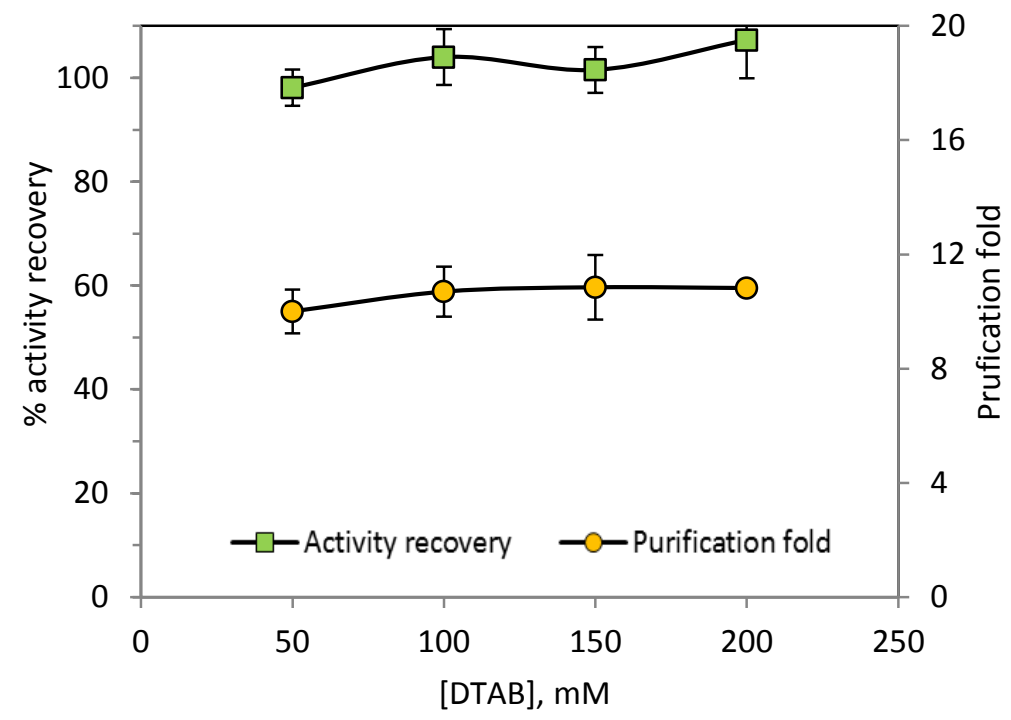

Figure 6.4 Effect of DTAB concentration in the forward extraction on activity recovery and purification fold of PPO.

\subsubsection{Backward extraction}

Forward extraction was performed at fixed conditions of $4{ }^{\circ} \mathrm{C}, \mathrm{pH}=7.2,100 \mathrm{mM}$ DTAB and no $\mathrm{KCl}$ added to the extraction medium. Reverse micellar phase was carried out with a stripping solution of sodium phosphate buffer at $\mathrm{pH}=6$ and $10 \% \mathrm{v} / \mathrm{v}$ of ethanol $(\mathrm{Imm} \&$ Kim, 2009). The effect of ionic strength of the stripping solution employed in the backward extraction was studied at different $\mathrm{KCl}$ concentrations in the range from 0.05 to $1 \mathrm{M}$ (Figure 6.5). An ionic strength around $0.5 \mathrm{M}$ of $\mathrm{KCl}$ was needed to achieve high activity recovery and purification fold factor. At this concentration, activity recovery and purification fold were $99 \pm 6 \%$ and $17 \pm 2$, respectively. Lower $\mathrm{KCl}$ concentrations were not enough to break the interactions between the solubilized PPO and the micelles, and both activity recovery and purification fold sharply decreased when decreasing $\mathrm{KCl}$ concentration. At $1 \mathrm{M} \mathrm{KCl}$, although activity recovery is still high, purification fold decreased down to $11 \pm 2$. Soni \& Madamwar (Soni \& Madamwar, 2000) found that at $0.2 \mathrm{M} \mathrm{KCl}$, acid cellular phosphatase activity recovery from fermentation broth was maximum, observing also a decreasing trend in back transfer protein recovery by further increasing ionic strength. At $0.75 \mathrm{M} \mathrm{KCl}$, backward extraction was also carried out in the 
absence of ethanol (Figure 6.5). Although purification fold factor was similar in the absence or presence of ethanol, activity recovery was significantly lower when no ethanol was present in the stripping solution. In this regard, in the literature, it has been reported that alcohol helps to disrupt the strong hydrophobic interaction of the protein with the surfactant favoring PPO release (Mathew \& Juang, 2007).

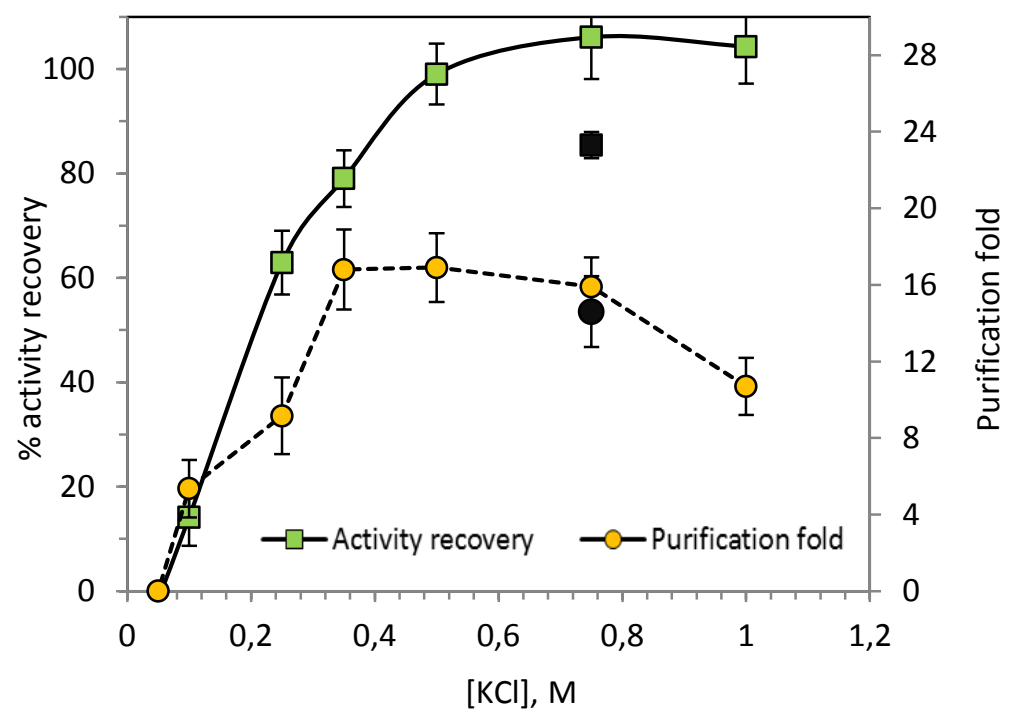

Figure 6.5 Effect of $\mathrm{KCl}$ concentration in the stripping solution of the backward extraction on activity recovery and purification fold of PPO. Black symbols correspond to backward extraction performed in the absence of ethanol.

In the literature, purification fold of the same order as the one obtained in this work has been reported for micellar reverse extraction. Imm \& Kim (Imm \& Kim, 2009) reported a purification fold of 13 (with $71 \%$ of activity recovery) for PPO recovery from apple skin by using DTAB. A purification factor of nearly 10 has been reported by Liu et al. (Liu et al., 2006) in the study of concentration of nattokinase by AOT/isooctane from fermentation broth. A maximum purification factor value of around 32 has been even reported from lysozyme extraction from free-dried egg-white of hen eggs by using cetyl dimethyl ammonium bromide (CDAB) (Noh \& Imm, 2005).

In any case, the maximum purification factor obtained by reverse micellar extraction in this work, was lower than those reported by Marrufo-Hernández et al. (Marrufo- 
Hernández et al., 2017) for PPO purification from Golden delicious apple with values of 30 and higher than 300 by fast protein liquid chromatography with a column packed with phenylsepharose and subsequent ion-exchange purification step, respectively. These results showed that reverse micellar extraction is an easy technique to perform a first concentration step, but further purification steps are needed to isolate the enzyme.

\subsection{Effect of HPCD and TS on protein extract with PPO activity}

Enough amount of protein extract with high PPO activity by revere micellar extraction was obtained and treated by High Pressure Carbon Dioxide and Thermosonication. Forward extraction conditions were the following, $4{ }^{\circ} \mathrm{C}, \mathrm{pH}=7.2,100 \mathrm{mM}$ DTAB and no $\mathrm{KCl}$ added Backward extraction conditions were $4{ }^{\circ} \mathrm{C}, \mathrm{pH}=6,0.75 \mathrm{M} \mathrm{KCl}$ and $10 \% \mathrm{v} / \mathrm{v}$ of ethanol.

Previous to the HPCD and TS treatments, salt concentration of the extract was decreased by centrifuge ultrafiltration by using Amicon $^{\circledR}$ Ultra centrifugal filters. A further purification fold factor of $2 \pm 0.4$ was achieved while PPO activity recovery was higher than $95 \%$.

PPO has been recognized as the main enzyme related with the enzymatic browning of apple; however, POD enzymes can also contribute to the discoloration in fresh-cut products. Therefore, before TS and HPCD treatment, the final protein extract obtained was checked for POD activity, founding no POD activity after centrifuge ultrafiltration process, although POD activity was found in the crude extract. In any case, after HPCD and TS treatment, POD activity was also measured, but no POD activity was found after both treatments.

Inactivation of PPO by HPCD was carried out at $45^{\circ} \mathrm{C}$ and $20 \mathrm{MPa}$ for $60 \mathrm{~min}$, reaching a PPO residual activity of $15.5 \pm 2.5 \%$. When PPO extract was treated by TS in a continuous mode during $20 \mathrm{~min}$ at a final temperature of $64{ }^{\circ} \mathrm{C}$, a PPO residual activity of $8.7 \pm 0.8 \%$ was obtained. In the literature, previous studies of PPO inactivation in its natural matrix in cloudy juice from Golden delicious apples by HPCD and TS treatments, at the same working conditions, reported PPO residual activity values of $13.4 \%$ and $16.4 \%$, 
respectively. Similar inactivation degree was obtained for the PPO extract treated by HPCD than in the real cloudy apple juice; however lower residual activity was observed for the PPO extract than for the cloudy apple juice at the same working conditions. In this regard, inactivation treatment has been reported as more effective in buffer systems than in real food systems, probably due to the protective effects of food components (Terefe et al., 2009).

\subsubsection{Conformational changes of protein extract with PPO activity after} HPCD and TS

The fluorescence properties of non-treated and HPCD and TS-treated protein extract were investigated through intrinsic fluorescence and quenching studies. The $\lambda_{\max }$ for the nontreated extract was $318 \mathrm{~nm}$. According to the literature, values of $\lambda_{\max }<330 \mathrm{~nm}$ show that tryptophan (Trp) is being buried and in a "nonpolar" environment (Jiang et al., 2014). After HPCD and TS treatment of protein extracts, slightly changes were observed in $\lambda_{\max }$, with a blue shifted of TS-treated protein extract $\left(\lambda_{\max }=317 \mathrm{~nm}\right)$ and a red shifted HPCD-treated PPO extract $\left(\lambda_{\max }=319 \mathrm{~nm}\right)$. Fluorescence intensity decreased for HPCD and TS-treated extracts. The decrease in fluorescence intensity for ultrasound treated enzymes has been also reported in the literature. Liu et al. (Liu et al., 2017) also observed a decrease in intensity fluorescence in a protein purified solution from oriental sweet melon with PPO activity after ultrasonication process. These authors explained that the change in intensity could be due to complicated structural changes induced by ultrasound. Regarding HPCD effect on fluorescence spectroscopy of HPCD-treated enzymes, Hu et al. (Hu et al., 2013) reviewed different effects on fluorescence intensity reported in the literature related to structural change according to its origin and environment. For instance, intrinsic relative fluorescence intensity of horseradish POD increased after HPCD treatment, and the maximum wavelength red-shifted, indicating that Trp surroundings changed to a more polar environment (Gui et al., 2006). Li et al.(Li et al., 2014) also observed a red-shifted in $\lambda_{\max }$ and decreased intensities after HPCD treatment in thaumatin like protein with high PPO activity. These authors attributed this behavior to the formation of a more polar environment and a decreased solution $\mathrm{pH}$ due to the formation of bicarbonate, carbonate and $\mathrm{H}^{+}$. 
Although no POD activity was found in the protein extract before treatment, the interpretation of the data is very complicated since the obtained protein extract presented high PPO activity, but it contains also a protein fraction co-extracted with the PPO, since by micellar reverse extraction PPO could not be isolated.

Quenching studies of the protein extract with PPO activity by KI with PPO activity were performed to examine the different location of tryptophan residues in untreated and HPCD and TS treated extracts. In this work a linear Stern-Volmer plot (Eq. 6.3) was obtained and, from the slopes, the Stern-Volmer quenching constants, $\mathrm{K}_{\mathrm{SV}}$, for the untreated and HPCD and TS-treated PPO extracts were obtained (Table 6.2 and Figure 6.6). According to the literature, the greater exposure of the fluorophore to the quencher, the higher the $K_{S V}$ value (Möller \& Denicola, 2002). An ANOVA was performed to test the statistical significance of the terms in the regression model and it was found that there are statistically significant differences among the slopes, the Stern-Volmer quenching constants, for the non-treated and HPCD and TS treated extracts at the $95 \%$ confidence level. The lowest value for $K_{S V}$ was obtained for the untreated protein extract, while the HPCD-treated extract presented the highest $\mathrm{K}_{\mathrm{SV}}$ value. The different values obtained for the untreated and treated extract confirms conformational change on proteins in the extract obtained in this work with PPO activity, since fluorophore accessibility was affected.

Table 6.2 Terms of regression to the Stern-Volmer equation (Equation 6.3)

\begin{tabular}{cccc}
\hline PPO extract & $\mathbf{K}_{\mathrm{Sv}}, \mathbf{M}^{-1}$ & Intercept & $\mathbf{R}^{\mathbf{2}}$ \\
\hline Non-treated & $1.889 \pm 0.061$ & $1.031 \pm 0.012$ & 0.9980 \\
HPCD-treated & $2.609 \pm 0.091$ & $1.064 \pm 0.025$ & 0.9969 \\
TS-treated & $2.395 \pm 0.056$ & $1.049 \pm 0.018$ & 0.9987 \\
\hline
\end{tabular}




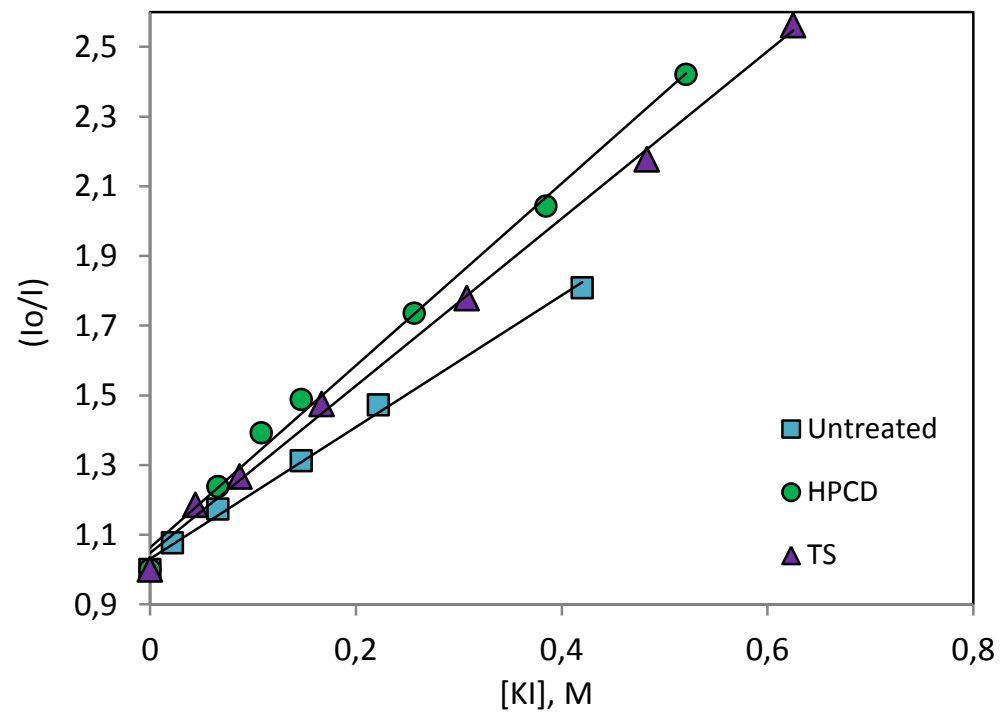

Figure 6.6 Stern-Volmer plot for the quenching by potassium iodide of untreated protein extracts with PPO activity, after HPCD treatment and after TS treatment.

\section{Conclusions}

In the present study, PPO from Golden delicious apple was concentrated by reverse micellar extraction. Under the best extraction conditions, PPO activity recovery was $99 \%$ and purification fold around 17 from a crude extract with high PPO activity. This extract was treated by HPCD and TS achieving low residual activity of PPO. However, by fluorescence analysis no convinced explanation of the PPO inactivation mechanism can be stablished since reverse micellar extraction is a concentration technique and PPO cannot be isolated. However, it has been observed that the protein fraction after treatment presents a great exposure of the fluorophore to the quencher, that is has been observed for other pure enzymes in the literature. 



\section{CHAPTER 7}

Effect of High Pressure Carbon Dioxide on tomato juice: inactivation kinetics of pectin methylesterase and polygalacturonase and determination of other quality parameters

Based on the article:

A.E. Illera, M. T. Sanz, E. Trigueros, S. Beltrán, R. Melgosa (2018)

"Effect of High Pressure Carbon Dioxide on tomato juice: inactivation kinetics of pectin methylesterase and polygalacturonase and determination of other quality parameters" Journal of Food Engineering, 239, 64-71 



\title{
Capítulo 7
}

\author{
Efecto del dióxido de carbono en las cinéticas de inactivación de \\ pectinmetilesterasa y poligalacturonasa y en diferentes propiedades de \\ calidad del zumo de tomate
}

\section{Resumen}

En este capítulo se trató zumo de tomate, Lycopersicon esculentem cv. Canario mediante $\mathrm{CO}_{2}$ presurizado (HPCD) y se determinaron las cinéticas de inactivación de la pectinmetilesterasa (PME) y poligalacturonasa (PG) a diferentes presiones (8.5 a $20 \mathrm{MPa}$ ) y temperaturas $\left(35\right.$ a $\left.55^{\circ} \mathrm{C}\right)$. A las condiciones de temperatura y presión más altas se observó que la PME fue prácticamente inactivada por completo, mientras que la PG mostró ser más resistente al tratamiento HPCD en dichas condiciones. El modelo de Weibull se ajustó correctamente a las curvas de inactivación de la PME, mientras que el modelo más apropiado para la PG fue el modelo de conversión fraccional, debido a un descenso inicial muy pronunciado. También se observó que el tratamiento HPCD causó una disminución en la distribución del tamaño de partícula del zumo de tomate. Se comparó el efecto de la tecnología HPCD con el de otra tecnología no térmica, las altas presiones hidrostáticas (HPP). Este tratamiento tuvo el efecto contrario al HPCD, ya que se consiguió la casi total inactivación de la PG, mientras que la PME mostró mucha resistencia a $600 \mathrm{MPa}$.

Palabras clave: Zumo de tomate, HPCD, inactivación enzimática, propiedades, HPP. 



\section{Abstract}

Tomato juice, Lycopersicon esculentem cv. Canario, has been treated by HPCD as nonthermal preservation treatment. The inactivation kinetics for pectin methylesterase (PME) and polygalacturonase (PG) were determined at different pressures (8.5 to $20 \mathrm{MPa}$ ) and temperatures $\left(35\right.$ to $55^{\circ} \mathrm{C}$ ). At the highest operating pressure and temperature essayed in this work, it was found that PME could be almost completely inactivated, whereas PG resulted to be more HPCD resistant at the working conditions. PME enzyme inactivation curves were properly described by a Weibull type model, while the fractional conversion model was the most appropriate for the PG with a sharp initial decrease in activity. High Pressure Processing (HPP) was also applied on tomato juice. This treatment led to a nearly complete inactivation of PG while PME was very resistant at $600 \mathrm{MPa}$. It was also found that HPCD treatment led to a smaller particle size distribution of tomato juice.

Keywords: Tomato juice, HPCD, enzyme inactivation, properties, HPP. 



\section{Introduction}

Tomatoes are usually consumed in a processed form, such as juice and pasta sauce, being viscosity one of the most important quality parameters. Viscosity is influenced by the concentration and type of cell wall polymers in the serum and pulp fraction (Kalamaki et al., 2012). Therefore, enzymes such as pectin methylesterase (PME) and polygalacturonase (PG), involved in the breakdown of pectins (Anthon et al., 2002), should be inactivated during processing. PME catalyzes pectin demethylation while PG hydrolyses the $\alpha-1,4-$ glycosidic bonds of the polygalacturonic acid chain. In this regard, two different effects of PME action on PG action have been described in the literature. On the one hand, partial demethylated pectin can bind bivalent calcium ions to form insoluble calcium pectate gels leading to a loss of juice cloud in a pH dependent manner (Croak \& Corredig, 2006). This cross-linked network also shows a higher resistance to PG attack, increasing viscosity. On the other hand, the lower the degree of esterification of the pectin molecules, the better substrate for PG they are, leading to the depolymerization of cell wall pectin chains and therefore a reduction in viscosity (Andreou et al., 2016; Crelier et al., 2001). Cold break and hot break thermal treatments are traditionally used in the tomato industry. Cold break treatment, by using temperatures around $60^{\circ} \mathrm{C}$, yields tomato products with a good retention of color and taste, but enzymes such as PME and PG are not completely inactivated and this fact is related to the low viscosity of cold break-treated products (Anthon et al., 2002). Hot break treatments, by using temperatures around $85-90^{\circ} \mathrm{C}$, get the inactivation of PG and PME. It is applied for the production of tomato products with high viscosity, but it results in loss of flavor, browned color and nutritional degradation (Wu et al., 2008).

In the last years, the Food Industry is searching for alternative technologies to replace conventional food heat treatments that may affect food quality in terms of nutritional and physicochemical parameters. Among these technologies, High Pressure Carbon Dioxide (HPCD) treatment has been proposed as an alternative non-thermal pasteurization. Typically, operating pressure does not exceed $50 \mathrm{MPa}$ and temperature ranges between 20 and $50^{\circ} \mathrm{C}$, below pasteurization temperature (Briongos et al., 2016). HPCD has been 
mainly applied to liquid foods such as fruit and vegetables juices (Amaral et al., 2018; Briongos et al., 2016; Illera et al., 2018a) and dairy products (Amaral et al., 2017).

To our knowledge, no previous studies on HPCD treatment of tomato juice have been found in the literature. Other non-thermal technologies have been applied to inactivate some of the deleterious enzymes in tomato juice. Most of the studies were focused on the use of High Pressure Processing (HPP), observing a different behavior for both enzymes with pressure. Generally, it was found that PME was more pressure resistant while PG can be inactivated at moderate pressure and temperature by HPP (Andreou et al., 2016; Crelier et al., 2001; Fachin et al., 2003; Hernández \& Cano, 1998; Houben et al., 2014; Hsu, 2008; Van Den Broeck et al., 2000). Other studies can be also found in the literature that employ other different non-thermal treatments, such as electric processing, cold plasma, membrane processing, ultrasound and ultraviolet irradiation (Bevilacqua et al., 2018).

The main objective of this work was to study the effect of HPCD on PME and PG inactivation from Canario tomato juice on a kinetic basis. Control samples of tomato juice treated in the same temperature range at atmospheric pressure, were studied in parallel. Additionally, enzyme inactivation was compared with results obtained by HPP performed at Hiperbaric (Burgos, Spain). The effect of HPCD on quality parameters of tomato juice such as particle size distribution (PSD) and $\zeta$ potential was also studied.

\section{Materials and methods}

\subsection{Juice preparation}

Fresh red tomato, Lycopersicon esculentem cv. Canario, from the local market, of uniform size, color and appearance were washed and chopped. Tomatoes were subsequently squeezed with a screw juice extractor. The liqueur was filtered through a screen of $1 \mathrm{~mm}$ size to remove peel and seeds. The initial pH of the tomato juice was $4.09 \pm 0.02$. 


\subsection{HPCD equipment and processing}

HPCD treatment was carried out in a stainless steel (SS-316) cell with an internal volume of $100 \mathrm{ml}$ and a maximum operating pressure and temperature of $30 \mathrm{MPa}$ and $80{ }^{\circ} \mathrm{C}$, respectively (Melgosa et al., 2017b). Tomato juice, $40 \mathrm{ml}$, was charged into the cell which was tightly closed and immersed in a water bath set at the operating temperature. Magnetic stirring was connected and the system was pressurized by using a syringe pump with a pressure controller (ISCO 260 D). $\mathrm{CO}_{2}$ was bubbled directly into the tomato juice through a sintered stainless steel micro-filter of $10 \mu \mathrm{m}$ (Briongos et al., 2016; Illera et al., 2018a) Experiments were carried out in the temperature range from 35 to $55^{\circ} \mathrm{C}$ and pressure from 8.5 to $20 \mathrm{MPa}$. Enzyme inactivation kinetics was followed by collecting samples periodically and enzymatic activity was determined.

Particle size distribution, $\xi$ potential and $\mathrm{pH}$ were also measured before and right after HPCD treatment for some of the experiments.

\subsection{HPP processing}

HPP treatment is currently applied to a great variety of juices and smoothies at industrial level. This experimental part was carried out at Hiperbaric España (Burgos). Tomato juice was sealed in plastic bottles of polyethylene terephthalate (PET) and introduced into a vessel subjected to $600 \mathrm{MPa}$ of isostatic pressure transmitted by water. Pressurization rate was $150 \mathrm{MPa} / \mathrm{min}$ and final pressure was held for 5 minutes. Depressurization occurred in about $2 \mathrm{~s}$. The initial operating temperature was $17.2^{\circ} \mathrm{C}$. Physical compression during pressure treatment results in a volume reduction and an increase in temperature and energy, approximately $3{ }^{\circ} \mathrm{C}$ per $100 \mathrm{MPa}$. Therefore, temperature of the juice during treatment was around $35^{\circ} \mathrm{C}$ (data provided by Hiperbaric, Burgos, Spain). However, due to fast temperature decrease during decompression, this treatment temperature was only held during treatment time (Yordanov \& Angelova, 2010).

Three different tomato juice samples were treated by HPP to analyze the effect of the nature of the dissolved gasses into the tomato juice on enzyme inactivation. In two of the 
samples, air dissolved in the juice was displaced by bubbling $\mathrm{CO}_{2}$ or $\mathrm{N}_{2}$ into the juice (HPP$\mathrm{CO}_{2}$ and HPP-N $\mathrm{N}_{2}$ samples, respectively) until the $\mathrm{O}_{2}$ concentration of the juice was below $0.4 \mathrm{mg} / \mathrm{L}$ (YSI ProODO optical dissolved oxygen meter). The air dissolved in the third sample was not removed (HPP-Air sample). All the three samples were treated together in the high pressure unit. $\mathrm{CO}_{2}$ permeability for PET is higher than for $\mathrm{O}_{2}$ and $\mathrm{N}_{2}$, coefficients of permeability for PET are $0.05,0.22$ and $1.53 \mathrm{ml} \mathrm{mm} \mathrm{cm} \mathrm{s}^{-1} \mathrm{cmHg}^{-1}$ for $\mathrm{N}_{2}, \mathrm{O}_{2}$ and $\mathrm{CO}_{2}$, respectively at $30^{\circ} \mathrm{C}$ (Zeman \& Kubík, 2007). However, $\mathrm{CO}_{2}$ loss is expected not to be high in the first hour after carbonation when HPP experiments were carried out.

\subsection{Physico-chemical analysis}

\subsubsection{Determination of enzyme activity}

Pectin methylesterase. Samples were analyzed by using an automatic titrator system (Metrohm $®$ Titrando) similar to Briongos et al. (Briongos et al., 2016) but with different amount of juice. $50 \mathrm{ml}$ of a $1 \%$ pectin solution (Alfa Aesar $®$ pectin citrus) prepared in $\mathrm{NaCl} 0.3 \mathrm{M}$ was used as substrate. After the addition of $100 \mu$ of tomato juice, $\mathrm{pH}$ was adjusted to 7.5 with $\mathrm{NaOH} 0.02 \mathrm{~N}$. During pectin hydrolysis at $30^{\circ} \mathrm{C}, \mathrm{pH}$ was maintained at 7.5 by adding $\mathrm{NaOH} 0.02 \mathrm{~N}$. The amount of $\mathrm{NaOH}$ added for $15 \mathrm{~min}$ was recorded. One PME activity unit (UPE) is defined as the micromoles of carboxylic groups produced per minute and $\mathrm{ml}$ of juice at $\mathrm{pH} 7.5$ and $30^{\circ} \mathrm{C}$.

Polygalacturonase. PG activity was determined by following a similar procedure to the one proposed by Anthon et al. (Anthon et al., 2002) and Fachin et al. (Fachin et al., 2003) with some modifications. First, PG was extracted from the tomato juice at $4{ }^{\circ} \mathrm{C} .1 \mathrm{ml}$ of tomato juice was centrifuged at $7500 \mathrm{~g}$ for $10 \mathrm{~min}$, the supernatant was replaced by cold distilled water (1:1) adjusted to $\mathrm{pH}=3$ with $0.1 \mathrm{M} \mathrm{HCl}$ and mixed for $30 \mathrm{~min}$. After centrifuging at $9000 \mathrm{~g}$ for $20 \mathrm{~min}$, the supernatant was removed and PG was extracted from the pellets with $1.2 \mathrm{M}$ of $\mathrm{NaCl}$ (1:1) for $1 \mathrm{~h}$. Subsequently, the mixture was centrifuged at $18200 \mathrm{~g}$ for $10 \mathrm{~min}$ and the supernatant was collected to determine the PG activity. $0.2 \mathrm{ml}$ of the extracted enzyme solution were mixed with $0.6 \mathrm{ml}$ of a $0.2 \%$ 
polygalacturonic acid solution at $35^{\circ} \mathrm{C}$ for $10 \mathrm{~min}$. Polygalacturonic acid was prepared in a acetate buffer solution $0.05 \mathrm{M}(\mathrm{pH}=4.5) .4 \mathrm{ml}$ of $0.1 \mathrm{M}$ borate buffer solution $(\mathrm{pH}=9)$ and $0.8 \mathrm{ml}$ of $1 \%$ cyanoacetamide were added to the mixture to stop the reaction and boiled in sealed bottles for $10 \mathrm{~min}$. After cooling, absorbance was measured at $276 \mathrm{~nm}$ using a Jasco V-750 spectrophotometer equipped with a Peltier thermostated cell holder and a water pump to keep the temperature constant at $30^{\circ} \mathrm{C}$.

Each enzyme activity was measured at least in duplicate. Relative residual enzyme activities were evaluated as the ratio of the measured activity after treatment, $A$, and the enzyme activity before treatment, $A_{\circ}$ :

Residual activity $(\%)=\frac{\text { Enzyme specific activity after treatment }}{\text { Enzyme specific activity of the untreated juice }} \cdot 100=\frac{A}{A_{O}} \cdot 100$

\subsubsection{Particle size distribution (PSD)}

Particle size distribution of tomato juice was determined by laser diffraction at $750 \mathrm{~nm}$ with a Mastersizer 2000 (Malvern $^{\circledR}$ Inst., MA) (Illera et al., 2018a). Size distributions (volume fractions against particle size) before and after HPCD treatment were calculated and the weight-average sizes expressed as:

- The equivalent surface area mean diameter:

$$
\mathrm{D}(3,2)=\sum \mathrm{n}_{\mathrm{c}} \mathrm{d}_{\mathrm{lc}}^{3} / \sum \mathrm{n}_{\mathrm{c}} \mathrm{d}_{\mathrm{lc}}^{2}
$$

- The equivalent volume mean diameter:

$$
\mathrm{D}(4,3)=\sum \mathrm{n}_{\mathrm{c}} \mathrm{d}_{\mathrm{lc}}^{4} / \sum \mathrm{n}_{\mathrm{c}} \mathrm{d}_{\mathrm{lc}}^{3}
$$

Where $d_{l c}$ is the diameter of the particle and $n_{c}$ is the percentage of particles. Both properties were evaluated since the $D[4,3]$ is highly influenced by large particles, whereas $D[3,2]$ is more influenced by the small ones (Augusto et al., 2013). 
Other useful parameters $d_{v, 0.9}, d_{v, 0.5}$ and $d_{v 0.1}$ correspond to the particle size bellow which, $90 \%, 50 \%$ and $10 \%$ of the particles lie. PSD measurements of the treated samples were carried out immediately after treatment and for the untreated tomato juice, PSD was determined right after juice preparation.

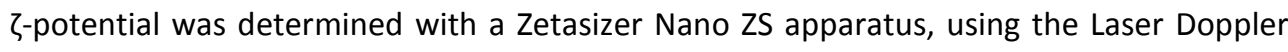
Velocimetry techniques. Samples were diluted 1:50 with deionized water and filtered through $5 \mu \mathrm{m}$ filter (Illera et al., 2018a). Z-potential gives an indication of the potential stability of a colloidal system and it is a good index of the colloidal electrostatic repulsive forces. Soluble pectin carries negative charge being important to keep a high $\zeta$-potential. Particles with $\zeta$-potentials more positive or negative than $30 \mathrm{mV}$ or $-30 \mathrm{mV}$ are usually considered stable (Genovese \& Lozano, 2001).

\subsection{Kinetic data analysis}

Enzyme inactivation by applying pressure and/or temperature has been described in the literature by different models, such as the first order, two-fraction, fractional-conversion and Weibull models. In this work, PG inactivation data were fitted to the fractional conversion model, while the Weibull model described PME inactivation data.

Fractional-conversion model. The fractional-conversion model is a special case of the first order kinetic model that takes into account the non-zero residual activity after prolonged heating and/or pressure $\left(A_{\infty}\right)$ treatment and it can be expressed as (Hu et al., 2013):

$A=A_{\infty}+\left(A_{o}-A_{\infty}\right) \exp (-k t)$

Where $A_{o}$ is the initial activity of the enzyme, $A$ is the residual activity at different treatment times, $A_{\infty}$ is the non-zero activity after prolonged heating and/or pressure treatment, $\mathrm{k}$ is the inactivation rate constant of the inactivated fraction at the operating conditions $\left(\mathrm{min}^{-1}\right)$ and $\mathrm{t}$ is the treatment time, min. By plotting $\mathrm{A}$ versus treatment time at constant pressure and temperature, the inactivation rate constant, $k$, and the remaining activity, $A_{\infty}$, can be estimated by nonlinear regression analysis (Hu et al., 2013). 
From the decimal reduction time, D, treatment time needed to achieve a $90 \%$ inactivation of the initial enzyme activity at a certain operating pressure and temperature, $z_{T}$ and $z_{p}$ (temperature and pressure increase needed for a $90 \%$ reduction of the $D$ value, respectively) were evaluated as the negative reciprocal slope of the regression line of $\log D$ as function of $T$ or $p$ respectively:

$\log \left[\frac{\mathrm{D}_{1}}{\mathrm{D}_{2}}\right]=\frac{\mathrm{T}_{2}-\mathrm{T}_{1}}{\mathrm{z}_{\mathrm{T}}}$

$\log \left[\frac{D_{1}}{D_{2}}\right]=\frac{p_{2}-p_{1}}{z_{p}}$

The dependence of the inactivation rate constant on temperature and pressure can be expressed through the Arrhenius and Eyring equations respectively:

$\ln \left[\frac{\mathrm{k}_{1}}{\mathrm{k}_{2}}\right]=\frac{\mathrm{E}_{\mathrm{a}}}{\mathrm{RT}}\left[\frac{1}{\mathrm{~T}_{2}}-\frac{1}{\mathrm{~T}_{1}}\right]$

$\ln \left[\frac{k_{1}}{k_{2}}\right]=\frac{\mathrm{V}_{\mathrm{a}}}{\mathrm{RT}}\left[p_{2}-\mathrm{p}_{1}\right]$

Where $p_{2}, p_{1}, T_{2}$ and $T_{1}$ are pressures and temperatures corresponding to the decimal reduction times $D_{1}$ and $D_{2}$ or constants $k_{1}$ and $k_{2}$, respectively, $R$ is the universal gas constant, $E_{a}$, the activation energy $(\mathrm{kJ} / \mathrm{mol})$ and $V_{a}\left(\mathrm{~cm}^{3} / \mathrm{mol}\right)$, is the activation volume.

Weibull model. The non-linear Weibull model can be written in the power-law form (Boekel, 2002):

$\log \frac{A}{A_{o}}=-\frac{1}{2.303}\left(\frac{t}{\alpha}\right)^{\beta}$

where $\alpha$ is the scale parameter (a characteristic time) and $\beta$ is the shape parameter. The time required to achieve a number of decimal reductions, $d$, can be calculated by using the shape and scale parameters (Boekel, 2002):

$t_{d}=\alpha\left(-\ln \left(10^{-d}\right)^{\frac{1}{\beta}}\right)$ 


\subsection{Statistical analysis}

Statistical analysis were conducted using software Statgraphics X64. The results are presented as a mean \pm standard deviation of at least three replicates. The significance of the differences was determined based on an analysis of the variance with the Tukey's honestly significant difference (HSD) method at $p$-value $\leq 0.05$.

To estimate the kinetic parameters for the different models essayed in this work, nonlinear regression was performed by using the Marquardt algorithm (Statgraphics X64).

\section{Results and discussion}

\subsection{Mild thermal and HPCD inactivation of PME}

Figure 7.1a shows the thermal inactivation curves of PME under mild thermal treatment in the temperature range from 35 to $55^{\circ} \mathrm{C}$ for $120 \mathrm{~min}$ heating. No thermal inactivation was observed at the lowest temperatures essayed, 35 and $45^{\circ} \mathrm{C}$. At $55^{\circ} \mathrm{C}$, inactivation of tomato PME was observed reaching a lowest residual activity of $70 \pm 4 \%$ after $120 \mathrm{~min}$.

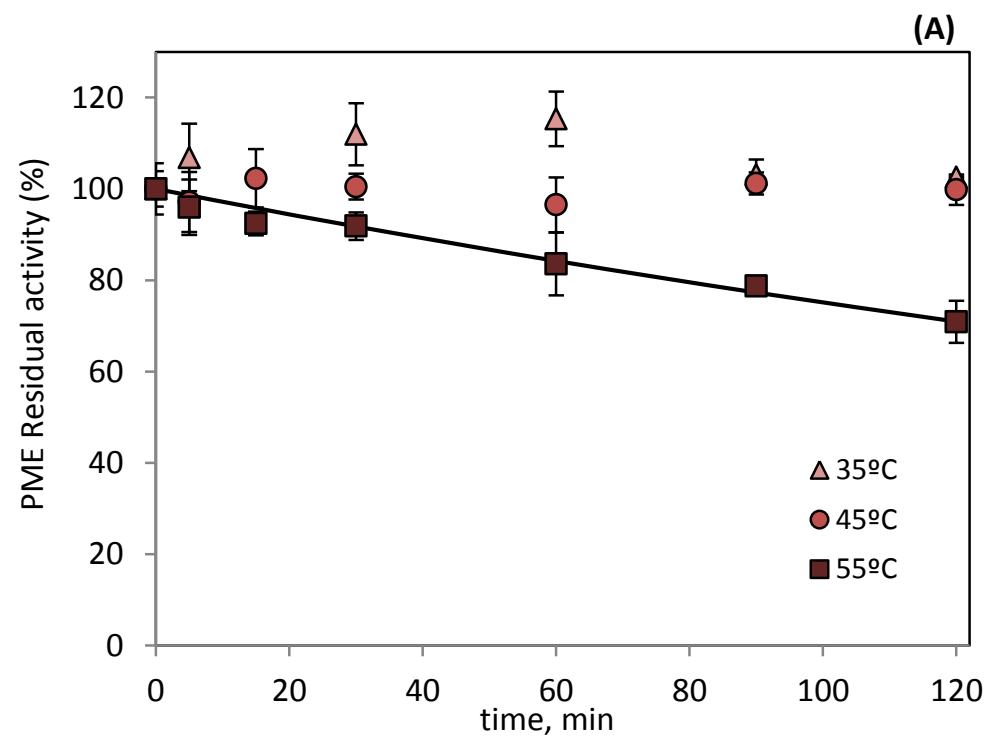




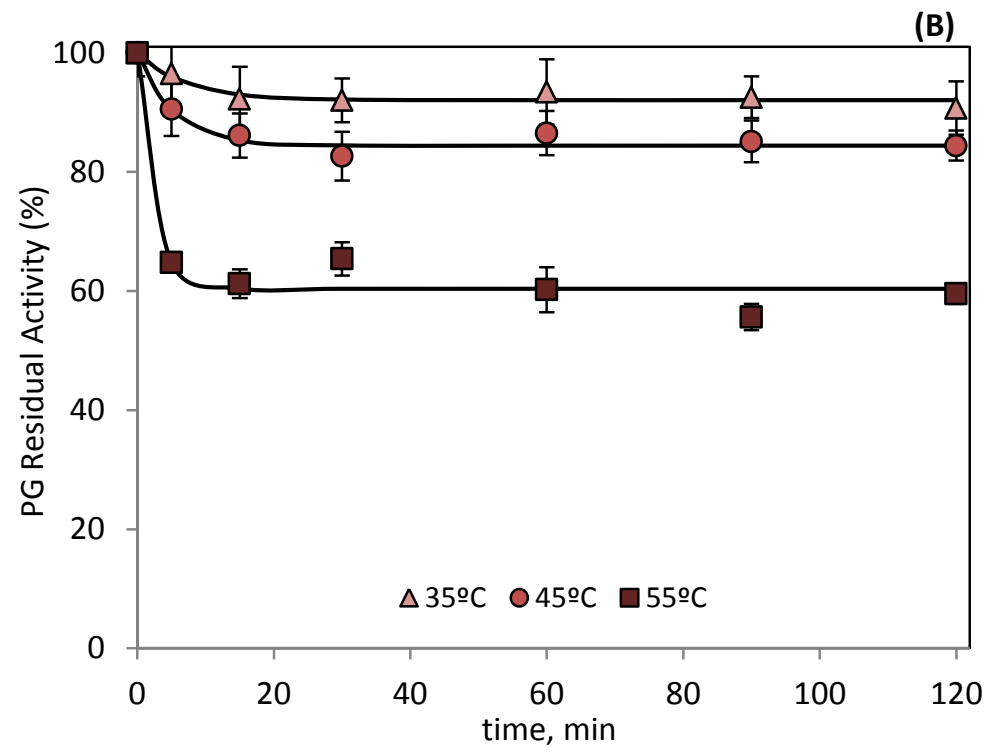

Figure 7.1 Inactivation kinetic data by mild heating treatment (a) PME (b) PG at different temperatures. Continuous lines represent the Weibull model (a) and the fractionalconversion model (b).

Different values have been reported in the literature regarding mild thermal treatment of different tomato varieties $\left(\mathrm{T} \leq 60^{\circ} \mathrm{C}\right.$ ). For tomatoes of Alamanda $\mathrm{cv}$., a PME residual activity of $50 \%$ was reported after $60 \mathrm{~min}$ heating at $55{ }^{\circ} \mathrm{C}$ (Andreou et al., 2016). These authors reported inactivation rate constants of $0.012 \pm 0.002$ and $0.088 \pm 0.005 \mathrm{~min}^{-1}$ at 45 and $55^{\circ} \mathrm{C}$, respectively. Temperatures higher than $60^{\circ} \mathrm{C}$ were needed to get some PME inactivation by 5 min thermal treatment of tomatoes cv. Patrona (Houben et al., 2014). Inactivation rate constants for a first order kinetic model of $0.026 \pm 0.003$ and $0.0097 \pm 0.0005 \mathrm{~min}^{-1}$ were obtained at $60^{\circ} \mathrm{C}$ for ripened tomatoes, Heinz 3402 variety and Nema 1401 variety, respectively (Terefe et al., 2009). The different inactivation data reported indicated that tomato variety played an important role on PME inactivation. The fastest PME inactivation kinetics were reported by Van Den Broeck et al. (Van Den Broeck et al., 2000) with a value of the inactivation rate constant of $0.152 \pm 0.004 \mathrm{~min}^{-1}$ at $60{ }^{\circ} \mathrm{C}$. However, in this case, tomato PME was not in its natural media but as commercial lyophilized powder dissolved in water, and in general, an enzyme is more stable in an intact tissue or in a homogenate where it is protected by the presence of other materials, such as proteins, carbohydrates and pectins, than in its purified form (Terefe et al., 2009). 
PME inactivation kinetics by HPCD are plotted in Figures 7.2a and 7.2b. Figure 7.2a shows the effect of operating pressure in the range from 8.5 to $20 \mathrm{MPa}$ at constant temperature of $45^{\circ} \mathrm{C}$. At this temperature, PME inactivation was observed for all the working pressures, unlike the results obtained at atmospheric pressure in which no PME inactivation was found at $45^{\circ} \mathrm{C}$. A pressure increase led to a faster inactivation rate. At $45^{\circ} \mathrm{C}$, in the pressure range from 8.5 to $20 \mathrm{MPa}, \mathrm{CO}_{2}$ is in supercritical state, and a pressure increase, results in an increase in $\mathrm{CO}_{2}$ density from $282 \mathrm{~kg} / \mathrm{m}^{3}$ at $8.5 \mathrm{MPa}$ to 813 $\mathrm{kg} / \mathrm{m}^{3}$ at $20 \mathrm{MPa}$. In any case, at $45^{\circ} \mathrm{C}$ and $20 \mathrm{MPa}$ and after $120 \mathrm{~min}$ of treatment, still $42 \%$ of PME residual activity was obtained.

At constant pressure, $20 \mathrm{MPa}$, enzyme inactivation rate increased by increasing temperature (from 35 to $55^{\circ} \mathrm{C}$ ) (Figure 7.2b). In addition to the intrinsic effect of temperature on enzyme inactivation, by increasing temperature, although $\mathrm{CO}_{2}$ density decreases, there is an improvement of mass transport properties of $\mathrm{CO}_{2}$, enhancing $\mathrm{CO}_{2}$ diffusivity and the number of collisions between the $\mathrm{CO}_{2}$ and the enzyme. At $55{ }^{\circ} \mathrm{C}$, nearly complete PME inactivation was determined $(1.5 \pm 0.5 \%)$ after 90 min of treatment at $20 \mathrm{MPa}$.

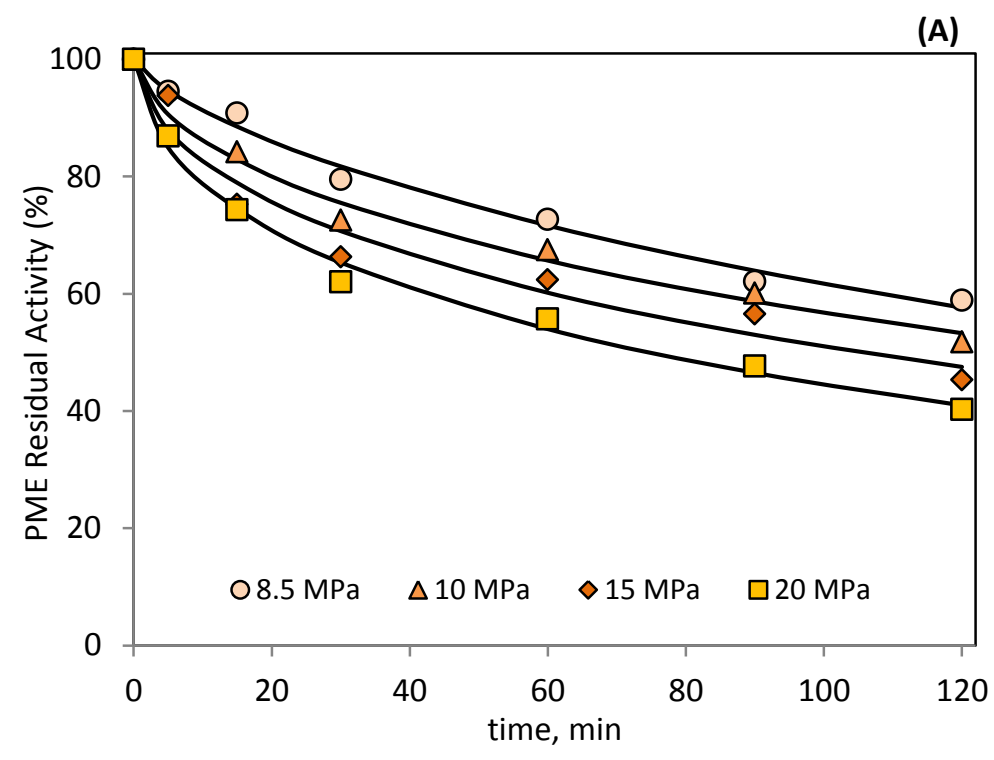




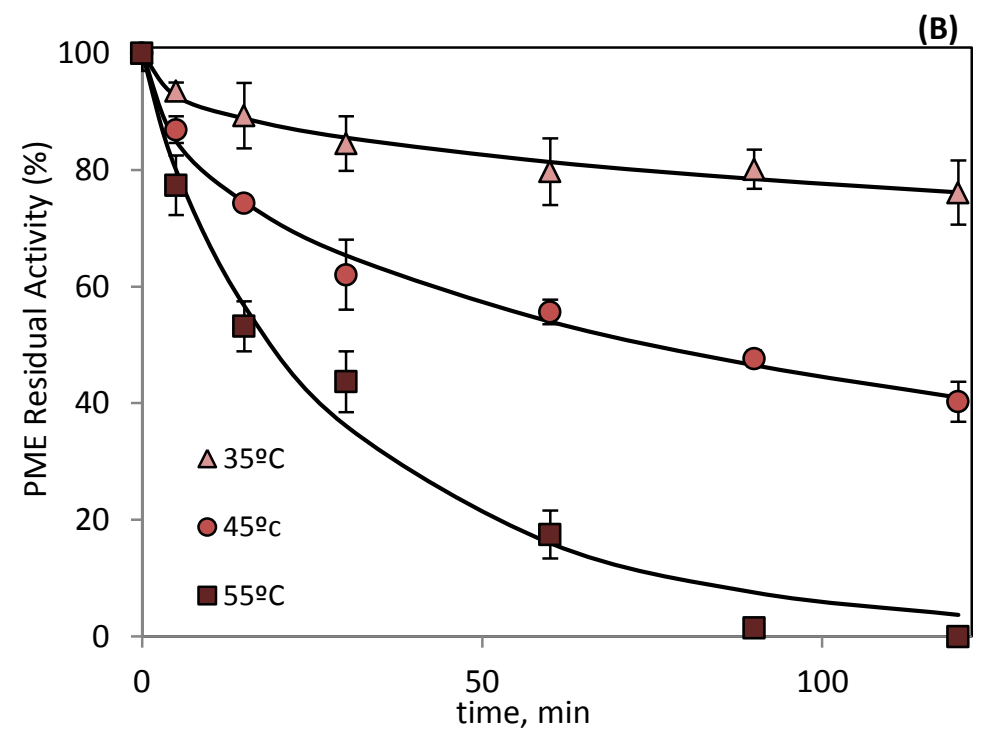

Figure 7.2 PME inactivation kinetic data by HPCD (a) At constant temperature $\left(45^{\circ} \mathrm{C}\right)$ and different operating pressures (b) At constant pressure (20 MPa) and different operating temperatures. Continuous lines represent the Weibull model.

In the literature, it has been reviewed that enzyme inactivation by HPCD could be due to different causes such as $\mathrm{pH}$ lowering, conformational changes of the enzyme and inhibitory effects of molecular $\mathrm{CO}_{2}$ due to formation of different complexes or decomposition of the enzyme by $\mathrm{CO}_{2}$ ( $\mathrm{Hu}$ et al., 2013). The lowering of $\mathrm{pH}$ has been attributed to $\mathrm{CO}_{2}$ dissolution into liquid food, and dissociation into bicarbonate and carbonate, and hydrogen ions. However, in acidic juices, such as tomato juice $(\mathrm{pH}=4.09)$, carbonic acid will hardly dissociate because the dissociation constant of carbonic acid and bicarbonate are $\mathrm{pK}_{\mathrm{a}}=6.57$ and $\mathrm{pK}_{\mathrm{a}}=10.62$, respectively (Zhou et al., 2015). Zhou et al. (Zhou et al., 2009) studied the alteration in activity and structure of PME from peel of Valencia oranges treated by HPCD, founding changes in the secondary and tertiary structures. Conformational changes were also found in other type of enzymes such as lipases (Chen et al., 2013; Melgosa et al., 2015) concluding that a decrease or increase in fluorescence intensity of HPCD treated enzyme is related to its tertiary structure and with changes in enzyme activity.

PME inactivation kinetics was fitted to the first order kinetic model and the Weibull model. At atmospheric pressure (Figure 7.1a), good fitting was obtained for both, the 
linear and the Weibull model. At atmospheric pressure, the decimal reduction time determined by the first order kinetic model at $55^{\circ} \mathrm{C}$ was $807 \pm 45 \mathrm{~min}$. Some of the PME inactivation curves by HPCD were not properly described by a first order kinetic model; therefore, only kinetic parameters for the Weibull are listed in Table 7.1. Scale parameter, $\alpha$, decreased with pressure and temperature. The shape factor, $\beta$, was less than 1 and it was found to increase with temperature. However, there was not clear trend of the shape factor with pressure, being nearly independent on pressure in the range from 10 to $20 \mathrm{MPa}$, and increasing at the lowest pressure studied, 8.5 MPa. Scale, $\alpha$, and shape, $\beta$ parameters were used to calculate the time required to inactivate $1 \log \left(t_{d=1}\right)$ of PME. According to the values of $\alpha$ and $\beta, t_{d=1}$ decreased with pressure in the range from 10 to $20 \mathrm{MPa}$, and an anomalous value of $t_{d=1}$ was obtained at $8.5 \mathrm{MPa}$. Although, as it was previously described, faster kinetics at the beginning of the treatment were observed by increasing pressure as it was also indicated by the values of the scale parameter. $t_{d=1}$ was found to decrease also with operating temperature at $20 \mathrm{MPa}$. At $55^{\circ} \mathrm{C}$, a $\mathrm{t}_{\mathrm{d}=1}$ of $77 \mathrm{~min}$ was calculated, being much lower than the value obtained at atmospheric pressure at the same temperature, $1305 \mathrm{~min}$. These results indicated that temperatures higher than $45^{\circ} \mathrm{C}$, around $55^{\circ} \mathrm{C}$, are needed in $\mathrm{HPCD}$ treatment to get nearly complete PME inactivation at $20 \mathrm{MPa}$.

Table 7.1 Kinetic parameters of the Weibull model for the inactivation of tomato PME by thermal and HPCD treatment

\begin{tabular}{|c|c|c|c|c|c|}
\hline $\mathrm{p}, \mathrm{MPa}$ & $\mathrm{T},{ }^{\circ} \mathrm{C}$ & $\alpha, \min$ & $\beta$ & $\mathbf{R}^{2}$ & $\mathrm{td}=1, \mathrm{~min}$ \\
\hline 0.1 & 55 & $472 \pm 95$ & $0.82 \pm 0.09$ & 0.9794 & 1305 \\
\hline 20 & 35 & $3082 \pm 1298$ & $0.40 \pm 0.04$ & 0.9830 & 24795 \\
\hline 20 & 45 & $148 \pm 12$ & $0.53 \pm 0.03$ & 0.9930 & 714 \\
\hline \multirow[t]{3}{*}{20} & 55 & $29 \pm 3$ & $0.85 \pm 0.09$ & 0.9822 & 77 \\
\hline & & \multicolumn{4}{|c|}{$\mathbf{z}_{\mathrm{T}}^{\prime}=10 \pm 2{ }^{\circ} \mathrm{C}\left(\mathbf{R}^{2}=0.9706\right)$} \\
\hline & & \multicolumn{4}{|c|}{ In $(1 / \alpha)$ vs $(1 / T): 197 \pm 31 \mathrm{~kJ} / \mathrm{mol}\left(\mathbf{R}^{2}=0.9764\right)$} \\
\hline 8.5 & 45 & $273 \pm 31$ & $0.72 \pm 0.06$ & 0.9894 & 869 \\
\hline 10 & 45 & $265 \pm 40$ & $0.58 \pm 0.06$ & 0.9878 & 1116 \\
\hline \multirow[t]{3}{*}{15} & 45 & $205 \pm 45$ & $0.55 \pm 0.09$ & 0.9611 & 934 \\
\hline & & \multicolumn{4}{|c|}{$\mathbf{z}_{\mathbf{P}}^{\prime}=43 \pm 3 \mathrm{MPa}\left(\mathbf{R}^{2}=0.9877\right)$} \\
\hline & & \multicolumn{4}{|c|}{$\ln (1 / \alpha)$ vs $(p):-14 \pm 1 \mathrm{cc} / \mathrm{mol}\left(\mathbf{R}^{2}=0.9877\right)$} \\
\hline
\end{tabular}


According to Boekel (Boekel, 2002), the scale parameter, $\alpha$, could be modelled in a similar way to the classical $D$ value of the first order kinetic model, suggesting a linear dependence of the $\log \alpha$ on temperature and considering that the shape parameter, $\beta$, did not depend on temperature:

$\log \alpha=a_{1}-b_{1} T$

Although, in this work $\beta$ was statistically significant dependent on temperature when tested at the $95 \%$ significance level for a linear relationship, a $\mathrm{z}_{\mathrm{T}}{ }^{\prime}$ value was defined as suggested by Boekel (Boekel, 2002):

$z_{T}^{\prime}=\frac{1}{b_{1}}$

The value of the $z_{T}^{\prime}$ is listed in Table 7.1, together with the quality of the fitting to equation 7.11. The $z_{T}^{\prime}$ value obtained in this work by HPCD is similar to the values reported in the literature for thermal treatment, $\mathrm{z}_{\mathrm{T}}$. Terefe et al. (Terefe et al., 2009) reported a $z_{T}$ value of $11.4{ }^{\circ} \mathrm{C}$ in the temperature range from 60 to $75{ }^{\circ} \mathrm{C}$ for Heinz 3402 variety. A similar value was reported by Raviyan et al. (Raviyan et al., 2005), with $\mathrm{z}_{\mathrm{T}}=12.3^{\circ} \mathrm{C}$, for tomato $\mathrm{cv}$ Roma for thermal inactivation in the temperature range from 50 to $72{ }^{\circ} \mathrm{C}$. An Arrhenius type equation was considered to relate the inverse of the scale parameter, $1 / \alpha$, with temperature. Although $1 / \alpha$ cannot be considered a kinetic constant, the value obtained from the slope was calculated as $197 \pm 31 \mathrm{~kJ} / \mathrm{mol}$. This value was similar to the one reported by Terefe et al. (Terefe et al., 2009) for the inactivation of tomato PME by thermal treatment, $193 \pm 28 \mathrm{~kJ} / \mathrm{mol}$, in the temperature range from 60 to $75^{\circ} \mathrm{C}$. Therefore, similar PME sensitivity to temperature was determined by HPCD and by thermal treatment, although the HPCD temperature range, $35-55^{\circ} \mathrm{C}$ was lower than the temperature range employed by thermal inactivation.

In this work, a linear dependence of the log $\alpha$ on pressure was also found, being the shape parameter not statistically significant dependent on pressure, when tested at the $95 \%$ significance level for a linear relationship:

$\log \alpha=a_{2}-b_{2} p$ 
The inverse of the slope of $\log \alpha$ versus $p$ was also evaluated. Analogous to $z^{\prime}{ }_{T}, z_{p}^{\prime}$ was defined:

$z_{p}^{\prime}=-\frac{1}{b_{2}}$

$z_{p}^{\prime}$ value was evaluated as $43 \pm 3 \mathrm{MPa}$. Comparing $z_{T}^{\prime}$ and $z_{p}^{\prime}$ values for PME it can be concluded that PME was more sensitive to changes in temperature than in pressure. An Eyring type equation was considered to relate the inverse of the scale parameter, $1 / \alpha$, with pressure. Although $1 / \alpha$ is not a kinetic constant, $\mathrm{V}^{\prime}{ }_{\mathrm{a}}$ was evaluated from the slope as $-14 \pm 1 \mathrm{cc} / \mathrm{mol}$. The negative value of this parameter indicated that PME inactivation was favored by increasing operating pressure. However, this value is much higher (lower in absolute value) than other $V_{a}$ reported in the literature for different enzymes in juices treated by HPCD, such as PPO in cloudy apple juice with values of $-251 \mathrm{~cm}^{3} / \mathrm{mol}$ (Illera et al., 2018a).

\subsection{Thermal and HPCD inactivation of PG}

The inactivation kinetics of PG at atmospheric pressure is shown in Figure $\mathbf{7 . 1 \mathbf { b }}$ in the temperature range from 35 to $55^{\circ} \mathrm{C}$. The shape of the inactivation curves indicates that some fraction of the PG remained stable even after long treatment in this temperature range. In this regard, the existence of two fractions with different PG activity in tomato fruit has been extensively documented in the literature: a thermolabile (PG2) and a thermostable fraction (PG1) (Fachin et al., 2003). At 35 and $45^{\circ} \mathrm{C}$, low inactivation degree, with residual activities of $93 \pm 5 \%$ and $84 \pm 3 \%$ respectively, was observed. At $55{ }^{\circ} \mathrm{C}$, higher partial PG inactivation was obtained with residual activities of around $60 \pm 2 \%$. As for tomato PME, different values have been reported for PG inactivation under mild thermal treatment of different tomato varieties $\left(T \leq 60^{\circ} \mathrm{C}\right.$ ). Andreou et al. (Andreou et al., 2016) determined the thermal inactivation of $P G$ at $55{ }^{\circ} \mathrm{C}$ with a residual activity around $80 \%$ after 60 min of treatment for Alamanda cv. Terefe et al. (Terefe et al., 2009) found that thermal treatment at $50{ }^{\circ} \mathrm{C}$ did not have a significant effect on the PG activity of tomato Heinz $3402 \mathrm{cv}$, while residual activity of $37 \%$ was reached at $60{ }^{\circ} \mathrm{C}$ after $60 \mathrm{~min}$ of heating. Lower PG residual activity for ripened tomato var. Flandria prince was obtained, 
being around $20 \%$ at 50 and $60^{\circ} \mathrm{C}$ after 120 min heating (Fachin et al., 2003). At $55^{\circ} \mathrm{C}$, a residual activity of $80 \%$ after 5 min heating was observed for Patrona cv. (Houben et al., 2014). Based on these results, it can be concluded that tomato variety plays an important role in PG inactivation, similar to PME.

Figures 7.3a and 7.3b show the PG inactivation kinetics by HPCD at constant temperature, $45^{\circ} \mathrm{C}$, in the pressure range from 8.5 to $20 \mathrm{MPa}$ and at constant pressure, $20 \mathrm{MPa}$, in the temperature range from 35 to $55^{\circ} \mathrm{C}$, respectively. The shape of the inactivation kinetics curves was similar to that described above for mild heating treatment. This indicated that PG also presented two fractions with different HPCD resistance. Although a higher degree of inactivation was obtained for all HPCD experiments compared to the results obtained for mild heating, a complete inactivation of the enzyme was not obtained in any of the experiments carried out. A pressure increase led to lower residual activity, although based on the inactivation curves at different operating pressures, PG was not very HPCD pressure sensitive in the pressure range from 8.5 to $20 \mathrm{MPa}$. At $8.5 \mathrm{MPa}$, the residual activity was $72 \pm 2 \%$, and it only decreased down to $55 \pm 5 \%$ at $20 \mathrm{MPa}$.

Based on the kinetic curves, the fractional conversion model was found to adequately describe mild thermal and HPCD inactivation curves. The kinetic parameters for tomato PG are presented in Table 7.2. The inactivation rate constant increased both, with pressure and temperature. The corresponding $D$ values for the labile fraction are also listed in Table 7.2. Lower D values were obtained by HPCD than under mild heating treatment. In any case, the residual PG activity was still $41 \pm 4 \%$ at the hardest conditions used in this work, $20 \mathrm{MPa}$ and $55^{\circ} \mathrm{C}$. 


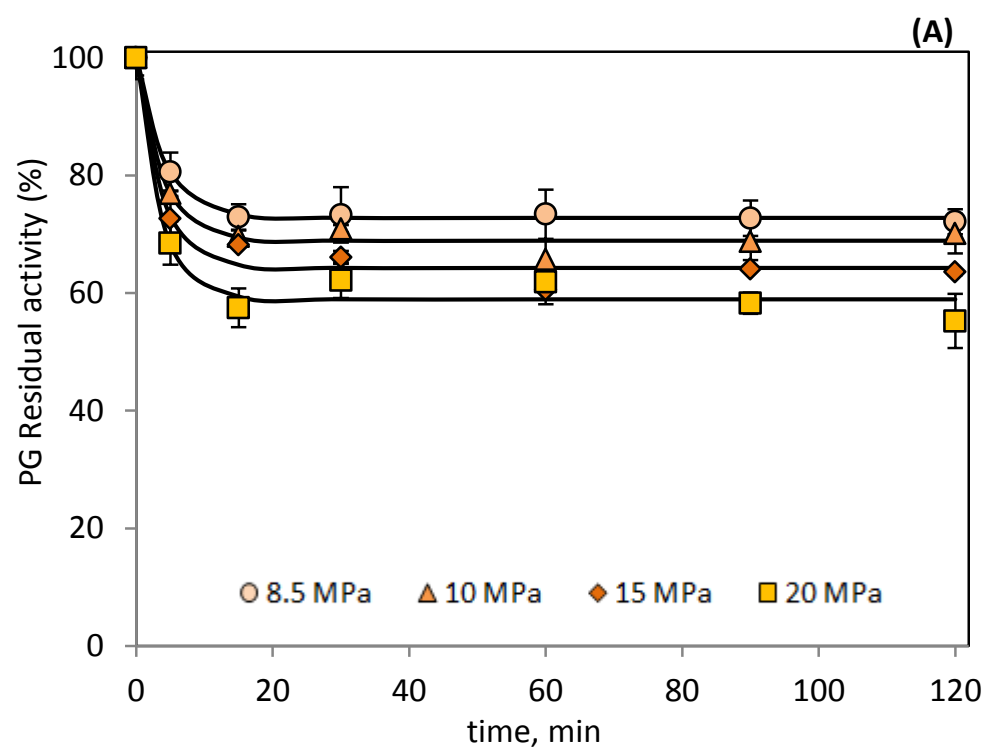

(B)

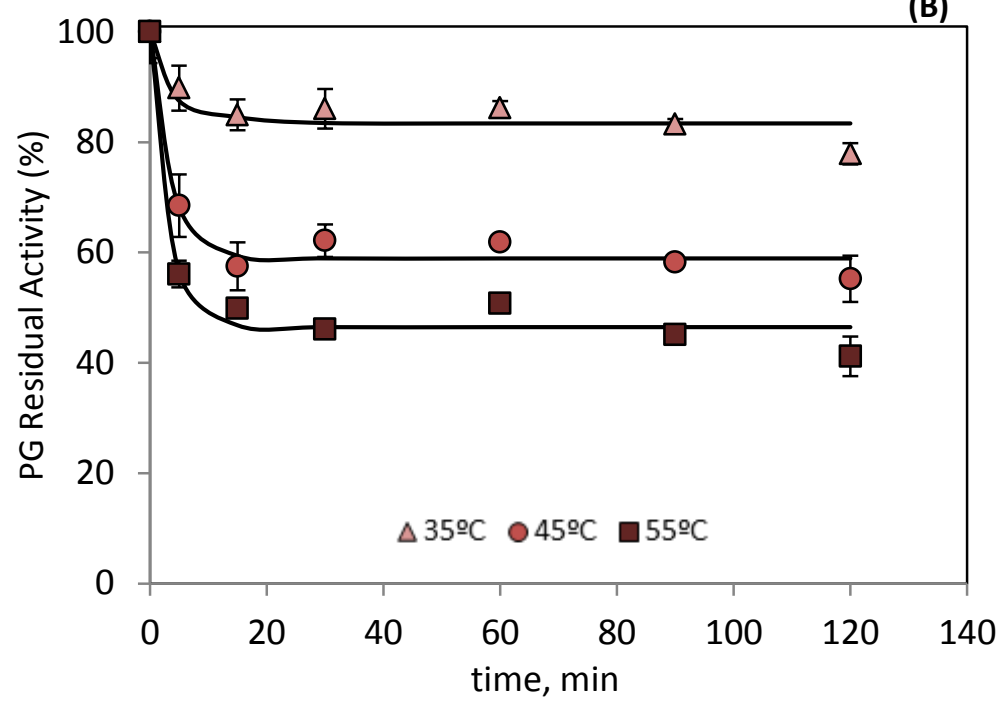

Figure 7.3 PG inactivation kinetic data by HPCD (a) At constant temperature $\left(45^{\circ} \mathrm{C}\right)$ and different operating pressures. (b) At constant pressure (20 MPa) and different operating temperature. Continuous lines represent the fractional-conversion model. 
Table 7.2 Kinetic parameters of the fractional model for the inactivation of tomato PG by thermal and HPCD treatment

\begin{tabular}{|c|c|c|c|c|c|}
\hline $\mathrm{p}, \mathrm{MPa}$ & $\mathrm{T},{ }^{\circ} \mathrm{C}$ & $\mathbf{A}_{\infty}$ & $k, \min ^{-1}$ & $\mathbf{R}^{2}$ & $\mathrm{D}, \mathrm{min}$ \\
\hline 0.1 & 35 & $92.0 \pm 0.5$ & $0.14 \pm 0.05$ & 0.9236 & 16.5 \\
\hline 0.1 & 45 & $84.4 \pm 0.6$ & $0.19 \pm 0.04$ & 0.9594 & 12.1 \\
\hline \multirow[t]{3}{*}{0.1} & 55 & $60 \pm 1$ & $0.44 \pm 0.15$ & 0.9637 & 5.3 \\
\hline & & \multicolumn{4}{|c|}{$\mathbf{z}_{\mathrm{T}}=40 \pm 11^{\circ} \mathrm{C} ;\left(\mathbf{R}^{2}=0.9334\right)$} \\
\hline & & \multicolumn{4}{|c|}{$E_{a}=48 \pm 14 \mathrm{~kJ} / \mathrm{mol} ;\left(\mathbf{R}^{2}=0.9607\right)$} \\
\hline 20 & 35 & $83 \pm 2$ & $0.18 \pm 0.09$ & 0.8373 & 12.8 \\
\hline 20 & 45 & $59 \pm 1$ & $0.30 \pm 0.06$ & 0.9751 & 7.7 \\
\hline \multirow[t]{3}{*}{20} & 55 & $46 \pm 2$ & $0.34 \pm 0.07$ & 0.9764 & 6.8 \\
\hline & & \multicolumn{4}{|c|}{$\mathbf{z}_{\mathrm{T}}=72 \pm 25^{\circ} \mathrm{C} ;\left(\mathbf{R}^{2}=0.8908\right)$} \\
\hline & & \multicolumn{4}{|c|}{$\mathbf{E}_{\mathrm{a}}=27 \pm 9 \mathrm{~kJ} / \mathrm{mol} ;\left(\mathbf{R}^{2}=0.9019\right)$} \\
\hline 8.5 & 45 & $72.8 \pm 0.2$ & $0.25 \pm 0.01$ & 0.9978 & 9.2 \\
\hline 10 & 45 & $68.9 \pm 0.8$ & $0.27 \pm 0.05$ & 0.9809 & 8.5 \\
\hline \multirow[t]{3}{*}{15} & 45 & $64 \pm 1$ & $0.28 \pm 0.06$ & 0.9734 & 8.2 \\
\hline & & \multicolumn{4}{|c|}{$\mathbf{z}_{\mathrm{P}}=166 \pm 38 \mathrm{MPa}\left(\mathbf{R}^{2}=0.9074\right)$} \\
\hline & & \multicolumn{4}{|c|}{$\ln (1 / \alpha)$ vs $(p):-3.7 \pm 0.8 \mathrm{cc} / \mathrm{mol}\left(\mathbf{R}^{2}=0.9074\right)$} \\
\hline
\end{tabular}

In this work, first order kinetic model could not describe satisfactorily PG inactivation kinetics neither at atmospheric pressure nor by HPCD. However, Andreou et al. (Andreou et al., 2016) found that PG inactivation followed a first order kinetic model, in the temperature range from 55 to $75^{\circ} \mathrm{C}$ at atmospheric pressure for Alamanda cv., with values of the inactivation rate constant ranging from $0.030 \pm 0.005$ to $0.137 \pm 0.015 \mathrm{~min}^{-1}$. The fractional conversion model has been also used in the literature to describe thermal inactivation kinetics of PG in tomato juice of different varieties such as Heinz $3402 \mathrm{cV}$ (Terefe et al., 2014) and Flandria prince (Fachin et al., 2003) in the temperature range from 60 to $75^{\circ} \mathrm{C}$ and 55 to $70{ }^{\circ} \mathrm{C}$, respectively. For these two varieties different kinetic parameters (percentage of the stable fraction, $A_{\infty}$, and inactivation rate constant for the labile fraction, k) have been reported. For instance, at $60^{\circ} \mathrm{C}$, for Heinz $3402 \mathrm{cv}$, $A_{\infty}=37 \pm 6 \%$ and $k=0.085 \pm 0.024 \mathrm{~min}^{-1}$ (Terefe et al., 2009) while for Flandria prince cv, $A_{\infty}=14 \pm 4 \%$ and lower kinetic reaction constant, $k=0.048 \pm 0.005 \mathrm{~min}^{-1}$, were reported for the labile fraction (Fachin et al., 2003). 
An Arrhenius type equation was considered to relate the inactivation rate constant of the labile fraction with temperature. From the slope, the activation energy of the labile fraction was calculated as $48 \pm 14 \mathrm{~kJ} / \mathrm{mol}$ and $27 \pm 9 \mathrm{~kJ} / \mathrm{mol}$ at atmospheric pressure and at $20 \mathrm{MPa}$ by HPCD respectively, in the temperature range from 35 to $45^{\circ} \mathrm{C}$. These values are much lower than the values reported in the literature for the PG labile fraction, $116 \pm 25$ and $228.35 \mathrm{~kJ} / \mathrm{mol}$, for Heinz $3402 \mathrm{cv}$ and Flandria prince cv respectively (Fachin et al., 2003; Terefe et al., 2009) and also compared with the values obtained for the PME. These differences could be attributed to different tomato varieties and degree of ripening, among other factors, and indicated that the PG labile fraction of Canario cv. is not very temperature sensitive in the temperature range from 35 to $55^{\circ} \mathrm{C}$. This can be also observed in the values of $z_{T}$ presented in Table 7.2, being much higher than $z_{T}$ values for thermal inactivation of enzymes under pasteurization conditions. Sensitive pressure parameters were evaluated through equations 7.6 and $7.8, \mathrm{Va}=-3.7 \pm 0.8 \mathrm{cc} / \mathrm{mol}$ and $\mathrm{Z}_{\mathrm{P}}=166 \pm 38 \mathrm{MPa}$. These values showed that PG was neither very sensitive to temperature nor to pressure changes by HPCD treatment in the range covered in this work, from 35 to $55^{\circ} \mathrm{C}$ and 8.5 to $20 \mathrm{MPa}$, respectively.

\subsection{Effect of HPCD treatment on particle size distribution}

As described in the literature, tomato juice consists of suspended particles greater than $150 \mu \mathrm{m}$ in diameter in colloidal serum (Wu et al., 2008). Figure 7.4 shows the PSD of the untreated tomato juice and HPCD treated samples at $45^{\circ} \mathrm{C}$ for $60 \mathrm{~min}$ at different operating pressures in the range from 10 to $20 \mathrm{MPa}$. A bimodal PSD was obtained for all samples, both in the untreated juice and in HPCD treated samples. HPCD treatment resulted in a reduction of the particle size diameter of the tomato juice particles. On the one hand, the maximum peak corresponding to the larger particles moved from values of $416.9 \mu \mathrm{m}$ to values of $182.0 \mu \mathrm{m}$ for the juice treated at $10 \mathrm{MPa}$ and $120 \mu \mathrm{m}$ for the juice treated at 15 and $20 \mathrm{MPa}$. On the other hand, the peak corresponding to the smallest particles remains constant in all samples and around $0.7-0.8 \mu \mathrm{m}$, but, the number of particles with this size increased after HPCD treatment with operating pressure. For the untreated tomato juice, the total volume of all particles with diameter less than $10 \mu \mathrm{m}$ represented $7 \%$ of the total particles volume, while this number increased up to 11,37 
and $49 \%$ at 10, 15 and $20 \mathrm{MPa}$, respectively. This trend can be also observed in the values of $D[4,3], D[3,2]$ and $d_{v}(0.1), d_{v}(0.5)$ and $d_{v}(0.9)$ that progressively decreased by increasing operating pressure (Table 7.3).

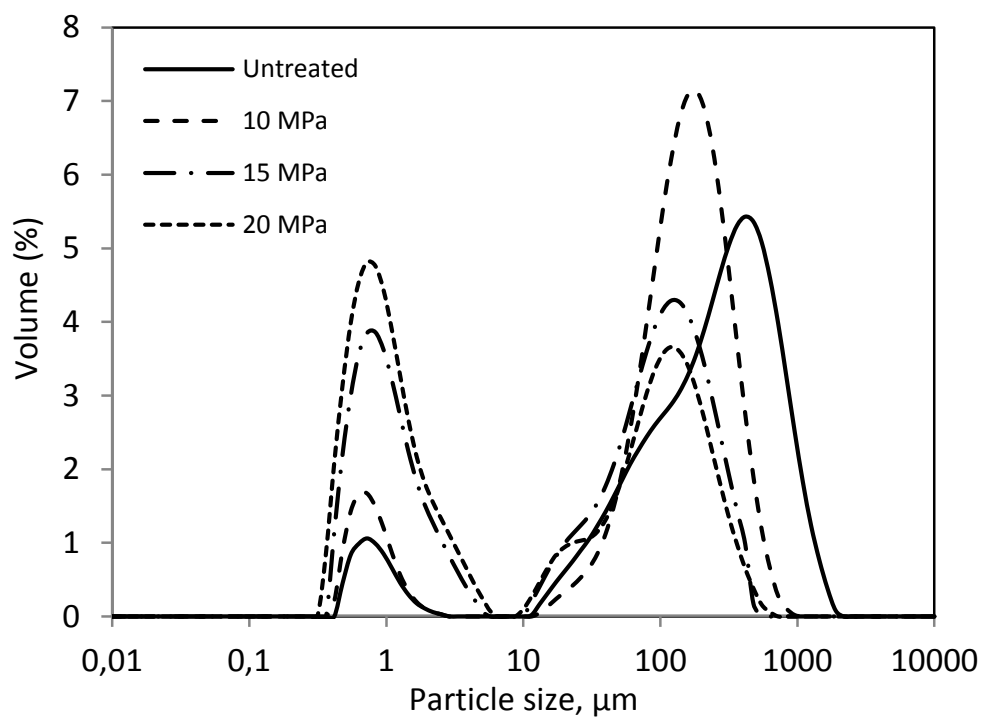

Figure 7.4 Particle size distribution of fresh tomato juice and treated by HPCD at different operating pressures: $10 \mathrm{MPa}, 15 \mathrm{MPa}, 20 \mathrm{MPa}\left(\mathrm{T}=45^{\circ} \mathrm{C}\right.$, treatment time $\left.=60 \mathrm{~min}\right)$.

Table 7.3 Effect of operating pressure of HPCD treatment on the particle size distribution $(\mu \mathrm{m})$ of tomato juice.

\begin{tabular}{cccccc}
\hline & $D[3,2]$ & $D[4,3]$ & $d_{v}(\mathbf{0 . 1})$ & $d_{v}(\mathbf{0 . 5})$ & $d_{v}(\mathbf{0 . 9})$ \\
\hline Untreated & $10.7 \pm 0.2^{d}$ & $355.7 \pm 6.5^{\mathrm{d}}$ & $27.65 \pm 0.23^{\mathrm{d}}$ & $284.9 \pm 3.9$ & $762.9 \pm 1.7^{\mathrm{d}}$ \\
$10 \mathrm{MPa}$ & $6.9 \pm 0.2^{\mathrm{c}}$ & $181.2 \pm 3.2^{\mathrm{c}}$ & $14.44 \pm 0.22^{\mathrm{c}}$ & $153.6 \pm 1.2^{\mathrm{b}}$ & $370.5 \pm 1.9^{\mathrm{c}}$ \\
$15 \mathrm{MPa}$ & $2.5 \pm 0.1^{\mathrm{b}}$ & $90.9 \pm 1.8^{\mathrm{b}}$ & $0.73 \pm 0.03^{\mathrm{b}}$ & $54.3 \pm 0.4^{\mathrm{a}}$ & $245.3 \pm 2.8^{\mathrm{b}}$ \\
$20 \mathrm{MPa}$ & $1.8 \pm 0.1^{\mathrm{a}}$ & $71.6 \pm 1.2^{\mathrm{a}}$ & $0.63 \pm 0.01^{\mathrm{a}}$ & $16.2 \pm 0.8^{\mathrm{a}}$ & $211.8 \pm 1.2^{\mathrm{a}}$ \\
\hline
\end{tabular}

Data: mean \pm SD $(n=3)$. Different letters in a column indicate significant differences by the Tukey's honestly significant difference (HSD) method at $p$-value $\leq 0.05$.

This fact has been explained in terms of the homogenization effect caused by HPCD treatment due to several reasons, such as high internal stress surpassing the tensile strength of the particles when $\mathrm{CO}_{2}$ is removed from the vessel (Niu et al., 2010a). This 
effect has been also observed in other juices treated by HPCD such as orange or apple juice (Briongos et al., 2016; Illera et al., 2018a).

The PSD changes of tomato juice caused by HPCD could involve modifications of the properties of particles and serum due to cell disruption and subsequent fragmentation. The suspended particles in tomato juice include intact or broken cells, long-chain polymers of cellulose, lignin, hemicellulose and water insoluble pectic materials (Wu et al., 2008). Cell fragmentation and released cell wall constituents, such as pectins and proteins, caused by HPCD might modify particle-particle interactions and hence juice stability. $\xi$ potential was determined as an indicator of the colloidal stability of the juice before and after HPCD treatment. Untreated tomato juice presented a $\xi$ potential value of $-16.8 \pm 1.6 \mathrm{mV}$. This negative value indicated that the juice particles were negatively charged. After HPCD treatment, slightly lower values of $\xi$ potential were obtained with values of $-18.4 \pm 0.6,-15.9 \pm 1.7,-20.5 \pm 1.5$ and $-18.6 \pm 0.5 \mathrm{mV}$ at 8.5, 10, 15 and $20 \mathrm{MPa}$, respectively. However, this increase is not very important and it can be concluded that colloid stability is not modified after HPCD treatment.

\subsection{Enzyme inactivation by HPP}

Enzyme inactivation data obtained by HPCD were compared with data obtained by using High Pressure Processing treatment (Figure 7.5). At the standard operating conditions at Hipebaric, PME activity of tomato juices (HPP-Air sample) was not affected by HPP, with a residual activity of $104 \pm 7 \%$. These results agree with the literature that reported tomato PME was very resistant to pressure up to $800 \mathrm{MPa}$ (Crelier et al., 2001; Tangwongcha et al., 2000). Other authors even found an increase on PME activity with pressure in the range from 335 to $500 \mathrm{MPa}$, with a higher efficiency for PME inactivation of low pressure/mild temperature treatments $\left(150 \mathrm{MPa} / 30^{\circ} \mathrm{C}\right)$ (Hernández \& Cano, 1998). 


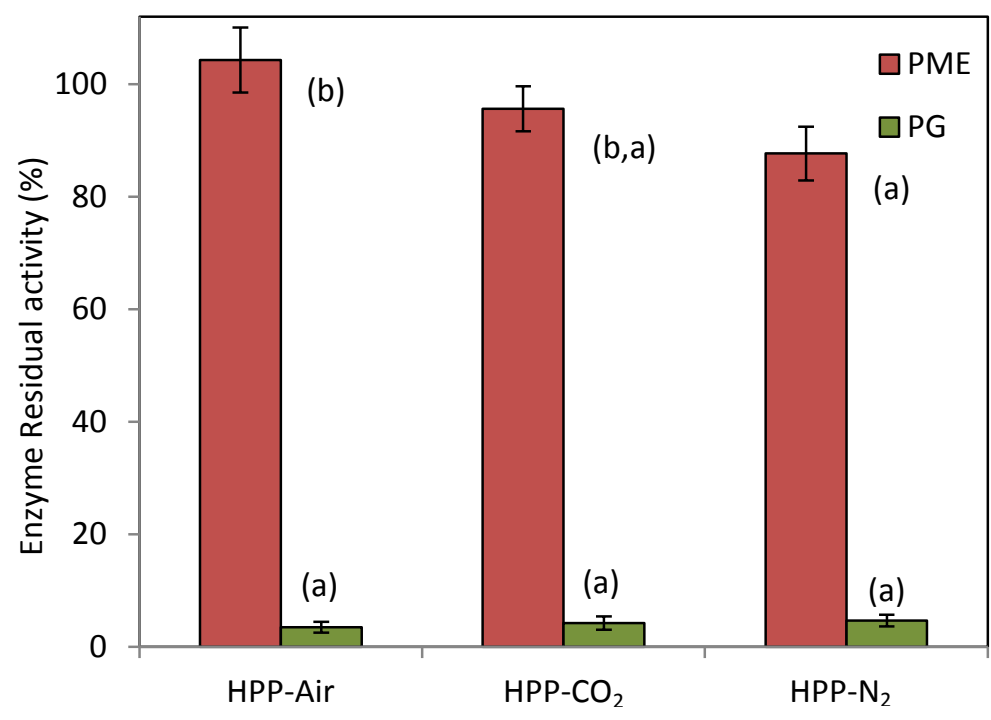

Figure 7.5 Residual PME and PG activity in tomato juice after HPP with different dissolved gases in the tomato juice. Data: mean $\pm S D(n=3)$. Different letters for each enzyme indicate significant differences by the Tukey's honestly significant difference (HSD) method at $p$-value $\leq 0.05$

In the literature, it has been described a positive interaction of pressure with the presence of $\mathrm{CO}_{2}$ in the sample, which could destroy or damage the structure of the enzyme (Ortuño et al., 2013). However, at the working conditions of $600 \mathrm{MPa}$, the presence of $\mathrm{CO}_{2}$ did not bring an important additional inactivation of tomato PME, with a PME residual activity of the carbonate sample of $96 \pm 4 \%$. This indicated that there was no significant interaction between HPP and $\mathrm{CO}_{2}$. Slightly lower PME residual activity was obtained in the sample HPP- $\mathrm{N}_{2}$. However, this difference might be considered practically unimportant since still high residual activity was observed. Corwin and Shellhammer (Corwin \& Shellhammer, 2002) followed a similar experimental procedure, these authors first carbonated enzyme preparation at atmospheric pressure and then the samples were treated by HPP, observing that $\mathrm{CO}_{2}$ had an additional inactivation effect on PME from orange juice at $500 \mathrm{MPa}$ and $25^{\circ} \mathrm{C}$ for $3 \mathrm{~min}$, but not at $800 \mathrm{MPa}$ and $25^{\circ} \mathrm{C}$ for $1 \mathrm{~min}$. Ortuño et al. (Ortuño et al., 2013) applied HPP in carbonated samples and also a combination of carbonated samples and addition of gaseous $\mathrm{CO}_{2}$ in the headspace of the packaged liquid food before HPP treatment. According to these authors, gaseous $\mathrm{CO}_{2}$ into the headspace could dissolve into the sample during the HPP treatment and the $\mathrm{CO}_{2}$ concentration inside 
the sample could be higher than in carbonated samples. These authors found that, on average, the addition of $\mathrm{CO}_{2}$ did not improve the inactivation of PME of feijoa puree in a HPP process in the pressure range from 300 to $600 \mathrm{MPa}$.

Regarding PG inactivation by HPP, almost complete inactivation at $600 \mathrm{MPa}$ for 5 min was obtained for all samples, although still a 3 - $4 \%$ of HPP resistant PG fraction was observed. In the literature it has been also described that PG in tomato juice can be totally inactivated at some temperature/ pressure combination from pressure above $500 \mathrm{MPa}$ and temperature around $20^{\circ} \mathrm{C}$ (Crelier et al., 2001; Tangwongchai et al., 2000).

\section{Conclusions}

HPCD treatment has been found as a promising non-thermal technology to process tomato juice being more effective than mild thermal treatment in the same temperature range. Nearly complete PME inactivation was reached at $55^{\circ} \mathrm{C}$ and $20 \mathrm{MPa}$ while PG was found to be more HPCD resistant. The non-linear Weibull model and the fractionalconversion model fitted PME and PG inactivation kinetics, respectively.

HPP processing was also applied to tomato juices obtaining a different behavior in enzyme inactivation, reaching a nearly complete inactivation of PG and no PME inactivation.

HPCD induced a homogenization effect on tomato juice since particle size distribution was shifted to smaller particle size and colloidal stability was not affected by HPCD treatment.

Based on these results and regarding the enzyme inactivation it can be concluded that a selective inactivation of either PME or PG can be achieved by combining different nonthermal treatments. Further research should be done to elucidate the mechanism for enzyme inactivation by HPCD as well as to develop industrial applications for food preservation by HPCD. 


\section{CHAPTER 8}

Effect of High Pressure Carbon Dioxide on polyphenol oxidase from Litopenaeus vannamei

Based on the article:

A.E. Illera, M. T. Sanz, S. Beltrán, O. Benito-Román (2019)

"Effect of High Pressure Carbon Dioxide on polyphenoloxidase from Litopenaeus vannamei"

LWT-Food Science \& Technology, 109, 359-365 



\section{Capítulo 8}

Efecto del $\mathrm{CO}_{2}$ a alta presión en la actividad de la polifenoloxidasa de Litopenaeus vannamei

\section{Resumen}

En este último capítulo se estudió el efecto del tratamiento HPCD sobre polifenoloxidasa (PPO) de origen animal, así como su efecto sobre un alimento sólido. En concreto, se estudió la extracción de PPO de Litopenaeus vannamei a diferentes condiciones de temperatura, $\mathrm{pH}$ y fuerza iónica. Los extractos óptimos, a pH 7,2, se trataron mediante tratamientos HPCD a $20 \mathrm{MPa}$ y en un rango de temperatura de 35 a $50^{\circ} \mathrm{C}$. Se determinaron las cinéticas de inactivación para los extractos de PPO y se ajustaron al modelo de Weibull. También se estudió el efecto de la tecnología HPCD sobre langostinos in vivo, donde se pudo comprobar que la PPO se inactivaba más fácilmente que en el extracto crudo de PPO. Por otra parte, también se realizó un estudio del color de Litopenaeus vannamei justo tras el tratamiento HPCD y tras un tratamiento térmico a la misma temperatura. Se siguieron visualmente los cambios durante almacenamiento de una semana a $4{ }^{\circ} \mathrm{C}$, mostrando buenos resultados en los langostinos que habían sido tratados mediante HPCD en ausencia de agua.

Palabras clave: Litopenaeus vannamei, HPCD, muestras sólidas, inactivación de PPO. 



\section{Abstract}

The extraction of PPO from Litopenaeus vannamei was studied at different temperatures, $\mathrm{pH}$ and ionic strength conditions. Optimum extracts at $\mathrm{pH}=7.2$ were treated by HPCD technology at $20 \mathrm{MPa}$ and temperature range from 35 to $50{ }^{\circ} \mathrm{C}$. Inactivation kinetics for polyphenol oxidase extracts were determined and fitted to the Weibull model. The effect of HPCD on PPO was also evaluated in shrimps in vivo, finding that PPO could be easier inactivated than in the crude PPO extract. Color of Litopenaeus vannamei was visually followed right after HPCD treatment and thermal treatment at the same temperature and during storage at $4{ }^{\circ} \mathrm{C}$ during a week, showing good results when shrimps were treated with HPCD in the absence of water.

Keywords: Litopenaeus vannamei, HPCD, solid samples, PPO inactivation. 



\section{Introduction}

Pacific white shrimp (Litopenaeus vannamei) accounts for $90 \%$ of the Western hemisphere aquaculture shrimp production. The most common problem in shrimps during post-harvest storage is melanosis. It is a natural post-mortem process, where the polymerization of phenols into insoluble black pigments, the melanins, takes place. Phenol polymerization is catalysed by polyphenol oxidases (PPO) enzymes. Despite not being harmful, melanosis can affect the sensory properties of the product, reducing its quality.

During harvest and storage of shrimps, sulphites, mainly sodium metabisulphite (SMS), are used for preventing melanosis. SMS reduces the o-quinones, which are coloured, to diphenols, which don't have any color. Nevertheless, sulphites have potentially pathological effects associated to allergies and asthmatic attacks. For that reason, many alternatives to sulphites can be found in the literature with the aim of avoiding browning in shrimps. Pacific white shrimps have been treated with a wide range of natural preservatives to inhibit PPO activity, such as ferulic acid and lead seed (Nirmal \& Benjakul, 2009), and extracts from different leaves (Sae-leaw \& Benjakul, 2019). However, usually big concentrations of extract or combinations with other technologies were needed.

Traditionally, thermal treatments have been applied for inhibiting PPO activity. Verhaeghe et al. (2016) probed that after treating brown shrimp PPO extract during 2 minutes at $65^{\circ} \mathrm{C}$, the enzyme was completely inactivated. Manheem et al. (2012) found out, that after treating shrimps at $80{ }^{\circ} \mathrm{C}$, melanosis formation decreased after 7 days in refrigerated storage. However, thermal treatment produces a big change in food properties (Ferrentino \& Spilimbergo, 2011). For that reason, different non-thermal technologies are being investigated as an alternative.

One of them is the use of HPCD (High Pressure Carbon Dioxide) technology. HPCD is a cold pasteurization method that affects microorganisms and enzymes by using pressures below $50 \mathrm{MPa}$ and temperatures usually lower than $50{ }^{\circ} \mathrm{C}$. This technology is gaining interest since $\mathrm{CO}_{2}$ is nontoxic, inexpensive, nonflammable, recyclable and after depressurization it 
doesn't leave residues in the product (Briongos et al., 2016). Effectiveness of HPCD on PPO inactivation has been extensively reported for different fruits and vegetables juices, such as orange juice (Briongos et al., 2016), apple and tomato juice (Illera et al., 2018a, 2018b) or carrot juice (Zhou et al., 2009b) among others. However, compared to liquids, HPCD application to solid foods has been less studied. According to Ferrentino and Spilimbergo, (2011), the complexity of the matrix, which can make the $\mathrm{CO}_{2}$ action more difficult, and the few information available about the inactivation mechanism make the use of this technology on solid foods less attractive.

The objective of this work was to study the effect of HPCD at $20 \mathrm{MPa}$ and different temperatures $\left(35-50^{\circ} \mathrm{C}\right.$ ) on PPO crude extracts from Litopenaeus vannamei on a kinetic basis, by previously studying the optimal conditions for the extraction. The fresh product (whole piece), with no addition of any additive, was also treated and, after HPCD treatment of the shrimps, PPO was extracted under the previously selected conditions to determine the effect of the treatment on PPO activity. Color was visually analyzed in treated shrimps right after treatment and during a shelf life study of 7 days at refrigerated storage $\left(4^{\circ} \mathrm{C}\right)$. A temperature control was prepared by treating the shrimps at the same temperature conditions under atmospheric pressure to distinguish the effect of pressurized $\mathrm{CO}_{2}$

\section{Materials and methods}

\subsection{Raw material}

Pacific white shrimps (Litopenaeus vannamei) with an average size of 40 - 60 shrimps/ kg were kindly donated by "Gamba Natural" (Medina del Campo, Valladolid, Spain), where shrimps were harvested right before being sent to our laboratory without any addition of sulphites or other additives. Shrimps were kept at refrigeration temperature during transport and also in arrival until used (not more than 1 hour from arrival). 


\subsection{Crude extract preparation}

The tails of the shrimps were separated and the heads were grounded into a fine powder by using liquid nitrogen in a blender. The obtained powder was kept at $-20^{\circ} \mathrm{C}$ until used for the different PPO extraction trials. The extraction procedure of PPO was carried out from the head of Pacific white shrimp (Litopenaeus vannamei) according to the method described by Chen et al. (1992) with slight modifications. The powder was mixed with the extraction buffer in a 1:3 proportion. The extraction buffer consisted in sodium phosphate buffer $0.05 \mathrm{M}$ containing $0.2 \%$ Brij 35 (Merck KGaA). Different extraction buffer pH values were tested in the extraction: $5.7,6.5,7.2$ and $8 . \mathrm{NaCl}$ concentration effect was also studied, being $0,0.25,0.5,1$ and $1.5 \mathrm{M}$ in the different experiments carried out at each different $\mathrm{pH}$ conditions. The mixture was stirred continuously during 30 minutes at $4{ }^{\circ} \mathrm{C}$, and then centrifuged at $5000 \mathrm{~g}$ at $4{ }^{\circ} \mathrm{C}$ during 30 minutes using a refrigerated centrifuge (Thermofisher, model Sorvall ST 16R). The effect of temperature during the mixing phase on the extraction yield was also studied, varying from 4 to $30^{\circ} \mathrm{C}$. The supernatant was collected and considered as PPO crude extract. Extracts were kept at $-20{ }^{\circ} \mathrm{C}$ until use. The addition of an anion exchange resin AG2-X8 (Biorad Laboratories) in the preparation of the crude extract was also analyzed at $\mathrm{pH}=7.2, \mathrm{NaCl} 1 \mathrm{M}$ and $0.2 \%$ Brij 35 at $4{ }^{\circ} \mathrm{C}$. Resin AG2-X8 was added in a 1:2 (w/w) proportion to the mix of shrimp powder and extraction buffer before mixing. This anion exchange resin has been shown to improve PPO activity in crude extracts from Fuji apples skin due to the adsorption of phenolic compounds during the extraction (Imm \& Kim, 2009).

\subsection{HPCD equipment and processing}

\subsubsection{Treatment of PPO extracts by HPCD}

HPCD treatment was carried out in a stainless steel (SS-316) cell with an internal volume of $100 \mathrm{ml}$ and a maximum operating pressure and temperature of $30 \mathrm{MPa}$ and $80^{\circ} \mathrm{C}$, respectively (Melgosa et al., 2017a). $25 \mathrm{ml}$ of PPO extract were charged into the cell, which was tightly closed and immersed in a water bath set at the operating temperature. 
Magnetic stirring was connected and the system was pressurized to the desired pressure by using a syringe pump with a pressure controller (ISCO $260 \mathrm{D}$ ). $\mathrm{CO}_{2}$ was bubbled directly into the extract through a sintered stainless steel micro-filter of $10 \mu \mathrm{m}$ (Briongos et al., 2016; Illera et al., 2018a; Illera et al., 2018c). PPO extracts were treated at $20 \mathrm{MPa}$ in the temperature range from 35 to $50^{\circ} \mathrm{C}$. Enzyme inactivation kinetics of PPO crude extracts was followed by collecting samples periodically for 60 minutes. Samples were kept at $4{ }^{\circ} \mathrm{C}$ until being analyzed.

\subsubsection{Treatment of shrimps by HPCD}

Whole shrimps were also exposed to HPCD in vivo. For these treatments, a bigger cell was used $\left(\mathrm{V}_{\text {cell }}=500 \mathrm{ml}\right)$, with a maximum operating pressure of $15 \mathrm{MPa}$. Operation conditions were $12 \mathrm{MPa}$ and $40{ }^{\circ} \mathrm{C}$ during $30 \mathrm{~min}$ in a dry treatment (no water added) or shrimps submerged in water $(300 \mathrm{ml})$. After treatment, the cell was slowly depressurized and the shrimps were kept in an ice batch (Zhang et al., 2011). Right after treatment, PPO was extracted at $4{ }^{\circ} \mathrm{C}$ under the previously selected conditions, to determine the effect of HPCD on enzyme activity when applying it directly on the solid pieces. The color of the pieces was also visually analyzed right after treatment and along storage during 7 days at $4{ }^{\circ} \mathrm{C}$ stored in properly closed food grade bags.

\subsection{Thermal treatment}

Thermal treatment was applied both to PPO extracts and to whole shrimps in the same temperature conditions as their respective HPCD treatments but at atmospheric pressure. These samples were used as a control to know the real effect of supercritical $\mathrm{CO}_{2}$ despite of temperature effect. PPO activity and color evolution were also studied in these samples. 


\subsection{Physico-chemical analysis}

\subsubsection{Determination of PPO activity}

PPO activity was determined spectrophotometrically by using L-3,4-dihidroxifenilalanine (L-DOPA, Sigma Aldrich) solution (5 mM) prepared in $20 \mathrm{mM}$ phosphate buffer (pH 6.5) as substrate. PPO activity was analyzed by adding $800 \mu$ l of PPO extract into $2.2 \mathrm{ml}$ substrate solution. Oxidation of L-DOPA was determined immediately by the increase in absorbance at $475 \mathrm{~nm}$ and $25^{\circ} \mathrm{C}$ by using a Jasco V-750 spectrophotometer equipped with a Peltier thermostated cell holder. The PPO activity was determined as the very first linear part of the reaction curve. One unit of PPO activity was defined as the amount of enzyme required for $0.001 / \mathrm{min}$ absorbance increase under the reaction conditions, $U$.

Relative residual activity of PPO after HPCD treatment was evaluated as:

Residual activity $(\%)=\frac{\text { Enzyme specific activity after HPCD treatment }}{\text { Enzyme specific activity in the crude extract }} \cdot 100=\frac{A}{A_{o}} \cdot 100$

\subsubsection{Protein content in the PPO extract}

Total protein content in the crude extract was determined by using the kit $R C D C^{\mathrm{TM}}$ (BioRad Laboratories), which allows protein determination in the presence of reducing agents and detergents. Bovine serum albumin was used as standard. For each extraction process, the specific PPO activity and total protein ratio was evaluated as:

$U / m g$ protein $=\frac{P P O \text { specific activity }}{\text { Total protein content }}=\frac{U / g \text { shrimp head }}{m g \text { protein } / g \text { shrimp head }}$

\subsection{Kinetic data analysis}

The Weibull model has been used to describe PPO inactivation in the crude extracts. According to Boekel (2002), it can be written in the power-law form: 
$\log \frac{\mathrm{A}}{\mathrm{A}_{\mathrm{o}}}=-\frac{1}{2.303}\left(\frac{t}{\alpha}\right)^{\beta}$

Where $\alpha$ is the scale parameter (a characteristic time) and $\beta$ is the shape parameter. The time required to achieve a number of decimal reductions, $d$, can be calculated by using the shape and scale parameters:

$t_{d}=\alpha\left(-\ln \left(10^{-d}\right)^{\frac{1}{\beta}}\right)$

According to Boekel (Boekel, 2002), the scale parameter, $\alpha$, was modelled in a similar way to the classical D value of the first order kinetic model, suggesting a linear dependence of the $\log \alpha$ on temperature, considering that the shape parameter, $\beta$, did not depend on temperature:

$\log \alpha=a_{1}-b_{1} T$

$A z_{\top}{ }^{\prime}$ value was defined as suggested by Boekel (Boekel, 2002), similar to the $z_{T}$ evaluated for first order kinetic models (Illera et al., 2018a):

$z_{T}^{\prime}=\frac{1}{b_{1}}$

\subsection{Statistical analysis}

Statistical analyses were conducted using software Statgraphics X64. The results are presented as the mean \pm standard deviation of at least three replicates. The significance of the differences was determined based on an analysis of the variance with Fisher's least significant method at $p$-value $\leq 0.05$.

To estimate the kinetic parameters, non-linear regression was performed by using the Marquardt algorithm (Statgraphics X64). 


\section{Results and discussion}

\subsection{Preparation of crude PPO extract}

\subsubsection{Effect of the presence of an anion exchange resin}

First, the effect of the anion exchange resin AG2-X8 on PPO activity in the crude extract was evaluated by using a ratio of 1:2 ( $\mathrm{g}$ resine: $\mathrm{g}$ shrimp head). Sodium phosphate $0.05 \mathrm{M}$ at $\mathrm{pH}=7.2$ in the presence of $0.2 \%$ of Brij 35 and $1 \mathrm{M} \mathrm{NaCl}$ at $4{ }^{\circ} \mathrm{C}$ was used as extracting medium (Table 8.1). It can be observed that there were no significant differences ( $p \leq 0.05)$ between using or not resin in PPO activity and total protein content in both extracts.

Table 8.1 PPO activity expressed as $U$ per $\mathrm{g}$ of shrimp head and $\mathrm{mg}$ of protein after extraction with and without resin AG2-X8 (1 g resin: $2 \mathrm{~g}$ shrimp head) using a sodium phosphate extraction buffer $\mathrm{pH} 7.2,1 \mathrm{M} \mathrm{NaCl}$ and $0.2 \%$ Brij 35 at $4{ }^{\circ} \mathrm{C}$.

\begin{tabular}{ccc}
\hline & With resin & Without resin \\
\hline U/g shrimp head & $190 \pm 1^{\mathrm{a}}$ & $182 \pm 12^{\mathrm{a}}$ \\
U/mg protein & $3.9 \pm 0.2^{\mathrm{a}}$ & $3.6 \pm 0.4^{\mathrm{a}}$ \\
\hline
\end{tabular}

Values with different letters in each row are significantly different when applying the Fisher's (LSD) test at $p$-value $\leq 0.05$.

In the study carried out by Imm and Kim (Imm \& Kim, 2009), where PPO was extracted from the skin of Fuji apples, a significant difference was observed when using resin AG2-X8, improving the enzyme recovery value. In this case, resin didn't affect PPO extraction, for that reason, further extractions were carried out without addition of the anion exchange resin.

\subsubsection{Effect of $\mathrm{pH}$}

Figures 8.1a and 8.1b show the effect of $\mathrm{pH}$ of the extraction medium on the PPO extract activity and protein content when using $0.2 \%$ of Brij 35 and $1 \mathrm{M} \mathrm{NaCl}$ at $4{ }^{\circ} \mathrm{C}$. Four 
different $\mathrm{pH}$ values were tested $(5.6,6.5,7.2$ and 8), showing that by increasing the $\mathrm{pH}$ of the medium, PPO activity per $g$ of shrimp head and total protein increased. For example, at $\mathrm{pH}=5.6, \mathrm{U} / \mathrm{g}$ shrimp head and $\mathrm{U} / \mathrm{mg}$ protein were $91 \pm 3$ and $1.7 \pm 0.1$, respectively; while at $\mathrm{pH}$ value of 8 , those values increased more than double to $212 \pm 4$ and $4.0 \pm 0.4$, respectively. There is scarce literature regarding the isoelectric point of PPO enzyme. Ali et al. (1994) found out that it was $4.76 \pm 0.03$ for Florida Spiny Lobster (Panulirus argus), and it was around 5.2 in PPO from Penaeus japonicus prawns according to Montero et al. (2001). pH values of the extraction buffer used in this work and in the literature are higher than this isoelectric point; therefore, PPO will present a negative charge. On the other hand, when $\mathrm{pH}$ is increased, the concentration of dissolved sodium ions increased, what may produce higher electrostatic interactions, and in consequence, a higher protein extraction.

Other studies in crustaceans tried to determine the best $\mathrm{pH}$ conditions for PPO extraction. Montero et al. (2001) chose $\mathrm{pH}=8$ as the optimum $\mathrm{pH}$ for extracting the enzyme from prawns (Penaeus japonicus), and Lv et al. (2018) determined pH $=6.2$ as the optimum for extracting it from Penaeus vannamei. Nirmal and Benjakul (2012) also worked with Pacific white shrimp and chose $\mathrm{pH}=6$ as the optimum for PPO extraction.

\subsubsection{Effect of extraction temperature}

The effect of temperature was studied in an extraction buffer at $\mathrm{pH}=8$ containing $1 \mathrm{M}$ $\mathrm{NaCl}$ and $0.2 \%$ Brij 35. Three different temperatures were studied, 4,21 and $30{ }^{\circ} \mathrm{C}$, and results are compiled in Table 8.2. As it can be observed, there is no significant difference among temperatures in PPO activity or protein content. Therefore, no denaturalization of the enzyme has occurred at the highest temperature assayed $\left(30^{\circ} \mathrm{C}\right)$. Although there was no difference between extraction temperatures, $4{ }^{\circ} \mathrm{C}$ was chosen as working temperature for further work, since it is the usual temperature employed in the literature (Chen et al., 1992; Manheem et al., 2012; Montero et al., 2001; Pal \& Rao, 2017; Verhaeghe et al., 2016; Wanyou et al., 2014). 

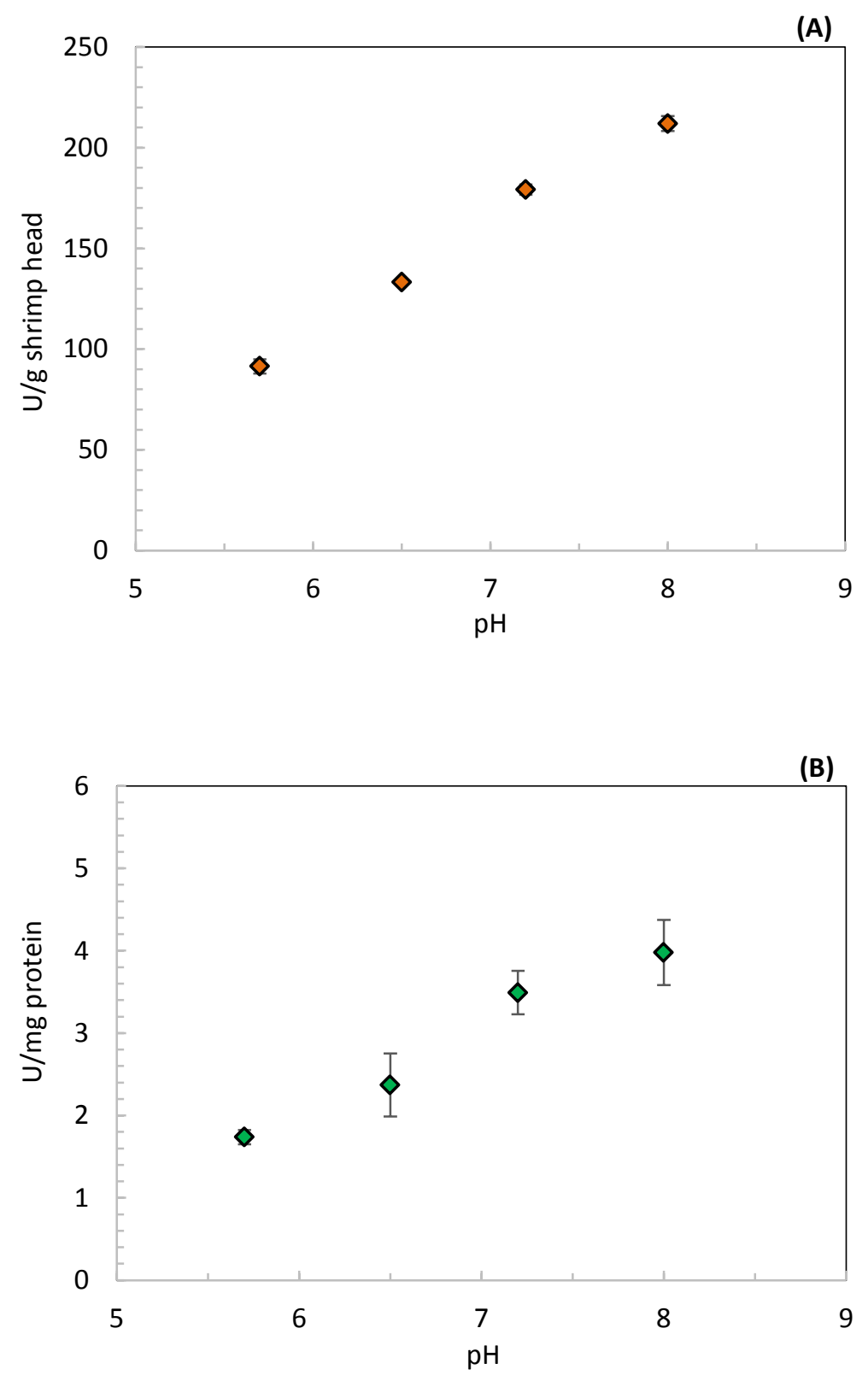

Figure 8.1 Effect of $\mathrm{pH}$ of the extraction sodium phosphate buffer on (a) PPO activity and (b) extract protein content when using $1 \mathrm{~mol} / \mathrm{L} \mathrm{NaCl}$ and $0.2 \mathrm{~g} / 100 \mathrm{ml}$ of Brij 35 at $4{ }^{\circ} \mathrm{C}$. 
Table 8.2 PPO activity expressed as $U$ per $g$ of shrimp head and $\mathrm{mg}$ of protein after extraction at different temperatures using a sodium phosphate extraction buffer $\mathrm{pH} 8$, $1 \mathrm{M} \mathrm{NaCl}$ and $0.2 \%$ Brij 35 .

\begin{tabular}{cccc}
\hline & $\mathbf{4}^{\circ} \mathrm{C}$ & $\mathbf{2 1}{ }^{\circ} \mathrm{C}$ & $30{ }^{\circ} \mathrm{C}$ \\
\hline U/g shrimp head & $212 \pm 4^{\mathrm{a}}$ & $209 \pm 7^{\mathrm{a}}$ & $211 \pm 3^{\mathrm{a}}$ \\
U/mg protein & $4.0 \pm 0.4^{\mathrm{a}}$ & $4.2 \pm 0.2^{\mathrm{a}}$ & $4.3 \pm 0.2^{\mathrm{a}}$ \\
\hline
\end{tabular}

Values with different letters in each row are significantly different when applying the Fisher's (LSD) test at $p$-value $\leq 0.05$.

\subsubsection{Effect of salt concentration (ionic strength)}

Figures $\mathbf{8 . 2 a}$ and $\mathbf{8 . 2 b}$ show the effect of salt concentration on PPO extraction in the range from 0 to $1.5 \mathrm{M} \mathrm{NaCl}$ at different $\mathrm{pH}$ values of the extraction buffer $(6.5,7.2$ and 8$)$. It can be observed that PPO extraction depends on the ionic strength of the medium, whatever it is the $\mathrm{pH}$. When $\mathrm{NaCl}$ concentration increased in the extraction medium its extraction capacity decreased. Best results were obtained when no $\mathrm{NaCl}$ was added to the extraction buffers, so further experiments were carried without using $\mathrm{NaCl}$. Verhaeghe et al. (2016) extracted PPO from brown shrimp (Crangon crangon) with no $\mathrm{NaCl}$ added into the extraction medium; however, in the literature most of the extraction protocols for crustaceans use $\mathrm{NaCl}$ for enzymatic extraction. For extracting PPO from Litopenaeus vannamei, Nirmal and Benjakul (2012) used $1 \mathrm{M} \mathrm{NaCl}$, meanwhile Wanyou et al. (2014) and Zhang et al. (2011) used 0.5 M. For extraction in other crustaceans, $1 \mathrm{M} \mathrm{NaCl}$ was also used (Montero et al., 2001; Pal \& Rao, 2017; Zamorano et al., 2009). All the mentioned studies used an existing protocol and they didn't test the effect of salt concentration. Imm and Kim (2009) studied the effect of salt concentration on PPO activity recovery from apple skin and they also obtained much higher enzyme recovery without adding any salt to the medium. 

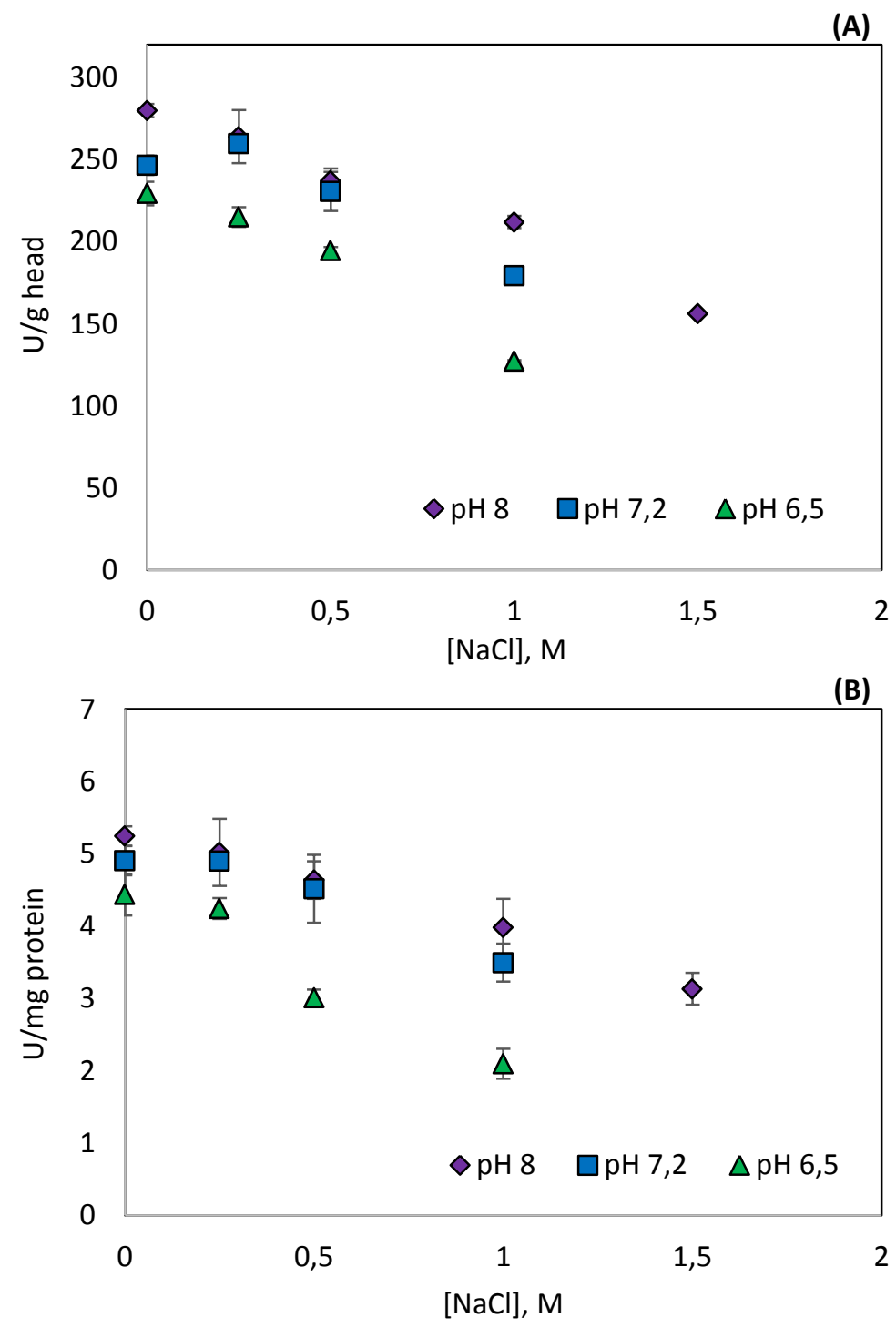

Figure 8.2 Effect of extraction sodium phosphate buffer ionic concentration (expressed as $\mathrm{NaCl}, \mathrm{mol} / \mathrm{L}$ ) on (a) extraction yield and (b) extract protein content when using buffer at different $\mathrm{pH}$ values with $0.2 \mathrm{~g} / 100 \mathrm{ml}$ Brij 35 at $4{ }^{\circ} \mathrm{C}$.

\subsection{HPCD inactivation of PPO crude extract}

PPO inactivation kinetics in the crude extract was determined at $20 \mathrm{MPa}$ and $35^{\circ} \mathrm{C}$. Crude PPO extracts were obtained at two different values of $\mathrm{pH}, 6.5$ and 7.2 with no $\mathrm{NaCl}$ added to the extraction medium. Although higher PPO activity was obtained at the highest $\mathrm{pH}$ 
studied in this work $(\mathrm{pH}=8)$, inactivation kinetics were determined at $\mathrm{pH}=6.5$ and 7.2 since, according to the literature, fresh prawns have a $\mathrm{pH}$ varying between 6.5 and 6.9 (Shaikhmahamud \& Magar, 1965) and the $\mathrm{pH}$ of the carapace of the cephalothorax of Penaeus japonicus prawns was 7.2.

Figure 8.3 shows similar PPO inactivation kinetics at both values of $\mathrm{pH}$, with a minimum residual activity of $35.0 \pm 0.7 \%$ after 60 min of treatment. Therefore, the effect of HPCD temperature has been only studied at $\mathrm{pH}=7.2$, in order to compare with other previously published results, where the extract was also obtained at $\mathrm{pH}=7.2$ (Chen et al., 1992; Zhang et al., 2011). The similar results between the two $\mathrm{pH}$ values can be related to the $\mathrm{CO}_{2}$ solubility in the extracts. In this work, the solubility of pressurized $\mathrm{CO}_{2}$ in a phosphate buffer containing $0.2 \%$ Brij 35 was determined by using the method and equipment previously reported by Illera et al. (Illera et al., 2019). The solubility values were $0.59 \pm 0.01 \mathrm{~g} \mathrm{CO}_{2}$ per $\mathrm{ml}$ of buffer at $\mathrm{pH}=6.5$, and $0.56 \pm 0.02$ at $\mathrm{pH}=7.2$ at $20 \mathrm{MPa}$ and $45^{\circ} \mathrm{C}$, what indicated that $\mathrm{CO}_{2}$ solubility was very similar.

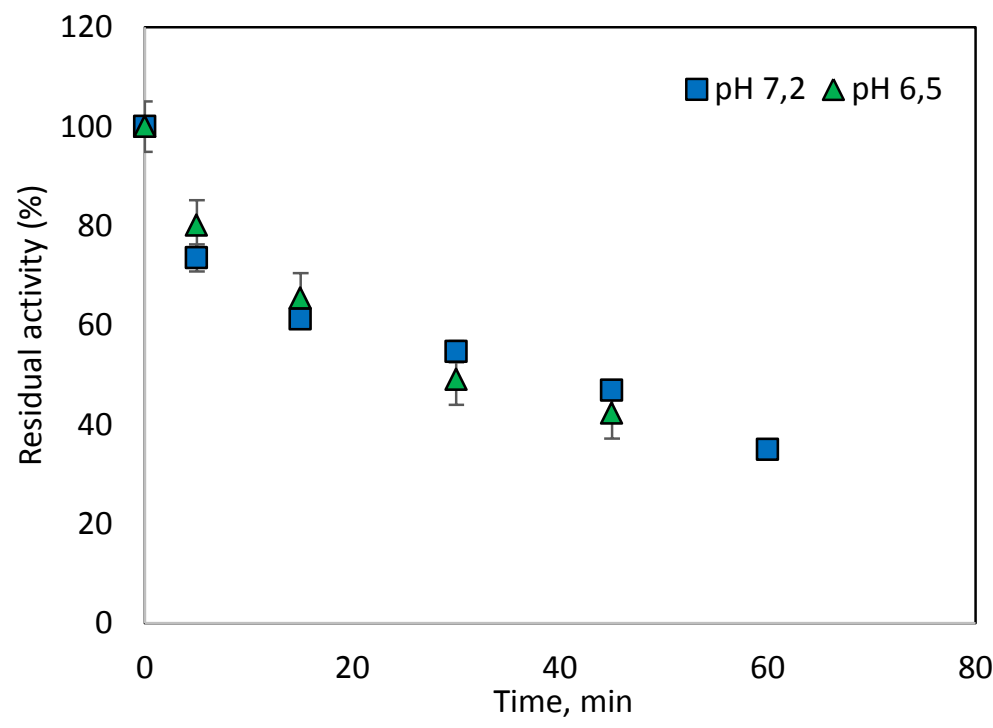

Figure 8.3 Inactivation kinetic of PPO by HPCD treatment at $20 \mathrm{MPa}$ and $35^{\circ} \mathrm{C}$ in PPO extract obtained at $\mathrm{pH}=6.5$ and $\mathrm{pH}=7.2$. $\mathrm{PPO}$ was extracted with a sodium phosphate buffer with $0.2 \mathrm{~g} / 100 \mathrm{ml}$ Brij 35 at $4{ }^{\circ} \mathrm{C}$. 
Inactivation kinetics at $20 \mathrm{MPa}$ in the temperature range from 35 to $50{ }^{\circ} \mathrm{C}$ is plotted in Figure 8.4. Enzyme inactivation rate increased significantly by increasing temperature (from 35 to $50{ }^{\circ} \mathrm{C}$ ). At $50{ }^{\circ} \mathrm{C}$, PPO activity was $9 \pm 3 \%$ after $60 \mathrm{~min}$ of treatment. In this regard, in addition to the intrinsic effect of temperature on enzyme inactivation, an increasing temperature could lead to an improvement of mass transport properties of $\mathrm{CO}_{2}$, enhancing $\mathrm{CO}_{2}$ diffusivity and the number of collisions between the $\mathrm{CO}_{2}$ and the enzyme (Illera et al., 2018a). Similar values for the PPO residual activity have been reported in the literature when treating PPO extracts from Pacific white shrimps by HPCD at $37^{\circ} \mathrm{C}$ and $20 \mathrm{MPa}, 10 \%$ of residual activity after $30 \mathrm{~min}$ of treatment and total inactivation was reported when increasing pressure to $25 \mathrm{MPa}$ at same temperature and time conditions (Zhang et al., 2011). Chen et al. (1992) achieved total inactivation in shorter treatment time ( 4 minutes) when they treated PPO extract from brown shrimp and in only one minute when the extract was from Florida spiny lobster. To assess the effect of pressurized carbon dioxide on enzyme inactivation, PPO crude extracts were also treated in the same temperature range but at atmospheric pressure. Figure $\mathbf{8 . 5}$ clearly shows that higher inactivation degree was obtained when the PPO crude extract was treated by pressurized $\mathrm{CO}_{2}$. At $50{ }^{\circ} \mathrm{C}$, PPO inactivation after 60 minutes at atmospheric pressure was only around $30 \%$ (residual activity, $70 \%$ ) compared to the $90 \%$ after HPCD treatment (residual activity, $10 \%$ ). Wanyou et al. (2014) also treated a PPO extract from Pacific white shrimp by thermal treatment, and they determined that a minimum temperature of $60{ }^{\circ} \mathrm{C}$ was necessary for enzymatic inactivation, since they observed no inactivation when treating it at $50{ }^{\circ} \mathrm{C}(95.2 \%$ residual activity). This indicates that PPO is not mainly inactivated by the temperature effect, but pressurized $\mathrm{CO}_{2}$ has an important role in enzymatic inactivation. Furthermore, Zhang et al. (2011), explained that PPO activity is not only affected by pressure, but also by $\mathrm{CO}_{2}$ molecular effects under pressure. 


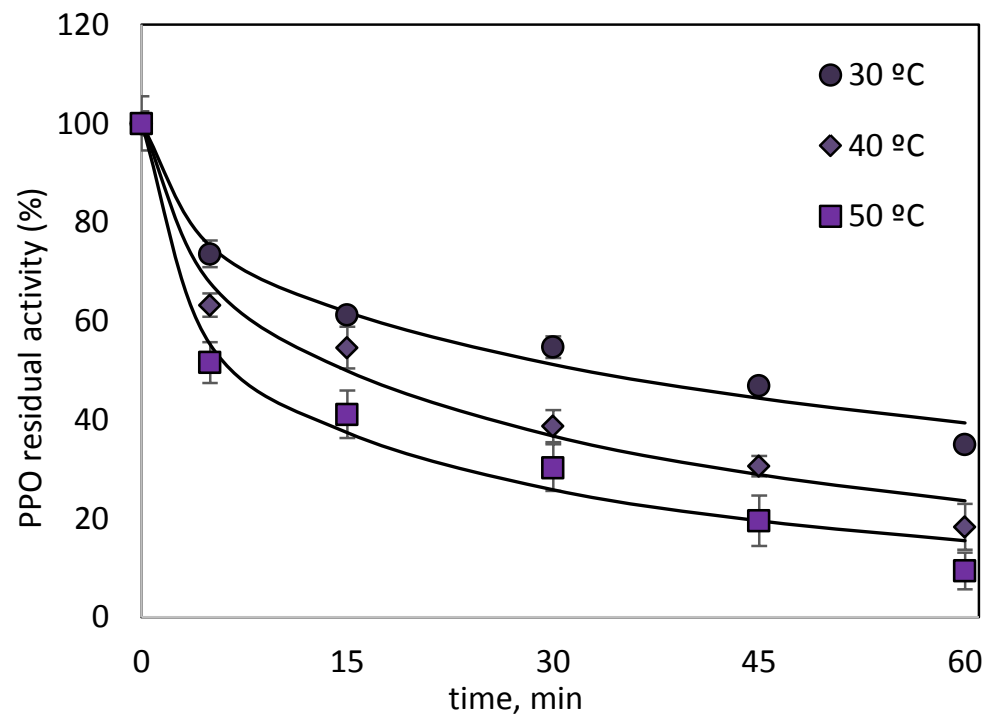

Figure 8.4 Inactivation kinetics of PPO extracts by HPCD treatment at $20 \mathrm{MPa}$ and different temperatures. PPO was extracted using phosphate buffer at $\mathrm{pH}=7.2$ with $0.2 \mathrm{~g} / 100 \mathrm{ml} \mathrm{Brij} 35$ at $4{ }^{\circ} \mathrm{C}$. Symbols represent the experimental results, and lines represent the calculated values for the Weibull model (Eq. 8.3).

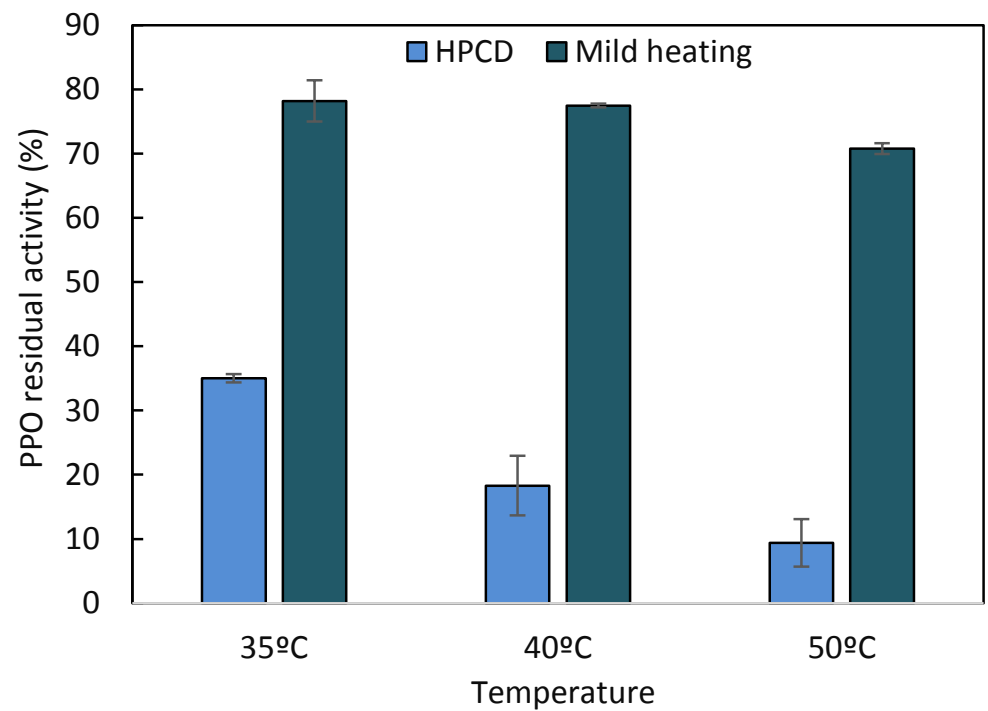

Figure 8.5 PPO residual activity of PPO extracts after 60 min of HPCD treatment at $20 \mathrm{MPa}$ or mild heating treatment at different temperatures. PPO was extracted using phosphate buffer $\mathrm{pH}=7.2$ with $0.2 \mathrm{~g} / 100 \mathrm{ml} \mathrm{Brij} 35$ at $4{ }^{\circ} \mathrm{C}$. 
PPO inactivation kinetics were fitted to the Weibull model, since the first order kinetic model was found not to be able to properly describe PPO inactivation kinetics by HPCD. Fitting parameters of the Weibull model are listed in Table 8.3. The scale parameter, $\alpha$, decreased with temperature, however, the shape factor, $\beta$, did not show any dependence on temperature, with values lower than the unity. Scale, $\alpha$, and shape, $\beta$, parameters were used to calculate the time required to inactivate $1 \log \left(t_{d=1}\right)$ of PPO. According to the values of $\alpha, t_{d=1}$ decreased with temperature from 392 to $98 \mathrm{~min}$ at 35 and $50{ }^{\circ} \mathrm{C}$, respectively.

Table 8.3 Kinetic parameters of the Weibull model for the inactivation of PPO by HPCD treatment

\begin{tabular}{ccccc}
\hline $\mathbf{T},{ }^{\circ} \mathbf{C}$ & $\boldsymbol{\alpha}, \min$ & $\boldsymbol{\beta}$ & $\mathbf{R}^{\mathbf{2}}$ & $\mathbf{t}_{\mathbf{d}=1, \mathbf{m i n}}$ \\
\hline 35 & $69 \pm 10$ & $0.48 \pm 0.06$ & 0.984 & 392 \\
40 & $30 \pm 3$ & $0.53 \pm 0.07$ & 0.982 & 145 \\
50 & $16 \pm 2$ & $0.46 \pm 0.07$ & 0.984 & 98 \\
\hline \multicolumn{5}{c}{$\ln (1 / \alpha)$ vs $(1 / T): 77 \pm 20 \mathrm{~kJ} / \mathrm{mol}\left(\mathbf{R}^{\mathbf{2}}=0.940\right)$} \\
\hline
\end{tabular}

The value of the $\mathrm{z}_{\mathrm{T}}{ }^{\prime}$ (Eq. 8.6) has been also included in Table 8.3, with the quality of the fitting of equation 8.5. The $\mathrm{z}_{\mathrm{T}}$ value obtained in this work by HPCD, $25 \pm 6{ }^{\circ} \mathrm{C}$, was slightly higher than the values reported in the literature for thermal treatment. Wanyou et al. (2014), obtained a $z_{T}$ value of $18.83{ }^{\circ} \mathrm{C}$ after treating Pacific white shrimp from 60 to $100{ }^{\circ} \mathrm{C}$. An Arrhenius type equation was considered to relate the inverse of the scale parameter, $1 / \alpha$, with temperature (Illera et al., 2018b). Although $1 / \alpha$ cannot be considered a kinetic constant, the value obtained from the slope was calculated as $77 \pm 20 \mathrm{~kJ} / \mathrm{mol}$.

\subsection{HPCD inactivation of PPO in whole shrimps}

Shrimps were treated in vivo by $\mathrm{HPCD}$ at $12 \mathrm{MPa}$ and $40^{\circ} \mathrm{C}$ during 30 minutes in the presence or absence of water. Shrimps were also treated at atmospheric pressure and $40{ }^{\circ} \mathrm{C}$ as control, in order to assess the effect of temperature on PPO inactivation and on 
visual changes of colour. After treatment, PPO was extracted and activity was determined and compared to a PPO crude extract of non-treated shrimps (Table 8.4). The PPO inactivation degree obtained when heating the shrimps at $40{ }^{\circ} \mathrm{C}$ in water or in the absence of water was similar to the inactivation obtained when treating the PPO crude extract by mild heating at $35-40{ }^{\circ} \mathrm{C}$. However, no PPO activity was detected, according to the experimental procedure previously described, when treating the shrimps in vivo by HPCD, nor in absence neither in presence of water (Table 8.4). As previously reported, residual activity in crude PPO extracts treated by HPCD at higher operating pressure, $20 \mathrm{MPa}$, but at the same temperature, $40^{\circ} \mathrm{C}$, was much higher $(38.7 \pm 3.2)$ than the values obtained in the sample in vivo. These results agree with the residual activity of PPO reported by Zhang et al. (2011) after treatment of Pacific white shrimps in vivo at $20-25 \mathrm{MPa}$ at $37^{\circ} \mathrm{C}$ for 10 min, with residual activity values lower than $6 \%$, and total inactivation for treatment time of 30 minutes. Therefore, we can conclude that PPO in vivo was easier to be inactivated than in crude extracts. This was corroborated by Zhang et al. (2011), that attributed this finding to a bigger contact area between PPO and HPCD.

Table 8.4 PPO residual activity after HPCD and mild heating treatment (MH) at $40{ }^{\circ} \mathrm{C}$ with and without liquid (water). PPO was extracted at $\mathrm{pH}=7.2$ with $0.2 \% \mathrm{Brij} 35$ at $4{ }^{\circ} \mathrm{C}$.

\begin{tabular}{ccccc}
\hline Treatment & MH (water) & MH & HPCD (water) & HPCD \\
\hline PPO residual activity & $72.5 \%$ & $83.3 \%$ & n.d. & n.d. \\
\hline n.d (Non detected). & & & &
\end{tabular}

Visual control of color was carried out, with shrimps stored in plastic bags at $4{ }^{\circ} \mathrm{C}$ during 7 days. Untreated shrimps were used as controls for color. Pictures from the shrimps during the shelf life study can be seen in Figure 8.6. Untreated shrimps and the ones that were only thermally treated showed up browning in the cephalothorax soon, in the second day of storage. HPCD treated shrimps in absence of water presented a similar aspect to cooked shrimps, slightly orange and white appearance, and light browning in cephalothorax appeared in the fifth day of storage. On the other hand, the shrimps that were HPCD treated but in water showed a similar behaviour to the mild thermally treated ones, starting to show browning on the second day of storage, although browning intensity was lower than the control and the thermally treated ones. By the 7 th day of 
storage, melanosis is present in all the samples, being a bit lower in the HPCD treated one in absence of water (Figure 8.6d). Zhang et al. (Zhang et al., 2011) treated whole Pacific white shrimps by HPCD observing their appearance during 3 days of storage at $4{ }^{\circ} \mathrm{C}$. In that time, no melanosis appeared in HPCD treated shrimps in absence of water, while untreated samples showed advanced browning, as in the present work.

Furthermore, color of shrimps after dry HPCD treatment was light orange. Wei et al. (1991) also noticed a cooked appearance after HPCD treatment of shrimps. Li et al. (2012) observed the same effect in color after treating Litopenaeus vannamei by HPP. They explained that the change in color is related to protein coagulation, which changes the sample surface properties, increasing light reflection and, therefore, a whitened color. After studying melanosis in different parts of shrimps, Zamorano et al. (Zamorano et al., 2009) explained that the presence of the cephalothorax was required for melanosis to be initiated, where they observed melanosis in just one day in an untreated shrimp. 


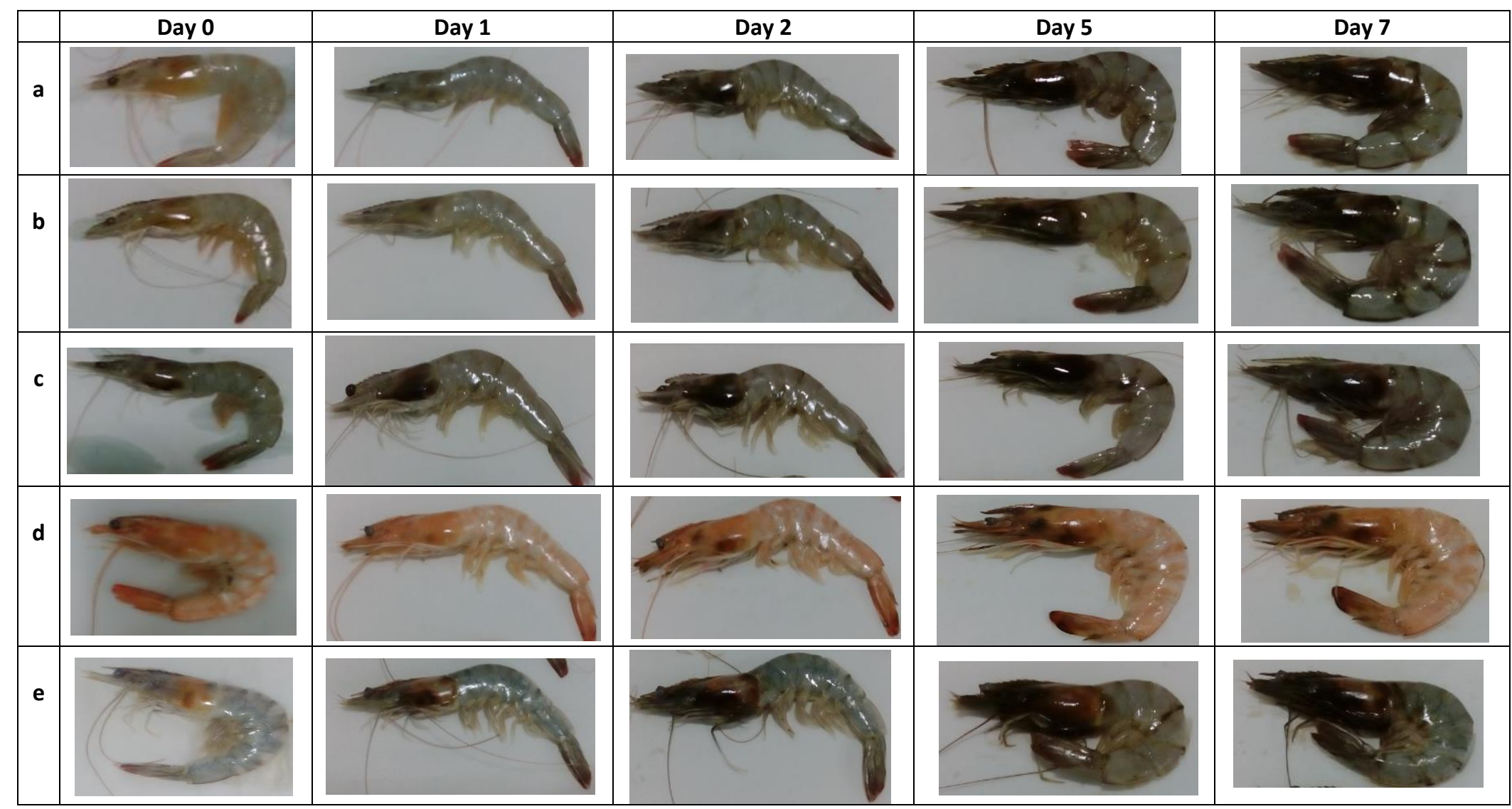

Figure 8.6 Appearance of untreated shrimps (a) and treated ones at atmospheric pressure, $40^{\circ} \mathrm{C}$ in absence (b) and in presence of water (c) and by HPCD treatment at $12 \mathrm{MPa}, 40^{\circ} \mathrm{C}$ in absence (d) and in presence of water (e) during 7 days of storage at $4{ }^{\circ} \mathrm{C}$. 


\section{Conclusions}

The study of PPO extraction from cephalothorax of Pacific white shrimps concluded that higher $\mathrm{pH}$ values improved the extraction, while the presence of $\mathrm{NaCl}$ or anionic exchange resin (AG2-X8) didn't show any benefit. Extraction yield was no dependent on temperature, in the range from 4 to $30^{\circ} \mathrm{C}$.

HPCD treatment resulted to be effective in PPO inactivation of these extracts. An increase of treatment temperature, in the range from 35 to $50{ }^{\circ} \mathrm{C}$, increased enzymatic inactivation and inactivation rate. HPCD treatment showed better results in PPO inactivation of shrimps in vivo, where the enzyme was totally inactivated according to our analytical procedure, although melanosis quickly appeared in all samples except in the HPCD treated one in absence of water, which showed good visual aspect during 5 days of storage at $4{ }^{\circ} \mathrm{C}$. In conclusion, HPCD technology has been found to be a promising non-thermal technology for the processing of shrimps, and it can be considered as an alternative to the use of sulphites in this product. 

CONCLUSIONS 



\section{CONCLUSIONS}

Although each chapter contains its own conclusions from the different experimental studies carried out in this PhD Thesis, the following general conclusions can be established:

- The HPCD, TS and CP treatments showed to be valid alternatives to process Golden delicious cloudy apple juice, being more effective on enzymatic inactivation than mild heat treatment in the same temperature range. No enzyme reactivation was observed during storage after any of these treatments.

- Enzyme inactivation showed to be highly influenced by the source of the enzyme and by the matrix where it is present. For example, PME was found to be more resistant than PPO to HPCD and TS treatments in cloudy apple juice, but it was nearly totally inactivated by HPCD in tomato juice.

- The enzymatic inactivation rate achieved by HPCD increased with operating pressure and temperature. Also the stirring speed increased $\mathrm{CO}_{2}$ diffusivity and thus, inactivation of enzymes. An increase on the US amplitude in the TS treatment also increased enzyme inactivation in apple juice, thus, faster inactivation kinetics were obtained when the air dissolved in the juice was displaced by nitrogen. In all the different technologies used, when the treatment time increased, higher enzymatic inactivation was found.

- HPCD and TS treatments induced a change in the particle size distribution of juices, shifting the particle size towards lower particle diameters, what is reflected in a homogenization effect in the juice. Meanwhile, plasma treatments did not significantly change this property.

- The three non-thermal technologies showed an increase or maintenance in total phenolic compounds and antioxidant capacity in cloudy apple juice. After HPCD treatment, color slightly changed, but a more significant change was observed after TS and $\mathrm{CP}$ treatments, were color was much lighter after being treated. In general, these changes in properties were maintained during storage. 
- After the HPCD treatments, good results in PPO inactivation were obtained, both in liquid and solid samples as well as in PPO extracts from apples and shrimps.

- The HPCD technology has been found to be a promising non-thermal technology for the processing of shrimps, and it can be considered as an alternative to the use of sulphites in this product.

- $\mathrm{CO}_{2}$ solubility in aqueous solutions depends on the composition of the solutions. Sugars present in fruit or vegetable juices, led to significant lower values of $\mathrm{CO}_{2}$ solubility. $\mathrm{CO}_{2}$ solubility data were successfully fitted to a Chrastil type equation, according to Fornari's approach to relate the liquid phase composition with the density of the supercritical fluid. An additional term was added, to account for the decrease in solubility of $\mathrm{CO}_{2}$ in the presence of sugars, obtaining a good fitting.

- The non-linear Weibull model performed a better fitting of the enzyme inactivation kinetics by HPCD in cloudy apple juice than the classical first order kinetic model. This model also fitted very well enzyme inactivation kinetics by plasma. In tomato juice, the Weibull model and the fractional-conversion model fitted PME and PG inactivation kinetics, respectively.

- Further research is needed to elucidate the enzyme inactivation mechanism of these technologies and reach a better understanding and optimization of the processes. Anyway, it has been proved that enzymatic inactivation is highly affected by changes in the tertiary structure of the protein.

- Also sensory quality, shelf life studies and economic aspects are needed to be performed for a posterior industrial application. 
REFERENCES 



\section{REFERENCES}

Abdullah, N., \& Chin, N. L. (2014). Application of thermosonication treatment in processing and production of high quality and safe-to-drink fruit juices. Agriculture and Agricultural Science Procedia, 2, 320-327.

Abid, M., Jabbar, S., Wu, T., Muhammad, M., Hu, B., Lei, S., \& Zeng, X. (2013). Effect of ultrasound on different quality parameters of apple juice. Ultrasonics Sonochemistry, 20(5), 1182-1187.

Abid, M., Jabbar, S., Hu, B., Muhammad, M., Wu, T., Lei, S., \& Zeng, X. (2014). Thermosonication as a potential quality enhancement technique of apple juice. Ultrasonics - Sonochemistry, 21(3), 984-990.

Abid, M., Jabbar, S., Wu, T. A. O., Hashim, M. M., Hu, B., Saeeduddin, M., \& Zeng, X. (2015). Qualitative assessment of sonicated apple juice during storage. Journal of Food Processing and Preservation, 39, 1299-1308.

Aguiló-aguayo, I., Soliva-fortuny, R., \& Martín-belloso, O. (2009). Avoiding non-enzymatic browning by high-intensity pulsed electric fields in strawberry, tomato and watermelon juices. Journal of Food Engineering, 92(1), 37-43.

Al-Juboori, R. A., Yusaf, T., \& Bowtell, L. (2015). Energy conversion efficiency of pulsed ultrasound. Energy Procedia, 75, 1560-1568.

Alexandre, E., Brandao, T., \& Silva, C. (2012). Emerging technologies to improve the safety and quality of fruits and vegetables. McElhatton, A., Sobral, P. \& Kristbergsson, K. (Eds.), Novel Technologies in Food Science (pp. 261-298). Springer.

Ali, M. T., Marshall, M. R., Wei, C. I., Gleeson, R. A., Box, P., \& Augustine, S. (1994). Monophenol oxidase activity from the cuticle of Florida Spiny Lobster (Panulirus argus). Journal of Agricultural and Food Chemistry, 42(1), 53-58. 
Amaral, R. D. A., Benedetti, B. C., Pujola, M., Achaerandio, I. \& Bachelli, M. L. B. (2015). Effect of ultrasound on quality of fresh-cut potatoes during refrigerated storage. Food Engineering Reviews, 7, 176-184.

Amaral, G. V., Silva, E. K., Cavalcanti, R. N., Cappato, L. P., Guimaraes, J. T., Alvarenga, V. O., \& Cruz, A. G. (2017). Dairy processing using supercritical carbon dioxide technology: Theoretical fundamentals, quality and safety aspects. Trends in Food Science and Technology, 64, 94-101.

Amaral, G. V., Silva, E. K., Cavalcanti, R. N., Martins, C. P. C., Andrade, L. G. Z. S., Moraes, J., \& Cruz, A. G. (2018). Whey-grape juice drink processed by supercritical carbon dioxide technology: Physicochemical characteristics, bioactive compounds and volatile profile. Food Chemistry, 239, 697-703.

Anaya-Esparza, L. M., Velázquez-Estrada, R. M., Roig, A. X., García-Galindo, H. S., SayagoAyerdi, S. G., \& Montalvo-González, E. (2017). Thermosonication: An alternative processing for fruit and vegetable juices. Trends in Food Science and Technology, 61 26-37.

Andreou, V., Dimopoulos, G., Katsaros, G., \& Taoukis, P. (2016). Comparison of the application of high pressure and pulsed electric fields technologies on the selective inactivation of endogenous enzymes in tomato products. Innovative Food Science and Emerging Technologies, 38, 349-355.

Angus, S., Armstrong, B., \& de Reuck, K. M. (1976). International Thermodynamic Tables of the Fluid State. Pergamon Press.

Anthon, G. E., Sekine, Y., Watanabe, N., \& Barrett, D. M. (2002). Thermal inactivation of pectin methylesterase, polygalacturonase, and peroxidase in tomato juice. Journal of Agricultural and Food Chemistry, 50(21), 6153-6159.

Augusto, P. E. D., Ibarz, A., \& Cristianini, M. (2013). Effect of high pressure homogenization (HPH) on the rheological properties of tomato juice: Creep and recovery behaviours. Food Research International, 54(1), 169-176. 
Baker, R. A. \& Cameron, R. (1999). Cloud of citrus juices and juice drinks. Food Technology, 53(1), 64-69.

Balaban, M. O. (2012). Effects of DPCD on Enzymes. M. O. Balaban \& G. Ferrentino (Eds.), Dense Phase Carbon Dioxide: Food and Pharmaceutical Applications (pp. 113-134). Blackwell.

Balogh, T., Smout, C., Nguyen, B. L., Loey, A. M. Van, \& Hendrickx, M. E. (2004). Thermal and high-pressure inactivation kinetics of carrot pectinmethylesterase: From model system to real foods. Innovative Food Science and Emerging Technologies, 5, 429-436.

Baltacioglu, H., Bayindirli, A. \& Severcan, F. (2017). Secondary structure and conformational changes of mushroom polyphenol oxidase during thermosonication treatment by using FTIR spectroscopy. Food Chemistry, 214, 507-514.

Bamberger, A., Sieder, G., \& Maurer, G. (2004). High-pressure phase equilibrium of the ternary system carbon dioxide + water + acetic acid at temperatures from 313 to 353 K. Journal of Supercritical Fluids, 32(1-3), 15-25.

Başlar, M. \& Ertugay, M. F. (2013). The effect of ultrasound and photosonication treatment on polyphenoloxidase (PPO) activity, total phenolic component and colour of apple juice. International Journal of Food Science and Technology, 48(4), 886-892.

Baslar, M. \& Ertugay, M. F. (2014). The effect of ultrasonic treatments on cloudy qualityrelated quality parameters in apple juice. Innovative Food, 26, 226-231.

Beveridge, T. (2002). Opalescent and cloudy fruit juices: Formation and particle stability. Critical Reviews in Food Science and Nutrition, 42, 317-337. 
Bevilacqua, A., Petruzzi, L., Perricone, M., Speranza, B., Campaniello, D., Sinigaglia, M., \& Corbo, M. R. (2018). Nonthermal technologies for fruit and vegetable juices and beverages: Overview and advances. Comprehensive Reviews in Food Science and Food Safety, 17.

Bhat, R., Shuaidda, N., Che, B., Min-tze, L. \& Karim, A. A. (2011). Sonication improves kasturi lime (Citrus microcarpa) juice quality. Ultrasonics - Sonochemistry, 18(6), 1295-1300.

Boekel, M. A. J. S. Van. (2002). On the use of the Weibull model to describe thermal inactivation of microbial vegetative cells. International Journal of Food Microbiology, 74, 139-159.

Briongos, H., Illera, A. E., Sanz, M. T., Melgosa, R., Beltrán, S. \& Solaesa, A. G. (2016). Effect of high pressure carbon dioxide processing on pectin methylesterase activity and other orange juice properties. LWT - Food Science and Technology, 74, 411-419.

Brunner, G. (1994). Gas extraction: an introduction to fundamentals of supercritical fluids and the application to separation processes. New York: Springer.

Buckow, R., Weiss, U. \& Knorr, D. (2009). Inactivation kinetics of apple polyphenol oxidase in different pressure-temperature domains. Innovative Food Science and Emerging Technologies, 10(4), 441-448.

Butz, P. \& Tauscher, B. (2002). Emerging technologies: chemical aspects. Food Research International, 35, 279-284.

Calix, T. F., Ferrentino, G., \& Balaban, M. O. (2008). Measurement of high-pressure carbon dioxide solubility in orange juice, apple juice, and model liquid foods. Journal of Food Science, 73(9), 439-445. 
Chemat, F., Rombaut, N., Sicaire, A., Meullemiestre, A., \& Abert-vian, M. (2017). Ultrasound assisted extraction of food and natural products. Mechanisms, techniques, combinations, protocols and applications. A review. UltrasonicsSonochemistry, 34, 540-560.

Chen, D., Peng, C., Zhang, H., \& Yan, Y. (2013). Assessment of activities and conformation of lipases treated with sub and supercritical carbon dioxide. Applied Biochemistry and Biotechnology, 169(7), 2189-2201.

Chen, J. S., Balaban, M., Wei, C., Marshall, M. R., \& Hsu, W. Y. (1992). Inactivation of polyphenol oxidase by high-pressure carbon dioxide. Journal of Agricultural and Food Chemistry, 2, 2345-2349.

Cheng, L. H., Soh, C. Y., Liew, S. C., \& Teh, F. F. (2007). Effects of sonication and carbonation on guava juice quality. Food Chemistry, 104, 1396-1401.

Cheng, X. F., Zhang, M., \& Adhikari, B. (2013). The inactivation kinetics of polyphenol oxidase in mushroom (Agaricus bisporus) during thermal and thermosonic treatments. Ultrasonics Sonochemistry, 20(2), 674-679.

Chrastil, J. (1982). Solubility of solids and liquids in supercritical gases. Journal of Physical Chemistry, 86(15), 3016-3021.

Clifford, A. A. \& Williams, J. R. (2000). Introduction to supercritical fluids and their applications. In Supercriticial Fluids: Methods and Protocols, 1-16.

Cohen, E., Birk, Y., Mannheim, C. H. \& Saguy, I. S. (1998). A rapid method to monitor quality of apple juice during thermal processing. LWT - Food Science and Technology, $616,612-616$.

Corwin, H. \& Shellhammer, T. H. (2002). Combined carbon dioxide and high-pressure inactivation of pectin methylesterase, polyphenol oxdiase, Lactobacillus plantarum and Escherichia coli. J. Food Sci., 67, 697. 
Costa, M. G. M., Fonteles, T. V., de Jesus, A. L. T., Almeida, F. D. L., de Miranda, M. R. A., Fernandes, F. A. N. \& Rodrigues, S. (2013). High-intensity ultrasound processing of pineapple juice. Food and Bioprocess Technology, 6(4), 997-1006.

Coutinho, N. M., Silveira, M. R., Rocha, R. S., Moraes, J., Vinicius, M., Ferreira, S., \& Cruz, A. G. (2018). Cold plasma processing of milk and dairy products. Trends in Food Science \& Technology, 74, 56-68.

Crelier, S., Robert, M., Claude, J., \& Juillerat, M. (2001). Tomato (Lycopersicon esculentum) pectin methylesterase and polygalacturonase behaviours regarding heat and pressure induced inactivation. Journal of Agricultural and Food Chemistry, 49, 55665575.

Croak, S. \& Corredig, M. (2006). The role of pectin in orange juice stabilization: Effect of pectin methylesterase and pectinase activity on the size of cloud particles. Food Hydrocolloids, 20(7), 961-965.

Damar, S., \& Balaban, M. O. (2006). Review of dense phase $\mathrm{CO}_{2}$ Technology: Microbial and enzyme inactivation, and effects on food quality. Concise Reviews in Food Science, 71(1), 1-11.

Dasan, B. G. \& Boyaci, I. H. (2018). Effect of cold atmospheric plasma on inactivation of Escherichia coli and physicochemical properties of apple, orange, tomato juices, and sour cherry nectar. Food Bioprocess Technology, 11, 334-343.

Dias, D. da R. C., Barros, Z. M. P., Carvalho, C. B. O. de, Honorato, F. A., Guerra, N. B. \& Azoubel, P. M. (2015). Effect of sonication on soursop juice quality. LWT - Food Science and Technology, 62(1), 883-889.

Dodds, W. S., Stutzman, L. F., \& Sollami, B. J. (1956). Carbon dioxide solubility in water. Journal of Chemical \& Engineering Data, 1, 92-95. 
Dohrn, R., Bünz, A. P., Devlieghere, F. \& Thelen, D. (1993). Experimental measurements of phase equilibria for ternary and quaternary systems of glucose, water, $\mathrm{CO}_{2}$ and ethanol with a novel apparatus. Fluid Phase Equilibria, 83, 149-158.

Donnell, C. P. O., Tiwari, B. K., Bourke, P. \& Cullen, P. J. (2010). Effect of ultrasonic processing on food enzymes of industrial importance. Trends in Food Science \& Technology, 21(7), 358-367.

Duvetter, T., Sila, D. N., Buggenhout, S. Van, Jolie, R., Loey, A. \& Hendrickx, M. (2009). Pectins in processed fruit and vegetables: Part I: Stability and catalytic pectinases. Comprehensive Reviews in Food Science and Food Safety, 8, 75-85.

Fachin, D., Van Loey, A. M., Ly Nguyen, B., Verlent, I., Indrawati, A. \& Hendrickx, M. E. (2003). Inactivation kinetics of polygalacturonase in tomato juice. Innovative Food Science and Emerging Technologies, 4(2), 135-142.

Faria, W., Kumar, B., Rodriguez, Ó., Sousa, E., Brito, D., André, F., Rodrigues, S. (2017). Effect of ultrasound followed by high pressure processing on prebiotic cranberry juice. Food Chemistry, 218, 261-268.

Ferrentino, G., Bruno, M., Ferrari, G., Poletto, M., \& Balaban, M. O. (2009). Microbial inactivation and shelf life of apple juice treated with high pressure carbon dioxide. Journal of Biological Engineering, 9, 1-9.

Ferrentino, G., Barletta, D., Balaban, M. O., Ferrari, G., \& Poletto, M. (2010a). Measurement and prediction of $\mathrm{CO}_{2}$ solubility in sodium phosphate monobasic solutions for food treatment with high pressure carbon dioxide. Journal of Supercritical Fluids, 52(1), 142-150.

Ferrentino, G., Barletta, D., Donsì, F., Ferrari, G. \& Poletto, M. (2010b). Experimental measurements and thermodynamic modeling of $\mathrm{CO}_{2}$ solubility at high pressure in model apple juices. Industrial \& Engineering Chemistry Research, 49(6), 2992-3000. 
Ferrentino, G. \& Spilimbergo, S. (2011). High pressure carbon dioxide pasteurization of solid foods: Current knowledge and future outlooks. TIFS, 22(8), 427-441.

Fonteles, T. V., Costa, M. G. M., de Jesus, A. L. T., de Miranda, M. R. A., Fernandes, F. A. N., \& Rodrigues, S. (2012). Power ultrasound processing of cantaloupe melon juice: Effects on quality parameters. Food Research International, 48(1), 41-48.

Fonteles, T. V., \& Rodrigues, S. (2018). Prebiotic in fruit juice: processing challenges, advances, and perspectives. Current Opinion in Food Science, 22, 55-61.

Fornari, T., Hernández, E. J., \& Reglero, G. (2009). Solubility of supercritical gases in organic liquids. Journal of Supercritical Fluids, 51(2), 115-122.

Fricks, A. T., Souza, D. P. B., Guillermo, E., Antunes, O. A. C., \& Girardi, J. S. (2006). Evaluation of radish (Raphanus sativus L.) peroxidase activity after high-pressure treatment with carbon dioxide. Journal of Supercritical, 38, 347-353.

Gao, Y., Zhang, S., Sun, H., Wang, R., Tu, X., \& Shao, T. (2018). Highly efficient conversion of methane using microsecond and nanosecond pulsed spark discharges. Applied Energy, 226, 534-545.

García-González, L., Geeraerd, A. H., K., Van Ginneken, L., Van Impe, J. F. \& Devlieghere, F. (2009). Inactivation of naturally occurring microorganisms in liquid whole egg using high pressure carbon dioxide processing as an alternative to heat pasteurization. Journal of Supercritical Fluids, 51(1), 74-82.

Gasperi, F., Aprea, E., Biasioli, F., Carlin, S., Endrizzi, I., Pirretti, G. \& Spilimbergo, S. (2009). Effects of supercritical $\mathrm{CO}_{2}$ and $\mathrm{N}_{2} \mathrm{O}$ pasteurisation on the quality of fresh apple juice. Food Chemistry, 115(1), 129-136.

Genovese, D. B. \& Lozano, J. E. (2001). The effect of hydrocolloids on the stability and viscosity of cloudy apple juices. Food Hydrocolloids, 15(1), 1-7. 
Gielen, B., Marchal, S., Jordens, J., Thomassen, L. C. J., Braeken, L., \& Gerven, T. Van. (2016). Influence of dissolved gases on sonochemistry and sonoluminescence in a flow reactor. Ultrasonics Sonochemistry, 31, 463-472.

Gogus, F., Fadiloglu, S., \& Soysal, C. (2010). Biological oxidations: enzymatic and nonenzymatic browning reactions and control mechanisms. Adv. Food Biochem., 341-382.

Grintsevich, E. E., Adzerikho, I. E., Mrochek, A. G., \& Metelitza, D. I. (2001). Polydisulfides of substituted phenols as effective protectors of peroxidase against inactivation by ultrasonic cavitation. Biochemistry 66(7), 740-746.

Gross, M. \& Jaenicke, R. (1994). Proteins under pressure: The influence of high hydrostatic pressure on structure, function and assembly of proteins and protein complexes. European Journal of Biochemistry, 221, 617-630.

Gui, F., Chen, F., Wu, J., Wang, Z., Liao, X., \& Hu, X. (2006a). Inactivation and structural change of horseradish peroxidase treated with supercritical carbon dioxide. Food Chemistry, 97(3), 480-489.

Gui, F., Wu, J., Chen, F., Liao, X., Hu, X., Zhang, Z., \& Wang, Z. (2006b). Change of polyphenol oxidase activity, color, and browning degree during storage of cloudy apple juice treated by supercritical carbon dioxide. European Food Research and Technology, 223(3), 427-432.

Gui, F., Wu, J., Chen, F., Liao, X., Hu, X., Zhang, Z., \& Wang, Z. (2007). Inactivation of polyphenol oxidases in cloudy apple juice exposed to supercritical carbon dioxide. Food Chemistry, 100(4), 1678-1685.

Hendrickx, M., Ludikhuyze, L., Broeck, I. Van Den, \& Weemaes, C. (1998). Effects of high pressure on enzymes related to food quality. Trends in Food Science \& Technology, 9, 197-203. 
Hernández, A. \& Cano, M. P. (1998). High-Pressure and temperature effects on enzyme inactivation in tomato puree. Journal of Agricultural and Food Chemistry, 46(1), 266270.

Houben, K., Jamsazzadeh, Z., Van Buggenhout, S., Van Loey, A. M., \& Hendrickx, M. E. (2014). Thermal and High-Pressure stability of pectin-converting enzymes in broccoli and carrot purée: Towards the creation of specific endogenous enzyme populations through processing. Food and Bioprocess Technology, 7(6), 1713-1724.

Hsu, K. C. (2008). Evaluation of processing qualities of tomato juice induced by thermal and pressure processing. LWT - Food Science and Technology, 41(3), 450-459.

Hu, W., Zhou, L., Xu, Z., \& Zhang, Y. A. N. (2013a). Enzyme inactivation in food processing using high pressure. Critical Reviews in Food Science and Nutrition, 53, 145-161.

Ibarz, A., Pagán, A., Tribaldo, F., \& Pagán, J. (2006). Improvement in the measurement of spectrophotometric data in the m-hydroxydiphenyl pectin determination methods. Food Control, 17(11), 890-893.

Illera, A. E., Sanz, M. T., Beltran, S., \& Solaesa, A. G. (2018a). Evaluation of HPCD batch treatments on enzyme inactivation kinetics and selected quality characteristics of cloudy juice from Golden delicious apples. Journal of Food Engineering, 221, 141-150.

Illera, A. E., Sanz, M. T., Benito-Román, O., Varona, S., Beltrán, S., Melgosa, R., \& Solaesa, A. G. (2018b). Effect of thermosonication batch treatment on enzyme inactivation kinetics and other quality parameters of cloudy apple juice. Innovative Food Science and Emerging Technologies, 47, 71-80.

Illera, A. E., Sanz, M. T., Trigueros, E., \& Beltrán, S. (2018c). Effect of high pressure carbon dioxide on tomato juice: Inactivation kinetics of pectin methylesterase and polygalacturonase and determination of other quality parameters. Journal of Food Engineering, 239, 64-71. 
Illera, A. E., Sanz, M. T., \& Beltrán, S. (2019). The journal of supercritical fluids high pressure $\mathrm{CO}_{2}$ solubility in food model solutions and fruit juices. The Journal of Supercritical Fluids, 143, 120-125.

Imm, J. Y., \& Kim, S. C. (2009). Convenient partial purification of polyphenol oxidase from apple skin by cationic reversed micellar extraction. Food Chemistry, 113(1), 302-306.

Ishikawa, H., Shimoda, M., Kawano, T., \& Osajime, Y. (1995). Inactivation of enzymes in an aqueous solution by micro-bubbles of supercritical carbon dioxide. Bioscience, Biotechnology and Biochemistry, 59(4), 628-632.

Islam, M. N., Zhang, M. \& Adhikari, B. (2014). The inactivation of enzymes by ultrasound: A review of potential mechanisms. Food Reviews International, 30(1), 1-21.

Jabbar, S., Abid, M., Hu, B., Hashim, M. M., Lei, S., Wu, T. \& Zeng, X. (2015). Exploring the potential of thermosonication in carrot juice processing. Journal of Food Science and Technology, 52, 7002-7013.

Jaenicke, R. (1991). Protein stability and molecular adaptation to extreme conditions. European Journal of Biotechnology, 728, 715-728.

Janovitz-Klapp, A., Richard, F., \& Nicolas, J. (1989). Polyphenoloxidase from apple, partial purification and some properties. Phytochemistry, 28(11), 2903-2907.

Jiang, L., Wang, J., Li, Y., Wang, Z., Liang, J., Wang, R., Zhang, M. (2014). Effects of ultrasound on the structure and physical properties of black bean protein isolates. Food Research International, 62, 595-601.

Juarez-Enriquez, E., Salmeron-Ochoa, I., Gutierrez-Mendez, N., Ramaswamy, H. S. \& Ortega-Rivas, E. (2015). Shelf life studies on apple juice pasteurised by ultrahigh hydrostatic pressure. LWT - Food Science and Technology, 62(1), 915-919.

Julák, J., Hujacová, A., Scholtz, V., Khun, J., \& Holada, K. (2018). Contribution to the chemistry of Plasma-activated water. Plasma Physics Reports, 44(1), 125-136. 
Kadkhodaee, R. \& Povey, M. J. W. (2008). Ultrasonic inactivation of Bacillus-amylase I. Effect of gas content and emitting face of probe. Ultrasonics Sonochemistry, 15(2), $133-142$.

Kamat, S. V., Beckman, E. J. \& Russell, A. J. (1995). Enzyme activity in supercritical fluids. Critical Reviews in Biotechnology, 15, 41-71.

Kasche, V., Schlothauer, R. \& Brunner, G. (1988). Enzyme denaturation in supercritical $\mathrm{CO}_{2}$ : Stabilizing effect of S-S bonds during the depressurization step. Biotechnology Letters, 10, 569-574.

Kaur, B. \& Rao, P. S. (2017). Kinetic modeling of polyphenoloxidase inactivation during thermal-assisted high pressure processing in black tiger shrimp (Penaeus monodon). Food Control, 80, 388-394.

Khani, M., Shokri, B., \& Khajeh, K. (2017). Studying the performance of dielectric barrier discharge and gliding arc plasma reactors in tomato peroxidase inactivation. Journal of Food Engineering, 197, 107-112.

Kincal, D., Hill, W. S., Balaban, M., Portier, K. M., Sims, C. A., Wei, C. I., \& Marshall, M. R. (2006). A continuous high-pressure carbon dioxide system for cloud and quality retention in orange juice. Food Chemistry and Toxicology, 71(6), 338-344.

Klomklao, S., Benjakul, S. \& Simpson, B. K. (2012). Seafood enzymes: Biochemical properties and their impact on quality. Simpson, B. K., Nollet, L., Paliyath, G., Benjakul, S., Nip, W. K. \& Hui, Y. (Eds.), Food Biochemistry and Food Processing (2nd ed., 263-284). New York: Blackwell.

Krapfenbauer, G., Kinner, M., Gossinger, M., Schonlechner, R., \& Berghofer, E. (2006). Effect of thermal treatment on the quality of cloudy apple juice. J Agric Food Chem, 54(15), 5453-5460.

Levenspiel, O. (1999). Chemical reaction engineering. 3rd Edition. John Wiley \& Sons, New York, 54. 
Li, R., Wang, Y., Hu, W., \& Liao, X. (2014). Changes in the activity, dissociation, aggregation, and the secondary and tertiary structures of a thaumatin-like protein with a high polyphenol oxidase activity induced by high pressure $\mathrm{CO}_{2}$. Innovative Food Science and Emerging Technologies, 23, 68-78.

Li, X., Tian, X. \& Li, J. (2012). Effect of high hydrostatic pressure on the microbiological, biochemical characteristics of white shrimp Litopenaeus vannamei. Food Science and Technology International, 22(4), 302-312.

Liao, X., Zhang, Y., Bei, J., Hu, X. \& Wu, J. (2009). Alterations of molecular properties of lipoxygenase induced by dense phase carbon dioxide. Innovative Food Science and Emerging Technologies, 10, 47-53.

Liao, X., Liu, D., Xiang, Q., Ahn, J., Chen, S. \& Ye, X. (2017). Inactivation mechanisms of nonthermal plasma on microbes: A review. Food Control, 75, 83-91.

Liao, X., Li, J., Muhammad, A. I., Suo, Y., Chen, S., Ye, X. \& Ding, T. (2018). Application of a dielectric barrier discharge atmospheric cold plasma (Dbd-Acp) for Eshcerichia coli inactivation in apple juice. Journal of Food Science, 83(2), 401-408.

Liu, J. G., Xing, J. M., Chang, T. S., \& Liu, H. Z. (2006). Purification of nattokinase by reverse micelles extraction from fermentation broth: Effect of temperature and phase volume ratio. Bioprocess and Biosystems Engineering, 28(4), 267-273.

Liu, S., Liu, Y., Huang, X., Yang, W., Hu, W., \& Pan, S. (2017). Effect of ultrasonic processing on the changes in activity, aggregation and the secondary and tertiary structure of polyphenol oxidase in oriental sweet melon (Cucumis melo var. makuwa Makino). Journal of the Science of Food and Agriculture, 97(4), 1326-1334.

Liu, X., Gao, Y., Xu, H., Hao, Q., Liu, G. \& Wang, Q. (2008). Inactivation of peroxidase and polyphenol oxidase in red beet (Beta vulgaris L.) extract with continuous high pressure carbon dioxide. Food Chemistry, 9(1), 24-31. 
Liu, Y., Hu, X. S., Zhao, X. Y. \& Zhang, C. (2013). Inactivation of polyphenol oxidase from watermelon juice by high pressure carbon dioxide treatment. Journal of Food Science and Technology, 50, 317-324.

Lopez, P., Sala, F., De la Fuente, J. L., Condon, S., Raso, J. \& Burgos, J. (1994). Inactivation of peroxidase, lipoxygenase, and polyphenol oxidase by manothermosonication. Journal of Agricultural and Food Chemistry, 42(2), 252-256.

Lu, P., Boehm, D., Bourke, P., \& Cullen, P. J. (2017). Achieving reactive species specificity within plasma-activated water through selective generation using air spark and glow discharges. Plasma Processes and Polymers, 1-9.

Lv, Y., Cai, L., Yang, M., Liu, X., Hui, N. \& Li, J. (2018). Purification, characterisation and thermal denaturation of polyphenoloxidase from prawns (Penaeus vannamei). International Journal of Food Properties, 20(3), 3345-3359.

Ma, R., Wang, G., Tian, Y., Wang, K., Zhang, J. \& Fang, J. (2015). Non-thermal plasmaactivated water inactivation of food-borne pathogen on fresh produce. Journal of Hazardous Materials, 300, 643-651.

MacRichie, F. (1978). Proteins at interfaces. Protein Chemistry, 32, 283-311.

Mandal, R. \& Singh, A. P. (2018). Recent developments in cold plasma decontamination technology in the food industry. Trends in Food Science \& Technology, 80, 93-103.

Manheem, K., Benjakul, S., Kijroongrojana, K., \& Visessanguan, W. (2012). The effect of heating conditions on polyphenol oxidase, proteases and melanosis in pre-cooked Pacific white shrimp during refrigerated storage. Food Chemistry, 131(4), 1370-1375.

Manzocco, L., Ignat, A., Valoppi, F., Burrafato, K. R., Lippe, G., Spilimbergo, S., \& Nicoli, M. (2016). Inactivation of mushroom polyphenoloxidase in model systems exposed to high-pressure carbon dioxide. Journal of Supercritical Fluids, 107, 669-675. 
Markowski, J., Baron, A., Le Quéré, J. M. \& Plocharski, W. (2015). Composition of clear and cloudy juices from french and polish apples in relation to processing technology. LWT - Food Science and Technology, 62(1), 813-820.

Marrufo-Hernández, N. A., Palma-Orozco, G., Beltrán, H. I., \& Nájera, H. (2017). Purification, partial biochemical characterization and inactivation of polyphenol oxidase from mexican Golden delicious apple (Malus domestica). Journal of Food Biochemistry, 41(3), 1-10.

Mason, T. J., Paniwnyk, L., \& Lorimer, J. P. (1996). The uses of ultrasound in food technology. Ultrasonics Sonochemistry, 3, 253-260.

Mathew, D. S., \& Juang, R. S. (2007). Role of alcohols in the formation of inverse microemulsions and back extraction of proteins/enzymes in a reverse micellar system. Separation and Purification Technology, 53(3), 199-215.

Mead, E. L., Sutherland, R. G., \& Verrall, R. E. (1976). The effect of ultrasound on water in the presence of dissolved gases. Canadian Journal of Chemistry, 54(7), 1114-1120.

Melgosa, R., Sanz, M. T., Solaesa, Á. G., Bucio, S. L. \& Beltrán, S. (2015). Enzymatic activity and conformational and morphological studies of four commercial lipases treated with supercritical carbon dioxide. Journal of Supercritical Fluids, 97.

Melgosa, R., Sanz, M. T., Solaesa, Á. G., \& Beltrán, S. (2017a). Phase behaviour of the pseudo-ternary system carbon dioxide + ethanol + fish oil at high pressures. Journal of Chemical Thermodynamics, 115, 106-113.

Melgosa, R., Sanz, M. T., Solaesa, Á. G., De Paz, E., Beltrán, S. \& Lamas, D. L. (2017b). Supercritical carbon dioxide as solvent in the lipase-catalyzed ethanolysis of fish oil: Kinetic study. Journal of $\mathrm{CO}_{2}$ Utilization, 17, 170-179.

Misra, N. N., Tiwari, B., Raghavarao, K. S. M. \& Cullen, P. (2011). Nonthermal plasma inactivation of food-borne pathogens. Food Engineering Reviews, 3, 159-170. 
Misra, N. N., Keener, K. M., Bourke, P., Mosnier, J. \& Cullen, P. J. (2014). In-package atmospheric pressure cold plasma treatment of cherry tomatoes. Journal of Bioscience and Bioengineering, 118(2), 177-182.

Misra, N. N., Pankaj, S. K., Segat, A. \& Ishikawa, K. (2016). Cold plasma interactions with enzymes in foods and model systems. Trends in Food Science \& Technology, 55, 39-47.

Misra, N. N., Koubaa, M., Roohinejad, S., Juliano, P., Alpas, H., Inácio, R. S., Barba, F. J. (2017). Landmarks in the historical development of twenty first century food processing technologies. Food Research International, 97, 318-339.

Möller, M. \& Denicola, A. (2002). Protein tryptophan accessibility studied by fluorescence quenching. Biochemistry and Molecular Biology Education, 30(3), 175-178.

Montero, P., Ávalos, A. \& Pérez-Mateos, M. (2001). Characterization of polyphenoloxidase of prawns (Penaeus japonicus). Alternatives to inhibition: additives and highpressure treatment. Food Chemistry, 75, 317-324.

Muhammad, A. I., Liao, X., Cullen, P. J., Liu, D., Xiang, Q., Wang, J., Ye, X. (2018). Effects of nonthermal plasma technology on functional food components. Comprehensive Reviews in Food Science and Food Safety, 17, 1379-1394.

Nguyen, B. L., Loey, A. Van, Fachin, D., Verlent, I. \& Hendrickx, I. M. (2002). Purification, characterization, thermal and high-pressure inactivation of pectin methylesterase from bananas (cv Cavendish). Biotechnology Bioengineering, 78, 683-691.

Nirmal, N. P. \& Benjakul, S. (2009). Effect of ferulic acid on inhibition of polyphenoloxidase and quality changes of Pacific white shrimp (Litopenaeus vannamei) during iced storage. Food Chemistry, 116(1), 323-331.

Nirmal, N. P. \& Benjakul, S. (2012). Biochemical properties of polyphenoloxidase from the cephalothorax of Pacific white shrimp (Litopenaeus vannamei). International Aquatic Research, 4(6), 1-13. 
Niu, L., Hu, X., Wu, J., Liao, X., Chen, F., Zhao, G. \& Wang, Z. (2010a). Effect of dense phase carbon dioxide process on physicochemical properties and flavor compounds of orange juice. Journal of Food Processing and Preservation, 34(2010), 530-548.

Niu, S., Xu, Z., Fang, Y., Zhang, L., Yang, Y., Liao, X. \& Hu, X. (2010b). Comparative study on cloudy apple juice qualities from apple slices treated by high pressure carbon dioxide and mild heat. Innovative Food Science and Emerging Technologies, 11(1), 91-97.

Noh, K. H. \& Imm, J. Y. (2005). One-step separation of lysozyme by reverse micelles formed by the cationic surfactant, cetyldimethylammonium bromide. Food Chemistry, 93(1), 95-101.

Ortuño, C., Duong, T., Balaban, M. \& Benedito, J. (2013). Combined high hydrostatic pressure and carbon dioxide inactivation of pectin methylesterase, polyphenol oxidase and peroxidase in feijoa puree. Journal of Supercritical Fluids, 82, 56-62.

Oszmianski, J., Wolniak, M., Wojdylo, A. \& Wawer, I. (2007). Comparative study of polyphenolic content and antiradical activity of cloudy and clear apple juices. Journal of the Science of Food and Agriculture, 87, 573-579.

Pal, B. \& Rao, P. S. (2017). Kinetic modeling of polyphenoloxidase inactivation during thermal-assisted high pressure processing in black tiger shrimp (Penaeus monodon). Food Control, 80, 388-394.

Panjak, S. K., Misra, N. N. \& Cullen, P. J. (2013). Kinetics of tomato peroxidase inactivation by atmospheric pressure cold plasma based on dielectric barrier discharge. Innovative Food Science and Emerging Technologies, 19, 153-157.

Pankaj, S. K. \& Keener, K. M. (2017a). Cold plasma: background, applications and current trends. Current Opinion in Food Science, 16, 49-52. 
Pankaj, S. K., Wan, Z., Colonna, W. \& Keener, K. (2017b). Effect of high voltage atmospheric cold plasma on white grape juice quality. Journal of Science and Food Agriculture, 97, 4016-4021.

Pires, M. J. \& Cabral, J. M. S. (1996). Liquid - Liquid Extraction of Proteins with Reversed Micelles. Biotechnol. Prog., 12(3), 290-301.

Queiroz, C., Jorge, A., Lúcia, M., Lopes, M., Fialho, E. \& Valente-mesquita, V. L. (2011). Polyphenol oxidase activity, phenolic acid composition and browning in cashew apple (Anacardium occidentale, L.) after processing. Food Chemistry, 125, 128-132.

Qiang, L., Hongyan, C., Kuanhong, L. \& Yajun, S. (1998). Biochemical Engineering Journal. Biochemical Engineering Journal, 53, 45-52.

Ramazzina, I., Berardinelli, A., Rizzi, F., Tappi, S., Ragni, L., Sacchetti, G. \& Rocculi, P. (2015). Postharvest biology and technology effect of cold plasma treatment on physico-chemical parameters and antioxidant activity of minimally processed kiwifruit. Postharvest Biology and Technology, 107, 55-65.

Ramazzina, I., Tappi, S., Rocculi, P., Sacchetti, G., Berardinelli, A., Marseglia, A. \& Rizzi, F. (2016). Effect of cold plasma treatment on the functional properties of fresh-cut apples. Journal of Agricultural and Food Chemistry, 64, 8010-8018.

Raso, J., Mañas, P., Pagán, R. \& Sala, F. J. (1999). Influence of different factors on the output power transferred into medium by ultrasound. Ultrasonics Sonochemistry, 5(4), 157-162.

Rattanathanalerk, M., Chiewchan, N. \& Srichumpoung, W. (2005). Effect of thermal processing on the quality loss of pineapple juice. Journal of Food Engineering, 66, 259-265. 
Raventós, M., Duarte, S. \& Alarcón, R. (2002). Application and possibilities of supercritical $\mathrm{CO}_{2}$ extraction in food processing industry: An overview. Food Science and Technology International, 8(5), 269-284.

Raviyan, P., Zhang, Z. \& Feng, H. (2005). Ultrasonication for tomato pectinmethylesterase inactivation: effect of cavitation intensity and temperature on inactivation. Journal of Food Engineering, 70, 189-196.

Re, R., Pellegrini, N., Proteggente, A., Pannala, A., Yang, M. \& Rice-Evans, C. (1999). Antioxidant activity applying an improved abts radical cation decolorization assay. Free Radical Biology and Medicine, 26(9), 1231-1237.

Robertson, G. L. (1979). The fractional extraction and quantitative determination of pectic substances in grapes and musts. American Journal of Enology and Viticulture, 30(3), $182-186$.

Rocha, A. M. C. N. \& Morais, A. M. M. B. (2001). Characterization of polyphenoloxidase (PPO) extracted from “Jonagored" apple. Food Control, 12(2), 85-90.

Rodríguez, Ó., Gomes, W. F., Rodrigues, S. \& Fernandes, F. A. N. (2017). Effect of indirect cold plasma treatment on cashew apple juice (Anacardium occidentale L.). LWT Food Science and Technology, 84, 457-463.

Rooze, J., Rebrov, E. V, Schouten, J. C. \& Keurentjes, J. T. F. (2013). Ultrasonics sonochemistry dissolved gas and ultrasonic cavitation: A review. UltrasonicsSonochemistry, 20(1), 1-11.

Sae-leaw, T. \& Benjakul, S. (2019). Prevention of quality loss and melanosis of Pacific white shrimp by cashew leaf extracts. Food Control, 95, 257-266.

Sala, F. J., Burgos, J., \& Lopez, P. (1995). Effect of heat and ultrasound on microorganisms and enzymes. In G. W. Gould (Ed.), New methods of food preservation (176-204). Glasgow: Blackie Academic and Professional. 
Sampedro, F. \& Zhang, H. Q. (2012). Recent developments in non-thermal processess. In N. T. Dunford (Ed.), Food and Industrial Bioproducts and Bioprocessing (313-331). Wiley-Blackwell.

Shaikhmahamud, F. \& Magar, N. G. (1965). Evaluation of chemical tests for the quality of prawns. Fishing Techonology, 2(1), 102-108.

Shao, T., Tarasenko, V. F., Zhang, C., Baksht, E. K., Zhang, D., Erofeev, M. V., \& Ren, C. (2013). Diffuse discharge produced by repetitive nanosecond pulses in open air, nitrogen, and helium. Journal of Applied Physics, 113.

Sharma, A., \& Satyanarayana, T. (2017). Extremophiles as potential resource for food processing enzymes. In R. C. Ray \& C. M. Rosell (Eds.), Microbial Enzyme Technology in Food Applications (p. 426). CRC Press.

Shishikura, A., Takahashi, H., Hirohama, S. \& Arai, K. (1992). Citric acid purification process using compressed carbon dioxides. The Journal of Supercritical Fluids, 5(4), 303-312.

Sila, D. N., Buggenhout, S. Van, Duvetter, T., Fraeye, I., Roeck, A. De, Loey, A. Van \& Hendrickx, M. (2009). Pectins in processed fruits and vegetables: Part II: Structure Function Relationships. Comprehensive Reviews in Food Science and Food Safety, 8, 86-104.

Soni, K. \& Madamwar, D. (2000). Reversed micellar extraction of an extracellular acid phosphatase from fermentation broth. Process Biochemistry, 36(4), 311-315.

Soysal, C., Soylemez, Z. \& Bozoglu, F. (2004). Effect of high hydrostatic pressure and temperature on carrot peroxidase inactivation. European Food Research and Technology, 218, 152-156.

Stara, Z., \& Krcma, F. (2004). The study of $\mathrm{H}_{2} \mathrm{O}_{2}$ generation by DC diaphragm discharge in liquids. Czechoslovak Journal of Physics, 54, 1050-1055. 
Sulaiman, A., Soo, M. J., Yoon, M. M. L., Farid, M. \& Silva, F. V. M. (2015). Modeling the polyphenoloxidase inactivation kinetics in pear, apple and strawberry purees after High Pressure Processing. Journal of Food Engineering, 147, 89-94.

Sulaiman, A., Farid, M. \& Silva, F. V. M. (2017). Quality stability and sensory attributes of apple juice processed by thermosonication, pulsed electric field and thermal processing. Food Science and Technology International, 23(3), 265-276.

Supeno \& Kruus, P. (2000). Sonochemical formation of nitrate and nitrite in water. Ultrasonics Sonochemistry, 7, 109-113.

Surowsky, B., Fischer, A., Schlueter, O. \& Knorr, D. (2013). Cold plasma effects on enzyme activity in a model food system. Innovative Food Science and Emerging Technologies, 19, 146-152.

Surowsky, B., Fröhling, A., Gottschalk, N., Schlüter, O. \& Knorr, D. (2014). Impact of cold plasma on Citrobacter freundii in apple juice: Inactivation kinetics and mechanisms. International Journal of Food Microbiology, 174, 63-71.

Takai, E., Kitano, K., Kuwabara, J. \& Shiraki, K. (2012). Protein inactivation by lowtemperature atmospheric pressure plasma in aqueous solution. Plasma Processes and Polymers, 9(1), 77-82.

Tangwongchai, R., Ledward, D. A. \& Ames, J. M. (2000). Effect of high-pressure treatment on the texture of cherry tomato. Journal of Agricultural and Food Chemistry, 48(5), 1434-1441.

Tappi, S., Berardinelli, A., Ragni, L., Dalla, M., Guarnieri, A. \& Rocculi, P. (2014). Atmospheric gas plasma treatment of fresh-cut apples. Innovative Food Science and Emerging Technologies, 21, 114-122.

Tappi, S., Gozzi, G., Vannini, L., Berardinelli, A., Romani, S., Ragni, L. \& Rocculi, P. (2016). Cold plasma treatment for fresh-cut melon stabilization. Innovative Food Science and Emerging Technologies, 33, 225-233. 
Teleszko, M., Nowicka, P. \& Wojdyło, A. (2016). Chemical, enzymatic and physical characteristic of cloudy apple juices. Agricultural and Food Science, 25(1), 34-43.

Terefe, N. S., Gamage, M., Vilkhu, K., Simons, L., Mawson, R. \& Versteeg, C. (2009). The kinetics of inactivation of pectin methylesterase and polygalacturonase in tomato juice by thermosonication. Food Chemistry, 117(1), 20-27.

Terefe, N. S., Buckow, R. \& Versteeg, C. (2014). Quality-related enzymes in fruit and vegetable products: Effects of novel food processing technologies, Part 1: HighPressure Processing. Critical Reviews in Food Science and Nutrition, 54(1), 24-63.

Terefe, N. S., Buckow, R. \& Versteeg, C. (2015). Quality-related enzymes in plant-based products: Effects of novel food-processing technologies, Part 3: Ultrasonic Processing. Crtical Reviews in Food Science and Nutrition, 8398, 147-158.

Thirumdas, R. \& Sarangapani, C. (2014). Cold Plasma: A novel non-thermal technology for food processing. Food Biophysics, 10, 1-11.

Thirumdas, R., Kothakota, A., Annapure, U. \& Siliveru, K. (2018). Plasma activated water (PAW): Chemistry, physico-chemical properties, applications in food and agriculture. Trends in Food Science \& Technology, 77, 21-31.

Tiwari, B. K., Muthukumarappan, K., O’Donnell, C. P. \& Cullen, P. J. (2008). Effects of sonication on the kinetics of orange juice quality parameters. Journal of Agricultural and Food Chemistry, 56(7), 2423-2428.

USDA (2015). USDA Food Composition Databases. United States Department of Agriculture Agricultural Research Service. 2018.

Van Den Broeck, I., Ludikhuyze, L. R., Van Loey, A. M. \& Hendrickx, M. E. (2000). Effect of temperature and/or pressure on tomato pectinesterase activity. Journal of Agricultural and Food Chemistry, 48(2), 551-558. 
Vercet, A., Lopez, P. \& Burgos, J. (1998). Free radical production by manothermosonication. Ultrasonics, 36, 615-618.

Verhaeghe, T., Vlaemynck, G., Block, J. De, Weyenberg, S. Van \& Hendrickx, M. (2016). Thermal inactivation kinetics of proteases and polyphenoloxidase in brown shrimp (Crangon crangon). Food Chemistry, 197, 641-647.

Versteeg, C., Rombouts, F. M., Spaansen, C. H. \& Pilnik, W. (1980). Thermostability and orange juice cloud destabilizing properties of multiple pectinesterases from orange. Journal of Food Science, 45(4), 969-971.

Wang, S. S., Lai, J. T., Huang, M. S., Tai, C. Y. \& Liu, H. S. (2010). Deactivation of isoamylase and $\beta$-amylase in the agitated reactor under supercritical carbon dioxide. Bioprocess and Biosystems Engineering, 33(8), 1007-1015.

Wanyou, H., Hongwu, J., Shucheng, L., Chaohua, Z., Yali, C., Minghui, G. \& Jiming, H. (2014). Inactivation effects and kinetics of polyphenol oxidase from Litopenaeus vannamei by ultra-high pressure and heat. Innovative Food Science and Emerging Technologies, 26, 108-115.

Weder, J. K. P. \& Bokor, M. V. (1992). Effect of supercritical carbon dioxide on arginine. Food Chemistry, 44, 287-290.

Wei, C. I., Balaban, M. O., Fernando, S. Y., Peplow, A. J. \& Florida, G. (1991). Bacterial effect of high pressure $\mathrm{CO}_{2}$ treatment on foods spiked with Listeria or Salmonella. Journal of Food Protection, 54(3), 189-193.

Wiebe, R. \& Gaddy, V. L. (1940). The solubility of carbon dioxide in water at various temperatures from 12 to $40{ }^{\circ} \mathrm{C}$ and at pressures to 500 atmospheres. Critical Phenomena. Journal of the American Chemical Society, 62(4), 815-817.

Wu, J., Gao, H., Zhao, L., Liao, X., Chen, F., Wang, Z. \& Hu, X. (2007). Chemical compositional characterization of some apple cultivars. Food Chemistry, 103(1), 88-93. 
Wu, J., Gamage, T. V., Vilkhu, K. S., Simons, L. K. \& Mawson, R. (2008). Effect of thermosonication on quality improvement of tomato juice. Innovative Food Science and Emerging Technologies, 9(2), 186-195.

Xiang, Q., Liu, X., Li, J., Liu, S. \& Zhang, H. (2018). Effects of dielectric barrier discharge plasma on the inactivation of Zygosaccharomyces rouxii and quality of apple juice. Food Chemistry, 254(136), 201-207.

Xu, Y., Tian, Y., Ma, R., Liu, Q. \& Zhang, J. (2016). Effect of plasma activated water on the postharvest quality of button mushrooms, Agaricus bisporus. Food Chemistry, 197, 436-444.

Xu, Z., Zhang, L., Wang, Y., Bi, X., Buckow, R. \& Liao, X. (2011). Effects of high pressure $\mathrm{CO}_{2}$ treatments on microflora, enzymes and some quality attributes of apple juice. Journal of Food Engineering, 104(4), 577-584.

Yang, R. J., Li, S. Q. \& Zhang, Q. H. (2004). Effects of pulsed electric fields on the activity of enzymes in aqueous solution. Food Chemistry and Toxicology, 69(4), 241-248.

Yordanov, D. G. \& Angelova, G. V. (2010). High pressure processing for foods preserving. Biotechnology and Biotechnological Equipment, 24(3), 1940-1945.

Yoruk, R. \& Marshall, M. R. (2003). Physicochemical properties and function of plant polyphenol oxidase: A review. Journal of Food Biochemistry, 27(352), 361-422.

Yoshimura, T., Furutera, M., Shimoda, M., Ishikawa, H., Miyake, M., Matsumoto, K., Hayakawa, I. (2002). Inactivation efficiency of enzymes in buffered system by continuous method with microbubbles of supercritical carbon dioxide. Journal of Food Science, 67(9), 3227-3231.

Yu, Y., Xiao, G., Wu, J., Xu, Y., Tang, D., Chen, Y., Fu, M. (2013). Comparing characteristic of banana juices from banana pulp treated by high pressure carbon dioxide and mild heat. Innovative Food Science and Emerging Technologies, 18, 95-100. 
Yuk, H. G., Sampedro, F., Fan, X. \& Geveke, D. J. (2014). Nonthermal processing of orange juice using a pilot-plant scale supercritical carbon dioxide system with a gas-liquid metal contactor. Journal of Food Processing, 38, 630-638.

Zafra-Rojas, Q. Y., Cruz-Cansino, N., Ramírez-Moreno, E., Delgado-Olivares, L., VillanuevaSánchez, J. \& Alanís-García, E. (2013). Effects of ultrasound treatment in purple cactus pear (Opuntia ficus-indica) juice. Ultrasonics Sonochemistry, 20(5), $1283-1288$.

Zamorano, J., Martínez-álvarez, O., Montero, P. \& Gómez-guillén, C. (2009). Characterisation and tissue distribution of polyphenol oxidase of deepwater pink shrimp (Parapenaeus longirostris). Food Chemistry, 112, 104-111.

Zeman, S. \& Kubík, L. (2007). Permeability of polymeric packaging materials. Technical Sciences, 10(1), 33-34.

Zhang, L., Liu, S., Ji, H., Zhang, C., Deng, C. \& Cao, W. (2011). Inactivation of polyphenol oxidase from Pacific white shrimp by dense phase carbon dioxide. Innovative Food Science and Emerging Technologies, 12(4), 635-641.

Zhao, G. Y., Zong, W. \& An, G. J. (2008). Effect of storage on cloud stability of cloudy apple juice. Food Science and Technology International, 14(1), 105-113.

Zhi, X., Zhang, Y., Hu, X., Wu, J. \& Liao, X. (2008). Inactivation of apple pectin methylesterase induced by dense phase carbon dioxide. Journal of Agricultural and Food Chemistry, 56(13), 5394-5400.

Zhong, M. T., Wan, M. X., Wang, S. P. \& Kang, J. Q. (2004). Effects of ultrasound and additives on the function and structure of trypsin. Ultrasonics Sonochemistry, 11, 399-404.

Zhou, L., Wang, Y., Hu, X., Wu, J. \& Liao, X. (2009a). Effect of high pressure carbon dioxide on the quality of carrot juice. Innovative Food Science and Emerging Technologies, 10(3), 321-327. 
Zhou, L., Wu, J., Hu, X., Zhi, X. \& Liao, X. (2009b). Alterations in the activity and structure of pectin methylesterase treated by high pressure carbon dioxide. Journal of Agricultural and Food Chemistry, 57, 1890-1895.

Zhou, L., Zhang, Y., Leng, X., Liao, X. \& Hu, X. (2010). Acceleration of precipitation formation in peach juice induced by high-pressure carbon dioxide. Journal of Agricultural and Food Chemistry, 58(17), 9605-9610.

Zhou, L., Bi, X., Xu, Z., Yang, Y. \& Liao, X. (2015). Effects of High-pressure $\mathrm{CO}_{2}$ processing on flavor, texture, and color of foods. Critical Reviews in Food Science and Nutrition, 55(6), 750-768.

Zhou, P., Smith, N. L. \& Lee, C. Y. (1993). Potential purification and some properties of monroe apple peel polyphenol oxidase. Journal of Agricultural and Food Chemistry, 41(4), 532-536.

Ziuzina, D., Han, L., Cullen, P. J. \& Bourke, P. (2015). Cold plasma inactivation of internalised bacteria and biofilms for Salmonella enterica serovar Typhimurium, Listeria monocytogenes and Escherichia coli. International Journal of Food Microbiology, 210, 53-61. 
CURRICULUM VITAE 



\title{
CURRICULUM VITAE
}

\author{
Alba Ester Illera Gigante \\ Born on September $5^{\text {th }}, 1991$ in Burgos (Spain)
}

\section{Education}

2015-2019 PhD student in the program "Advances on Food Science and Biotechnology", University of Burgos, Spain.

2014-2015 Master's Degree in "Food Safety and Biotechnology", University of Burgos, Spain.

2009-2014 Bachelor's Degree in "Food Science and Technology", University of Burgos, Spain.

Employment

2016-2018 Research technical assistant in the Department of Biotechnology and Food Science, University of Burgos, Spain.

(Ref.: CTQ2015-64396-R)

2014-2015 Research technical assistant in the Department of Biotechnology and Food Science, University of Burgos, Spain.

(Ref.: CTQ2012-39131-C02-01)

Short research visit

2018 (3 months) Environmental Sustainability and Health Institute (ESHI), Technological University Dublin, Republic of Ireland. 


\section{Publications compiled in the PhD Thesis}

1. Illera, A.E., Sanz, M.T., Beltrán, S. Enzyme inactivation and other properties of cloudy apple juice after High Pressure Carbon Dioxide (HPCD) and thermosonication (TS) treatments and during refrigerated storage, Journal of Food Processing and Preservation, (submitted).

2. Illera, A.E., Chaple, S., Sanz, M.T., Ng, S., Lu, P., Jones, J., Carey ,E., Bourke, P. Effect of Cold plasma on polyphenol oxidase inactivation in cloudy apple juice and on the quality parameters of the juice during storage, Food Chemistry (submitted).

3. Illera, A.E., Beltrán, S., Sanz, M.T. Optimization of polyphenol oxidase concentration by cationic reversed micellar extraction of Golden delicious apple: High Pressure Carbon Dioxide and Thermosonication enzyme inactivation. Scientific Reports (submitted).

4. Illera, A.E., Sanz, M.T., Beltrán, S., Benito-Román, O. (2019). Effect of High Pressure Carbon Dioxide on polyphenol oxidase from Litopenaeus vannamei. LWT-Food Science \& Technology, 109, 359-365.

5. Illera, A.E., Sanz, M.T., Beltrán, S. (2019). High pressure $\mathrm{CO}_{2}$ solubility in food model solutions and fruit juices. The Journal of Supercritical Fluids, 143, 120-125.

6. Illera, A.E., Sanz, M.T., Benito-Román, O., Varona, S., Beltrán, S., Melgosa, R., Solaesa, A. G. (2018). Effect of thermosonication batch treatment on enzyme inactivation kinetics and other quality parameters of cloudy apple juice. Innovative Food Science and Emerging Technologies, 47, 71-80.

7. Illera, A.E., Sanz, M.T., Trigueros, E., Beltrán, S. (2018). Effect of high pressure carbon dioxide on tomato juice: Inactivation kinetics of pectin methylesterase and polygalacturonase and determination of other quality parameters. Journal of Food Engineering, 239, 64-71. 
8. Illera, A.E., Sanz, M.T., Beltrán, S., Melgosa, R., Solaesa, A. G., Ruiz, M. O. (2018). Evaluation of HPCD batch treatments on enzyme inactivation kinetics and selected quality characteristics of cloudy juice from Golden delicious apples. Journal of Food Engineering, 221, 141-150.

\section{Co-authored publications}

9. Melgosa, R., Sanz, M.T., Benito-Román, O., Illera, A.E., Beltrán, S. (2019). Supercritical $\mathrm{CO}_{2}$ assisted synthesis and concentration of monoacylglycerides rich in omega-3 polyunsaturated fatty acids. Journal of $\mathrm{CO}_{2}$ utilization, 31, 65-74.

10. Benito-Román, O., Sanz, M.T., Illera, A.E., Melgosa, R., Benito, J.M., Beltrán, S. (2019) Pectin methylesterase inactivation by High Pressure Carbon Dioxide (HPCD). The Journal of Supercritical Fluids, 145, 111-121.

11. Briongos, H., Illera, A.E., Sanz, M.T., Melgosa, R., Beltrán, S., \& Solaesa, A. G. (2016). Effect of high pressure carbon dioxide processing on pectin methylesterase activity and other orange juice properties. LWT - Food Science and Technology, 74, 411-419.

\section{Oral communications}

Alba Ester Illera, María Teresa Sanz, Sagrario Beltrán, Rodrigo Melgosa. “Enzymatic inactivation of apple juice using HPCD (High Pressure Carbon Dioxide) technology and its effect on the quality parameters of the juice" in 16th European Meeting on Supercritical Fluids, 2017, Lisbon (Portugal).

\section{Poster presentations}

Alba Ester Illera, María Teresa Sanz, Lara Castro, Óscar Benito, Sagrario Beltrán, Rodrigo Melgosa, C. Apetrei. "Inactivation of polyphenoloxidase from Litopenaeus vannamei by High Pressure Carbon Dioxide (HPCD)" in 17th European Meeting on Supercritical 
Fluids- 7th European Meeting on High Pressure Technology, 2019, Ciudad Real (Spain).

Alba Ester Illera, María Teresa Sanz, Óscar Benito, Sagrario Beltrán, Rodrigo Melgosa. "Enzymatic inactivation of apple and tomato juices using HPCD (High Pressure Carbon Dioxide) technology and its effect on the quality parameters of the juice" in 6th International Congress on Green Process Engineering, 2018, Toulouse (France).

Alba Ester Illera, Rodrigo Melgosa, María Teresa Sanz, Sagrario Beltrán, Ángela García. "Effect of HPCD (High Pressure Carbon Dioxide) treatment on enzyme inactivation and properties of apple juice" in 15th European Meeting On Supercritical Fluids, 2016, Essen (Germany).

Alba Ester Illera, María Teresa Sanz, Heliodoro Briongos, Sagrario Beltrán. “Application of supercritical $\mathrm{CO}_{2}$ for the inactivation of PPO and PME enzymes in apple juice" in 1st National Congress for Junior Researchers in Food Science, Engineering and Technology, 2015, Palencia (Spain).

Alba Ester Illera, Heliodoro Briongos, Rodrigo Melgosa, María Teresa Sanz, Sagrario Beltrán. "Enzymatic inactivation of apple juice by the use of HPCD (High Pressure Carbon Dioxide) Technology" in the VIII Meeting of Experts on Supercritical Fluids, 2015, Cádiz (Spain). 

